\title{
UM MODELADOR DE SÓLIDOS MULTIRREPRESENTACIONAL: ESTUDO, PROJETO E IMPLEMENTAÇÃO
}

Ana Liddy Cenni de Castro Magaihães

Orientadora: Profa. Dra. Maria Cristina Ferreira de Oliveira - ICMSC

Dissertação apresentada ao Instituto de Ciências Matemáticas de São Carlos como parte dos requisitos para a obtenção do Título de Mestre em Ciências - Área: Ciências de Computação e Matemática Computacional

Instituto de Ciências Matemáticas de São Carlos

Universidade de São Paulo

Outubro de 1994 
Aos meus pais, Mário e Anna Maria, por tudo o que sou.

Ao Breno, pelo apoio, carinho, compreensão e incentivo demonstrados ao longo de nossa convivência.

Aos meus filhos, Breninho e Pedro, pelas inúmeras vezes em que privei-os de minha companhia para a realização deste trabalho. 


\section{AGRADECIMENTOS}

À Prof. Dra. Maria Cristina Ferreira de Oliveira, pela orientação, ensinamentos, dedicação, interesse, valorização e amizade no decorrer do desenvolvimento deste trabalho;

Ao Prof. Dr. Antônio Castelo Filho, pelas inúmeras dúvidas elucidadas referentes à teoria matemática envolvida neste trabalho, além da atenção e disponibilidade;

Aos colegas Marcelo Ferreira Siqueira e Carlos Neves Lenz César, pela cooperação e aprendizado durante a construção do $(\mathrm{SM})^{2}$, e à Rejane Joas Silveira pela ajuda no preparo da documentação;

À D. Carmen Lydia Ferolla de Castro Magalhães, pela preciosa revisão do texto, e às bibliotecárias da FEIS/UNESP, pela revisão das referências bibliográficas;

Aos funcionários do Laboratório Didático-Científico de Computação, Secretaria e Biblioteca do ICMSC/USP, sempre tão atenciosos;

Aos vigias do ICMSC/USP, pela companhia durante as longas noites que passei trabalhando nos equipamentos do LDCC;

A todos os colegas, professores e funcionários do ICMSC/USP que, de uma maneira ou de outra, colaboraram para o desenvolvimento deste trabalho;

À companheira Anilda Flores, por ter assumido meu papel de mãe e de dona-decasa nas diversas vezes em que viajei para São Carlos;

À amiga Soeli Maria Miguel, pela acolhida e incentivo;

À UNESP, por ter-me concedido afastamento, e aos colegas de trabalho do Pólo Computacional de Ilha Solteira / UNESP, por terem assumido parte de minhas atividades no período em que estive afastada. 


\section{RESUMO}

Esta dissertação apresenta um estudo sobre modelagem de sólidos, e descreve o projeto e a implementação (parcial) do $(\mathrm{SM})^{2}$ - Sistema de Modelagem de Sólidos Multirrepresentacional, em desenvolvimento pelo grupo de Computação Gráfica e Processamento de Imagens do ICMSC-USP. Em sua versão atual, o (SM) ${ }^{2}$ admite duas formas de representação de sólidos: por fronteira e implícita.

O estudo aqui apresentado abrange as diferentes técnicas de modelagem de sólidos, com ênfase na modelagem por fronteira e nas operações de descrição de sólidos por instanciamento de primitivas e por varredura rotacional e translacional de curvas e faces planares.

Como parte deste trabalho, foram implementadas no (SM) ${ }^{2}$ facilidades para a descrição de objetos por meio de operação de varredura rotacional e translacional, bem como por instanciamento de um conjunto pré-definido de primitivas maciças, ocas e vazadas. Os modelos assim definidos são convertidos para uma estrutura B-Rep (Boundary Representation), utilizada pelo modelador como a principal forma de representação interna para acesso por algoritmos de manipulação, visualização e aplicativos. 


\section{ABSTRACT}

This work presents a study on solid modeling, and describes the design and partial implementation of $(\mathrm{SM})^{2}$ - Sistema de Modelagem de Sólidos Multirrepresentacional (Multirepresentational Solid Modeling System), under development within the Computer Graphics and Image Processing Group of the ICMSC-USP. The current version of (SM) ${ }^{2}$ admits two representations of solids: boundary and implicit.

The study comprehends the various solid modeling techniques, emphasizing the boundary modeling approach and modeling operations based on primitive instancing as well as translational and rotational sweeping of plane curves and faces.

In this work, facilities for description of objects by primitive instancing (considering a pre-defined set of massive, "empty" and hollow primitives), and also by rotational and translational sweeping were implemented. The models thus described are then converted to a B-Rep (Boundary Representation) data structure, which is kept by the system as the main internal representation for access by external manipulation and visualization algorithms and applications. 


\section{SUMÁRIO}

\section{1 - INTRODUÇÃO}

1.1 - O QUE É UM MODELADOR DE SÓLIDOS POR FRONTEIRA . . . . . . 1

1.2 - MOTIVAÇÕES PARA O PRESENTE TRABALHO . . . . . . . . . . 3

1.2.1 - A Necessidade de um Modelador de Sólidos . . . . . . . . . . 3

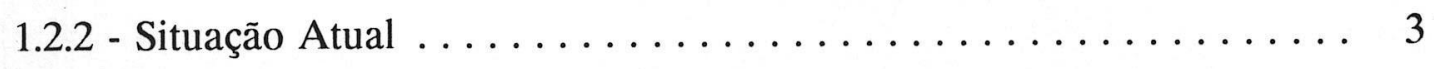

1.3 - OBJETIVOS DO TRABALHO $\ldots \ldots \ldots \ldots \ldots \ldots \ldots \ldots \ldots \ldots$

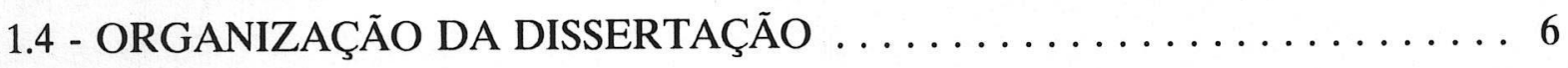

\section{2 - TEORIAS E TÉCNICAS DE MODELAGEM DE}

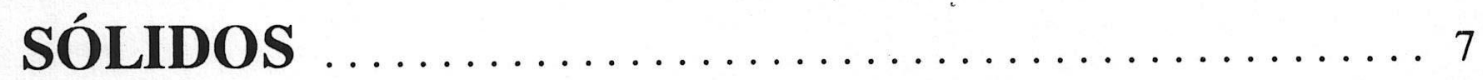

2.1 - CONSIDERAÇÕES INICIAIS $\ldots \ldots \ldots \ldots \ldots \ldots \ldots \ldots \ldots \ldots \ldots \ldots$

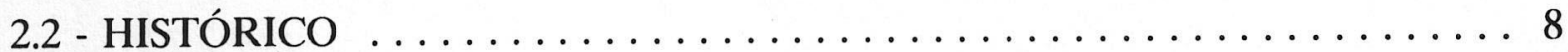

2.2 .1 - Primórdios $\ldots \ldots \ldots \ldots \ldots \ldots \ldots \ldots \ldots \ldots \ldots \ldots \ldots \ldots \ldots \ldots \ldots \ldots$

2.2.2 - Modelos Tridimensionais . . . . . . . . . . . . . 9

2.2 .3 - Modeladores de Sólidos . . . . . . . . . . . . . . 10

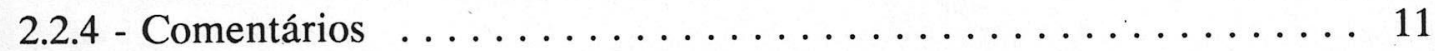

2.3 - REVISÃO DE MODELAGEM DE SÓLIDOS . . . . . . . . . . . . 12

2.3.1 - Requisitos para a Representação de objetos . . . . . . . . . . 12

2.3.2 - Principais Esquemas de Representação . . . . . . . . . . . . . . 13

2.3.3 - Esquemas Híbridos . . . . . . . . . . . . . . 15

2.4 - TEORIAS E TÉCNICAS DE MODELAGEM POR FRONTEIRA . . . . . . 17

2.4.1 - Variedades Bidimensionais, Não Bidimensionais e Modelos Planares 17

2.4 .2 - Operadores de Euler . . . . . . . . . . . . . . . . . 19

2.4 .3 - Validação de Representações . . . . . . . . . . . . . . 21

2.4 .4 - Geometria Exata x Aproximada . . . . . . . . . . . . . . 22

2.4 .5 - Inclusão de Superfícies Curvas . . . . . . . . . . . . . . 24

2.4.6 - Propriedades da Modelagem por Fronteira . . . . . . . . . . 26

2.5 - ESFORÇOS NO DESENVOLVIMENTO DE MODELADORES POR

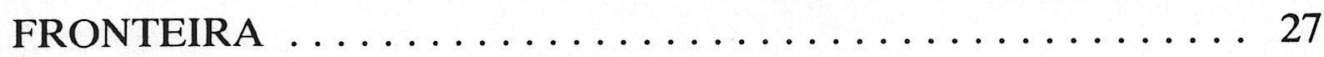

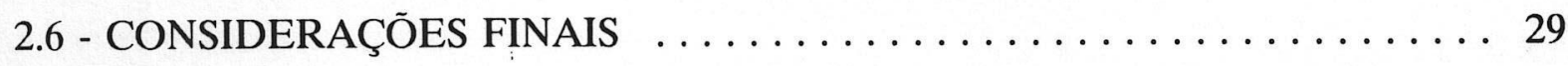




\section{3 - MODELADORES DE SÓLIDOS POR FRONTEIRA 30}

3.1 - CONSIDERAÇÕES INICIAIS $\ldots \ldots \ldots \ldots \ldots \ldots \ldots \ldots \ldots \ldots \ldots \ldots \ldots \ldots \ldots$

3.2 - ARQUITETURA DE MODELADORES $\ldots \ldots \ldots \ldots \ldots \ldots \ldots \ldots \ldots \ldots$

3.3 - REPRESENTAÇÃO INTERNA DE UM MODELADOR ......... 33

3.3.1 - Estruturas de Dados B-Rep . . . . . .............. 34

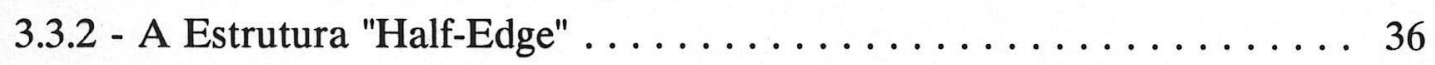

3.3.3 - Manipulação das Estruturas de Dados ............... 37

3.4 - OPERAÇÕES DE MANIPULAÇÃO DA FORMA $\ldots \ldots \ldots \ldots \ldots \ldots$

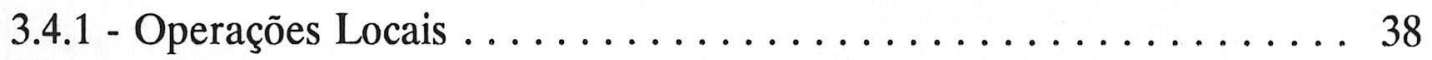

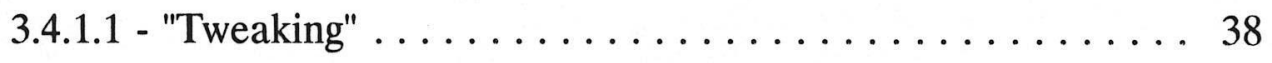

3.4.1.2 - "Chamfering" . . . . . . . . . . . . . . . . . . . 39

3.4.1.3 - "Rounding" . ................... 40

3.4.2 - Operações Globais e Combinação de Sólidos ............ 40

3.4.2.1 - Colagem ...................... 41

3.4.2.2 - Operação de corte ................ 41

3.4.2.3 - Operações booleanas ................ 43

3.5 - ELEMENTOS DE INTERFACE COM O USUÁRIO $\ldots \ldots \ldots \ldots \ldots 46$

3.5.1 - Mecanismos para Construção e Edição de Modelos ......... 46

3.5.2 - Sistemas Gerenciadores de Interface ............. 47

3.6 - APLICAÇÕES DE MODELADORES $\ldots \ldots \ldots \ldots \ldots \ldots \ldots \ldots \ldots$

3.6.1 - Cálculo de Propriedades Geométricas Integrais . ........ 48

3.6 .2 - Visualização ........................ 49

3.6.3 - Uso Industrial: Projeto, Análise e Manufatura .......... 49

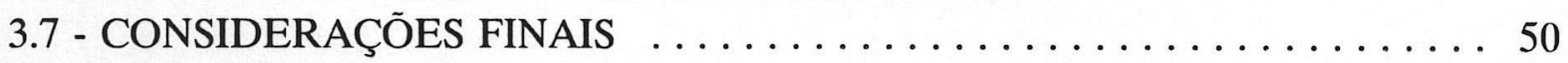

\section{4 - OPERAÇÕES BÁSICAS DE MODELAGEM ........ 51}

4.1 - CONSIDERAÇÕES INICIAIS $\ldots \ldots \ldots \ldots \ldots \ldots \ldots \ldots \ldots \ldots \ldots \ldots \ldots \ldots \ldots$

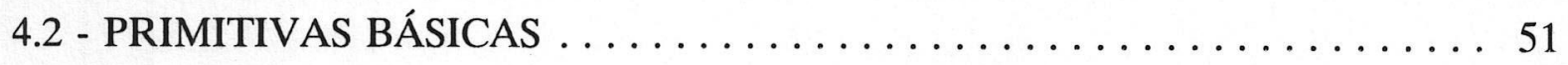

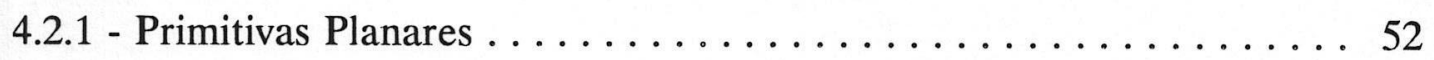

4.2.1.1 - Poli-linha .................... 53

4.2.1.2 - Arco de circunferência ............... 53

4.2.1.3 - Curvas de forma livre .................. 54

4.2.1.4 - Círculo ......................... 55

4.2.1.5 - Elipse ...................... 56

4.2.1.6 - Triângulo ..................... 56 
4.2.1.7 - Quadrilátero ..................... 57

4.2.1.8 - Polígono . . .................... 58

4.2.1.9 - Parâmetros utilizados pelas primitivas planares . . . . . 59

4.2.2 - Primitivas Sólidas . . . . . . . . . . . . . . 61

4.2.2.1 - Prisma ....................... 61

4.2.2.2 - Pirâmide ...................... 62

4.2.2.3 - Bloco ... . . . . . . . . . . . . . . . . 62

4.2.2.4 - Cilindro ....................... 64

4.2.2.5 - Cone ........................... 64

4.2.2.6 - Esfera .......................... 65

4.2.2.7 - Toro ......................... 66

4.2.2.8 - Definição de primitivas sólidas .............. 67

4.3 - TRANSFORMAÇÕES GEOMÉTRICAS $\ldots \ldots \ldots \ldots \ldots \ldots \ldots \ldots \ldots \ldots \ldots \ldots$

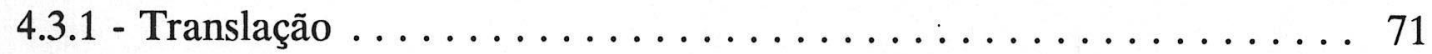

4.3 .2 - Rotação . . . . . . . . . . . . 72

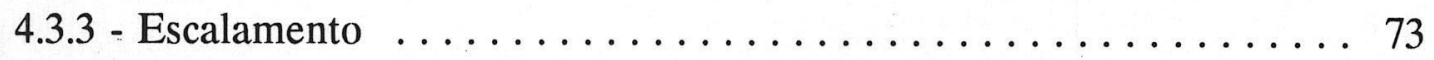

4.3 .4 - Espelhamento ou Reflexão . ................... 74

4.3 .5 - Deformação ........................... 75

4.3.6 - Composição de Transformações ................. 76

4.3.7 - Considerações em relação às Transformações Geométricas . . . . 78

4.4 - OPERAÇÕES DE VARREDURA . . . . . . . . . . . . . . . 79

4.4.1 - Varredura Translacional .......................... . 79

4.4.1.1 - Varredura translacional simples . . . . . . . . . . 80

4.4.1.2 - Varredura translacional cônica ............. 80

4.4.1.3 - Varredura translacional com torção . . . . . . . . 81

4.4.2 - Varredura Rotacional ................... 82

4.4.2.1 - Varredura rotacional simples aberta ......... 83

4.4.2.2 - Varredura rotacional simples fechada .......... 84

4.4.2.3 - Varredura rotacional helicoidal ............. 84

4.4.3 - Considerações sobre Operações de Varredura $\ldots \ldots \ldots \ldots \ldots .65$

4.5 - CONSIDERAÇÕES FINAIS $\ldots \ldots \ldots \ldots \ldots \ldots \ldots \ldots \ldots \ldots$ 
5 - O MODELADOR $(\mathbf{S M})^{2} \ldots \ldots \ldots \ldots \ldots \ldots \ldots \ldots$

5.1 - CONSIDERAÇÕES INICIAIS $\ldots \ldots \ldots \ldots \ldots \ldots \ldots \ldots \ldots \ldots \ldots$

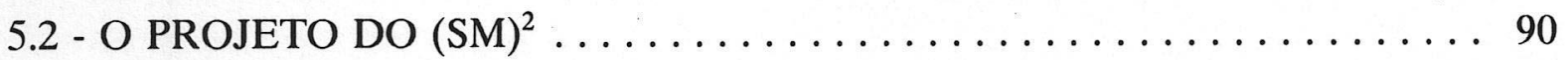

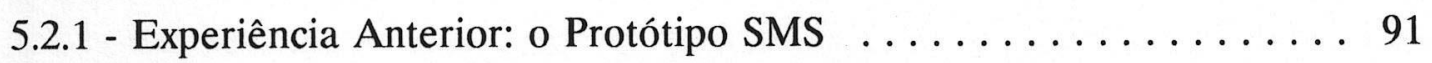

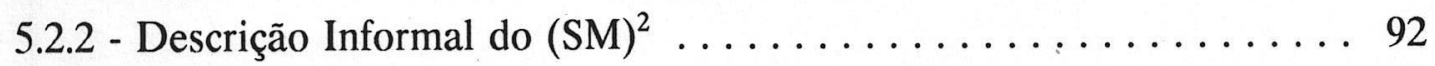

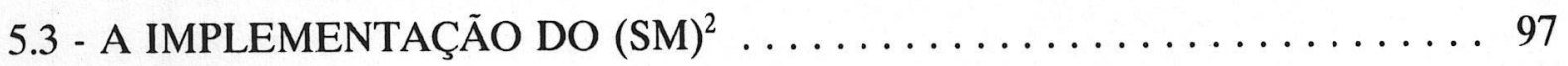

5.3.1 - Conteúdo dos módulos do $(\mathrm{SM})^{2} \ldots \ldots \ldots \ldots \ldots \ldots \ldots \ldots . \ldots 9$

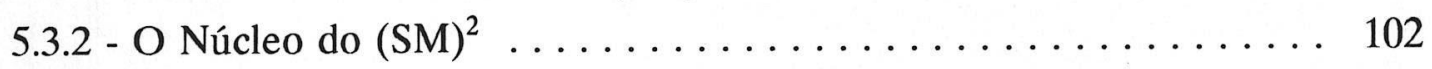

5.3 .3 - A Modelagem de Sólidos .................... 103

5.3 .4 - A Visualização de Objetos ...................... 105

5.3 .5 - A Interface . . . . . . . . . . . 106

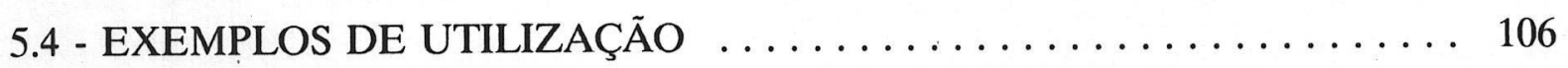

5.5 - CONSIDERAÇÕES FINAIS $\ldots \ldots \ldots \ldots \ldots \ldots \ldots \ldots \ldots \ldots \ldots \ldots \ldots \ldots \ldots$

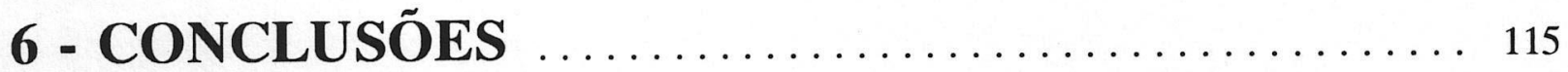

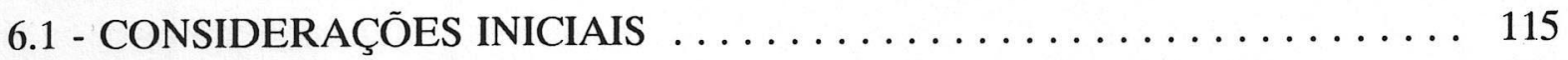

6.2 - CONTRIBUIÇÕES DO TRABALHO $\ldots \ldots \ldots \ldots \ldots \ldots \ldots \ldots \ldots . \ldots \ldots$

6.3 - SUGESTÕES PARA FUTUROS TRABALHOS $\ldots \ldots \ldots \ldots \ldots \ldots 117$

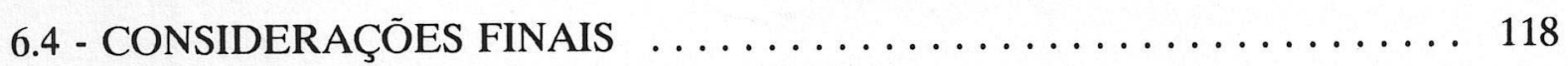

REFERÊNCIAS BIBLIOGRÁFICAS . . . . . . . . . . . . . 119 


\section{LISTA DAS ILUSTRAÇÕES}

\section{FIGURAS}

1.1 - Estrutura geral do sistema de modelagem de sólidos em desenvolvimento

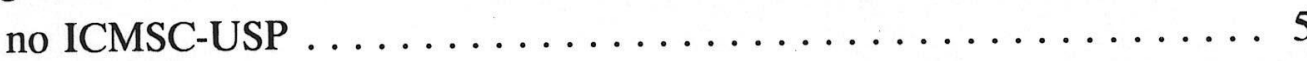

2.1 - Exemplo de visões ortogonais tradicionalmente modeladas . . . . . . . . . . 9

2.2 - Exemplo de representação "wireframe" de um objeto . . . . . . . . . . . 10

2.3 - Exemplo de montagem gerada por um modelador de sólidos . . . . . . . . . 10

2.4 - Abordagens para a arquitetura de sistemas de modelagem de sólidos . . . . . 16

2.5 - Exemplos de objetos de variedade bidimensional e não bidimensional . . . . . 18

2.6 - A topologia de um cubo representada por modelo planar . . . . . . . . . 18

2.7 - Operadores de Euler: descrição e representação gráfica . . . . . . . . . . . . . 19

2.8 - Seqüência para a geração de um modelo através de Operadores de Euler, representado em modelo planar ............... 20

2.9 - Exemplos de modelos utilizando geometria aproximada . . . . . . . . . . 22

2.10 - Perda de informação devido a aproximação . . . . . . . . . . . . . 23

3.1 - Componentes de um Sistema Geométrico . . . . . . . . . . . . . 31

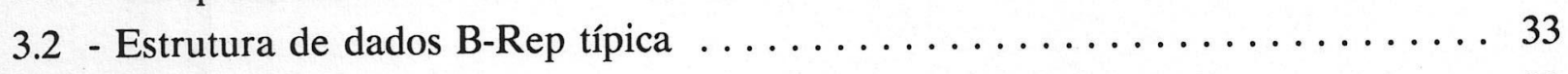

3.3 - Um exemplo de relação entre as entidades topológicas $\ldots \ldots \ldots \ldots \ldots . \ldots 33$

3.4 - Identificação de semi-arestas da estrutura "Half-Edge" . . . . . . . . . . . 36

3.5 - Exemplos de operações de "tweaking" . . . . . . . . . . . . . 38

3.6 - Exemplos de operações de chanfradura . . . . . . . . . . . . . . . . 39

3.7 - Exemplos de operações de arredondamento . . . . . . . . . . . . . 40

3.8 - Exemplo e seqüência da operação de colagem . . . . . . . . . . . . 41

3.9 - Exemplo e seqüência da operação de corte $\ldots \ldots \ldots \ldots \ldots \ldots \ldots \ldots$ 


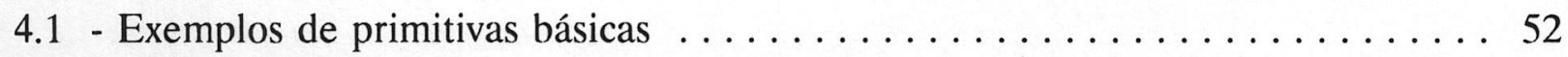

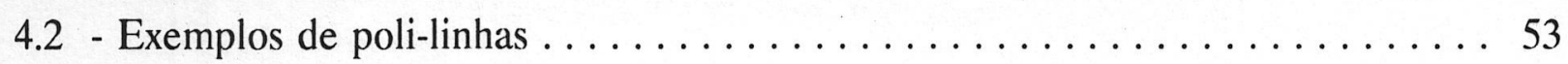

4.3 - Formas de geração de arcos disponíveis no $(\mathrm{SM})^{2} \ldots \ldots \ldots \ldots \ldots \ldots \ldots$

4.4 - Curvas B-Spline: controle local e formação de cantos . . . . . . . . . 55

4.5 - Formas de geração de círculo utilizadas no $(\mathrm{SM})^{2} \ldots \ldots \ldots \ldots \ldots \ldots \ldots$

4.6 - Elipse traçada pelos eixos vertical e horizontal $\ldots \ldots \ldots \ldots \ldots \ldots \ldots . \ldots \ldots$

4.7 - Classificação de triângulos utilizada no modelador . . . . . . . . . . 57

4.8 - Exemplos de quadriláteros notáveis com seus parâmetros . ........... 57

4.9 - Conceito e classificação de polígonos no contexto do $(\mathrm{SM})^{2} \ldots \ldots \ldots \ldots . \ldots 58$

4.10 - Exemplo dos tipos de polígonos disponíveis no $(\mathrm{SM})^{2} \ldots \ldots \ldots \ldots \ldots \ldots 58$

4.11 - Exemplos de prismas e seus parâmetros de definição $\ldots \ldots \ldots \ldots \ldots \ldots 61$

4.12 - Exemplos de pirâmides e seus parâmetros de definição ............. 62

4.13 - Tipos de blocos disponíveis no (SM) ${ }^{2}$ e seus parâmetros $\ldots \ldots \ldots \ldots \ldots 63$

4.14 - Exemplos de cilindro gerados pelo $(\mathrm{SM})^{2} \ldots \ldots \ldots \ldots \ldots \ldots \ldots \ldots 6$

4.15 - Tipos de cones disponíveis no modelador $\ldots \ldots \ldots \ldots \ldots \ldots \ldots \ldots \ldots 6$

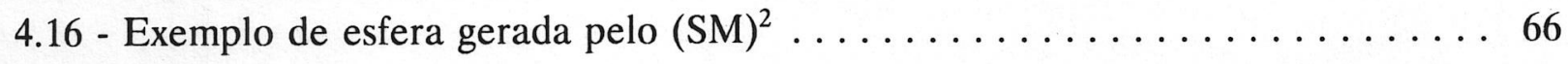

4.17 - Exemplo de toro gerado por rotação $\ldots \ldots \ldots \ldots \ldots \ldots \ldots \ldots \ldots \ldots 66$

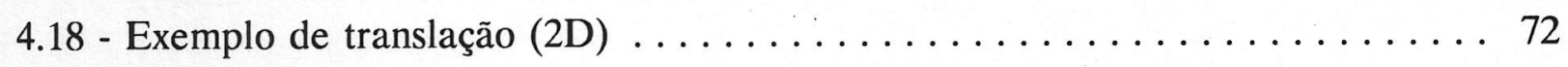

4.19 - Rotação em relação a um ponto qualquer (2D) $\ldots \ldots \ldots \ldots \ldots \ldots \ldots \ldots \ldots \ldots \ldots \ldots \ldots$

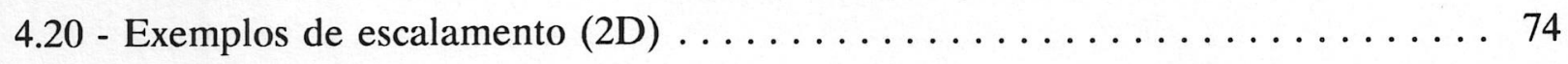

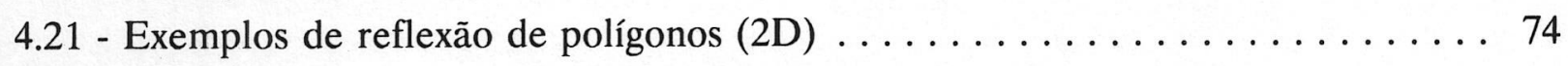

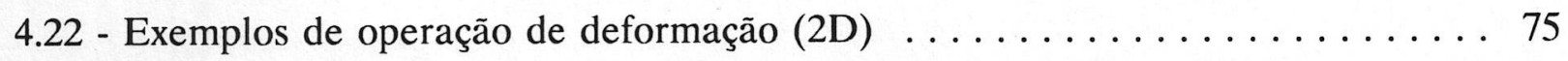

4.23 - Exemplos de varredura translacional simples . . . . . . . . . . . . 80

4.24 - Exemplos de varredura translacional cônica $\ldots \ldots \ldots \ldots \ldots \ldots \ldots \ldots . \ldots \ldots$

4.25 - Exemplo de varredura translacional com torção $\ldots \ldots \ldots \ldots \ldots \ldots \ldots . \ldots \ldots 2$

4.26 - Exemplos de varredura rotacional simples aberta $\ldots \ldots \ldots \ldots \ldots \ldots . \ldots 3$

4.27 - Exemplos de varredura rotacional simples fechada $\ldots \ldots \ldots \ldots \ldots \ldots . \ldots 4$

4.28 - Exemplo de varredura rotacional helicoidal . . . . . . . . . . . . 85

4.29 - Exemplo de degeneração em uma varredura genérica $\ldots \ldots \ldots \ldots \ldots \ldots 86$ 
5.1 - Componentes do modelador $(\mathrm{SM})^{2} \ldots \ldots \ldots \ldots \ldots \ldots \ldots \ldots \ldots \ldots \ldots \ldots \ldots \ldots$

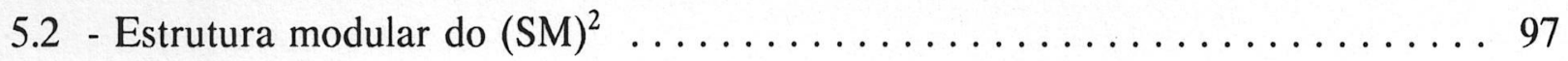

5.3 - Visão hierárquica da estrutura de dados utilizada no $(\mathrm{SM})^{2} \ldots \ldots \ldots \ldots 102$

5.4 - Primitiva esfera do $(\mathrm{SM})^{2}$, em diferentes resoluções $\ldots \ldots \ldots \ldots \ldots \ldots$

5.5 - Exemplos de primitivas vazadas (cilindro, bloco e cone), iluminadas com Flat Shading ................................. 107

5.6 - Esfera oca, iluminada com Flat Shading e efeito de transparência ....... 108

5.7 - Modelos gerados por varredura translacional simples de polígono definido através de seus pontos (Flat Shading) . . . . . . . . . . . . . . 108

5.8 - Modelo gerado por varredura rotacional de uma curva definida por B-Spline, poli-linha e arco . . . .......................... 109

5.9 - O mesmo modelo da figura anterior, iluminado com Flat Shading . . . . . . 109

5.10 - O mesmo modelo da figura anterior, iluminado com Phong Shading ...... 110

5.11 - Modelos gerados por varredura rotacional de uma curva B-Spline (à esquerda) e de uma poli-linha (à direita) . . . . . . . . . . . . . 110

5.12 - Modelo gerado por varredura rotacional helicoidal de uma elipse

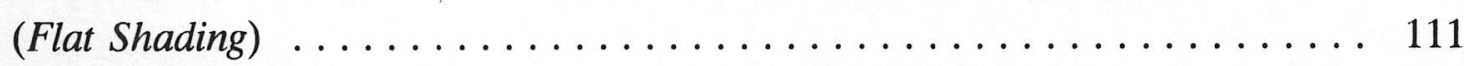

5.13 - Modelo gerado por varredura rotacional helicoidal de um círculo (Phong Shading) ............................. 111

5.14 - Modelos gerados pela varredura translacional com torção de um polígono

(rosca) e varredura translacional simples de um hexágono (cabeça)

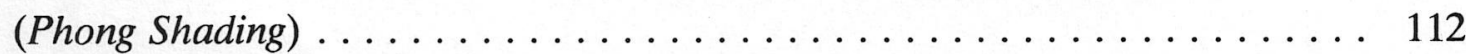

5.15 - Cena gerada utilizando primitivas e diferentes tipos de varredura

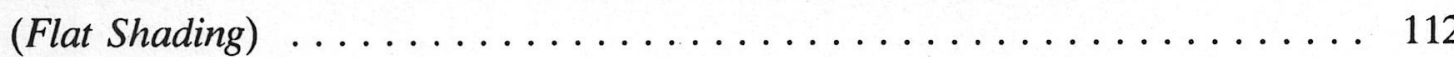




\section{QUADROS}

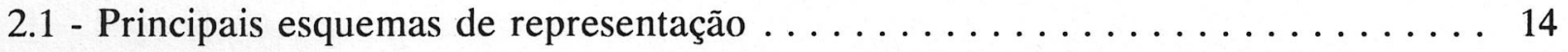

2.2 - Comparação entre os diversos tipos de superfícies ............... 25

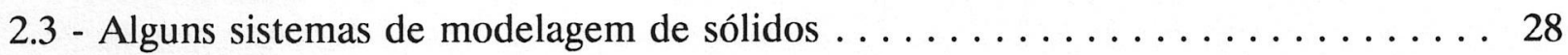

3.1 - Variações de aquiteturas em modeladores de sólidos . ............. 32

3.2 - Resumo das estruturas de dados B-Rep mais conhecidas . . . . . . . . . 35

3.3 - Uma variedade de situações de modelagem por operações booleanas ...... 43

3.4 - Quatro propriedades gerais dos modelos booleanos .............. 44

3.5 - Algumas abordagens para operações booleanas em modeladores poliedrais ... 45

4.1 - Resumo das primitivas planares do $(\mathrm{SM})^{2}$ e seus parâmetros . . . . . . . 60

4.2 - Definição e preenchimento das primitivas disponíveis no $(\mathrm{SM})^{2} \ldots \ldots \ldots \ldots 67$

4.3 - Resumo das primitivas sólidas e seus parâmetros $\ldots \ldots \ldots \ldots \ldots \ldots \ldots$

4.4 - Matrizes de transformação no plano e no espaço $\ldots \ldots \ldots \ldots \ldots \ldots \ldots 77$

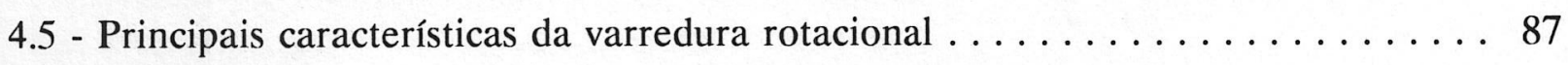

4.6 - Principais características da varredura translacional $\ldots \ldots \ldots \ldots \ldots \ldots \ldots 88$

5.1 - Conteúdo dos módulos existentes no modelador $(\mathrm{SM})^{2} \ldots \ldots \ldots \ldots \ldots$. . 99

5.2 - Descrição dos procedimentos e funções do módulo Primitiv.c . . . . . . . . 101

5.3 - Componentes da estrutura de dados B-Rep do (SM) $)^{2} \ldots \ldots \ldots \ldots \ldots$

5.4 - Operadores de Euler e seus respectivos formatos . . . . . . . . . . . 104

5.5 - Lista de argumentos dos operadores de Euler, utilizados nos arquivos ".log" $\ldots 105$ 


\section{INTRODUÇÃO}

\section{1 - O QUE É UM MODELADOR DE SÓLIDOS POR FRONTEIRA}

Um modelo é uma representação construída artificialmente com a finalidade de tornar mais fácil a observação de um objeto. O nível de detalhe e informações do modelo deve ser definido levando-se em conta a necessidade imposta pelas aplicações em que ele será empregado.

Muitos dos problemas cuja resolução demanda o uso de modelos são inerentemente geométricos, sendo conveniente destacar os dados que se referem à forma geométrica. $\mathrm{O}$ conjunto total de dados necessários para uma classe particular de problemas é chamado de modelo do objeto, enquanto dados puramente geométricos constituem o modelo geométrico. A coleção de métodos usados para descrever a forma e outras características geométricas de um objeto, bem como para simular processos dinâmicos, ficou conhecida por modelagem geométrica a partir do início dos anos 70 [Mor85].

A modelagem geométrica utiliza e aplica conceitos de geometria analítica, cálculo vetorial, topologia, teoria dos conjuntos, além de um arsenal de métodos computacionais. A combinação de ferramentas matemáticas e a complexidade potencial do modelo requerem o poder computacional de um computador. Um sistema de modelagem geométrica é, portanto, um sistema computacional que permite a criação, modificação e acesso à representação de objetos através de modelos geométricos.

A modelagem de sólidos - um ramo importante da modelagem geométrica - é usada para criar e comunicar informação sobre a forma de objetos sólidos, e envolve a criação e a manutenção de um modelo para futuro acesso e análise, permitindo formular e responder questões sobre propriedades volumétricas, como peso e momento de inércia, além de propriedades topológicas, como a conectividade e a verificação de pertinência. 
Um modelador de sólidos é um sistema computacional de modelagem que associa entidades geométricas (sólidos abstratos) a representações simbólicas, gerando esquemas de representação. $\mathrm{Na}$ modelagem de sólidos, um dos mais importantes esquemas de representação é o da representação por fronteira, no qual um sólido é descrito em termos de sua fronteira no espaço, composta por uma superfície fechada com alguma convenção para indicar de que lado da superfície está o sólido. A fronteira de um sólido é uma superfície bidimensional, representada como uma coleção de faces. As faces, por sua vez, representadas em termos de sua fronteira, são formadas por curvas unidimensionais, onde se localizam as arestas. Nas extremidades das arestas estão os vértices.

Um modelador por fronteira deve descrever como as faces, arestas e vértices que definem um objeto estão conectados entre si, ou seja, a topologia do objeto. Deve, ainda, armazenar as informações geométricas associadas, como equações das superfícies e das curvas sobre as quais estão as faces e as arestas, além das coordenadas dos vértices.

Modeladores por fronteira contam com uma variedade de operações para a construção de modelos. Operadores de Euler, freqüentemente usados para construir objetos definindo-se suas faces, arestas e vértices de forma a garantir a consistência e a validade topológica, são específicos deste tipo de modelador. Operações booleanas são ferramentas poderosas que utilizam operadores booleanos como a união, a intersecção e a diferença para formar objetos a partir de outros já modelados. Operações de varredura geram formas tridimensionais pelo deslocamento de um objeto normalmente bidimensional ao longo de uma trajetória, utilizando regras translacionais ou varredura rotacional. Existem ainda diversas operações para realizar modificações locais em um modelo.

A princípio, modeladores de sólidos são potencialmente capazes de suportar algoritmos totalmente automáticos para qualquer aplicação geométrica. Os modelos atuais, porém, possuem restrições quanto à robustez e completeza da informação, permitindo somente um conjunto limitado de aplicações. A tecnologia de hardware e software, necessária para manipular modelos geométricos, é extremamente complexa, com vários algoritmos sofisticados e questões numéricas delicadas. Muito do conhecimento requerido para atingir um nível ótimo de automação está ainda por ser desenvolvido. Existe uma grande variedade de pesquisas em andamento visando suprir estas deficiências e explorar ainda mais a aplicabilidade de modeladores de sólidos [Pra90, Req92]. 


\section{2 - MOTIVAÇÕES PARA O PRESENTE TRABALHO}

\subsection{1 - A Necessidade de um Modelador de Sólidos}

Um modelador deve fornecer ao projetista a sensação de estar em contato direto com o modelo que está sendo construído no computador, e para que isto seja possível existem dois requisitos cruciais em qualquer sistema de modelagem:

a) a existência de uma forma efetiva de interagir com o modelo armazenado no computador, tornando possível "caminhar" ao redor do objeto e alterá-lo sem necessitar reconstruí-lo (o que requer o conhecimento de como o mesmo foi inicialmente projetado). O sistema deve suportar um estilo de interação gráfica que seja natural e expresse com clareza o que o projetista deseja representar;

b) um modelo completo e preciso dos componentes deve ser produzido. O usuário necessita uma "descrição do produto" completa, incluindo geometria, definição de limites das superfícies, dimensões e outros atributos. Isto requer que toda face e aresta do modelo seja representada precisamente, e que outros atributos possam ser ligados a estas entidades na estrutura de dados. O projetista pode ainda desejar obter propriedades do produto (massa, volume, etc), avaliar a interferência entre componentes, gerar animações dos mecanismos projetados e produzir figuras de alta qualidade.

Do ponto de vista da organização, a descrição do produto elaborada pelo projetista deve ser usada por vários especialistas. As informações geradas necessitam ser padronizadas de forma a permitir sua integração com vários "pacotes" comprados ou desenvolvidos.

\subsection{2 - Situação Atual}

No âmbito mundial, a modelagem de sólidos estabeleceu um ponto de apoio em CAD/CAM comercial em muito pouco tempo, apesar de requerer algum treinamento de usuários e de comportar poucas aplicações diretas. O tempo de latência - tempo requerido para transformar o resultado de uma pesquisa em um produto de mercado - é menor na modelagem de sólidos do que muitas outras tecnologias CAD/CAM [Req83, Req92]. 
No Brasil existem também trabalhos relacionados à modelagem geométrica e de sólidos em várias instituições de ensino e pesquisa, mas são iniciativas isoladas com enfoque principalmente didático. Na UFRS foi criado um modelador de sólidos híbrido, que utiliza instanciamento primitivo e varredura na definição de objetos e cenas [Cas90]. Na EP-USP foi desenvolvido um Modelador de Sólidos Didático utilizando representação por fronteira, com estudos correlacionados enfatizando reconhecimento e escalonamento automático de "features" [Fis91a, Gar91, To191]. Na PUC-RJ existem estudos sobre formas de representação para objetos tridimensionais, incluindo a implementação de um modelador de sólidos por fronteira [Fis90, Fis91], além de trabalhos relacionados a modelagem geométrica implícita para qualquer tipo de superfície orientável [Tav92]. No IMPA são desenvolvidos trabalhos em modelagem geométrica, mas não especificamente de sólidos [Fig92, Cav92].

\section{3 - OBJETIVOS DO TRABALHO}

Existe um projeto em andamento, do grupo de Computação Gráfica e Processamento de Imagens do ICMSC-USP, que visa ao desenvolvimento de pesquisas em modelagem híbrida de objetos. Um dos objetivos desse projeto é construir um modelador de sólidos tridimensionais multirrepresentacional, que inclua técnicas convencionais de modelagem de sólidos associadas a representações paramétricas de superfícies. Pretende-se, com a construção do modelador, fornecer ao grupo uma ferramenta voltada para fins didáticos e de pesquisa em tópicos como modelagem tridimensional, conversão entre representações, visualização de objetos e CAD - Computer-Aided Design. Uma vez implementado, o modelador deverá englobar dispositivos para a especificação dos objetos a serem projetados, para a manipulação e análise desses objetos, bem como técnicas eficientes para a visualização dos resultados.

Em linhas gerais, o modelador será constituído de três subsistemas principais:

- um subsistema de representação, responsável pela manutenção, gerenciamento e acesso a representações internas;

- um subsistema de modelagem, responsável pelas operações que atuam sobre a representação interna, gerando objetos e cenas e respondendo a questões geométricas e topológicas; 
- um subsistema de interface, responsável pela visualização da cena e interação do modelador com o usuário;

Acoplado ao modelador poderão ser desenvolvidos programas aplicativos e interfaces para comunicação com outros sistemas. A figura 1.1 apresenta a estrutura geral descrita.

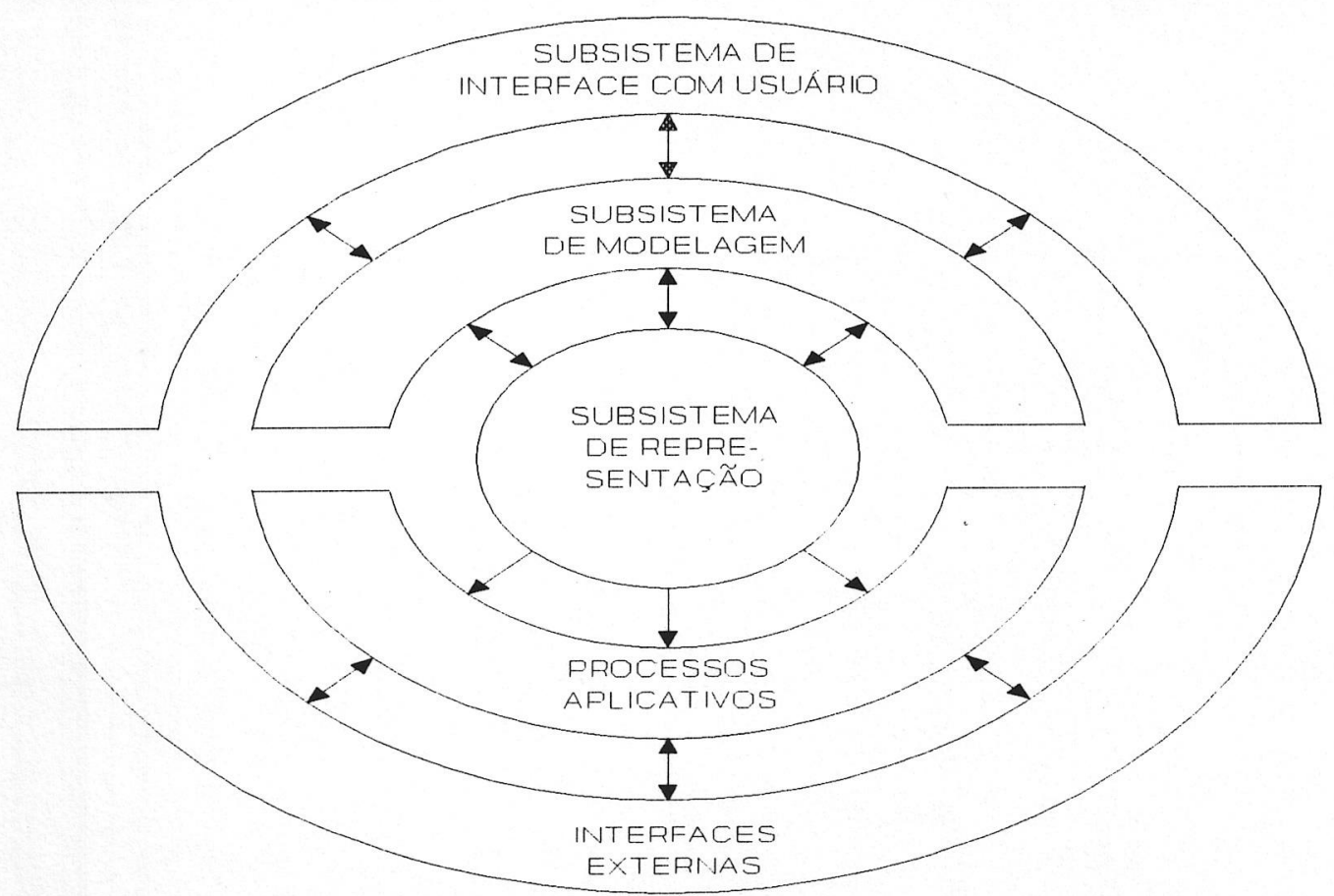

Figura 1.1 - Estrutura geral do sistema de modelagem de sólidos em desenvolvimento no ICMSC-USP

O trabalho aqui apresentado está inserido no contexto do projeto acima, e tem por objetivo submeter à discussão e à crítica o que foi desenvolvido na Dissertação de Mestrado, que envolveu um estudo sobre modelagem de sólidos, o projeto global do (SM) ${ }^{2}$ - Sistema de Modelagem de Sólidos Multirrepresentacional e a implementação de operações básicas de manipulação e de geração de sólidos por instanciamento de primitivas e varredura, utilizando representação interna por fronteira baseada em faces planas e deixando canais abertos para a inclusão de outros tipos de superfícies.

Visando facilitar a manutenção e evolução do sistema, procurou-se selecionar técnicas adequadas de Engenharia de Software e utilizá-las durante o desenvolvimento, de forma a produzir um sistema bem documentado, modular, que possa ser estendido, aprimorado e, principalmente, integrado a outros módulos de software. 


\section{4 - ORGANIZAÇÃO DA DISSERTAÇÃO}

Este trabalho encontra-se subdividido em 6 capítulos.

Nesta Introdução foram feitas algumas considerações gerais e definidos conceitos básicos necessários à compreensão e desenvolvimento do trabalho, como modelagem geométrica, modelagem de sólidos e representação por fronteira. Também foram introduzidas as bases que motivaram sua proposta e alguns requisitos para o tratamento do problema.

No capítulo 2 são apresentados os pontos relevantes do estudo bibliográfico realizado, fornecendo a fundamentação teórica relacionada à modelagem de sólidos, com ênfase na representação por fronteira.

No capítulo 3 são focalizadas as principais características da representação por fronteira, considerando sua arquitetura, representação interna, operações de modelagem e interface com o usuário.

No capítulo 4 faz-se um estudo detalhado das operações implementadas no decorrer deste trabalho, examinando as primitivas planares e sólidas, as operações de transformação geométrica e as operações de varredura.

No capítulo 5, dedicado ao Projeto em andamento no ICMSC, são apresentadas as principais características do modelador e os critérios utilizados no decorrer de seu desenvolvimento (especificação, projeto e implementação).

No capítulo 6 faz-se um balanço da situação atual do projeto, analisando suas restrições, investigando possíveis melhorias e destacando as contribuições obtidas deste trabalho, seguidas de sugestões para futuras pesquisas.

Finalizando, é apresentada a bibliografia consultada, tanto para o referencial teórico quanto para o metodológico.

Também foram elaborados documentos específicos referentes ao projeto, à implementação e utilização do modelador [Mag94b, Mag94c, Mag94d], bem como uma nota técnica sobre o uso de operadores de Euler [Mag94a], que servem como referências adicionais à dissertação. 


\section{Capítulo 2}

\section{TEORIAS E TÉCNICAS DE MODELAGEM DE SÓLIDOS}

\section{1 - CONSIDERAÇÕES INICIAIS}

Todos os modeladores de sólidos possuem uma arquitetura de software dependente dos recursos de modelagem neles disponíveis, uma vez que estes recursos influenciam os componentes necessários ao modelador. As propriedades apresentadas pelos modeladores, como concisão e poder de descrição, estão diretamente relacionadas à sua arquitetura. Este capítulo apresenta as principais teorias e técnicas de modelagem de sólidos, visando a uma melhor compreensão do trabalho desenvolvido. A revisão bibliográfica realizada enfatizou os sistemas que possuem representação por fronteira, por ser esta a abordagem utilizada no modelador em construção no ICMSC.

Este capítulo está dividido em 5 seções. Na seção 2.2 realiza-se um levantamento histórico da modelagem de sólidos em geral. A seção 2.3 refere-se aos esquemas de representação mais difundidos na modelagem de sólidos, ressaltando as vantagens oferecidas por esquemas híbridos e multirrepresentacionais. Na seção 2.4 são apresentadas as principais teorias e técnicas de modelagem utilizando a abordagem por fronteira. Na seção 2.5 estão relacionados os principais esforços de desenvolvimento de sistemas de modelagem utilizando representação por fronteira. Finalmente, na seção 2.6 é feita uma avaliação da bibliografia revisada. 


\section{2 - HISTÓRICO}

\subsection{1 - Primórdios}

Pode-se considerar como datado de 1963 o início do uso de computadores no projeto e manufatura de produtos industriais, conforme os artigos de Coons [Coo63] sobre requisitos de sistemas auxiliados por computador, de Sutherland [Sut63] sobre o uso do "Sketchpad" e de Roberts [Rob63] sobre o problema clássico de remoção de linhas escondidas.

Alguns dos primeiros usos de sistemas CAD ocorreram na indústria automobilística (através dos trabalhos de De Casteljau, na empresa Citröen [Cas59, Boh84], e do sistema UNISURF, desenvolvido por Bézier, na Renault [Bez72, Hea86, Boh84]) e na indústria aeroespacial (relatado por Chansen em 1965 [Cha65]). Os métodos utilizados então, provenientes de estudos matemáticos desenvolvidos em fins dos anos 50 e início dos anos 60, demandavam recursos computacionais consideráveis, e só recentemente se tornaram proposições práticas para sistemas de projeto interativos. Sistemas deste tipo simplesmente modelavam curvas isoladas.

No final dos anos 60 , sistemas de projeto computadorizados estavam disponíveis para produzir desenhos semelhantes aos desenhos manuais, de maneira diferente e com mais eficiência. Tais sistemas evitavam muito do trabalho repetitivo inerente ao processo manual, e ao mesmo tempo permitiam ao projetista trabalhar de uma forma que lhe era familiar. Tal como os desenhos produzidos manualmente, aqueles produzidos em sistemas CAD/CAM eram compostos principalmente por linhas retas e arcos de circunferências, e carregados de anotações como dimensões, notas e outros tipos de informação. A principal diferença era o uso do vídeo gráfico em substituição às folhas de papel (apesar de ser possível gerar impressões em um plotter). $\mathrm{O}$ aspecto menos familiar deste método de desenho era a necessidade de interação com o computador, e muitos dos desenhistas e projetistas tradicionalmente treinados encontravam dificuldades na passagem para o novo modo de operação. 


\subsection{2 - Modelos Tridimensionais}

No início dos anos 70, a associação de informação sobre profundidade com as linhas de um desenho 2D permitiu a definição de uma classe de objetos conhecida como objetos semi-tridimensionais $\left(2 \frac{1}{2} \mathrm{D}\right)$ [Pra90]. Todas as superfícies de um objeto deste tipo ou são horizontais ou verticais, $\mathrm{O}$ computador pode então gerar uma representação unificada do objeto ao invés de três representações parciais complementares na forma de visões ortogonais tradicionalmente desenhadas, como as apresentadas na figura 2.1. Pela primeira vez, foi gerado um modelo computacional do produto, e não apenas desenhos isolados.

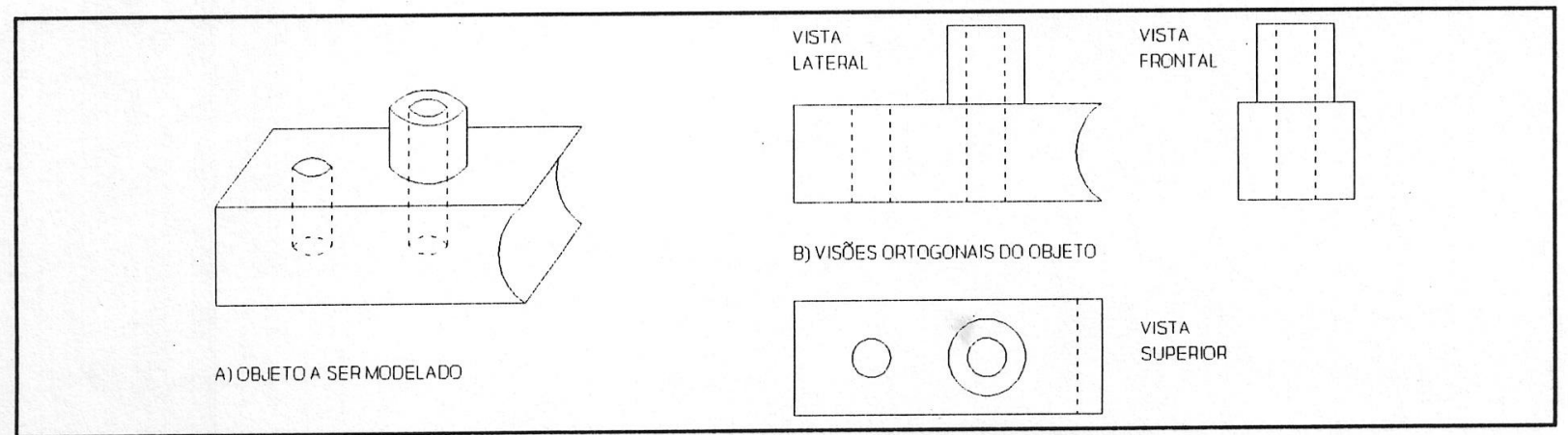

Figura 2.1 - Exemplo de visões ortogonais tradicionalmente modeladas

Através do computador, o objeto semi-tridimensional era representado como um conjunto de arestas no espaço, e logo foi possível generalizar essa idéia, o que permitiu a geração de modelos $3 \mathrm{D}$ completos do mesmo tipo. Tais modelos tornaram-se conhecidos como modelos fio-de-arame ("wireframe") [Fol90]. Uma vantagem imediata da representação "wireframe" é que o computador podia gerar automaticamente desenhos do objeto de qualquer ponto de vista e em qualquer projeção escolhida pelo usuário, como ilustrado na figura 2.2. Se os desenhos $2 \mathrm{D}$ eram requeridos, as projeções ortogonais poderiam ser derivadas do modelo unificado, simplesmente observando-o através de projeções paralelas aos três eixos.

Porém, como os desenhos eram compostos somente por um conjunto de arestas, desenhos obtidos a partir de certos pontos de vista tornavam-se muito congestionados para objetos complexos, uma vez que todas as arestas eram desenhadas. A falta de informação sobre superfícies do modelo dificultava a compreensão do desenho, conduzindo a interpretações ambíguas e impossibilitando a geração automática de visões com linhas e superfícies escondidas, que tornaria a visualização muito mais fácil. 

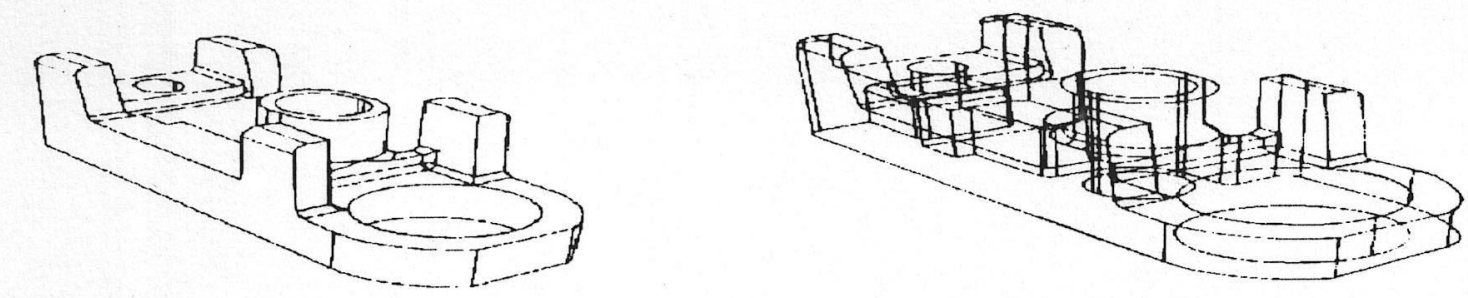

Figura 2.2 - Exemplo de representação "wireframe" de um objeto

\subsection{3 - Modeladores de Sólidos}

O desenvolvimento seguinte nesta seqüência de técnicas de representação de produtos foi o modelador de sólidos, que uniu as vantagens dos modeladores "wireframe" e dos modeladores de superfície. O modelo agora contém informações referentes a todas as faces do objeto, incluindo as superfícies e as arestas curvas que o limitam. Além disto, detalhes sobre a conectividade entre faces, arestas e outros elementos são armazenados. Do ponto de vista da computação gráfica, o computador pode agora gerar automaticamente figuras com linhas ou superfícies escondidas do objeto representado de qualquer ponto de vista. Pode ainda computar o volume, massa, momento de inércia do objeto, interferência entre componentes de uma montagem, o que é de grande conveniência em aplicações de engenharia.
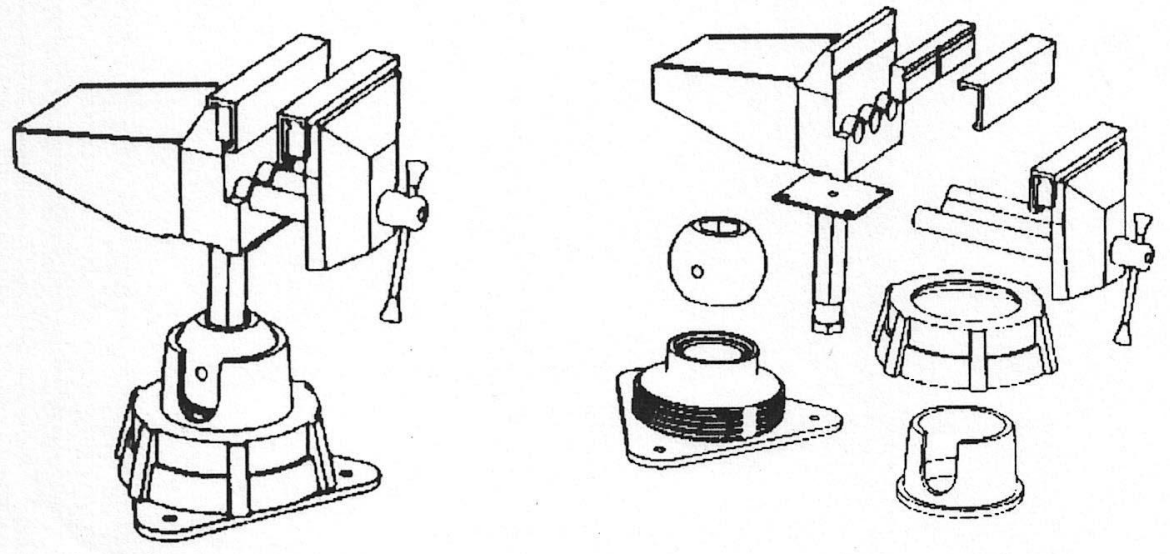

Figura 2.3 - Exemplo de uma montagem gerada por um modelador de sólidos 
A modelagem de sólidos progrediu rapidamente na década de 70 [Req82, Bad78], mas a tecnologia necessária para a sua implementação, em termos de hardware e software, é bastante complexa, havendo até hoje uma grande demanda por pesquisas [Pra90].

A técnica de modelagem por fronteira pode ser vista como a generalização não trivial da representação "wireframe" e é a técnica de modelagem não ambígua mais difundida.

\subsection{4 - Comentários}

O aspecto mais significativo da progressão ora descrita é a ampliação da possibilidade de interpretação do modelo pelo computador. $O$ desenho produzido manualmente era de interpretação exclusiva do projetista, engenheiro ou técnico. Mesmo quando um desenho similar era produzido usando um sistema de desenho 2D, a informação contida no computador não pretendia ter interpretação automática, sendo meramente uma codificação para o desenho a ser interpretado pelo homem. Com o "wireframe" aumentou-se a possibilidade de uso automático dos dados, pois o computador podia gerar desenhos do objeto a partir de qualquer ponto de vista. Contudo, muitas aplicações eram ainda impossíveis devido à ausência de informações sobre as superfícies e da noção de interior e exterior. Modeladores de superfície permitiam somente a definição de superfícies desconexas, que não definiam, necessariamente, um volume. Eles permitiam que certas aplicações fossem automatizadas, notavelmente a geração de dados para modelos de sólidos geometricamente completos, cujo potencial de automação para uma grande gama de aplicações começava a emergir.

Hoje, embora a maioria dos sistemas CAD/CAM poderosos, que foram desenvolvidos nos últimos 15 anos - originários dos modelos "wireframe" -, tenham incorporado a capacidade de modelagem de sólidos [Pra90], o número de aplicações que foram automatizadas é ainda restrito, devido à concentração inicial em aspectos puramente geométricos de modelagem. Só recentemente voltou-se a atenção para requisitos adicionais de "modelos informacionalmente completos", incluindo não apenas informações geométricas, mas também outras informações associadas ao modelo, que permitam automação de processos e operação sem intervenção humana. 


\section{3 - REVISÃO DE MODELAGEM DE SÓLIDOS}

Segundo Requicha [Req83], o termo "modelagem de sólidos" envolve um corpo de teorias, técnicas e sistemas que focalizam uma representação de sólidos "informacionalmente completa" permitindo - pelo menos em princípio - que qualquer propriedade geométrica bem definida de qualquer sólido representável seja calculada automaticamente.

A principal importância dos sistemas de modelagem de sólidos é a sua capacidade de distinguir entre o interior, o exterior e a superfície de um objeto tridimensional, o que faculta calcular propriedades dependentes desta distinção [Mor85]. Para atingir este objetivo, algumas restrições precisam ser obedecidas, de forma que os sólidos modelados sejam válidos.

\subsection{1 - Requisitos para a Representação de Objetos}

Como para a modelagem de sólidos o que interessa são as formas limitadas e conectadas, é importante estabelecer critérios para a definição das superfícies destas formas, denominadas faces. Segundo Mortenson, as faces devem ser limitadas, orientáveis, conexas, homogêneas, possuir área finita, dividir o espaço em domínios disjuntos e não se autointerceptar. Além disto, a forma a ser modelada deve conter um número finito (e maior que um) de faces que, unidas, definem sua fronteira [Mor85].

Requicha e outros pesquisadores estabeleceram um conjunto de propriedades necessárias para classificar um objeto como sólido válido, ou seja, manufaturável: rigidez, homogeneidade tridimensional, finitude, fechamento sob operações, finitude de descrição e determinismo de fronteira [Req77, Req80, Mor85, Män88]. Requicha também definiu propriedades desejáveis em esquemas de representação de modelos: não ambigüidade, unicidade, potência descritiva (domínio), validade, concisão, facilidade para utilização pelos usuários e eficiência do ponto de vista das aplicações que utilizarão o modelo [Req80]. Tais propriedades foram consideradas por Foley [Fol90] para fazer uma comparação entre esquemas de representação existentes. Diferentemente de Requicha, Mäntylä [Män88] e Foley [Fol90] incluem o fechamento sob operações como propriedade de um esquema de representação. 


\subsection{2 - Principais Esquemas de Representação}

Mortenson [Mor85] considera seis categorias principais de esquemas de representação: instanciamento primitivo, decomposição celular (incluindo enumeração da ocupação espacial), "wireframe", por varredura, geometria sólida construtiva e por fronteira. Um resumo destes esquemas de representação é apresentado no quadro da página a seguir (quadro 2.1).

Os seis métodos oferecem vantagens para alguns tipos de aplicações. Três deles são os mais importantes para os sistemas de modelagem contemporâneos: representação por varredura, geometria sólida construtiva e representação por fronteira. Destes, os dois últimos dominam os sistemas atuais e provavelmente irão dominar os futuros modeladores.

A geometria sólida construtiva (CSG), desenvolvida na Universidade de Rochester, é um esquema de representação no qual sólidos são definidos a partir de composições booleanas de sólidos primitivos [Req82]. Em CSG um objeto é descrito em termos de formas elementares (semi-espaços) ou primitivas (sólidos primitivos limitados) e é representado como uma árvore binária: os nós folhas são formas primitivas sólidas regulares, dimensionadas e posicionadas no espaço, e os nós internos são operadores booleanos regularizados como união, intersecção e diferença, que atuam sobre estas primitivas regulares e garantem que os sólidos formados são válidos.

Como o CSG armazena o processo de construção do sólido ao invés de informações sobre a fronteira do sólido com o espaço, ele é considerado um esquema de representação não avaliado, implícito, procedural e algorítmico.

Por outro lado, a representação por fronteira (B-Rep), considerado um esquema de modelagem de sólidos avaliado e explícito, descreve o sólido em termos de seus limites espaciais, normalmente uma superfície fechada com alguma convenção para indicar em que lado da superfície o sólido está. Sólidos são representados como união de faces, limitadas por arestas, que por sua vez são limitadas por vértices. Esta hierarquia define a topologia do objeto que, associada às informações geométricas - como equações das superfícies sobre as quais estão as faces, equações das curvas sobre as quais estão as arestas e as coordenadas do vértice - fornecem a rigidez do objeto representado. 


\begin{tabular}{|c|c|}
\hline $\begin{array}{l}\text { INSTANCIAMENTO PRIMITIVO } \\
\text { - Define um conjunto de formatos sólidos 3D } \\
\text { primitivos, que são relevantes para a área em que } \\
\text { os modelos estão sendo utilizados. } \\
\text { - A primitiva pode ser vista como a definição de } \\
\text { uma família de componentes cujos membros } \\
\text { variam em relação a alguns parâmetros. } \\
\text { - Objetos representados por tuplas de tamanho } \\
\text { fixo (ex: "esfera", coordenadas do centro, raio). } \\
\text { - Seu uso é combinado com outros esquemas para } \\
\text { definir objetos complexos. } \\
\text { [Reg80, Män88, Fol90] }\end{array}$ & $\begin{array}{l}\text { - O sólido é decomposto em células, sendo que } \\
\text { cada uma possui um número arbitrário de lados, } \\
\text { que compartilham } 1 \text { ponto, } 1 \text { aresta ou } 1 \text { face. } \\
\text { - Células primitivas são parametrizadas e } \\
\text { combinadas pela operação de colagem ("glue"). } \\
\text { - Uso em análise estrutural, como representação } \\
\text { básica para métodos de elementos finitos. } \\
\text { - A enumeração da ocupação espacial pode ser } \\
\text { vista como um caso especial, que possui células } \\
\text { cúbicas em um grid fixo e representação otimizada } \\
\text { pelo esquema "octree". } \\
\text { [Req } 80, \text { Män88, Fol90] }\end{array}$ \\
\hline $\begin{array}{l}\text { - Representa um objeto através de suas arestas e } \\
\text { consiste inteiramente de pontos, linhas e curvas, } \\
\text { dando a ilusão de solidez. } \\
\text { - Eficiente para gerar e representar desenhos. } \\
\text { - A falta de informação geométrica ao modelar } \\
\text { sólidos resulta em problemas: geração de modelos } \\
\text { ambíguos ou sem sentido físico; falta de coerência } \\
\text { visual; confusão devido ao excesso de linhas. } \\
\text { [Voe77, Reg80, Mor85, Män88, Pra90] }\end{array}$ & $\begin{array}{l}\text { - Representação baseada na noção de mover uma } \\
\text { região (gerador) por um caminho (diretor), } \\
\text { utilizando duas formas básicas: rotacional e } \\
\text { translacional, que podem ser combinadas entre si } \\
\text { e com o escalamento. } \\
\text { - Uso em automação industrial e animação. } \\
\text { - Utilizada por vários esquemas como alternativa } \\
\text { para a descrição de objetos. } \\
\text { [Req80, Män88, Fol90, Cas90] }\end{array}$ \\
\hline $\begin{array}{l}\text { GEOMETRIA SÓLIDA CONSTRUTIVA : CSG } \\
\text { - Sólidos descritos em termos de primitivas } \\
\text { simples, combinadas por operadores booleanos } \\
\text { regularizados e movimentos rígidos. } \\
\text { - Utilizam como representação árvores binárias, } \\
\text { onde cada folha é uma primitiva e cada nó interno } \\
\text { é um operador booleano ou um movimento rígido. } \\
\text { - Uso bastante difundido, devido ao embasamento } \\
\text { matemático, conhecimento de algoritmos e à } \\
\text { ampla área de aplicação. } \\
\text { [Reg80, Män88, Fol90, Pra90] }\end{array}$ & $\begin{array}{l}\text { - Sólidos descritos em termos de suas superfícies } \\
\text { limitantes. } \\
\text { - Topologia definida pelo conjunto de faces, } \\
\text { arestas e vértices que compõem o sólido. } \\
\text { - Geometria definida pelas coordenadas dos } \\
\text { vértices e pelas equações das curvas e superfícies. } \\
\text { - Uso muito amplo, devido à generalidade e } \\
\text { disponibilidade imediata da representação de } \\
\text { faces, arestas e das relações entre elas. } \\
\text { [Req80, Män88, Fol90, Pra90] }\end{array}$ \\
\hline
\end{tabular}

Quadro 2.1 - Principais esquemas de representação 


\subsection{3 - Esquemas Híbridos}

Do ponto de vista da construção de modelos, nenhuma representação possui propriedades uniformemente melhores que todas as outras. Para conseguir o máximo de flexibilidade em um sistema de modelagem de sólidos, não é razoável confiar em um único tipo de representação. Os esquemas híbridos podem então ser utilizados para combinar diferentes representações, procurando explorar o potencial de cada uma.

Do ponto de vista da edição de modelos, entretanto, existem técnicas de edição poderosas, baseadas na geometria construtiva, que não podem ser implementadas de maneira razoável em um esquema por fronteiras, uma vez que este não mantém o registro do processo de construção. A habilidade de modificar, substituir e remover primitivas ou subárvores numa árvore CSG permite que modificações significativas num modelo sejam especificadas com um mínimo de comandos por parte do projetista. Da mesma forma, existem métodos e operações baseados em representações por fronteira que não podem ser representados num contexto puramente construtivo.

Miller [Mil89] apresenta um hipotético sistema de modelagem ideal, capaz de manter e manipular representações por fronteira e CSG de maneira redundante, de forma a explorar as vantagens de cada uma. A viabilidade deste sistema exige, porém, que sejam resolvidos significativos problemas arquiteturais, conceituais e práticos, tais como limitações de hardware, inexistência de um conjunto de técnicas de modelagem eficiente e robusta que permita a conversão exata e bidirecional entre as representações, além da necessidade de alto investimento, somente justificável se forem obtidos um extenso poder de representação e uma fácil adaptação dos processos aplicativos. Assim sendo, a solução prática sugerida por Miller é adotar um modelo híbrido primariamente CSG ou B-Rep, conforme sua adequação à aplicação desejada. As três abordagens são ilustradas na figura a seguir, sendo que a de maior interesse para este trabalho é a primariamente B-Rep.

Devido à inexistência de conversão exata e bidirecional entre as representações utilizadas no modelador em desenvolvimento no ICMSC, optou-se pela utilização do termo multirrepresentacional ao invés de híbrido. 


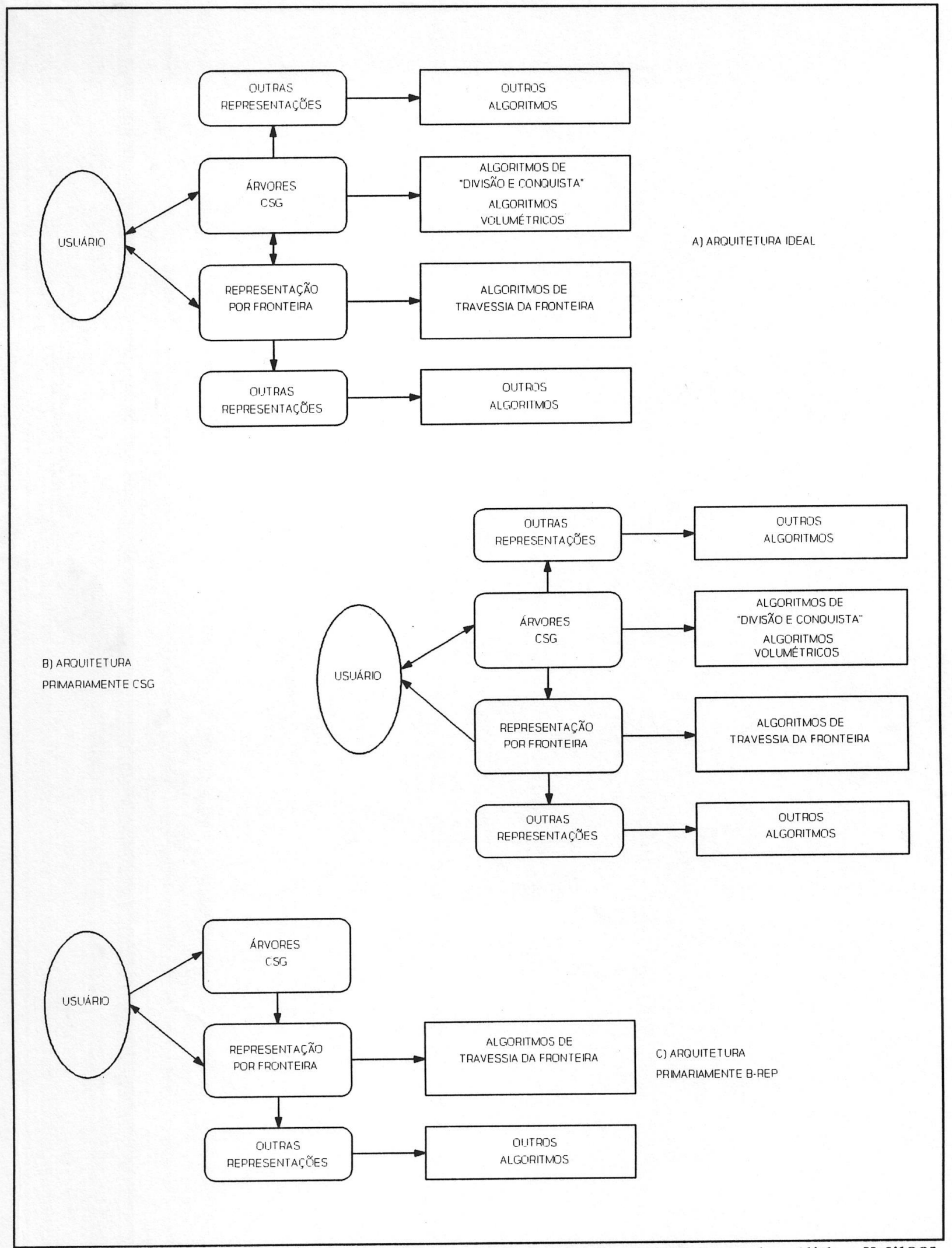

Figura 2.4 - Abordagens para a arquitetura de sistemas de modelagem de sólidos [Mil89] 


\section{4 - TEORIAS E TÉCNICAS DE MODELAGEM POR FRONTEIRA}

Apesar de haver várias técnicas de modelagem, dando suporte a todas elas existem alguns princípios e restrições aos quais objetos sólidos a serem modelados devem obedecer. Boa parte do embasamento teórico necessário para a modelagem por fronteira é detalhada por Mäntylä [Män88], Hoffman [Hof89] e Mortenson [Mor85] e encontra-se resumida a seguir.

\subsection{1 - Variedades Bidimensionais, Não Bidimen- sionais e Modelos Planares}

Muito do trabalho teórico em modelagem de sólidos foi inicialmente baseado na teoria dos "r-sets", que são subconjuntos do espaço Euclidiano 3D limitados, fechados, regulares e semi-analíticos [Req80, Män84, Des92] que satisfazem os requisitos para sólidos válidos apresentados na seção 2.3.1. Um modelo alternativo que emergiu e se destacou em decorrência da fundamentação teórica desenvolvida foi o "manifold" (também denominado sólido de variedade bidimensional), que é um subconjunto dos "r-sets" caracterizado por duas propriedades principais: as arestas são compartilhadas por exatamente duas faces e as fronteiras são superfícies que podem ser representadas matematicamente. Os "r-sets" que não satisfazem estas propriedades são denominados "não-manifolds" (ou sólidos de variedade não bidimensional). Exemplos de sólidos de variedade bidimensional e não bidimensional são apresentados na figura 2.5 .

A representação de variedade bidimensional é caracterizada por possuir todos os pontos pertencentes à sua fronteira rodeados por uma região "bidimensional" de pontos pertencentes à superfície. Assim, é possível deformar a superfície de forma a torná-la um plano, sem que seja necessário rompê-la ou "colar" pontos separados uns dos outros. 

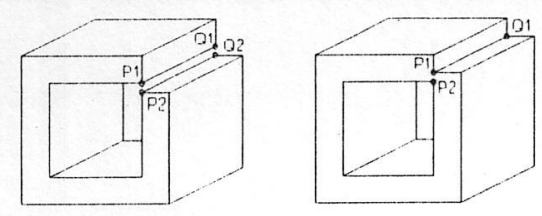
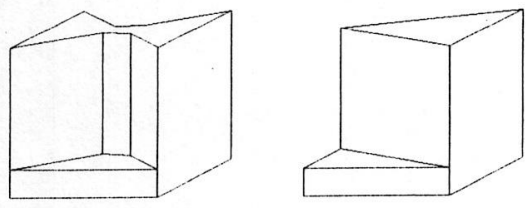

A) OBJETOS DE VARIEDADE BIDIMENSIONAL

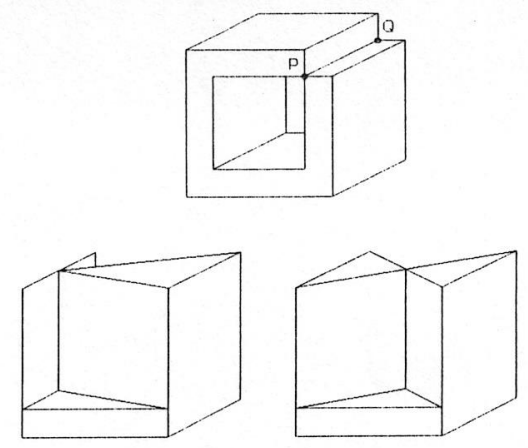

B) OB.JETOS DE VARIEQADE NÃO BIDIMENSIONAL

Figura 2.5 - Exemplos de objetos de variedade bidimensional e não bidimensional

Sólidos de variedade bidimensional podem, então, ser estudados através de um modelo planar - uma representação da superfície de um objeto sólido, decomposta em faces - que fornece uma abstração matemática útil e de aplicação direta na modelagem de sólidos por fronteira. A figura 2.6 a seguir ilustra a topologia de um cubo maciço e de um cubo vazado, que são sólidos de variedade bidimensional, e os modelos planares correspondentes.

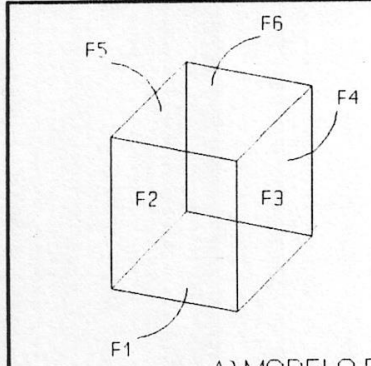

A) MODELO FLANAR DE UM CIJBO

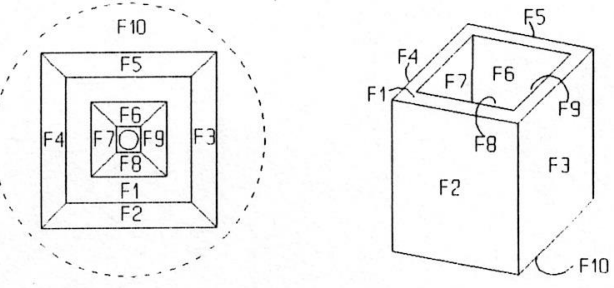

B) MODELO PLANAR DE UM IUBO VAZADO

Figura 2.6 - A topologia do cubo representada por modelo planar

Uma definição matemática formal de modelos planares é apresentada por Mäntylä [Män88], e uma descrição formal dos conceitos de topologia realacionados pode ser encontrada em Alexandroff [Ale61].

Um dos principais resultados da teoria desenvolvida para modelos planares é o Teorema da Invariância [Ale61], que garante às propriedades topológicas manterem-se constantes para todos os modelos planares que podem ser construídos. Assim, todos os modelos planares realizáveis podem ser criados por operações topológicas locais e globais, sendo que estas operações satisfazem os requisitos de fechamento e completeza [Män84, Män88]. A idéia persiste para modelos por fronteira, através dos operadores de Euler, apresentados a seguir. 


\subsection{2 - Operadores de Euler}

Pesquisas desenvolvidas no início dos anos 80 [Eas79, Bra80, Män82, Män84, Chi85] mostram que os operadores de Euler fornecem um meio natural de manipular representações por fronteira para sólidos de variedade bidimensional.

A denominação operadores de Euler é derivada da conhecida "Lei de Euler": em qualquer poliedro simples, a relação entre o número de faces $(F)$, arestas $(E)$ e vértices $(V)$ deve satisfazer à equação:

$$
\mathbf{V}-\mathbf{E}+\mathbf{F}=\mathbf{2}
$$

A fórmula pode ser generalizada para sólidos arbitrários pela introdução de três outros parâmetros, que são: o número total de anéis - cavidades em faces - existentes no sólido ( $\mathrm{R}$, de "Ring"); o número total de orifícios que atravessam o sólido (H, de "Hole"); o número de componentes conexos - cascas - em um conjunto de sólidos ( $\mathrm{S}$, de "Shell"). A fórmula geral é:

$$
V-E+F=2(S-H)+R
$$

Os operadores de Euler trabalham sobre a topologia do modelo. Cada vez que um operador de Euler é aplicado, o sólido resultante sempre satisfaz a equação, sendo topologicamente válido. A relação dos operadores, juntamente com a descrição abreviada e a ilustração de como os mesmos atuam no modelo planar é apresentada na figura 2.7.

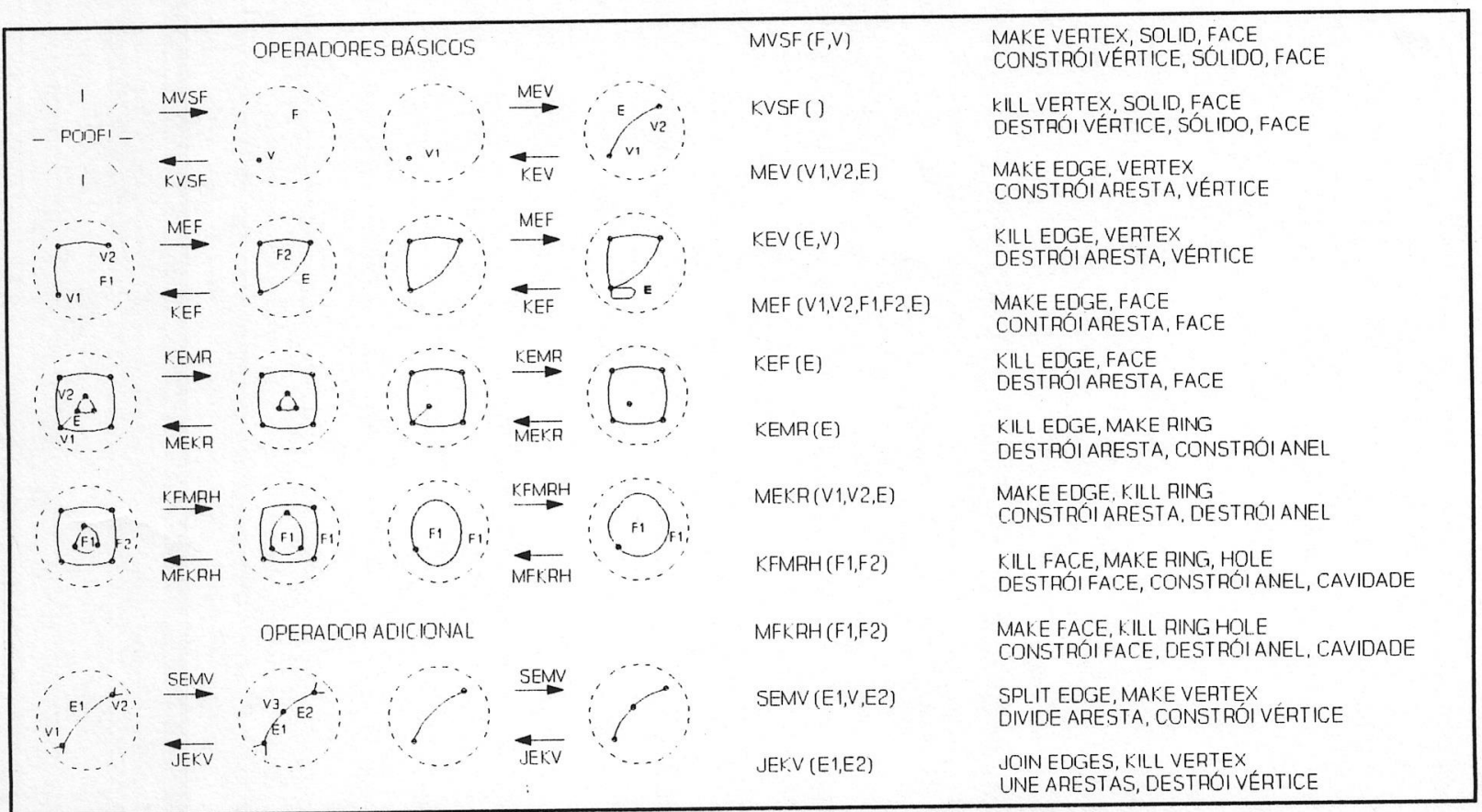

Figura 2.7 - Operadores de Euler: descrição e representação gráfica 
Apesar de serem suficientes os cinco primeiros operadores (e seus inversos) para descrever todos os objetos que satisfazem a fórmula acima, um sexto operador (semv, jekv) pode ser incluído para auxiliar as operações geométricas.

A geração do modelo de um objeto através de operadores de Euler e o modelo planar correspondente é exemplificada na figura 2.8 .

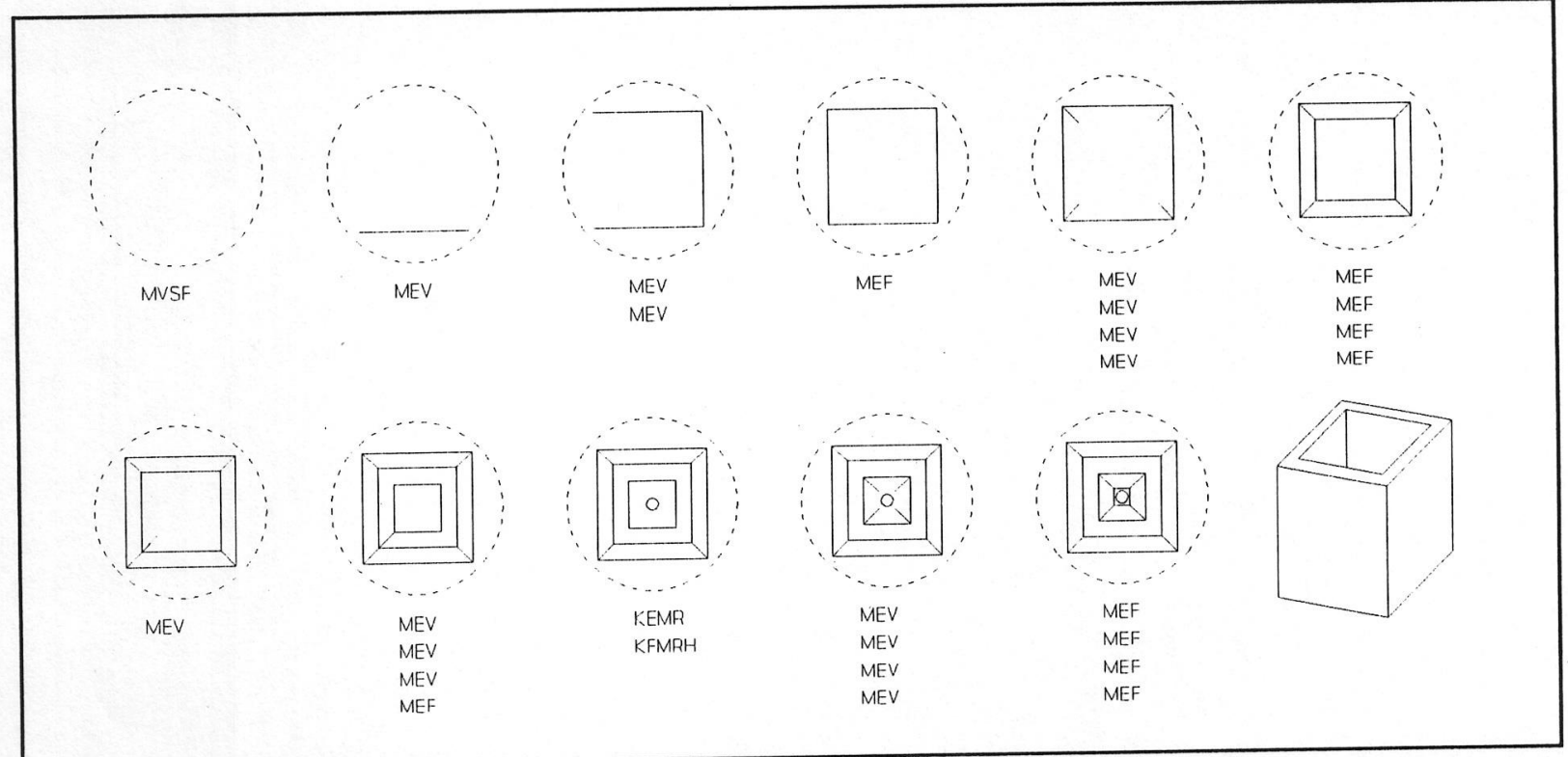

Figura 2.8 - Seqüência para a geração de um modelo através de Operadores de Euler, representado em modelo planar

Como resultado de suas pesquisas, Mäntylä mostrou que toda representação por fronteira válida para objetos de variedade bidimensional pode ser construída a partir dos operadores de Euler; uma representação por fronteira construída por operadores de Euler satisfaz todas as condições combinatórias (topológicas) para validade; se a representação é corretamente embutida no espaço Euclidiano, o resultado é um objeto de variedade bidimensional válido.

Os resultados de Mäntylä são importantes por fornecerem respostas definitivas para questionamentos que não haviam sido resolvidos na literatura anterior, porém não esclarecem se resultados similares valeriam para "r-sets" de variedade não bidimensional. Pesquisas mais recentes [Des92] descrevem uma extensão da representação de variedade bidimensional para "r-sets", introduzindo um conjunto mínimo de operadores de Euler generalizados, suficientes para a construção e manipulação de "r-sets". 


\subsection{3 - Validação de Representações}

Até meados dos anos 80, a maioria dos sistemas de modelagem geométrica transferia ao usuário a verificação da completude, validade e unicidade do modelo [Mor85]. Tal verificação ficava mais difícil à medida que o modelador se tornava mais complexo, mesmo com técnicas sofisticadas de exibição gráfica. Além disto, um modelo válido pode ser usado isoladamente como entrada para aplicações que introduzem automaticamente modificações no modelo, sejam transitórias ou permanentes. A necessidade de intervenção humana para a verificação de um modelo geométrico diminui de maneira inversamente proporcional ao aumento de sofisticação do processo de modelagem. Assim, a necessidade de auto-verificação da modelagem é inevitável e deve ser precedida por um profundo entendimento do que constitui um modelo válido, único e completo.

Representações B-Rep válidas são difíceis e tediosas de serem construídas manualmente, devido à necessidade de satisfazerem as combinações métricas e combinatoriais [Req80]. A integridade topológica de um modelo por fronteira impõe restrições na coleção de faces para assegurar a validade do modelo [Män82]. Por exemplo, cada aresta deve pertencer a exatamente dois ciclos - conjuntos fechados de arestas - não necessariamente distintos, e a orientação das arestas no ciclo deve ser consistente em todo o modelo. Para satisfazer esta última condição, ciclos externos podem ser especificados como orientados no sentido horário (visto de fora do sólido), enquanto anéis podem ser orientados em sentido anti-horário.

A integridade geométrica só poderá ser satisfeita se o formato atribuído às faces for consistente com a informação topológica. Por exemplo, as faces devem se interceptar somente em arestas ou vértices comuns.

Checagem completa de validade não é facilmente fornecida para um modelo B-Rep: meios eficientes foram desenvolvidos para assegurar validade topológica, mas a validade geométrica ainda requer verificações computacionalmente caras. A garantia da validade topológica é fornecida pelos operadores de Euler.

Os maiores problemas de confiabilidade em modeladores B-Rep estão relacionados com a geometria e não com a topologia. É possível a ocorrência de problemas de tolerância no cálculo de intersecção de curvas, que podem levar a um resultado errôneo quando uma situação real está muito próxima ao caso limite. Neste caso, a topologia do objeto pode não 
concordar com a geometria, e resultados totalmente errôneos podem ser gerados se procedimentos de modelagem forem baseados nesta situação inconsistente.

Visando evitar problemas deste tipo, sistemas que utilizam a abordagem por fronteira normalmente a constroem a partir de outra representação, através de cálculos geométricos e algoritmos de conversão.

\subsection{4 - Geometria Exata x Aproximada}

Modeladores B-Rep podem ser classificados como possuindo geometria exata ou aproximada. Os que contêm geometria aproximada geralmente representam objetos curvos como um conjunto de subfaces ou superfícies planares, conforme mostra a figura 2.9. Em decorrência, todos os cálculos de intersecção de superfícies são realizados em termos de intersecção entre planos, e a geração de desenhos com linhas escondidas é simplificada.
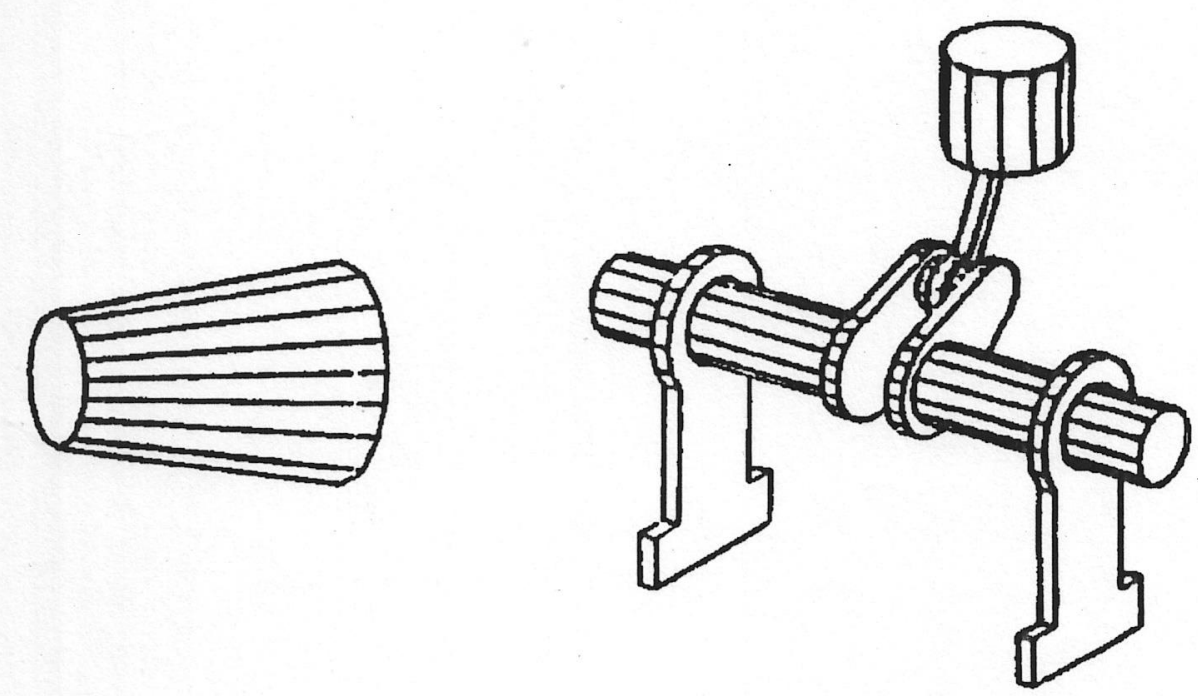

Figura 2.9 - Exemplos de modelos utilizando geometria aproximada

Uma subdivisão em facetas muito finas pode melhorar significativamente a representação, gerando uma aproximação razoável para as curvas exatas, porém vai requerer mais computação e pode acabar tomando mais tempo do que o cálculo da intersecção entre as superfícies exatas. 
Existem desvantagens óbvias no uso de facetas quando um modelador de sólidos é usado para a análise de interferência entre partes de uma montagem, como mostra a figura 2.10. A maioria dos sistemas por facetas (ou poliedrais) permite ao usuário selecionar a tolerância na aproximação, e muitos também fornecem alguma forma de representação exata das superfícies aproximadas. Geralmente, a representação aproximada não é adequada para operações com muita computação, como as booleanas, pois pode levar a resultados que são topologicamente errôneos quando comparados aos resultados exatos.

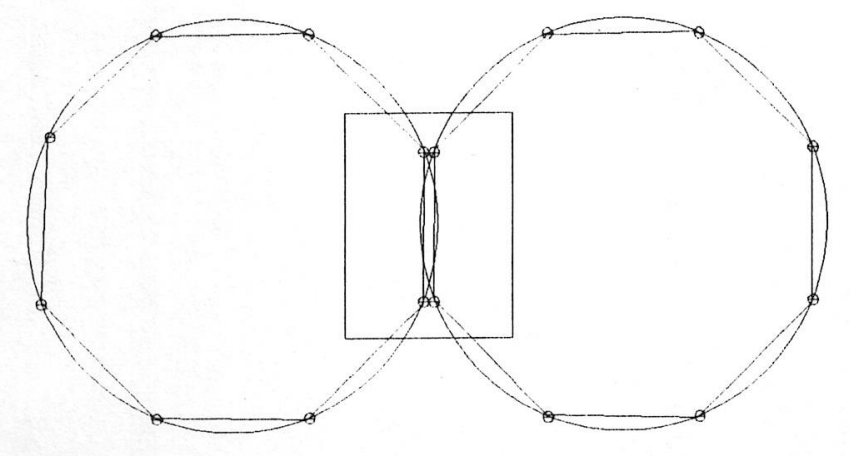

A) TRAÇADO POR APROXIMAÇÃO

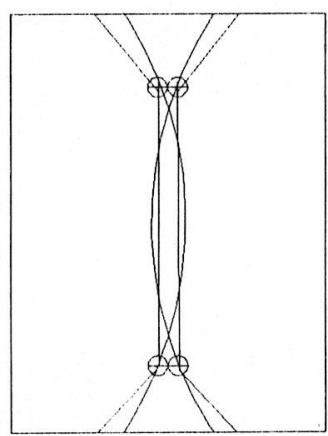

B) AMPLIAÇÃO

Figura 2.10 - Perda de informação devido a aproximação

Sistemas de modelagem que mantêm a geometria exata atingem um nível mais alto de precisão por possuírem superfícies curvas. Tais sistemas, contudo, introduzem muitas complicações topológicas, geométricas e numéricas. Turner [Tur88] desconsidera as formas exatas e aproximadas como alternativas, e apresenta um método que possibilita a modelos poliedrais obterem a avaliação da fronteira de um objeto com resultados comparáveis a um sistema que incorpora superfícies curvas, através da operação de "desfaceteamento" aplicada às operações envolvendo modelos poliedrais.

Preocupado com a precisão de modelos poliedrais, Segal [Seg90] introduz uma descrição do objeto que associa uma tolerância a cada um dos elementos topológicos (vértices, arestas e faces), levando a uma definição de consistência topológica, que pode ser diretamente aplicada à representação por fronteira. 


\subsection{5 - Inclusão de Superfícies Curvas}

Um modelo poliedral não é adequado para tarefas nas quais a modelagem exata de superfícies curvas é necessária, sendo valiosa a inclusão de outros tipos de superfícies além das planares. Para muitas aplicações, o conjunto de superfícies e curvas que um sistema admite influencia não só o conjunto de objetos que podem ser por ele modelados, mas também o seu desempenho. O conjunto de curvas admitidas por um modelador B-Rep é influenciado pela estrutura de dados e procedimentos geométricos disponíveis.

O uso de vários tipos de geometria em um modelador de sólidos possui a vantagem de possibilitar a representação de maneira exata de curvas e superfícies comuns, como círculos, seções cônicas, cilindros e esferas. A desvantagem desta abordagem está na dificuldade de adicionar um novo tipo de curva ou superfície ao modelador, uma vez que será necessário desenvolver um número significativo de rotinas de intersecção entre o novo tipo de curva e as já existentes. É por isto que muitos projetistas de modeladores optaram pela geometria por facetas ou pela inclusão de somente um tipo de superfície e curva, como por exemplo a B-Spline [Mor85, Rog90]. O quadro 2.2 apresenta uma comparação entre os principais tipos de superfícies que poderiam ser utilizados em modeladores de sólidos.

De forma a permitir a separação entre a geometria e a topologia na modelagem por fronteira, algumas restrições se tornam necessárias em relação aos elementos geométricos que podem ser usados. Exemplos: superfícies e curvas não podem conter descontinuidades de primeira e segunda ordem, assim como as curvas devem estar em representação paramétrica (ou poderão ser convertidas para esta), condição requerida para que as arestas possam ser diferenciadas e ordenadas usando um único valor como parâmetro.

Existe intensa pesquisa para a incorporação de superfícies de forma livre superfícies polinomiais cujo formato não possui classificação padrão [Mil86] - a modeladores de sólidos, o que permite aumentar significativamente o potencial descritivo do modelador. Miller apresenta uma série de questões relacionadas à funcionalidade da incorporação de superfícies de forma livre a modeladores de sólidos, que necessitam ainda de um profundo estudo. 


\begin{tabular}{|c|c|c|}
\hline NATUREZA, CONCEITOS \& APLICAÇĀO & PONTOS POSITIVOS & PONTOS NEGATIVOS \\
\hline $\begin{array}{l}\text { PLANOS [Bau75, Bra73, Voe78, Rot82, Tur88] } \\
\text { - Tipo de superfície algébrica mais simples possível. } \\
\text { - Usados para testar a efetividade da estrutura topológica } \\
\text { dos dados sem levar a cálculos matemáticos complicados. } \\
\text { - Adequados para aplicações em arquitetura e para } \\
\text { modelar partes mecânicas simples. }\end{array}$ & $\begin{array}{l}\text { - Simplifica processo de visualização. } \\
\text { - Algoritmos para remoção de linhas } \\
\text { e superfícies ocultas são simples. } \\
\text { - O cálculo de propriedades de } \\
\text { massa, tanto de forma exata quanto } \\
\text { aproximada, é simples. }\end{array}$ & $\begin{array}{l}\text { - Sistemas poliedrais gerados } \\
\text { não são suficientes para } \\
\text { modelar adequadamente muitas } \\
\text { das formas mais comumente } \\
\text { utilizadas, como cavidades e } \\
\text { cantos arredondados. }\end{array}$ \\
\hline $\begin{array}{l}\text { QUUÁDRICAS } \\
\text { [Bra } 73 \text { Lev76, Voe77] } \\
\text { - Superfícies algébricas de segunda ordem bem conhecidas } \\
\text { e fundamentadas. } \\
\text { - Possuem muito mais aplicação que um sistema poliedral. } \\
\text { - Usados em arquitetura para traçar cilindros, esferas, } \\
\text { cones, etc. } \\
\text { - Adequadas para modelar objetos rígidos como canos, } \\
\text { blocos de máquinas, rolamentos. } \\
\text { - Permitem a modelagem de partes mecânicas simples } \\
\text { mais realísticas e a definição de caminhos percorridos por } \\
\text { ferramentas de controle numérico. } \\
\text { - A incorporação de quádricas tornou os sistemas mais } \\
\text { úteis para aplicações existentes, mas ainda deixa a desejar. }\end{array}$ & $\begin{array}{l}\text { - Permite aplicações mais práticas, } \\
\text { mantendo a matemática simples. } \\
\text { - A interseção com um plano é } \\
\text { sempre uma seção cônica, o que } \\
\text { facilita o cálculo. } \\
\text { - A intersecção de duas quádricas } \\
\text { pode ser representada analiticamente. } \\
\text { - O "ray-firing" requer somente a } \\
\text { resolução de uma equação } \\
\text { quadrática. } \\
\text { - Fácil analizar propriedades de } \\
\text { massa através do "ray-firing". } \\
\text { - Fácil produzir imagens com } \\
\text { sombreamento (realísticas). } \\
\end{array}$ & $\begin{array}{l}\text { - Nem todas as quádricas são } \\
\text { necessárias em projetos (alguns } \\
\text { sistemas dispōem de um } \\
\text { subconjunto de quádricas: as } \\
\text { naturais e as de revolução). } \\
\text { - Apesar da teoria rigorosa } \\
\text { alguns algoritmos não são } \\
\text { robustos devido à falta de } \\
\text { precisão numérica. } \\
\text { - Ainda são inadequadas para } \\
\text { modelar objetos com } \\
\text { dobramentos e de forma livre } \\
\text { - Difícil combinar } 2 \text { quádricas } \\
\text { usando só outras quádricas. } \\
\end{array}$ \\
\hline $\begin{array}{l}\text { TOROS } \\
\text { - São superfícies algébricas quárticas. } \\
\text { - Arredondam e complementam sistemas com superfícies } \\
\text { quádricas, pois estas não permitem dobramentos. } \\
\text { - Não eliminam as inadequações das quádricas. } \\
\text { - Quádricas e toros juntos são suficientes para modelar a } \\
\text { maioria das partes mecânicas rígidas, mas ainda são inade- } \\
\text { quados para combinações complexas e de forma livre. } \\
\end{array}$ & $\begin{array}{l}\text { - "Ray-firing" em um toro requer } \\
\text { somente uma equação de grau } 4 . \\
\text { - Ainda é simples de geração de } \\
\text { imagens realísticas de modelos com } \\
\text { quádricas e toros, além de ser } \\
\text { relativamente fácil calcular } \\
\text { propriedades de massa através de } \\
\text { técnicas de "ray-firing" padrão. }\end{array}$ & $\begin{array}{l}\text { - A intersecção de dois toros é } \\
\text { problemática: gera uma curva } \\
\text { de grau } 16, \text { não sendo prático } \\
\text { utilizar uma representação } \\
\text { exata. } \\
\text { - A aproximação por técnica } \\
\text { numérica é em geral lenta e } \\
\text { pode introduzir inconsistências } \\
\text { geométricas e topológicas. } \\
\end{array}$ \\
\hline $\begin{array}{l}\text { VARREDURA } \\
\text { - Shiperfície polinomial paramétrica obtida através de um } \\
\text { gerador } 2 \mathrm{D} \text {, varrido através de uma reta ou um arco. } \\
\text { - Permite modelar quase todas as partes mecânicas } 2 \frac{1}{2} \mathrm{D} \text {. } \\
\text { - Aumenta o poder dos esquemas de modelagem com } \\
\text { toros e quádricas, permitindo gerar superfícies mais } \\
\text { genéricas. } \\
\text { - O poder descritivo continua restrito a partes mecânicas } \\
\text { rígidas. }\end{array}$ & $\begin{array}{l}\text { - Análise não é difícil. } \\
\text { - O "ray-firing" pode ser reduzido a } \\
\text { um problema em 2D. } \\
\text { - A geração de imagens realísticas e a } \\
\text { análise de propriedades de massa por } \\
\text { técnicas de "ray-firing" é simples. } \\
\text { - Boas aproximações para interseç̧ão } \\
\text { podem ser obtidas interceptando } \\
\text { linhas e círculos gerados na } \\
\text { superfície. }\end{array}$ & $\begin{array}{l}\text { - O cálculo de interseçõos } \\
\text { analíticas não é prático. } \\
\text { - Em sistemas B-Rep, pode } \\
\text { levar a novos tipos de } \\
\text { superfícies, mesmo restrito a } \\
\text { retas e cônicas. } \\
\text { - Só resultará em quádrica se a } \\
\text { cônica for varrida de forma } \\
\text { paralela ao plano de definição } \\
\text { ou pelo eixo de simetria. } \\
\end{array}$ \\
\hline $\begin{array}{l}\text { QUADRÁTICAS E BIQUADRÁTICAS [Gol87, Ste84] } \\
\text { - Com estas curvas paramétricas, começa-se a atingir o } \\
\text { projeto de forma livre real. } \\
\text { - Escolhida pela necessidade de possuir pelo menos grau } 2 \\
\text { nos parâmetros e obter superfícies com maior flexibilidade } \\
\text { - Retas interceptam superfícies quadráticas em até } 4 \\
\text { pontos, e biquadráticas em até } 8 \text { pontos. } \\
\text { - Quadráticas racionais incluem quádricas e toro como } \\
\text { casos especiais, e acomodam todas as aplicaçōes anteriores } \\
\text { - Pouco aplicadas: sua combinação não é suave o } \\
\text { suficiente e sua capacidade de representação de objetos de } \\
\text { forma livre é ainda severamente restrito. }\end{array}$ & $\begin{array}{l}\text { - O "ray-firing" requer, no pior caso, } \\
\text { equação polinomial de grau } 4 \text { ou } 8 . \\
\text { - São ainda relativamente fáceis de } \\
\text { gerar imagens realísticas. } \\
\text { - Suas propriedades de massa não } \\
\text { são difíceis de analisar por "ray- } \\
\text { firing". } \\
\text { - Não é intrinsecamente mais } \\
\text { complexa que o toro. } \\
\text { - Adicionam flexibilidade ao esquema } \\
\text { de modelagem devido ao seu grau, } \\
\text { mas aumentam a sobrecarga no } \\
\text { algoritmo. }\end{array}$ & $\begin{array}{l}\text { - A intersecção de } 2 \text { quadráticas } \\
\text { possui grau 16, e a de } 2 \\
\text { biquadráticas possui grau } 64 . \\
\text { - Algoritmos de intersecção } \\
\text { exatos são impossíveis; } \\
\text { algoritmos numéricos } \\
\text { suficientemente robustos ainda } \\
\text { são um desafio. } \\
\text { - Apesar do grau elevado, não } \\
\text { conseguem bom poder de } \\
\text { representação. } \\
\text { - Não são tão flexíveis quanto } \\
\text { parecem a princípio. } \\
\end{array}$ \\
\hline $\begin{array}{l}\text { SUPERFÍCIES DE FORMA LIVRE [Til83, Sed84, Mil86] } \\
\text { - Superfícies paramétricas que podem ser polinômios de } \\
\text { Bernstein, B-Splines, } \beta \text {-Splines, entre outros. } \\
\text { - Escolha em função de suas propriedades, como controle } \\
\text { local, capacidade de subdivisão e refinamento do nó. } \\
\text { - No lugar de métodos analíticos, a subdivisão recursiva é } \\
\text { atualmente empregada para visualizar estes sólidos, } \\
\text { analisar suas propriedades de massa e interceptar suas } \\
\text { curvas e superfícies de fronteira ao mesmo tempo em que } \\
\text { realiza operações booleanas. }\end{array}$ & $\begin{array}{l}\text { - Poder de representação muito } \\
\text { maior que os outros tipos de } \\
\text { superfície. } \\
\text { - Em superfícies algébricas que } \\
\text { possuam grau baixo, o "ray-firing" é } \\
\text { realizado de forma analítica, através } \\
\text { da resolução de equações polinomiais } \\
\text { de grau baixo. } \\
\text { - Técnicas analíticas clássicas da } \\
\text { geometria algébrica são práticas para } \\
\text { calcular intersecçōes entre superfícies } \\
\text { requeridas por sistemas B-Rep. } \\
\end{array}$ & $\begin{array}{l}\text { - Análise é problemática, } \\
\text { mesmo utilizando superfícies } \\
\text { polinomiais paramétricas de } \\
\text { grau moderado. } \\
\text { - "Ray-firing" através da } \\
\text { resolução de equações } \\
\text { polinomiais é muito caro, } \\
\text { mesmo em grau moderado. } \\
\text { - O cálculo da intersecção de } 2 \\
\text { supefícies de forma livre } \\
\text { analíticas tem custo muito alto. }\end{array}$ \\
\hline
\end{tabular}

Quadro 2.2 - Comparação entre os diversos tipos de superfícies 


\subsection{6 - Propriedades da Modelagem por Fronteira}

Considerando as propriedades desejáveis em um esquema de representação, propostas por Requicha [Req80] e citadas na seção 2.3.1, a modelagem por fronteira pode ser assim caracterizada:

- não é ambígua, ou seja, um modelo válido corresponde a um único objeto sólido;

- não é única, sendo possível a decomposição e representação de um mesmo objeto de várias maneiras válidas e distintas;

- sua potência descritiva varia em função das superfícies que podem ser utilizadas, mas de todo modo representa uma classe de objetos mais ampla que a modelagem construtiva, além de fornecer maior variedade de técnicas de criação e edição, algumas delas bastante eficientes (ex: modificação local);

- em contrapartida, sua utilização para descrição direta pelo usuário é difícil, sendo necessário utilizar, por exemplo, interfaces baseadas em técnicas CSG e de varredura, com posterior conversão dos modelos para a representação B-Rep;

- sua validade é difícil de ser estabelecida, sendo necessário impor uma série de restrições geométricas e topológicas para garantir a integridade do modelo;

- por armazenar informações topológicas de forma explícita, é bem menos concisa que os esquemas construtivos; algumas implementações armazenam dados redundantes para acelerar algoritmos específicos, enquanto outras utilizam métodos para tornar o modelo mais conciso;

- a complexidade dos algoritmos é elevada, mas varia em função da estrutura de dados e critérios de validação automatizados;

Além destas propriedades, outras características importantes podem ser observadas na modelagem por fronteira:

- é útil para gerar saídas gráficas, por já dispor dos elementos de desenho necessários (vértices, arestas e faces);

- possui acesso eficiente às informações geométricas necessárias em muitas aplicações, como a geração automática de dados para a manufatura;

- sua representação interna fornece meios para incluir no modelo dados não geométricos (como requisitos de tolerância, tratamento de calor, resistência, etc); 
- é fácil, a princípio, estender o modelo para incorporar geometria esculpida ou de forma livre, requerida em muitas áreas de engenharia;

- é menos robusta que a modelagem construtiva, uma vez que a própria representação interna necessita de respostas a questões geométricas delicadas, relacionadas a coincidência ou paralelismo entre entidades geométricas, que podem levar a problemas de tolerância complicados.

\section{5 - ESFORÇOS NO DESENVOLVIMENTO DE MODELADORES POR FRONTEIRA}

As primeiras pesquisas em modelagem de sólidos tornaram-se públicas em meados dos anos 60 [Rob63, Gut64], e no decorrer da década de 70 surgiu a primeira geração de sistemas experimentais. Apesar de limitados e cheios de particularidades, estes sistemas despertaram grande interesse por prometerem um poder representacional capaz de permitir que muitas tarefas tradicionalmente manuais fossem completamente automatizadas. Ao final dos anos 70 já se tinha aprendido o suficiente sobre teoria de modelagem de sólidos, algoritmos chaves e aplicações principais para permitir que uma segunda geração de sistemas fosse projetada para serviço industrial nos anos 80 . Em meados dos anos 80 a modelagem de sólidos chegou ao mundo dos sistemas comerciais de CAD/CAM.

Vários sistemas foram desenvolvidos, muitos com objetivo de pesquisa (Build-1 e 2 [Bra73, Bra78], Compac [Spu78], Proren [Sei78], Geomap [Hos74], Glide [Eas77, Bae79], GWB [Män88], Padl-1 [Voe77]) alguns para uso interno de organizações (GMsolid [Boy82], Shapes [Lan79], GDP/Grin [Fit81]), outros com fins comerciais (Euclid [Ber75], Euklid [Eng73], TIPS-1 [Oki73], Synthavision [Gol79], Design e Romulus [Hil82], Padl-2 [Bro82]). Os sistemas de interesse para este trabalho são os que utilizam a abordagem por fronteira, e os mais importantes encontram-se relacionados no quadro 2.3. 


\begin{tabular}{|c|c|c|c|c|c|c|}
\hline \multirow{2}{*}{$\begin{array}{l}\text { Modelador } \\
\text { Local / Época }\end{array}$} & \multirow{2}{*}{$\begin{array}{l}\text { Fonte } \\
\text { Autor }\end{array}$} & \multirow{2}{*}{$\begin{array}{l}\text { Linguagem } \\
\text { Máquina }\end{array}$} & \multirow{2}{*}{ Aplicação } & \multicolumn{3}{|c|}{ Características } \\
\hline & & & & Interface & Operações & Representação \\
\hline $\begin{array}{l}\text { BUILD-1 } \\
\text { Un. Cambridge } \\
\text { Inglaterra } \\
\text { fim anos } 60\end{array}$ & $\begin{array}{l}{[\text { Hil82] }} \\
{[\text { Bae79] }} \\
{[\text { Req82] }} \\
\text { Braid }\end{array}$ & $\begin{array}{l}\text { Fortran } \\
\text { e SAL } \\
\text { máquina } \\
\text { especial }\end{array}$ & $\begin{array}{l}\text {-Experimental (tese de } \\
\text { doutorado) } \\
\text {-Geração de controle } \\
\text { numérico }\end{array}$ & $?$ & $?$ & $\begin{array}{l}\text {-Baseada em listas } \\
\text {-Exata por superfícies } \\
\text { analíticas }\end{array}$ \\
\hline $\begin{array}{l}\text { BUILD-2 } \\
\text { Un. Cambridge } \\
\text { Inglaterra } \\
1973\end{array}$ & $\begin{array}{l}{[\mathrm{Hil82}]} \\
{[\text { Bae } 79]} \\
{[\text { Req82] }} \\
\text { Braid }\end{array}$ & $\begin{array}{l}\text { Algol } 68 \\
\text { IBM } 370 \\
\text { Prime400 } \\
\text { Dec } 10\end{array}$ & $\begin{array}{l}\text {-Experimental (técnicas } \\
\text { e algoritmos de } \\
\text { modelagem) } \\
\text {-Análise estrutural e } \\
\text { controle numérico }\end{array}$ & $\begin{array}{l}\text {-CSG } \\
\text {-Operadores de Euler } \\
\text {-Chamada a subrotinas } \\
\text {-Orientação textual e } \\
\text { interativa }\end{array}$ & $\begin{array}{l}\text {-Tradicionais mais } \\
\text { "tweaking", "fillet" } \\
\text { "chamfering" e } \\
\text { "draftangles" }\end{array}$ & $\begin{array}{l}\text {-Aresta-alada } \\
\text {-Aproximação de } \\
\text { curvas paramétricas } \\
\text { B-spline }\end{array}$ \\
\hline $\begin{array}{l}\text { DESIGN } \\
\text { Schlumb. Co. } \\
\text { e MDSI, EUA } \\
1976\end{array}$ & $\begin{array}{l}\text { [Hil82] } \\
{[\text { Req82] }}\end{array}$ & $\begin{array}{l}\text { Pascal } \\
\text { (MDSI) } \\
\text { Dec } 10 \\
\text { Vax }\end{array}$ & $\begin{array}{l}\text {-Comercial (projeto } \\
\text { conceitual, layout de } \\
\text { montagens, relação de } \\
\text { materiais, verificação de } \\
\text { interferência) }\end{array}$ & $\begin{array}{l}\text {-CSG } \\
\text {-Interface gráfica } \\
\text { sofisticada } \\
\text {-Verifica propriedades } \\
\text { geométricas }\end{array}$ & $\begin{array}{l}\text {-Tradicionais mais } \\
\text { "tweaking", "gluing" } \\
\text { "sweep" (checadas) } \\
\text {-"Split", "slice" }\end{array}$ & $\begin{array}{l}\text {-Aresta-alada } \\
\text { modificada } \\
\text {-Curvas exatas com } \\
\text { representação } \\
\text { paramétrica }\end{array}$ \\
\hline $\begin{array}{l}\text { Shape Data e } \\
\text { E.Sutherland } \\
1974\end{array}$ & $\begin{array}{l}\text { [Hil82] } \\
\text { [Req82] } \\
\text { [Bis85] }\end{array}$ & $\begin{array}{l}\text { Fortran } \\
\text { Prime } \\
\text { Vax }\end{array}$ & $\begin{array}{l}\text {-Comercial (em função } \\
\text { do sistema acoplado } \\
\text { GNC-controle numérico } \\
\text { Femgen-análise de } \\
\text { elementos finitos) }\end{array}$ & $\begin{array}{l}\text {-Dependente do sistema } \\
\text {-CSG, "sweep", Op. Euler } \\
\text {-Chamada a subrotinas } \\
\text {-Textual e interativa } \\
\text {-Verifica propriedades } \\
\text { volumétricas }\end{array}$ & $\begin{array}{l}\text {-Tradicionais mais } \\
\text { "gluing", "split", } \\
\text { "unfolding" } \\
\text {-cálculo automático } \\
\text { da intersecção } \\
\text { entre superfícies }\end{array}$ & $\begin{array}{l}\text {-Aresta-alada com } \\
\text { arranjo de listas } \\
\text {-Superfícies quádricas } \\
\text { com armazenamento } \\
\text { implícito }\end{array}$ \\
\hline $\begin{array}{l}\text { BDS/GLIDE } \\
\text { Un. Carnegie- } \\
\text { Mellon, EUA } \\
\text { fim anos } 70\end{array}$ & $\begin{array}{l}{[\text { Bae 79] }} \\
{[\text { Req82] }} \\
\text { [Eas77] }\end{array}$ & $\begin{array}{l}\text { Pascal } \\
\text { (BLISS) } \\
\text { Dec }\end{array}$ & $\begin{array}{l}\text {-Experimental (sistemas } \\
\text { fisicamente grandes } \\
\text { construçōes e plantas } \\
\text { para detalhamento de } \\
\text { processos) }\end{array}$ & $\begin{array}{l}\text {-CSG, "sweep", Op. Euler } \\
\text {-Chamada a subrotinas } \\
\text {-Orientação textual e } \\
\text { interativa }\end{array}$ & $\begin{array}{l}\text {-Hierarquia de } \\
\text { menus } \\
\text {-Permite criar } \\
\text { novas primitivas }\end{array}$ & $\begin{array}{l}\text {-Subconjunto da } \\
\text { Aresta-alada } \\
\text {-Planar (armazena } \\
\text { milhares de objetos } \\
\text { poliedrais) }\end{array}$ \\
\hline $\begin{array}{l}\text { EUCLID } \\
\text { LIMSI } \\
\text { Orsay,França } \\
\text { fim anos } 70\end{array}$ & $\begin{array}{l}\text { [Bae79] } \\
\text { [Req82] } \\
\text { Bruns } \\
\text { et al. }\end{array}$ & $\begin{array}{l}\text { Fortran } \\
\text { (FOCAL) } \\
\text { Dec }\end{array}$ & $\begin{array}{l}\text {-Comercial (recurso na } \\
\text { descriçāo de entidades } \\
\text { geométricas em } \\
\text { aplicaçōes de } \\
\text { engenharia) }\end{array}$ & $\begin{array}{l}\text {-CSG, "sweep" } \\
\text {-Orientação textual e } \\
\text { interativa }\end{array}$ & $\begin{array}{l}\text {-Op. básicas mais } \\
\text { transformação } \\
\text { ortográfica e } \\
\text { perspectiva }\end{array}$ & $\begin{array}{l}\text {-Pontos, linhas e } \\
\text { superfícies } \\
\text {-Aproximação de } \\
\text { superfícies quádricas }\end{array}$ \\
\hline $\begin{array}{l}\text { EUKLID } \\
\text { Fides Co. } \\
\text { Zurich, Hol. } \\
\text { anos } 70\end{array}$ & [Bae79] & CDC 6500 & $\begin{array}{l}\text {-Comercial (geração de } \\
\text { figuras com pequena } \\
\text { quantidade de } \\
\text { sólidos) }\end{array}$ & $\begin{array}{l}\text {-Construção de funções } \\
\text { (primitivas definidas } \\
\text { como função, podendo } \\
\text { ser chamada por outra } \\
\text { função) }\end{array}$ & $\begin{array}{l}\text {-Aritmética real } \\
\text {-Remoção de linha } \\
\text {-Op. booleana em } \\
\text { face coplanar e } \\
\text { corpo fechado }\end{array}$ & $\begin{array}{l}\text {-Listas com uso } \\
\text { otimizado de espaço } \\
\text {-Representação } \\
\text { paramétrica de } \\
\text { superfícies (Bézier) }\end{array}$ \\
\hline $\begin{array}{l}\text { DESIGNBASE } \\
\text { Ricoh Co. } \\
\text { Japão } \\
\text { anos } 80\end{array}$ & [Tor86] & $\begin{array}{l}\text { C e Sun- } \\
\text { Windows } \\
\text { SUN Work } \\
\text { stations }\end{array}$ & $\begin{array}{l}\text {-Experimental, com fins } \\
\text { comerciais }\end{array}$ & $\begin{array}{l}\text {-CSG } \\
\text {-Mostra árvore de } \\
\text { construção do sólido e da } \\
\text { composição } \\
\text {-Permite "undo" e "redo" }\end{array}$ & $\begin{array}{l}\text {-Cerca de } 20 \text { op. } \\
\text { primitivas e suas } \\
\text { inversas, para } \\
\text { sólidos simples e } \\
\text { composição }\end{array}$ & $\begin{array}{l}\text {-Aresta-alada } \\
\text {-Armazena a história } \\
\text { da construção do } \\
\text { modelo } \\
\text {-Bézier }\end{array}$ \\
\hline $\begin{array}{l}\text { GWB } \\
\text { Un. Helsinky } \\
\text { Finlândia } \\
\text { anos } 80\end{array}$ & $\begin{array}{l}\text { [Tor86] } \\
\text { [Män82] } \\
\text { [Män88] } \\
\text { Mäntyla }\end{array}$ & $\begin{array}{l}\text { ambiente } \\
\text { UNIX }\end{array}$ & $\begin{array}{l}\text {-Experimental e didático } \\
\text { (modelador aberto, que } \\
\text { pode ser moldado para } \\
\text { uma aplicação em } \\
\text { particular) }\end{array}$ & $\begin{array}{l}\text {-CSG com interface em } \\
\text { "batch" } \\
\text {-"Sweep" } \\
\text {-Operações de desenho } \\
\text { com interface interativa }\end{array}$ & $\begin{array}{l}\text {-Tradicionais mais } \\
\text { "glue", "split", } \\
\text { "slice" e "sweep" } \\
\text {-Baseadas nos op. } \\
\text { de Euler }\end{array}$ & $\begin{array}{l}\text {-Semi-aresta } \\
\text {-Modelo poliedral } \\
\text { com estensão para } \\
\text { superfícies quádricas }\end{array}$ \\
\hline
\end{tabular}

Quadro 2.3 - Alguns sistemas de modelagem de sólidos (baseado em [Req82]) 


\section{6 - CONSIDERAÇÕES FINAIS}

Verifica-se um esforço crescente no sentido de aumentar o apoio computacional às atividades de modelagem. A literatura, em particular, descreve várias ferramentas para dar apoio por computador à modelagem de sólidos utilizando representação por fronteira. No entanto, não é grande a quantidade de ferramentas disponíveis comercialmente que oferecem um conjunto satisfatório de algoritmos capazes de responder a questões de âmbito geométrico, sendo cada modelador voltado para uma área de aplicação específica.

A bibliografia consultada, de um modo geral, não entra em detalhes sobre a implementação de modeladores, dificultando a avaliação do grau de complexidade do trabalho inicialmente proposto. No decorrer de seu desenvolvimento foi necessário redefinir sua extensão.

Foi escolhida, como base teórica para dar suporte ao estudo realizado e ao desenvolvimento do modelador, a abordagem desenvolvida por Mäntylä [Män88], por ser a fonte que melhor detalha características e procedimentos das operações implementadas neste trabalho. 


\section{Capítulo 3}

\section{MODELADORES DE SÓLIDOS POR FRONTEIRA}

\section{1 - CONSIDERAÇÕES INICIAIS}

$\mathrm{Na}$ modelagem de sólidos, a representação interna dos dados e os algoritmos de manipulação utilizados afetam de maneira significativa a área de aplicação para a qual um modelador é construído, constituindo elementos cruciais para o seu sucesso. Na modelagem de sólidos por fronteira, os dados representam os ítens de interesse do projetista, como montagens, componentes, faces, arestas e vértices. Mas só isto não basta. Um modelador deve ainda permitir ao usuário selecionar estes ítens através de uma interface gráfica amigável, oferecer uma grande variedade de operações de modelagem e gerar figuras adequadas, rapidamente, considerando ainda questões numéricas e certificação de validade.

Com o intuito de analisar tais aspectos, este capítulo encontra-se dividido em 5 seçōes. A seção 3.2 apresenta a arquitetura de software genérica de um modelador de sólidos por fronteira, destacando seus principais componentes. A seção 3.3 descreve as principais estruturas de dados utilizadas em modeladores por fronteira, bem como operações para a manipulação das mesmas. A seção 3.4 detalha as operações de manipulação da forma, que constituem um aspecto bastante delicado na implementação de um modelador de sólidos. $\mathrm{Na}$ seção 3.5 são discutidos alguns aspectos da interface com o usuário, enfatizando os mecanismos para descrição e edição de modelos, bem como o uso de Sistemas Gerenciadores de Interface com Usuários. Finalmente, a seção 3.6 apresenta algumas das áreas de aplicação mais importantes de modeladores de sólidos por fronteira.

O estudo aqui apresentado está fundamentado principalmente no modelador GWB (Geometric WorkBench) proposto por Mäntylä [Män88]. 


\section{2 - ARQUITETURA DE MODELADORES}

Uma das idéias fundamentais da modelagem geométrica é procurar técnicas de modelagem que sejam relativamente independentes do tipo de objeto modelado e do uso pretendido de modelos, ou seja, a separação funcional entre a modelagem e a aplicação [Män88]. Desta maneira, torna-se possível estabelecer uma distinção funcional entre a aplicação propriamente dita e o software que manipula modelos de sólidos e fornece respostas às questões geométricas - os modeladores de sólidos.

A figura 3.1 [Män88] apresenta os componentes de um sistema geométrico, destacando o papel do modelador de sólidos, que fornece facilidades para criar, armazenar e modificar representações de objetos. Ele é apresentado como um componente em separado por poder suportar uma grande variedade de aplicações.

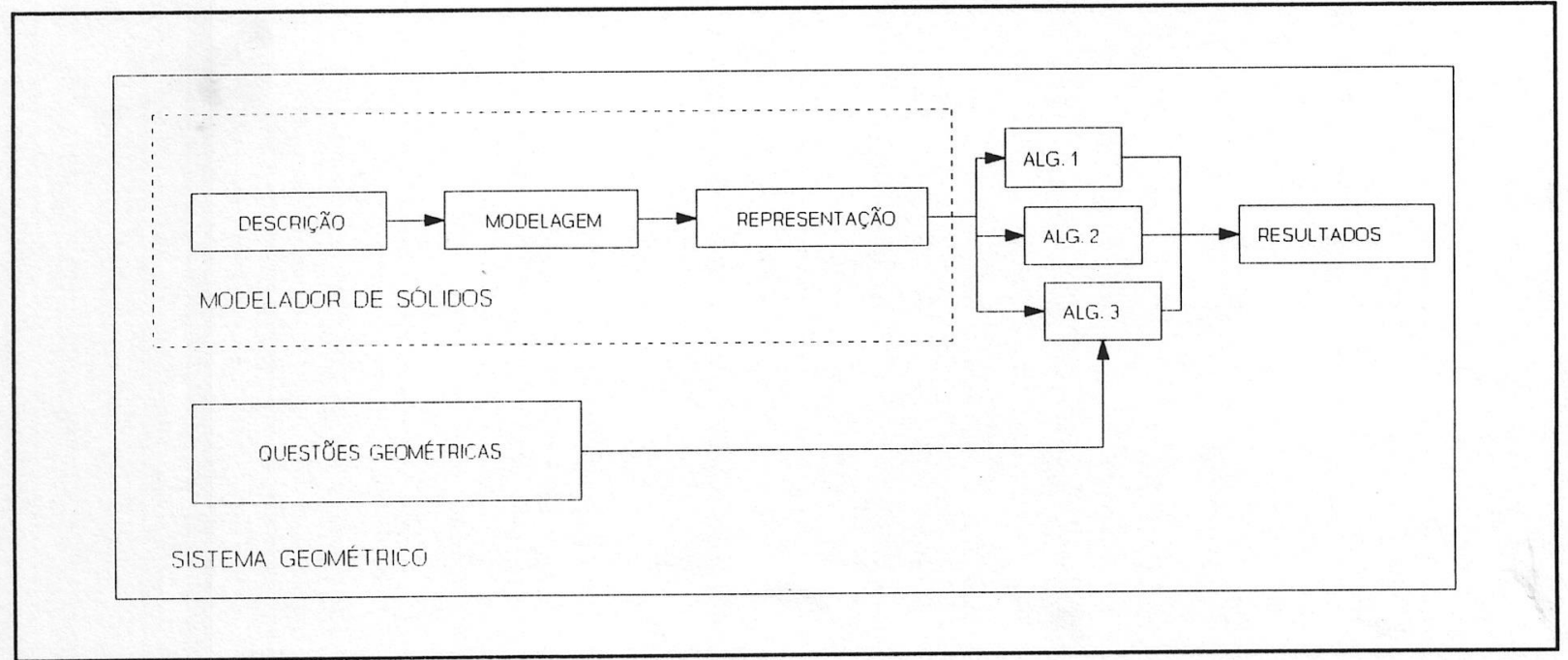

Figura 3.1 - Componentes de um Sistema Geométrico

É difícil estabelecer uma estrutura padrão para modeladores de sólidos, principalmente pela não disponibilidade de descrições técnicas sobre a organização interna dos modeladores existentes e pela variedade de implementações criadas em torno das representaçōes clássicas.

O quadro 3.1 [Req83] descreve algumas variações de arquitetura utilizadas em modeladores de sólidos, destacando as características principais de cada uma, bem como a generalização destas abordagens. 


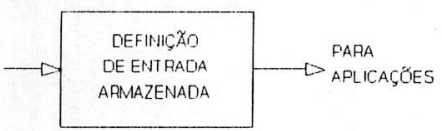

Sistema de modelagem mais simples possível -Armazena definições de entrada para processamento por programas de aplicação - Detalhes de interfaceamento não são relevantes: o importante é a completude e a validade das definições (especificação não ambígua do sólido) - Desvantagem: algoritmos de aplicação gerados a partir de definições de entrada são ineficientes e complexos -Nenhum modelador foi desenvolvido assim

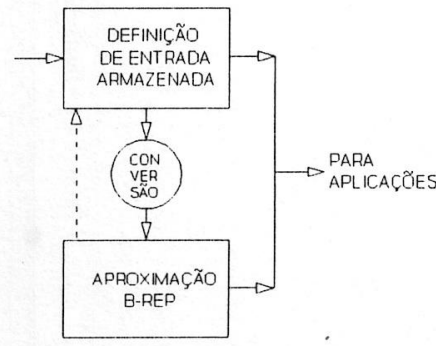

Sistema de modelagem mais elaborado -Possui representação auxiliar adicional, que pode ser exata ou aproximada (ex: B-Rep por facetas) -Se a definição de entrada é armazenada, pode-se refinar a aproximação para melhorar a precisão dos resultados computados -Utilizado no Euclid, Medusa e Geomod (B-Rep)

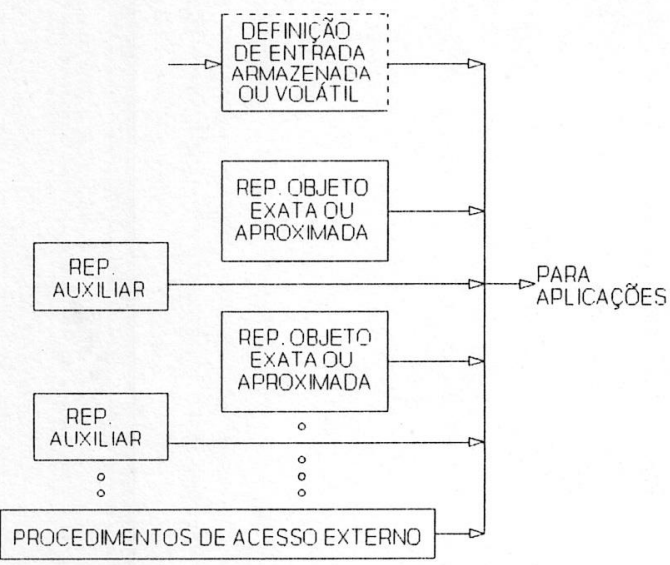

\section{Sistema de modelagem geométrica genérico}

-Possui uma coleção específica de esquemas de representação (exatas, aproximadas ou auxiliares), com pelo menos um sendo válido e completo -Possui uma coleção de procedimentos para gerenciar as representações e fazer a conversão entre as mesmas

-Executa outros cálculos geométricos 
Nota-se que modeladores de sólidos estão-se tornando multirrepresentacionais e que a diversidade da organização interna tende a aumentar. Tanto a conversão entre as representações de um modelador, como a variedade de organizações distintas que podem ser projetadas, governam-se, principalmente, pela disponibilidade de algoritmos de conversão. Ainda é possível, porém, considerar um sistema como primariamente CSG ou BRep, que são as representações mais utilizadas.

\section{3 - REPRESENTAÇÃO INTERNA DE UM MODELADOR}

Uma estrutura de dados típica de um modelador de sólidos por fronteira é uma rede hierárquica de entidades topológicas, com vértices no nível mais baixo, compondo arestas, faces e objetos completos. Vértices, arestas e faces possuem ponteiros adicionais para entidades geométricas, chamadas pontos, curvas e superfícies, respectivamente. A topologia sozinha representa um objeto deformável ou de borracha, que só fica rígido quando a geometria é especificada. A figura 3.2 apresenta esta estrutura e a figura 3.3 ilustra a relação entre as entidades topológicas.

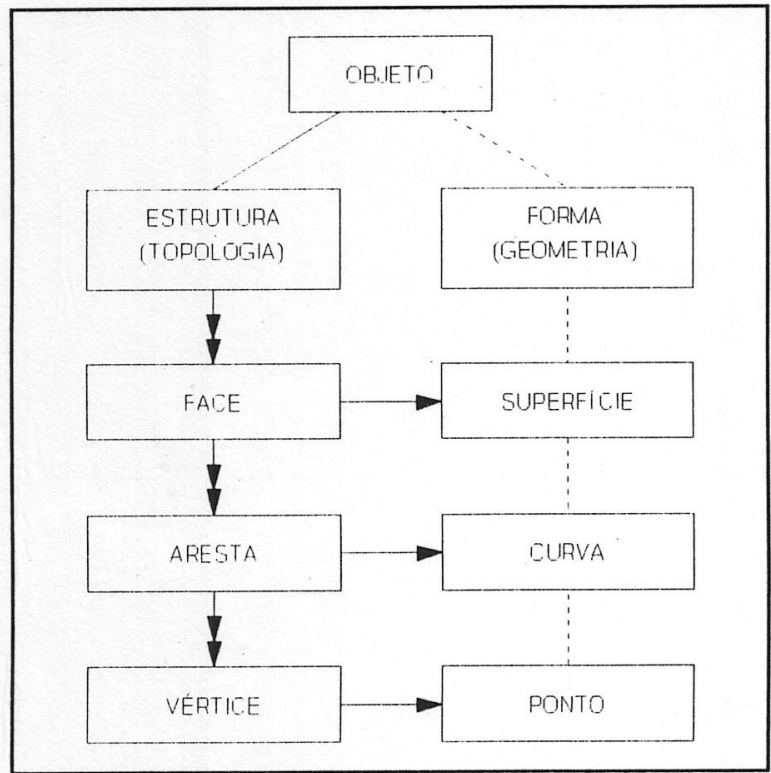

Figura 3.2 - Estrutura de dados B-Rep típica

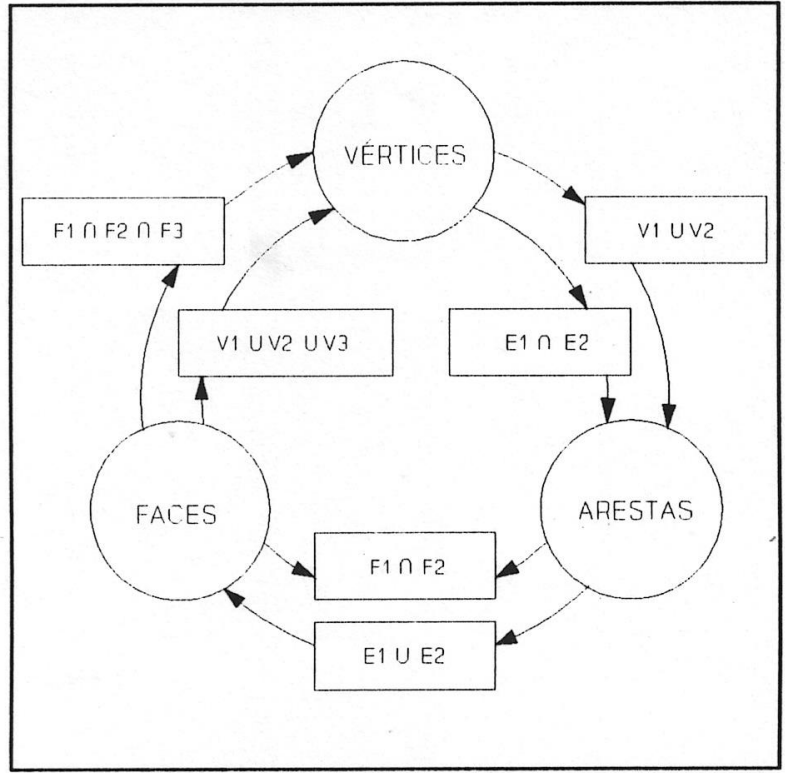

Figura 3.3 - Um exemplo de relação entre as entidades topológicas 
Alguns modeladores possuem níveis adicionais na hierarquia para especificar ciclos ("loops" - seqüência fechada de arestas) representando a fronteira da face e cascas ("shells" conjunto de faces conectadas que formam um sólido ou uma cavidade). Para um modelador de sólidos válidos, as faces do objeto devem formar pelo menos uma casca fechada, separando seu interior de seu exterior. O ideal seria que o modelador pudesse se responsabilizar pela garantia de uma fronteira completa para o objeto.

Em um modelador por fronteira, a estrutura de dados é incrementada à medida que a construção do modelo evolui. A escolha da estrutura de dados é importante devido à sua influência no conjunto de superfícies e curvas (e portanto objetos) que o modelador será capaz de representar adequadamente.

\subsection{1 - Estruturas de Dados B-Rep}

Existem vários tipos de estruturas de dados para representar a geometria e a topologia de um modelo por fronteira, sendo que as mais difundidas são as baseadas em arestas, ou seja, que utilizam a aresta como elemento de referência, representando faces em termos de ciclos de arestas e obtendo vértices indiretamente, a partir das arestas.

A maioria das estruturas de dados baseadas em arestas deriva da estrutura "WingedEdge" (Aresta-Alada), proposta por Baumgart em 1975 [Bau75]. De uma forma geral, elas possuem complexidade variável, dependendo da quantidade de informações sobre relações de adjacência que armazenam, e cada uma possui vantagens e desvantagens em termos de espaço para armazenamento, simplicidade dos algoritmos de manipulação e conjunto de sólidos admitidos. O quadro 3.2 apresenta um resumo das principais características, vantagens e desvantagens das estruturas mais conhecidas. 


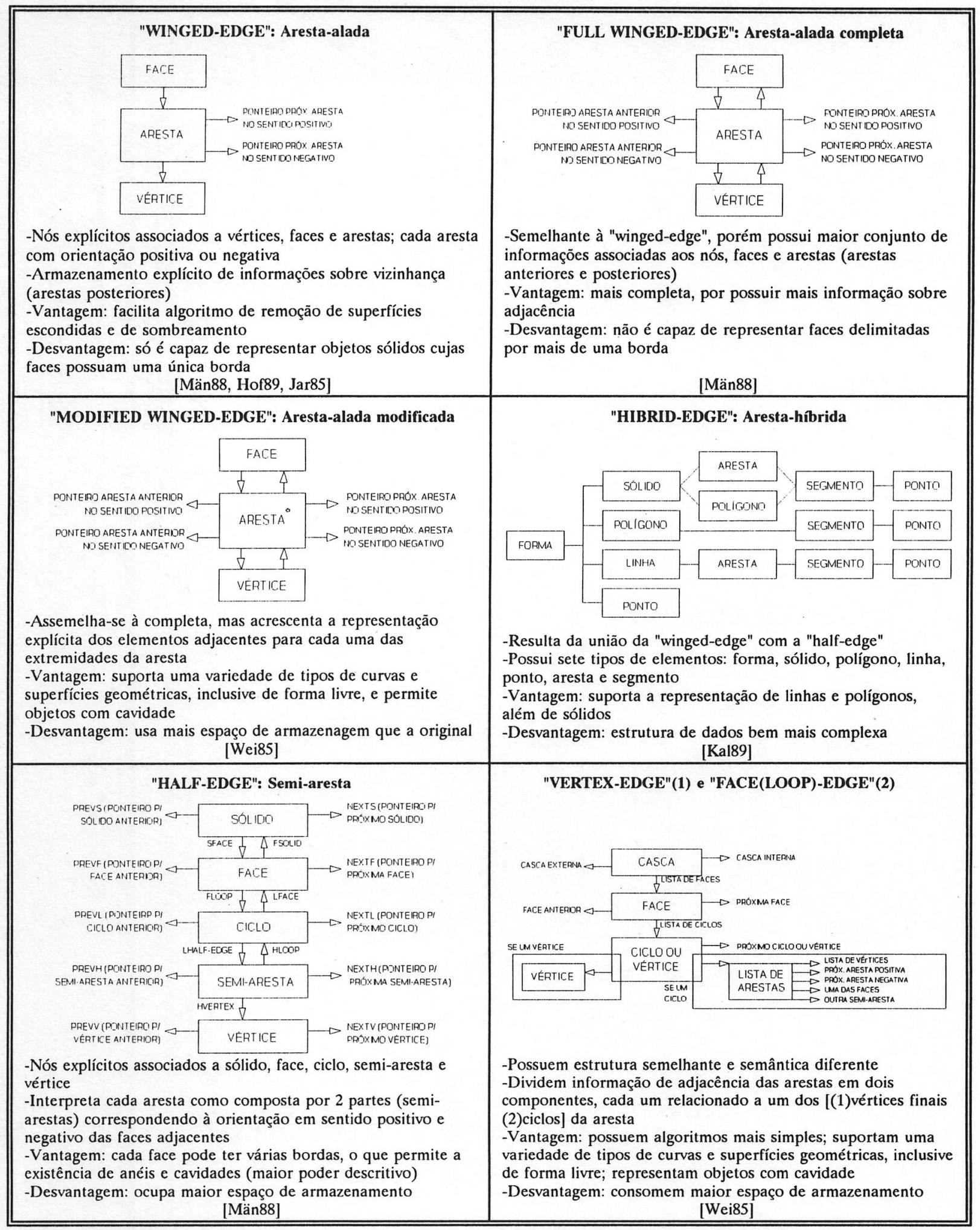

Quadro 3.2 - Resumo das estruturas de dados B-Rep mais conhecidas 


\subsection{2 - A Estrutura "Half-Edge"}

A estrutura de dados de maior importância para este trabalho é a "Half-Edge" (Semi-Aresta), que também é derivada da Aresta-Alada e foi utilizada no modelador GWB desenvolvido por Mäntylä [Män82, Män88]. Esta estrutura foi inicialmente proposta para modelos poliedrais, mas pode ser estendida para admitir vários tipos de superfície (quádricas, paramétricas, de forma livre). Em [Män88] é apresentada uma implementação desta estrutura em linguagem "C", e em [Män82a] são discutidas formas de armazenamento desta estrutura em memória secundária.

$\mathrm{Na}$ estrutura "Half-Edge", cada aresta do modelo é decomposta em duas semiarestas, que são segmentos de reta em um ciclo, correspondendo às ocorrências da aresta nos sentidos positivo e negativo das faces adjacentes, conforme apresentado na figura 3.4. Esta estrutura possui cinco níveis hierárquicos (Sólido, Face, Ciclo, Semi-Aresta e Vértice), mostrados no quadro 3.1. Uma de suas vantagens em relação à Aresta-Alada convencional é a de permitir que uma face possua várias bordas, devido à possibilidade de associar a cada face uma lista de ciclos. Quando uma face possui mais de uma borda, uma é considerada externa e as outras são consideradas como anéis ou cavidades. Como resultado, um maior número de objetos pode ser modelado.

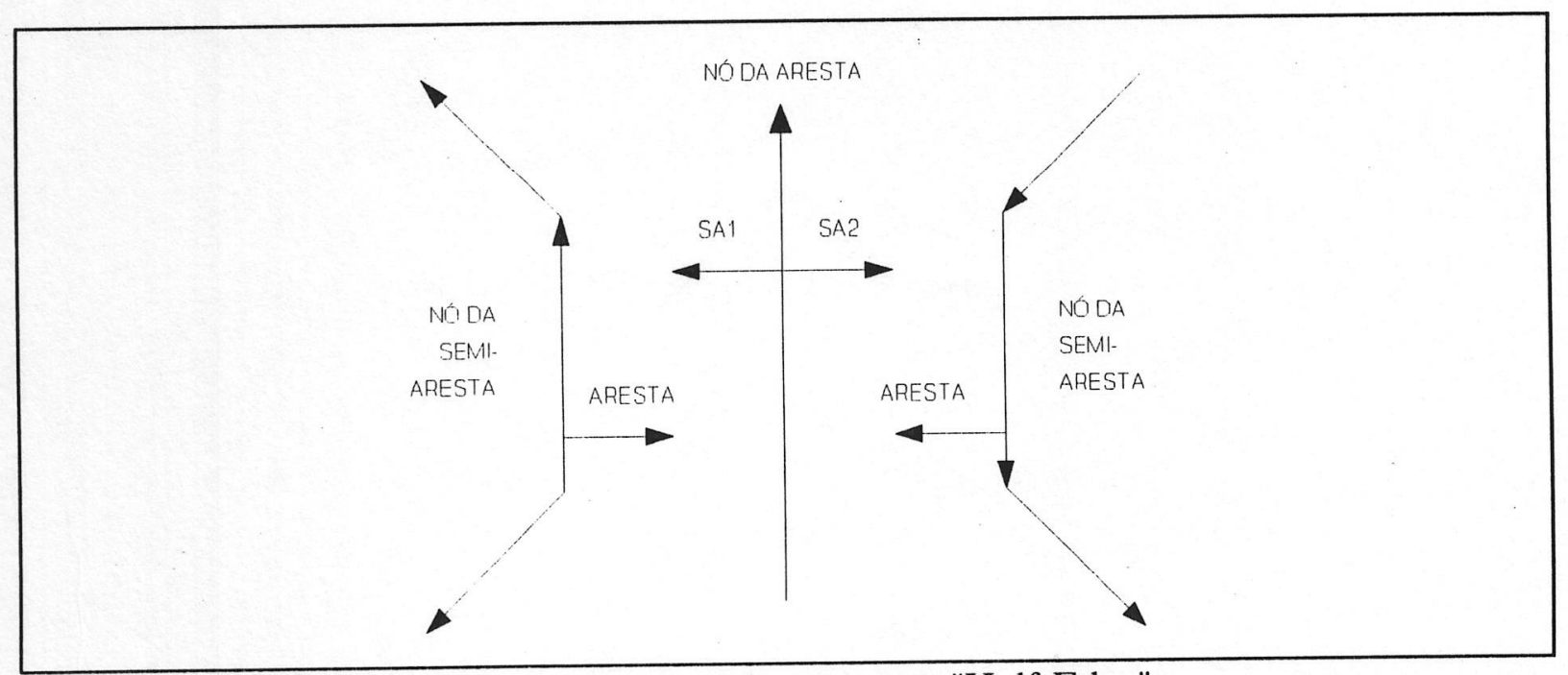

Figura 3.4 - Identificação de semi-arestas da estrutura "Half-Edge" 


\subsection{3 - Manipulação das Estruturas de Dados}

Os responsáveis pela manipulação direta das estruturas de dados B-Rep são os Operadores de Euler, também introduzidos por Baumgart no contexto das estruturas de Aresta-Alada [Bau75, Wei85]. As operações de Euler, originárias da teoria dos modelos planares [Ale61], atuam no domínio real sobre a topologia da estrutura de dados dos modeladores de fronteira. São operações completas e fechadas, que garantem a validade topológica dos objetos representados [Män88].

Operadores de Euler também são importantes por servirem de base para a definição de procedimentos de nível mais alto, como os que implementam operações booleanas e operações de modificação local nos objetos.

\section{4 - OPERAÇÕES DE MANIPULAÇÃO DA FORMA}

Os operadores de Euler e suas rotinas de suporte constituem as operações mais elementares que acessam diretamente a estrutura de dados B-Rep. Como não é desejável usar ferramentas desse nível diretamente para executar operações mais complexas sobre sólidos, devem ser desenvolvidos outros níveis mais altos de ferramentas de modelagem. $\mathrm{O}$ objetivo é a geração de uma camada independente, na arquitetura do modelador, que realize as funções de modelagem utilizando uma implementação concisa e econômica.

As operações de manipulação da forma podem ser classificadas em operações de modelagem básicas, operações locais e operações globais. As operações de modelagem básicas, que permitem gerar sólidos pelo instanciamento de primitivas tridimensionais ou pela definição de primitivas planares seguidas de operações de varredura, constituem objeto principal deste trabalho, e são detalhadas no capítulo a seguir. As operações locais realizam pequenas alterações sobre um único objeto, enquanto as operações globais atuam sobre um ou mais objetos realizando modificações maiores, normalmente gerando objetos mais complexos. As operações locais e globais não foram implementadas neste trabalho, mas foram estudadas visando o desenvolvimento do projeto do $(\mathrm{SM})^{2}$, e são detalhadas a seguir. 


\subsection{1 - Operações Locais}

Um procedimento de edição que está disponível em alguns modeladores B-Rep é o da operação local, que realiza pequenas alterações no objeto a ser definido, ajustando a geometria das faces ou usando operadores de Euler para adicionar poucos elementos à representação interna. Operações locais permitem a modificação eficiente de uma região localizada da estrutura de dados. Por exemplo, a geometria associada com uma única face pode ser redefinida e o resultado avaliado rapidamente, sem a necessidade de operações mais complexas, como as booleanas, descritas na seção 3.4.2.3.

\subsubsection{1 - "TWEAKING"}

Uma operação que ajusta a geometria das faces é o "tweaking", que pode ser de dois tipos: o que modifica a geometria das faces através de transformação linear (como rotação e translação) e o que substitui a superfície de uma face por outra de tipo diferente (como substituir uma superfície plana por uma cilíndrica) [Jar85]. Os dois tipos de operação "tweaking" são mostrados na figura 3.5, e podem ser implementados de forma semelhante. A geometria antiga deve ser retida até que toda a nova geometria tenha sido calculada e checada, permitindo que o processo seja abortado sem nenhum efeito sobre o objeto, caso tenha sido produzido um objeto inválido.

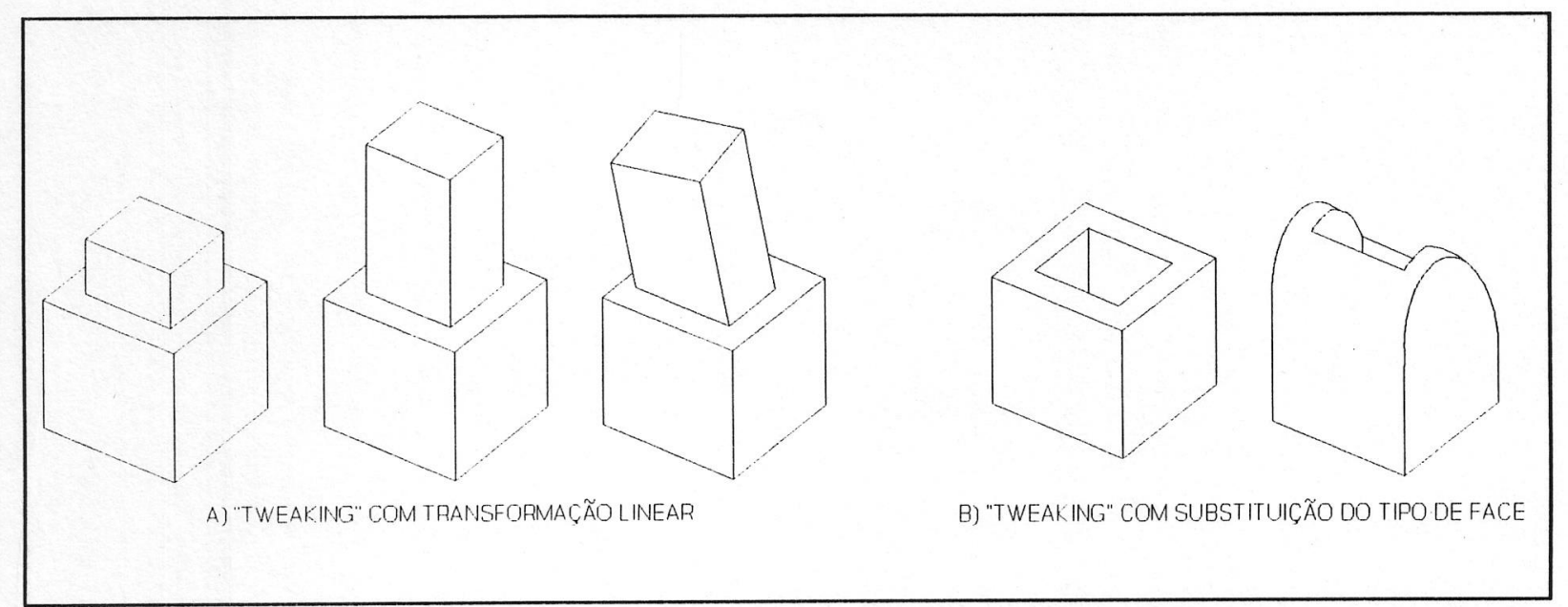

Figura 3.5 - Exemplos de operações de "tweaking" 


\subsubsection{2 - "CHAMFERING"}

Uma operação local que realiza alteração topológica em um objeto é a chanfradura ("chamfering"). A operação consiste em remover cantos agudos do objeto, substituindo uma aresta ou vértice por uma face planar pequena [Jar85]. É implementada através de operadores de Euler, que realizam as alterações necessárias na região definida.

$\mathrm{O}$ uso de operadores de Euler para fazer mudanças topológicas assegura que os objetos continuem topologicamente válidos depois das operações locais. Devido, porém, à independência existente entre a topologia e a geometria em modeladores B-Rep, é possível que ocorra a produção de objetos com topologia válida porém com geometria inconsistente, a menos que sejam realizadas certas verificações adicionais, tanto locais quanto globais. As verificações globais são necessárias para garantir a consistência dos objetos depois da operação, pois as verificações locais, embora sejam mais baratas e mais fáceis de serem implementadas, não satisfazem essa necessidade. A figura 3.6 a seguir ilustra exemplos de chanfradura.

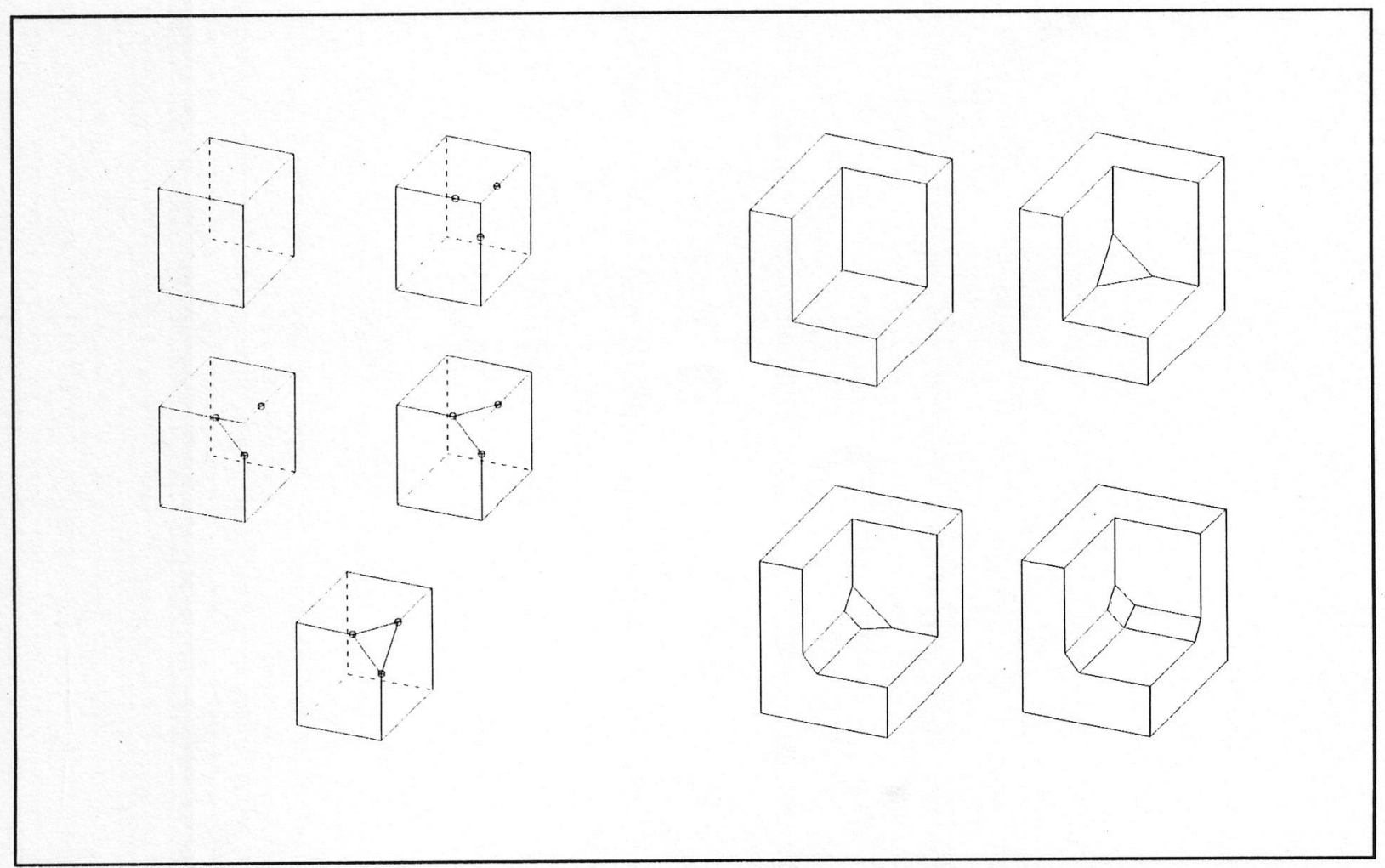

Figura 3.6 - Exemplos de operações de chanfradura 


\subsubsection{3 - "ROUNDING"}

Modelos curvos tridimensionais podem ser gerados pela operação de arredondamento ("rounding") [Chi85], que permite realizar modificações de forma precisa. Para o uso desta operação, o projetista deve adicionar informações que permitirão arredondar cantos e arestas para todo o modelo. As arestas do modelo curvo consistirão de curvas paramétricas (ex: Bézier ou B-Spline) e linhas retas. O modelo curvo mantém a mesma topologia do modelo base. A figura 3.7, a seguir, apresenta exemplos de arredondamento.

A operação de arredondamento é um recurso que pode ser utilizado para a geração de superfícies de forma livre em um modelador de sólidos.

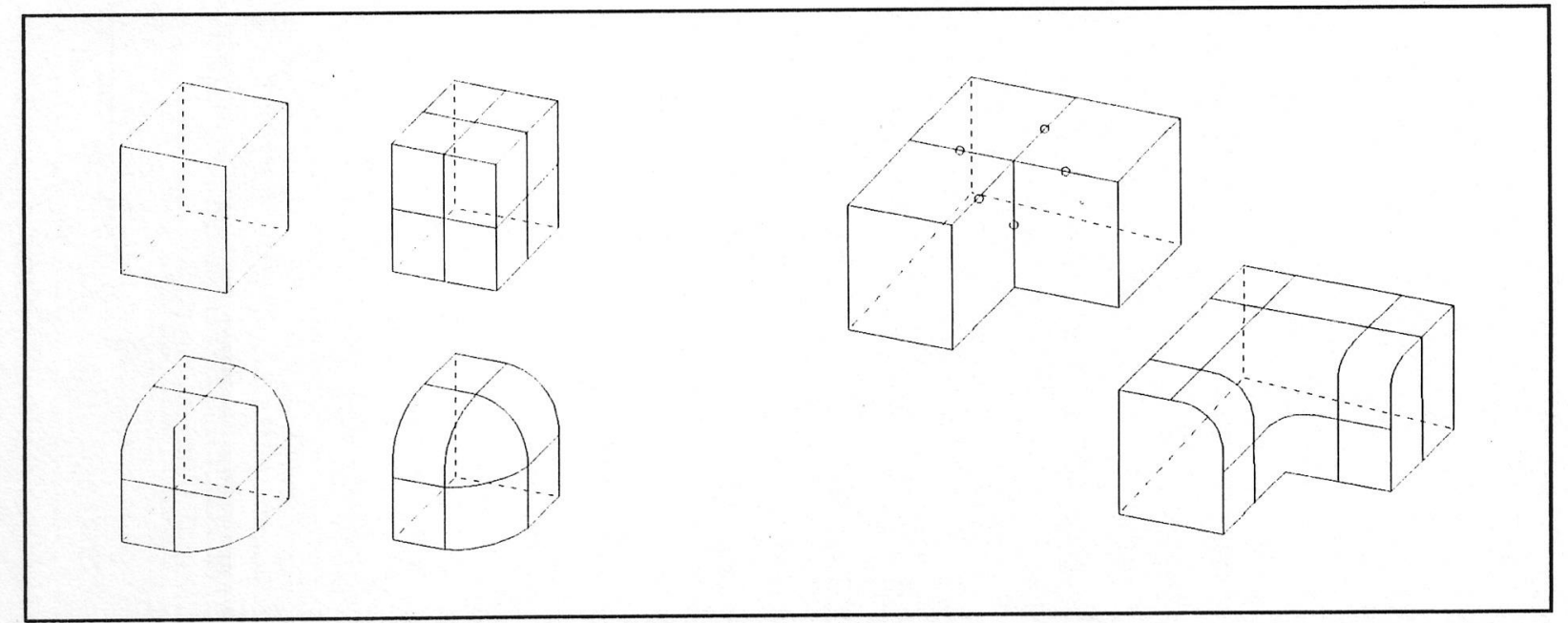

Figura 3.7 - Exemplos de operações de arredondamento

\subsection{2 - Operações Globais e Combinação de Sólidos}

Primitivas sólidas isoladas, geradas por varredura ou por parametrização da primitiva, conseguem representar apenas um pequeno conjunto de objetos reais. É, portanto, necessário acrescentar ao modelador operações que combinem sólidos primitivos para formar outros mais complexos, ou ainda, que seja possível obter novos sólidos derivados dos já existentes. Tais operações são apresentadas a seguir. 


\subsubsection{1 - COLAGEM}

A operação mais simples de combinação de sólidos consiste em colar dois sólidos sobre uma face comum, que poderá ser ou não totalmente coincidente. A colagem é uma forma restrita da operação booleana de união, na qual os componentes não se podem interceptar [Fol90, Mor85]. Outras restrições requerem que seja compartilhado um ponto, uma aresta ou uma face [Fol90]. A figura 3.8 ilustra uma operação de colagem através do modelo sólido e do modelo planar.

Uma possível solução para o problema da colagem de faces pode ser dividida em três partes: a mesclagem de duas estruturas de dados em uma que possua duas cascas; a junção destas cascas, fazendo com que a face de uma seja a borda interna da outra; a união das arestas e vértices coincidentes da face resultante da junção das cascas.

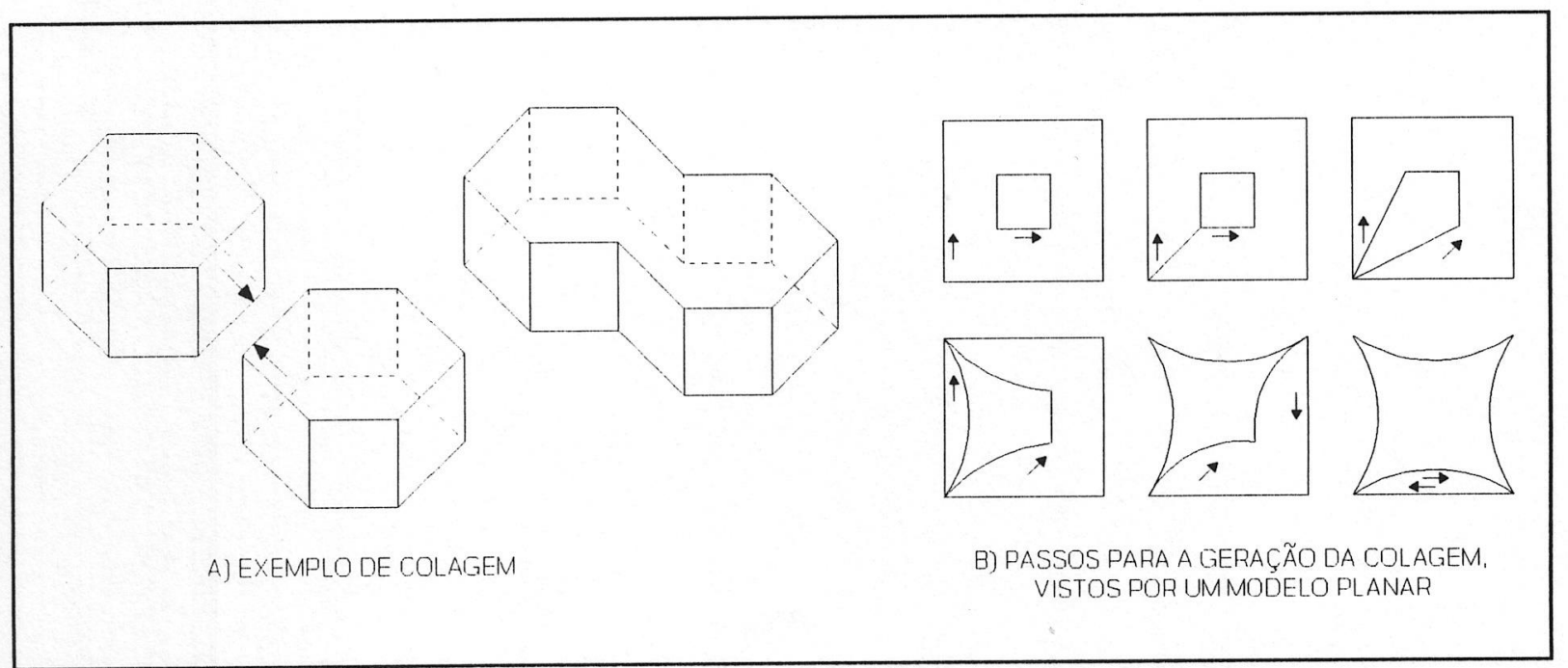

Figura 3.8 - Exemplo e seqüência da operação de colagem

\subsubsection{2 - OPERAÇÃO DE CORTE}

Outra operação importante é o particionamento ("splitting"), que realiza o corte de um sólido por um plano. Além de ser uma ferramenta de modelagem útil por si só, também forma a base para operações mais avançadas, denominadas operações booleanas, apresentadas na próxima seção. 
Dado um sólido e um plano de corte, o problema consiste em calcular dois sólidos, Acima e Abaixo, que representam as partes do sólido original que permanecem nos lados positivo e negativo do plano de corte, respectivamente. O lado positivo corresponde ao da direita (ou de cima), e o lado negativo, da esquerda (ou de baixo). Se o sólido está completamente em um lado do plano de corte, o sólido que representa o outro lado é vazio. A figura 3.9 apresenta os passos realizados em uma operação de corte, bem como um exemplo de objeto cortado.

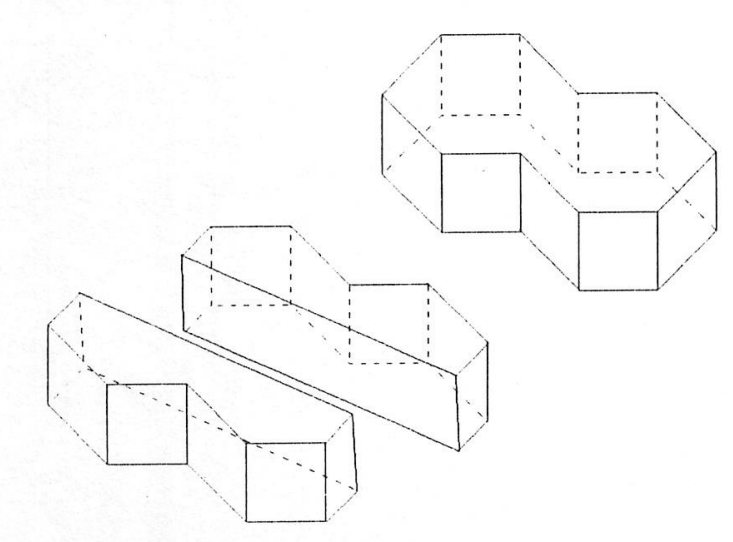

A) CORTE REALIZACIO SOBRE UM OBJETO
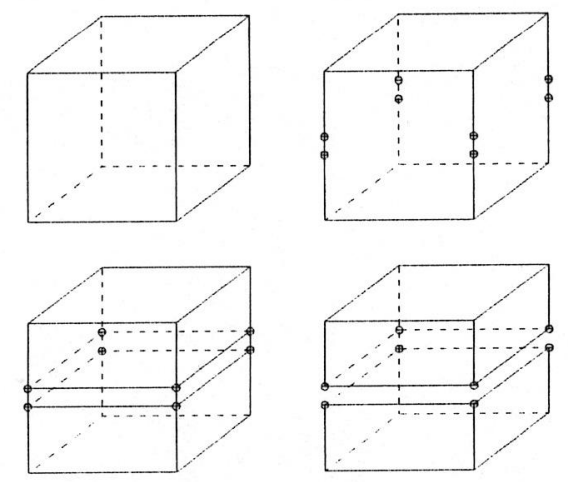

B) PASSOS PARA A OPERAÇÃO DE CORTE

Figura 3.9 - Exemplo e seqüência da operação de corte

A operação de corte pode ser realizada inserindo um par de faces em cada seção do sólido, uma face na parte Acima e outra na parte Abaixo, porém alguns cuidados devem ser tomados. Em primeiro lugar, a definição do problema requer que a operação seja fechada: seus resultados devem ser sólidos. Em segundo lugar, esta ou qualquer outra operação que trabalhe sobre sólidos pode ser repetidamente aplicada ao resultado. Isto significa que a operação de corte pode ser útil não só para gerar visões de seções do sólido, permitindo melhor visualização e compreensão do objeto projetado, mas também como uma ferramenta de modelagem real.

A operação de corte trabalha diretamente sobre a estrutura de dados de um sólido e a modifica para gerar os resultados. Assim, o objeto original desaparece. Uma variação simples desta operação permite obter os polígonos de secção e mantém os objetos originais intactos, sendo conhecida por "slicing". Ela é útil para visualizar objetos complicados. Somente pequenas adaptações são necessárias no algoritmo de particionamento para gerar a operação de "slicing". 


\subsubsection{3 - OPERAÇÕES BOOLEANAS}

Operações booleanas são usadas para unir, interseccionar e subtrair sólidos, oferecendo a facilidade de descrever objetos complexos em termos de uma série de operações em componentes mais simples. Além do poder descritivo, através de vários algoritmos estas operações oferecem um meio de descrever processos físicos aplicados a objetos como, por exemplo, determinar interferência entre componentes de uma montagem.

Permitir que sejam executadas operações booleanas sobre objetos sólidos é uma das possibilidades essenciais e mais poderosas disponíveis nos modeladores de sólidos. Para modeladores baseados em representação por fronteira, o algoritmo de execução das operações boolenas é também o componente que demanda mais técnica.

Se um objeto sólido é representado como uma combinação booleana de dois ou mais objetos simples, a representação é um modelo booleano. Esta representação é procedural e não avaliada. A rotina de avaliação de fronteira utiliza esta informação para construir a representação por fronteira.

Existem muitas situações interessantes, difíceis e delicadas que um sistema de modelagem geométrica deve considerar quando avaliando a fronteira de um objeto, como mostrado no quadro 3.3 .

\begin{tabular}{|c|c|c|}
\hline $\begin{array}{l}\text { União ou diferença do objeto } \\
\text { com si próprio }\end{array}$ & $\begin{array}{l}\text { União de primitivas disjuntas } \\
\text { (sem intersecção) }\end{array}$ & $\begin{array}{c}\text { A } \\
\text { Diferença de primitivas } \\
\text { disjuntas (sem intersecção) }\end{array}$ \\
\hline $\begin{array}{l}\text { União de primitivas em que } \\
\text { uma está toda contida na outra }\end{array}$ & $\begin{array}{l}\text { Diferença de primitivas em que } \\
\text { a positiva contém a negativa }\end{array}$ & $\begin{array}{l}\text { Diferença de primitivas em que } \\
\text { a negativa contém a positiva }\end{array}$ \\
\hline $\begin{array}{l}\text { Diferença de primitivas que cria } \\
2 \text { ou mais objetos novos }\end{array}$ & $\begin{array}{l}\text { União de primitivas que são } \\
\text { tangentes entre si }\end{array}$ & $\begin{array}{l}\text { União de primitivas que cria } \\
\text { ciclos ou cavidades internas }\end{array}$ \\
\hline
\end{tabular}

Quadro 3.3 - Uma variedade de situações de modelagem por operações booleanas [Mor85] 
Apesar de serem bidimensionais as situações apresentadas no quadro 3.3, todas elas correspondem a situações tridimensionais análogas. Algumas generalizações e propriedades são apresentadas no quadro 3.4 .

Se duas curvas coplanares fechadas A e B não se
interceptam e se um ponto da curva B está dentro
da curva A, então a curva B está totalmente
contida em A

Quadro 3.4 - Quatro propriedades gerais dos modelos booleanos [Mor85]

Infelizmente, algoritmos de operações booleanas para representação por fronteira sofrem, em geral, dois tipos de problemas. O primeiro é que, para serem efetivos, estes algoritmos devem ser capazes de tratar todos os tipos possíveis de intersecções geométricas que venham a aparecer entre faces, arestas e vértices de dois objetos, como os apresentados no quadro 3.4. O tratamento apropriado de todos os casos requer uma análise bastante complexa. O segundo problema refere-se à análise de todos os casos, que deve-se basear em vários testes de sobreposição, coplanaridade e intersecções, difíceis de implementar de forma robusta na presença de erros numéricos.

Uma possível estratégia a ser adotada é a de dividir o problema de operação booleana em um conjunto de problemas mais simples, que possam ser manipulados como uma análise de caso relativamente mais direta.

O quadro 3.5 apresenta algumas estratégias para a realização de operações booleanas em modeladores poliedrais.

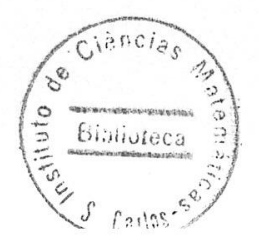




\begin{tabular}{|c|c|c|}
\hline ESTRATÉGIA & PONTOS POSITIVOS & PONTOS NEGATIVOS \\
\hline $\begin{array}{l}\text { INTERSECCÃO EXAUSTIVA } \\
\text { [Wes80, Mar80] } \\
\text { Polígonos de um objeto são interceptados com todos os } \\
\text { do outro objeto, e todos os objetos válidos são } \\
\text { construídos. } \\
\text { Planos são definidos; faces são construídas e testadas; } \\
\text { blocos são construídos a partir das faces, representando } \\
\text { partes sólidas ou cavidades; sólidos são construídos a } \\
\text { partir dos blocos; arestas supérfluas são removidas. }\end{array}$ & $\begin{array}{l}. E ́ \text { possível especificar } \\
\text { interativamente a região onde } \\
\text { ocorre intersecção, limitando o } \\
\text { processo à área afetada. }\end{array}$ & $\begin{array}{l}\text { Consome muito tempo. } \\
\text { Polígonos não afetados pela } \\
\text { operação também têm que ser } \\
\text { reconstruídos. } \\
\text { Transfere para o usuário a } \\
\text { responsabilidade de identificar a } \\
\text { área onde ocorrem as } \\
\text { intersecções. }\end{array}$ \\
\hline $\begin{array}{l}\text { GRIDS ADAPTATIVOS } \\
\text { [Fra82] } \\
\text { espaç̧o que contém o objeto, formando células sobre as } \\
\text { quais as arestas e faces são classificadas. } \\
\text {.Um algoritmo complexo constrói o objeto resultante a } \\
\text { partir das arestas produzidas pela intersecção de } \\
\text { polígonos e arestas. }\end{array}$ & $\begin{array}{l}\text { Identifica todas as intersecções } \\
\text { possíveis entre faces e arestas. } \\
\text { Reduz o tempo de procura por } \\
\text { intersecção: somente polígonos } \\
\text { que interceptam uma mesma } \\
\text { célula do grid são testados para } \\
\text { verificar a intersecção. }\end{array}$ & $\begin{array}{l}\text { Algumas intersecções especiais } \\
\text { não são manipuladas } \\
\text { corretamente: por exemplo, } \\
\text { arestas tocando arestas, arestas } \\
\text { tocando polígonos e polígonos } \\
\text { tocando polígonos podem } \\
\text { resultar em arestas supérfluas. }\end{array}$ \\
\hline $\begin{array}{l}\text { DIRETÓRIOS ESPACIAIS } \\
\text { [Män83] } \\
\text { particionado, e as células resultantes recebem ponteiros } \\
\text { para os componentes geométricos que as interceptam. } \\
\text { O número de células resultantes depende do objeto. } \\
\text {.Técnica utilizada no modelador GWB. }\end{array}$ & $\begin{array}{l}\text { Reduz o tempo de procura por } \\
\text { intersecção, pois somente arestas } \\
\text { contidas na mesma célula são } \\
\text { testadas para verificar a } \\
\text { ocorrência de intersecção. }\end{array}$ & $\begin{array}{l}. \text { O número de arestas que } \\
\text { podem interceptar cada célula é } \\
\text { limitado. } \\
\text {.Como utiliza operadores de } \\
\text { Euler, só modela objetos de } \\
\text { variedade bidimensional. }\end{array}$ \\
\hline $\begin{array}{l}\text { CLASSIFICACÃO DE ARESTAS [Til80, Tiil84, Req85] } \\
\text { Utiliza o método gerar-e-testar a partir da classificação } \\
\text { de arestas } \\
\text {.Cada aresta ou parte da aresta é classificada como } \\
\text { estando dentro, fora ou na superfície do objeto. } \\
\text {.A combinação do conjunto de arestas resultantes é } \\
\text { definida em função do tipo de operação aplicada. }\end{array}$ & $\begin{array}{l}\text { Explora a localidade estrutural e } \\
\text { espacial, o que reduz o tempo de } \\
\text { procura por intersecções. } \\
\text {.Informações sobre vizinhança } \\
\text { são associadas a cada face e } \\
\text { aresta, visando manipular casos } \\
\text { especiais de intersecção. }\end{array}$ & $\begin{array}{l}\text {.Informações sobre vizinhança } \\
\text { devem ser atualizadas após cada } \\
\text { operação e constituem um } \\
\text { processo complexo que realiza } \\
\text { uma manipulação elaborada de } \\
\text { ponteiros. }\end{array}$ \\
\hline $\begin{array}{l}\text { CLASSIFICACĀO DA VIZINHANCA DO VÉRTICE } \\
\text { [Män86] } \\
\text { Baseia-se na representação implícita da vizinhança do } \\
\text { vértice, e explora a informação de adjacência disponivel } \\
\text { na representaçăo B-Rep. } \\
\text { Classifica os vértices e aplica regras de vizinhança para } \\
\text { definir a posição relativa de cada vértice; define as } \\
\text { fronteiras e seleciona-as em função da operação aplicada. }\end{array}$ & $\begin{array}{l}\text { Casos especiais de interseçãa } \\
\text { são reduzidos à classificação de } \\
\text { pares de vértices coincidentes. } \\
\text {.Garante a consistência } \\
\text { topológica e a regularidade do } \\
\text { poliedro resultante. }\end{array}$ & $\begin{array}{l}\text { Abordagem limitada a objetos } \\
\text { de variedade bidimensional, } \\
\text { devido ao uso de operadores de } \\
\text { Euler, porém permite alguns } \\
\text { objetos com pseudo-variedade } \\
\text { não bidimensional como entrada } \\
\text { e resultado. }\end{array}$ \\
\hline $\begin{array}{l}\text { ESTRUTURA "POLYTREE" } \\
\text { [Car87] } \\
\text { Objetos poliedrais são representados em estruturas de } \\
\text { dados "polytree", uma variação da decomposição celular. } \\
\text { Os polígonos contidos em células correspondentes de } \\
\text { dois sólidos são gerados e testados para determinar quais } \\
\text { polígonos devem ser incluídos no conjunto resultante. } \\
\text { Utiliza a técnica de "hashing" para a classificação de } \\
\text { polígonos, o que aumenta sua eficiência. } \\
\text {.A estrutura "polytree" é vantajosa em outras operações, } \\
\text { como em cálculos de conectividade, no "clipping" e em } \\
\text { algoritmos de visibilidade. }\end{array}$ & $\begin{array}{l}\text { Permite operações localizadas, } \\
\text { reduzindo o tempo de procura } \\
\text { por interseç̧ões. } \\
\text {.Cada célula pode ser tratada de } \\
\text { forma autônoma, sendo possível } \\
\text { o processamento em paralelo e } \\
\text { implementação em hardware. } \\
\text { Todos os casos especiais de } \\
\text { intersecção podem ser } \\
\text { manipulados corretamente } \\
\text { devido a simplicidade das células } \\
\text { na estrutura de dados. }\end{array}$ & $\begin{array}{l}\text { A estrutura de dados pode se } \\
\text { tornar muito grande para } \\
\text { objetos complexos } \\
\text {.Ainda não se tem uma } \\
\text { representação ótima da } \\
\text { estrutura "polytree" } \\
\text {.O uso de "polytrees" introduz } \\
\text { problemas numéricos não } \\
\text { existentes em representações } \\
\text { tradicionais; por outro lado, } \\
\text { ajuda a resolver outros } \\
\text { problemas numéricos comuns a } \\
\text { todos os modeladores }\end{array}$ \\
\hline
\end{tabular}




\section{5 - ELEMENTOS DE INTERFACE COM O USUÁRIO}

A interface com usuários é extremamente importante para a aceitação e utilidade de um sistema de modelagem de sólidos. Constituem fatores decisivos a facilidade de uso, cordialidade no tratamento, visualização adequada, confiabilidade, desempenho e flexibilidade. A falta de uma facilidade de entrada gráfica interativa torna modeladores de sólidos utilizáveis somente por programadores e projetistas altamente experientes. Assim, a interface gráfica é freqüentemente mais importante para a aceitação de um sistema por parte do usuário do que a sofisticação técnica do modelador, principalmente nos estágios iniciais de uso.

\subsection{1 - Mecanismos para Construção e Edição de Modelos}

Vários métodos podem estar disponíveis em um modelador para a construção de modelos sólidos. Considerando a dificuldade inerente aos modeladores por fronteira para descrever sólidos diretamente, é importante que a camada de interface ofereça mecanismos adequados para a construção e edição de modelos, tais como:

- linguagem de descrição: é uma facilidade disponível ao usuário para especificar formas. Geralmente, modeladores por fronteira utilizam técnicas de modelagem construtiva para a descrição de formas, necessitando implementar algoritmos de conversão entre os dois tipos de representação, conhecidos como avaliadores de fronteira.

- construção baseada em técnicas de varredura: é a definição de objetos tridimensionais utilizando curvas de perfil bidimensional ou primitivas tridimensionais prédefinidas, que podem ser varridas linearmente pelo espaço para gerar uma extrusão, ou ser varrida rotacionalmente em relação a um eixo para criar um sólido rotacional (ver próximo capítulo). Estes métodos apresentam um poder descritivo ainda maior quando permitem que o perfil seja definido em faces de objetos existentes e seja varrido para dentro (criando buracos e depressões) ou para fora (criando protusões). 
- operações de modificação local: realizam pequenas alterações no objeto, ajustando a geometria das faces ou usando operadores de Euler para adicionar alguns elementos à representação interna (ver seção 3.4.1).

- mecanismos para desfazer operações ou refazer sólidos: permitem que operações indesejadas ou erradas, realizadas sobre a forma em geração, sejam desfeitas durante o processo de modelagem.

\subsection{2 - Sistemas Gerenciadores de Interface}

A interface homem/máquina pode fazer uma diferença significativa no tempo de aprendizado, no desempenho, número de erros e grau de satisfação do usuário. A preocupação com a melhoria da qualidade das interfaces proporcionou o surgimento de diversas ferramentas a fim de fornecer o apoio necessário à construção de interfaces, de forma que esta tarefa não se tornasse mais complexa que o desenvolvimento da própria aplicação. Com o tempo, as bibliotecas de rotinas para manipulação de interfaces evoluíram a ponto de se tornarem sistemas complexos, denominados Sistemas Gerenciadores de Interface com Usuários (SGIUs). Um dos componentes do SGIU é um Sistema Gerenciador de Janelas (SGJ), que oferece o suporte necessário à construção de interfaces construídas por múltiplas áreas de $\mathrm{E} / \mathrm{S}$ que se comportam como terminais virtuais independentes, seja dentro de uma aplicação ou em várias aplicações simultâneas. A utilização de um ambiente de janelas permite que o usuário selecione menus, botões e outros controles, geralmente através de um dispositivo apontador (mouse). Desta forma, um aplicativo pode utilizar várias janelas, com as quais o usuário interage através do mouse ou do teclado.

O ambiente de janelas que interessa neste trabalho é o XWindow, por ser um sistema baseado em um protocolo de interconexão, que funciona de maneira transparente em redes de computadores, em diferentes arquiteturas e diferentes sistema operacionais. Além disto, permite que programas sejam executados em uma certa máquina, enquanto os resultados (gráficos ou não) são mostrados em outra máquina.

Para ambiente XWindow, a ferramenta a ser utilizada é o "toolkit" XView, que permite ao programador construir interfaces gráficas para suas aplicações sem a necessidade de um conhecimento mais profundo das camadas de software do sistema XWindow. 


\section{6 - APLICAÇÕES DE MODELADORES}

\subsection{1 - Cálculo de Propriedades Geométricas Integrais}

Propriedade geométrica pode ser explicada como mapeamentos ou funções que, a partir de conjuntos regulares "r-sets" (e talvez outras entidades matemáticas), produzem entidades matemáticas bem definidas. Assim, "volume" é uma propriedade geométrica de um objeto porque ela pode ser definida através de uma função que mapeia conjuntos regulares em números reais positivos [Voe77].

A especificação de um objeto é geometricamente completa se ela contém informação suficiente para computar qualquer propriedade geométrica do objeto. A princípio, sistemas que admitem uma especificação geometricamente completa resolvem o "problema geométrico" de uma vez por todas. Voelcker e Requicha [Voe77] afirmam que qualquer representação que possua informação suficiente para computar a função "pointmembership" também contém informação suficiente para permitir que qualquer outra propriedade geométrica do objeto seja computada (ou seja, a representação é geometricamente completa).

Algoritmos para computar propriedades geométricas de objetos dependem acentuadamente de como os objetos estão representados. Vários algoritmos foram desenvolvidos para operar em objetos representados por sua fronteira [Fri82], mas existem ainda alguns problemas relacionados à computação automática de propriedades integrais para sólidos geometricamente complexos. Lee [Lee82] apresenta vários métodos para calcular as propriedades integrais de sólidos geometricamente complexos e aponta alguns dos problemas relacionados. Mäntylä [Män82] apresenta algoritmos para computar área e volume de sólidos representados por modelos poliedrais, e afirma que o cálculo de outras propriedades integrais pode ser realizado de forma bem semelhante. 


\subsection{2 - Visualização}

A visualização é uma área de aplicação da modelagem de sólidos muito difundida. A produção de desenhos fio-de-arame a partir da representação B-Rep é de simples implementação, pois toda a informação necessária está contida no modelo. A adição de linhas de silhueta e do horizonte melhora consideravelmente as visões fio-de-arame. $\mathrm{Na}$ prática, o cálculo de silhuetas consome a maior proporção dos recursos usados para produzir figuras fio-de-arame de objetos curvos.

Melhorias adicionais podem ser obtidas removendo linhas escondidas ou mostrando-as com diferentes estilos. Diversos algoritmos bem conhecidos são usados em modeladores B-Rep comerciais para mostrar figuras por meio da remoção de linhas escondidas. Um método popular é o método de subdivisão de Warnock [Jar85, Sut74].

Figuras com superfícies escondidas, sombreadas e coloridas podem ser facilmente geradas a partir de modeladores B-Rep. Figuras de alta qualidade podem ser obtidas - a custo considerável - utilizando técnicas de "ray-firing"; outra técnica que se está tornando popular por poder ser implementada em hardware é o "facetting" [Jar85].

Para fazer a computação da sombra, técnicas de "ray-tracing" podem ser usadas, permitindo a opção por múltiplas fontes de luz e levando em consideração a reflexividade da superfície dos objetos que compõem a cena e o efeito do reflexo da luz de um objeto no outro. Este método consome uma grande quantidade de recursos do computador, mas produz cenas com um alto grau de realismo [Jar85, Fol90].

\subsection{3 - Uso Industrial: Projeto, Análise e Manufatura}

Esta área de aplicação tem apresentado grande evolução, e será provavelmente, no futuro, o uso mais importante da modelagem de sólidos, como uma tecnologia que capacita a manufatura integrada ao computador. Modeladores de sólidos fornecem um meio de comunicação do formato e outras informações relacionadas ao sólido através de todos os estágios, desde o projeto até a manufatura. Também permitem a automação de tarefas de 
projeto e manufatura de baixo nível, como geração de malhas de elementos finitos e geração de dados para máquinas de controle numérico. Atualmente, muitos dos programas de aplicação que interfaceiam com modeladores de sólidos para usar a sua capacidade de descrição demandam grande interação. $\mathrm{O}$ desenvolvimento da tecnologia de modelagem e a introdução de técnicas de Inteligência Artificial permitirão a automação de tais tarefas. Existem hoje poucos pacotes comerciais que exploram completamente a modelagem de sólidos para fornecer aplicações altamente automatizadas, mas muitos destes conceitos estão em estágio de pesquisa e desenvolvimento.

\section{7 - CONSIDERAÇÕES FINAIS}

Este capítulo apresentou os componentes de um modelador de sólidos por fronteira, descrevendo estruturas de dados para representação de objetos e detalhando as principais operações de manipulação da forma de objetos. Também foram comentados mecanismos para a construção e edição de modelos, bem como aplicações de modeladores.

Vale a pena ressaltar que, ao utilizar modelos, deve-se tomar cuidado para não confundir o modelo de um objeto ou a simulação de um processo com o próprio objeto ou processo. Quando se fazem perguntas ao modelo, ou quando este é analisado para melhor entender ou prever o comportamento do que está sendo representado, deve-se ter em mente que as respostas e resultados dizem respeito somente ao modelo. Se, e somente se, existir uma correspondência próxima entre o modelo e o objeto ou processo, será possível inferir com segurança qual o comportamento do objeto ou processo a partir do comportamento do modelo. A exatidão dos métodos de representação é uma arte e uma ciência em si própria, com assunto suficiente para a elaboração de muitas dissertações e pesquisas. 


\section{Capítulo 4}

\section{OPERAÇÕES BÁSICAS DE MODELAGEM}

\section{1 - CONSIDERAÇÕES INICIAIS}

Neste capítulo é apresentado um estudo detalhado das operações implementadas no decorrer do trabalho. A seção 4.2 conceitua e caracteriza as primitivas planares e sólidas desenvolvidas para o modelador $(\mathrm{SM})^{2}$, que será descrito no capítulo 5 . A seção 4.3 examina as operações de transformação geométrica. A seção 4.4 descreve as operações de varredura translacional e rotacional básicas, bem como suas variações, implementadas no (SM) ${ }^{2}$. Fechando este capítulo, a seção 4.5 tece algumas considerações em relação às operações estudadas.

\section{2 - PRIMITIVAS BÁSICAS}

Nos sistemas de modelagem contemporâneos, a abordagem mais comum consiste em oferecer um conjunto finito de primitivas sólidas concisas e compactas, cujo tamanho, formato, posição e orientação são determinadas por um pequeno conjunto de parâmetros especificados pelo usuário. A maioria dos sistemas, por exemplo, fornece uma primitiva do tipo bloco, para a qual o usuário especifica comprimento, largura, altura e posição inicial. O modelador então checa a validade dos parâmetros e aceita ou rejeita os valores definidos. Outras primitivas comuns são cilindros, esferas, cones e toros. Estas e outras primitivas são mostradas na figura a seguir com seus parâmetros correspondentes (exceto posição e orientação) e com exemplos de sistemas de modelagem que as utilizam. 

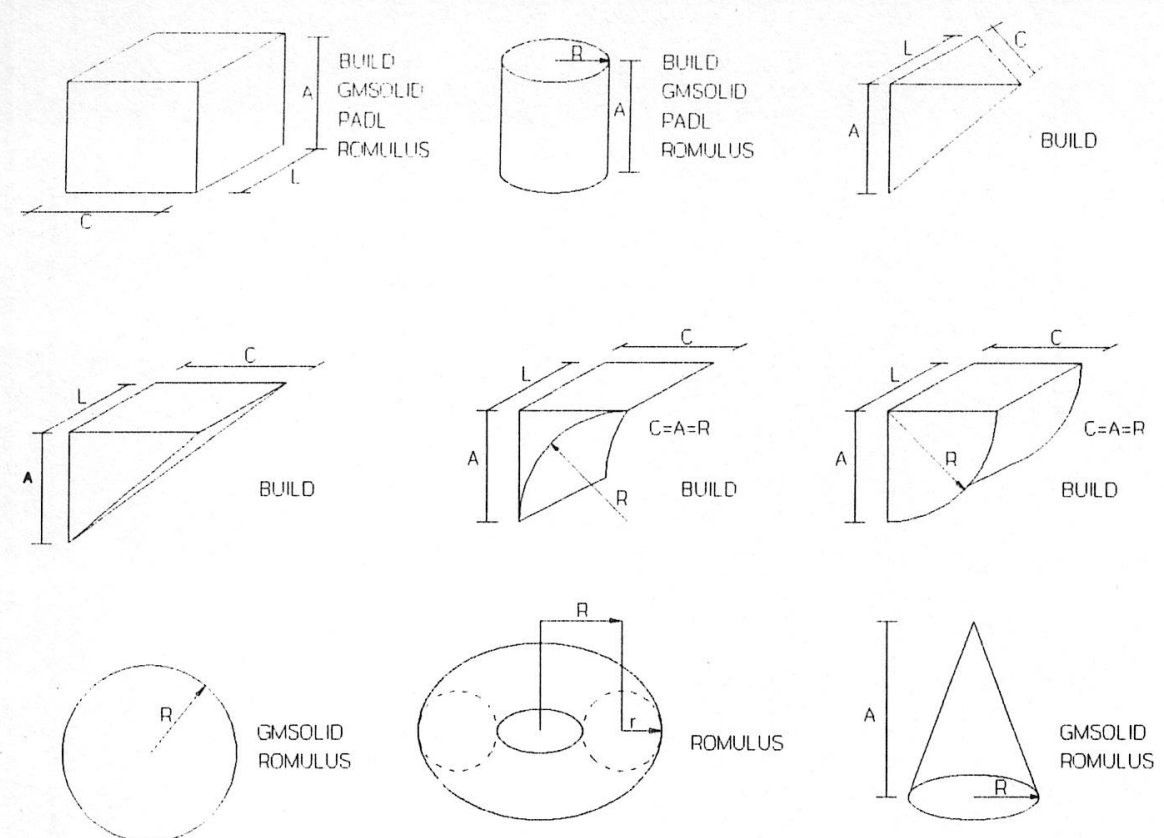

Figura 4.1 - Exemplos de primitivas básicas

Visando uma maior facilidade descritiva, foi implementado no (SM) ${ }^{2}$ um conjunto bem mais amplo de primitivas planares e sólidas, com possibilidade de descrição através de uma variada gama de parâmetros. As primitivas planares são utilizadas exclusivamente para a geração de sólidos através de operações de varredura, descritas na seção 4.4. Todas as primitivas definidas no modelador encontram-se descritas a seguir. As definições apresentadas para os elementos geométricos descritos foram baseadas em [Cen92, Dol85, Dol85a, Fer86, Rog90, Gom90]. A obtenção dos valores necessários para a con'strução das primitivas a partir dos parâmetros fornecidos tornou-se possível através do uso intenso de conceitos da geometria analítica planar e sólida e da trigonometria, encontrados em [Lei77, Kin76, Iez85, Iez85a, Iez85b, Bou87, Leh79, Car78, Ayr76, Ric72, Jud71].

\subsection{1 - Primitivas Planares}

As primitivas planares são descritas sobre um plano $x y$ fictício e encontram-se inicialmente posicionadas em relação à origem do sistema de coordenadas definido neste plano fictício. Logo após a entrada dos parâmetros de definição, a primitiva pode ser posicionada no plano, recebendo assim as coordenadas definidas pelo usuário. 


\subsubsection{1 - POLI-LINHA}

Uma poli-linha é um conjunto de segmentos de reta ligados entre si, de forma que o vértice final de um segmento coincida com o inicial do segmento seguinte, com exceção dos vértices inicial e final, que podem ou não ser coincidentes. No contexto do (SM) ${ }^{2}$, a polilinha é definida através de seus vértices, contidos em um único plano, não admitindo intersecção nem tangência de seus segmentos, sendo sempre aberta. Uma de suas características principais é que o conjunto desenhado constitui um só elemento geométrico. A Poli-linha pode ser vista como um arame contínuo dobrado, com o qual é impossível gerar uma face. Exemplos de poli-linhas estão ilustrados na figura 4.2, sendo os da esquerda válidos e as da direita inválidos no contexto do $(\mathrm{SM})^{2}$.

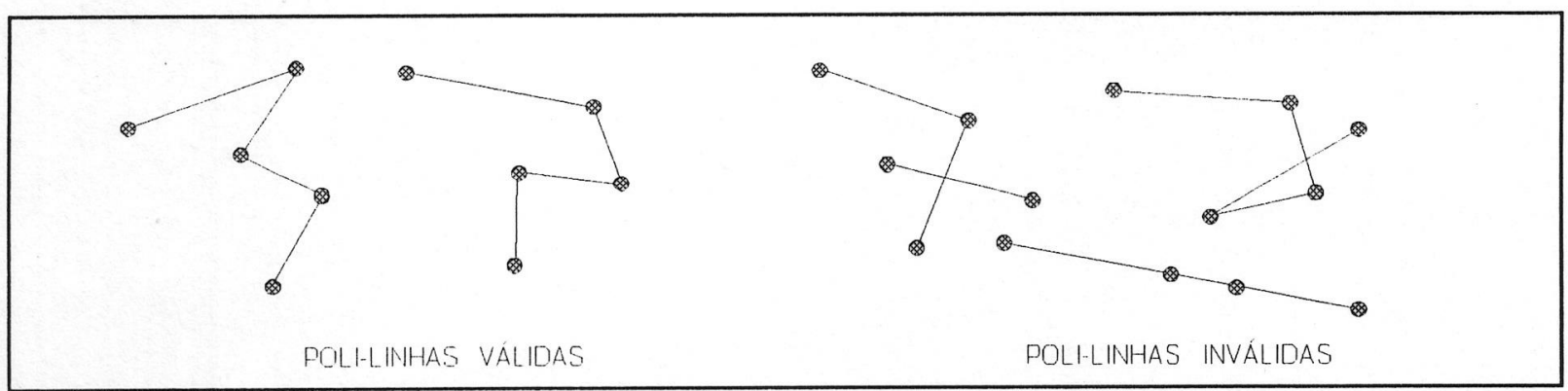

Figura 4.2 - Exemplos de poli-linhas

\subsubsection{2 - ARCO DE CIRCUNFERÊNCIA}

Denomina-se arco de circunferência o conjunto dos pontos compreendidos entre dois pontos A e B (inclusive) de uma circunferência, ou seja, é um segmento de circunferência. Existem vários métodos de geração de arcos que tomam pontos distintos como referência. Para o $(\mathrm{SM})^{2}$ foram escolhidos quatro métodos, apresentados na figura 4.3: pelos pontos inicial, centro e final; pelos pontos inicial e centro e ângulo de varredura; pelos pontos inicial e centro e tamanho da corda; por três pontos arbitrários. Com exceção do método de geração de arcos por três pontos, os demais métodos sempre irão desenhá-los no sentido anti-horário em relação ao ponto inicial. O sentido positivo para contagem de ângulos também é o anti-horário, assumindo a direção do ângulo inicial $\left(0^{\circ}\right)$ como sendo o correspondente a 3 horas. Como o $(\mathrm{SM})^{2}$ possui geometria aproximada, é possível definir a resolução a ser utilizada para a geração do arco. 


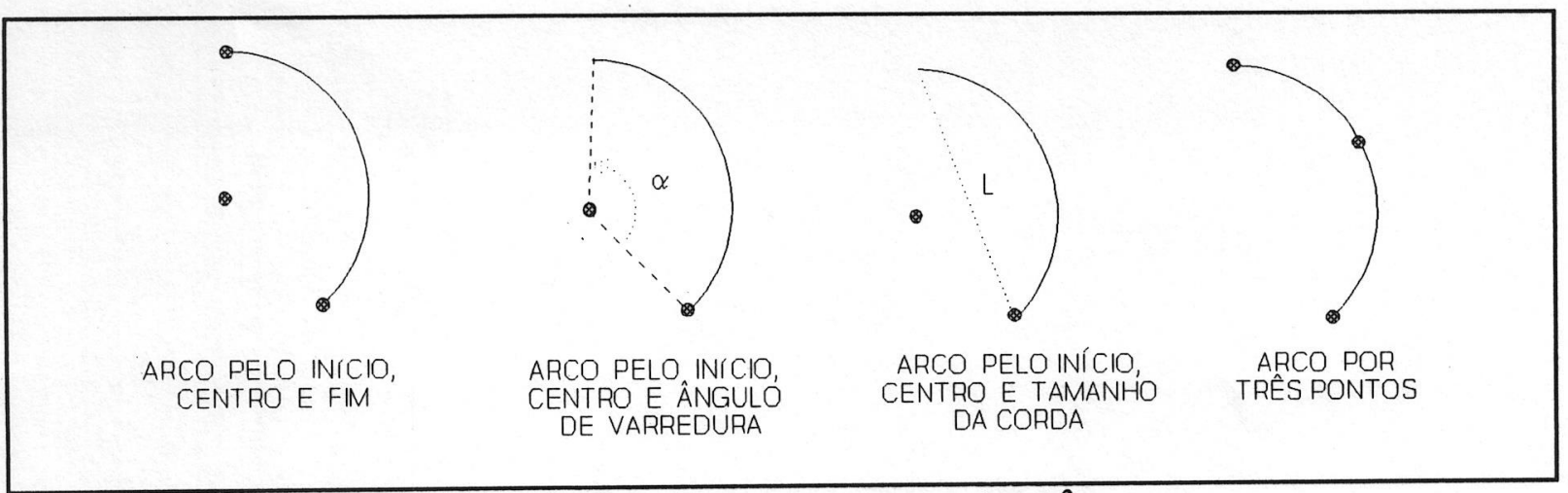

Figura 4.3 - Formas de geração de arcos disponíveis no (SM) ${ }^{2}$

\subsubsection{3 - CURVAS DE FORMA LIVRE}

Curvas polinomiais cujo formato não possui classificação padrão tornaram-se conhecidas como curvas de forma livre [Mil86].

Como comentado na seção 2.4.5, modelos poliedrais não são adequados para modelar de maneira exata curvas e superfícies, sendo interessante incluir outras entidades além de retas e planos. A inclusão de vários tipos de geometria em um modelador de sólidos aumenta em muito sua complexidade, devido à incorporação de um número significativo de rotinas de intersecção entre todos os tipos de curvas. Assim, muitos modeladores utilizam geometria por facetas [Eas77, Män82] ou possuem somente um tipo de curva [Hil82] [Req82], como por exemplo a B-Spline [Mor85, Rog90, New81, Har87].

Seguindo esta abordagem, foi incorporada ao $(\mathrm{SM})^{2}$ a possibilidade de geração de curvas "pseudo-livres", através da definição de B-Splines aproximadas. O algoritmo implementado foi adaptado do proposto por Newman [New81], sendo utilizadas B-Splines cúbicas definidas através de seus pontos de controle. A escolha por este tipo de curva deveuse ao seu grande poder descritivo: segundo Newman, B-Splines cúbicas são suficientes para um vasto número de aplicações, reduzindo a necessidade de agrupar diversas curvas para definir uma forma. Possuem ainda a característica de oferecer controle local da forma, o que facilita a tarefa de modelagem e permite a inclusão de cantos. Este efeito pode ser conseguido colocando múltiplos pontos de controle na mesma localização, como ilustrado na figura 4.4. A adição de pontos de controle não altera o grau da curva e nem aumenta a complexidade do sistema. 


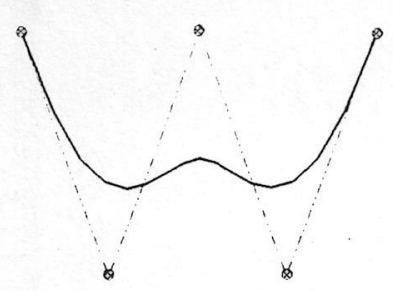

Q.SPLINE CIMM IMM POINTO DE CONTROLE POR POSICÃO

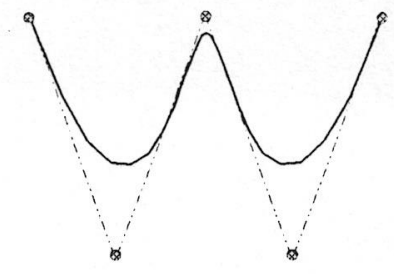

B-SPLINE COM [IOIS PIDNTOS DE CONTROLE NO CENTRO

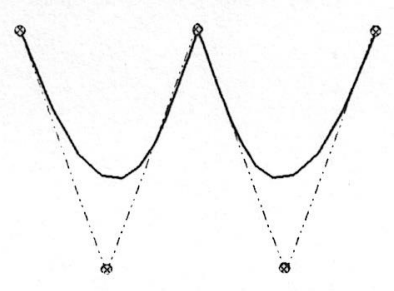

B-SPLINE COM TRÊS PONTOS DE CONTROLE NO CENTRO

Figura 4.4 - Curvas B-Spline: controle local e formação de cantos

\subsubsection{4 - CÍRCULO}

Círculo (ou disco) é um conjunto dos pontos de um plano cuja distância de um ponto dado deste plano é menor ou igual a uma distância não nula dada. Em outras palavras, é a reunião da circunferência com seu interior.

Para gerar um círculo, uma alternativa simples e eficiente seria construir um gerador de círculos no topo do gerador de arcos. No entanto, uma forma ainda mais eficiente é explorar sua simetria: se um ponto $(\mathrm{x}, \mathrm{y})$ pertence à circunferência, pode-se calcular de maneira trivial sete outros pontos da mesma. Conseqüentemente, basta computar um arco de circunferência de $45^{\circ}$ para obter a circunferência toda. Um círculo pode ser gerado a partir de vários parâmetros, conforme mostrado na figura 4.5 e implementado no (SM) ${ }^{2}$ : através da coordenada do centro e medida do raio ou diâmetro; pelo fornecimento de dois pontos diametralmente opostos; passando por três pontos.

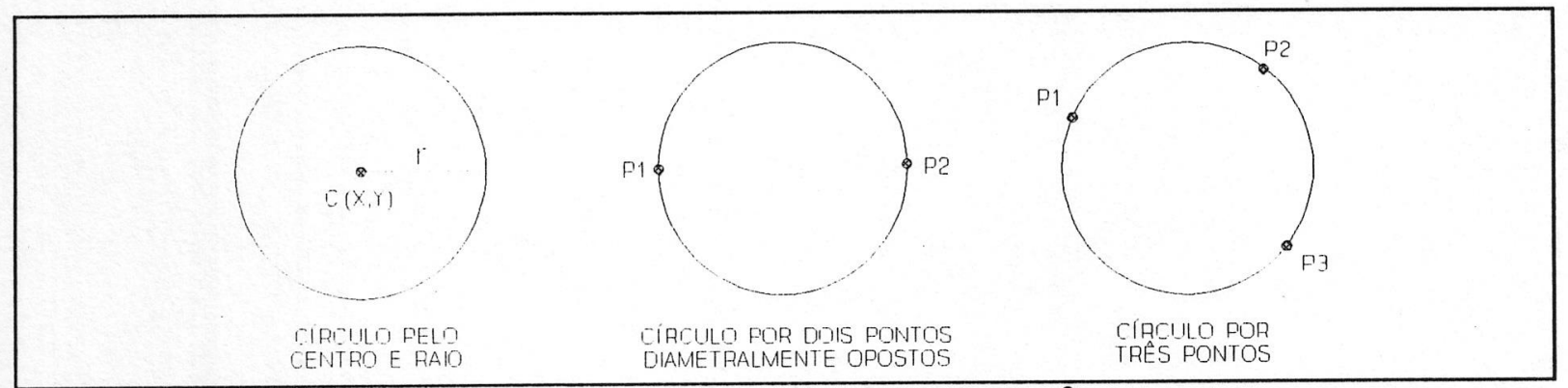

Figura 4.5 - Formas de geração de círculo utilizadas no $(\mathrm{SM})^{2}$ 


\subsubsection{5 - ELIPSE}

Elipse é conjunto de pontos do plano cuja distância de dois pontos fixos (focos) têm soma constante. Apesar de fazer parte de sua definição, a utilização dos focos não constitui uma maneira prática de se obter o traçado de elipses. Muito mais natural é traçá-la a partir da dimensão de seus eixos maior e menor. Sua simetria também pode ser explorada: para cada ponto $(x, y)$ pertencente à elipse, pode-se calcular de maneira trivial três outros pontos da mesma, sendo necessário calcular somente um quadrante para obtê-la por completo. A figura 4.6 ilustra uma elipse e seus parâmetros de definição. No (SM) ${ }^{2}$, a denominação elipse se refere à reunião da curva com seu interior, ou seja, à superfície elíptica.

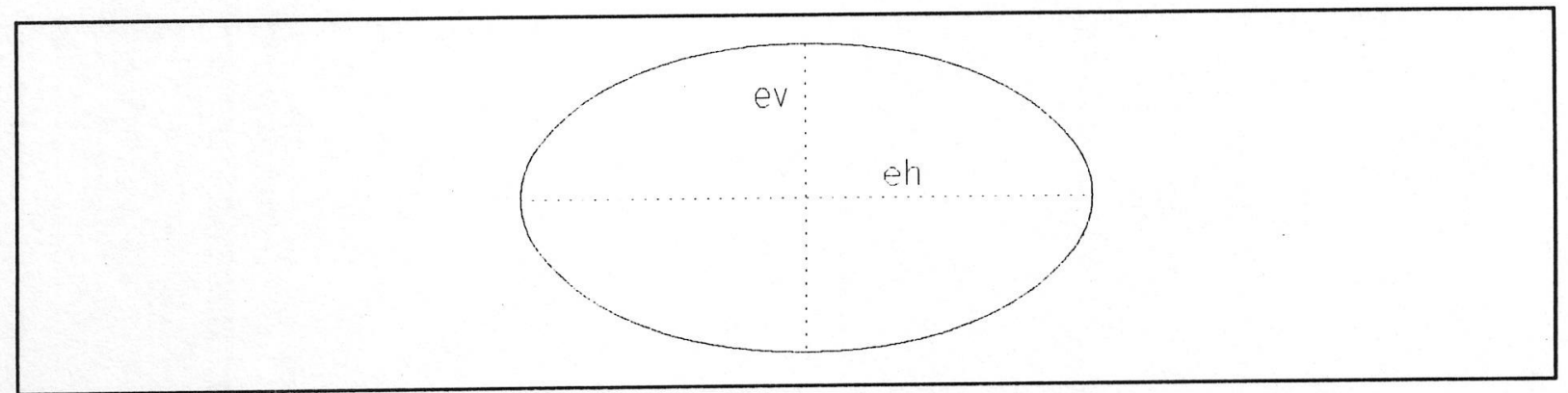

Figura 4.6 - Elipse traçada pelos eixos vertical e horizontal

\subsubsection{6 - TRIÂNGULO}

Dados três pontos G, H e I não colineares, triângulo é o conjunto de pontos comuns aos ângulos GĤI, HÎG e IĜH. Quanto aos lados, os triângulos se classificam em:

- equiláteros, quando têm os três lados congruentes;

- isósceles, quando têm dois lados congruentes;

- escalenos, quando dois lados quaisquer não são congruentes.

A reunião do triângulo com seu interior forma uma superfície triangular, sendo esta a entidade de interesse para o $(\mathrm{SM})^{2}$. A figura 4.7 apresenta exemplos de triângulos. 


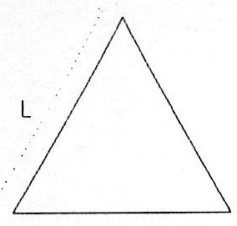

EQUILÁTERO

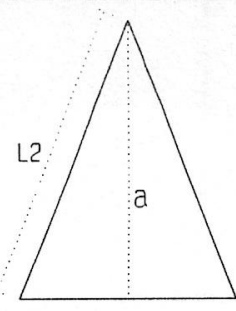

L1

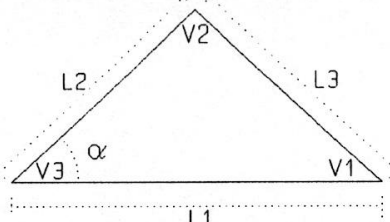

ESCALENO

Figura 4.7 - Classificação de triângulos utilizada no modelador

\subsubsection{7 - QUADRILÁTERO}

Quadrilátero pode ser entendido como uma região plana limitada por quatro lados quaisquer. Os quadriláteros notáveis, assim denominados por possuírem algumas características peculiares, são os de interesse para o $(\mathrm{SM})^{2}$ :

- o quadrado possui os quatro lados e os quatro ângulos congruentes;

- o retângulo possui os quatro ângulos congruentes;

- o losango possui os quatro lados congruentes;

- o trapézio possui dois lados paralelos, denominados bases do trapézio;

- o paralelogramo possui os lados opostos paralelos.

Exemplos de quadriláteros notáveis com seus parâmetros de definição encontram-se ilustrados na figura 4.8 .

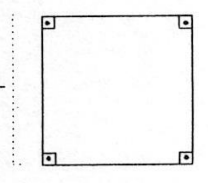

QUADRADO

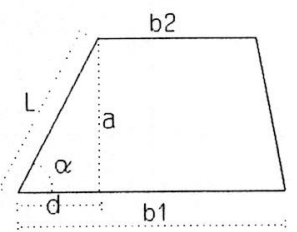

TRAPÉZ10

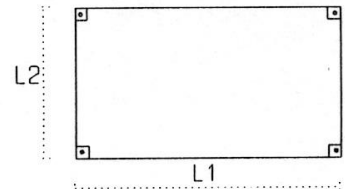

RETÂNGULO

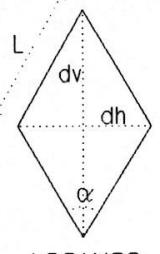

LOSANGO

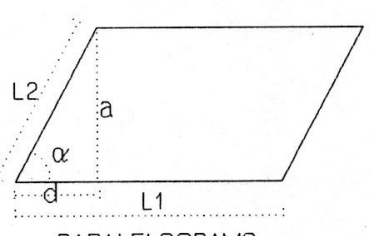

PARALELOGRAMO

Figura 4.8 - Exemplos de quadriláteros notáveis com seus parâmetros 


\subsubsection{8 - POLÍGONO}

Dada uma seqüência de pontos em um plano $\left(A_{1}, A_{2}, \ldots, A_{n}\right)$, todos distintos, em que três pontos consecutivos não são colineares, considerando-se consecutivos $A_{n-1}, A_{n}$ e $A_{1}$, assim como $A_{n}, A_{1}$ e $A_{2}$, denomina-se linha poligonal à seqüência de segmentos que unem estes pontos consecutivos, e polígono à reunião desta linha com sua região interna. Visando facilitar operações futuras e trabalhar apenas com objetos de variedade bidimensional, os polígonos permitidos no $(\mathrm{SM})^{2}$ podem possuir três pontos consecutivos colineares (desde que todos não o sejam) e a intersecção de quaisquer dois lados não consecutivos deve ser vazia. A figura 4.9 ilustra o conceito de polígono, separando-os em válidos e inválidos para o $(\mathrm{SM})^{2}$.
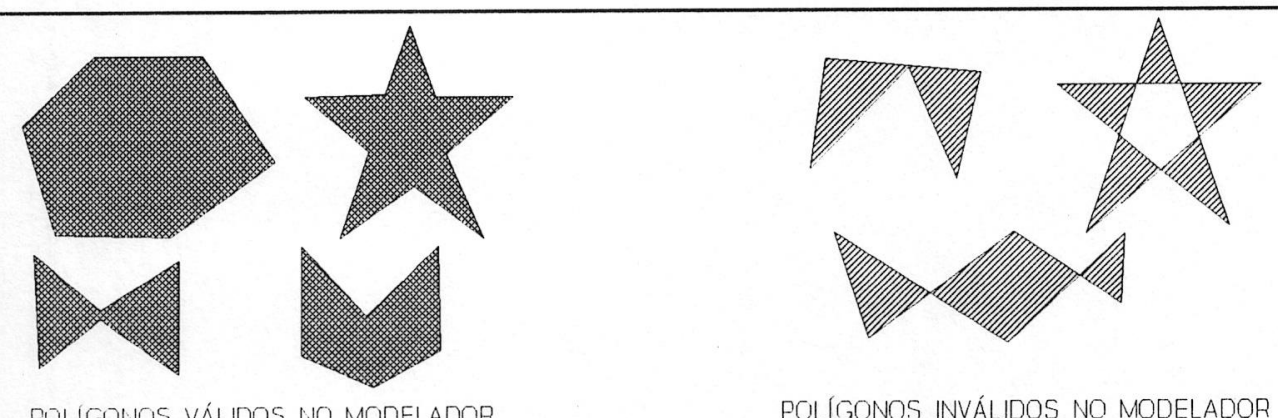

POLIGGONOS INVÁLIDOS NO MODELADOR

Figura 4.9 - Conceito e classificação de polígonos no contexto do (SM) ${ }^{2}$

Um polígono que possui os lados congruentes é equilátero; se possui os ângulos congruentes é equiângulo; se é equilátero e equiângulo, é denominado um polígono regular. Como todo polígono regular é inscritível ou circunscritível a uma circunferência, a forma mais simples de gerar polígonos regulares é através da definição do número de lados e do raio da circunferência ou do comprimento do lado. A figura 4.10 apresenta um exemplo de cada tipo de polígono disponível no $(\mathrm{SM})^{2}$.

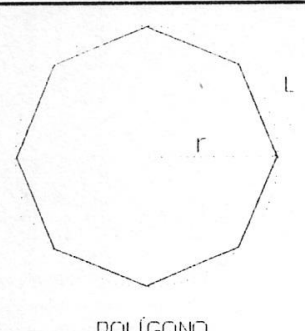

REGULAR INSCRITO
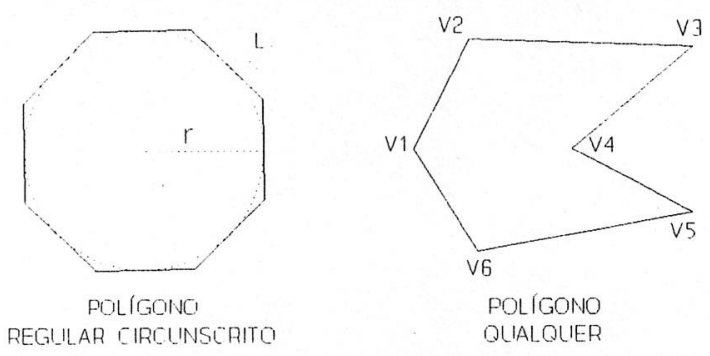

Figura 4.10 - Exemplo dos tipos de polígonos disponíveis no (SM) 


\subsubsection{9 - PARÂMETROS UTILIZADOS PELAS PRIMITIVAS PLANARES}

O quadro 4.1 resume os tipos de primitivas planares anteriormente descritas, relacionando os parâmetros de definição utilizados em cada caso, bem como as consistências realizadas após o fornecimento destes parâmetros.

\begin{tabular}{|c|c|c|c|}
\hline & PARÂMETROS & DOMÍNIO & CONSISTÊNCIAS \\
\hline $\begin{array}{l}\mathrm{A} \\
\mathrm{R} \\
\mathrm{C} \\
\mathrm{O}\end{array}$ & $\begin{array}{l}\text { - resolução } \\
\text { Opção } 1 . \\
\text { - coord. início } \\
\text { - coord. centro } \\
\text { - coord. fim } \\
\text { Opção } 2 \\
\text { - coord. início } \\
\text { - coord. centro } \\
\text { - ângulo de varredura } \\
\text { Opção } 3 \\
\text { - coord. início } \\
\text { - coord. centro } \\
\text { - comprimento da corda } \\
\text { Opção } 4 \\
\text { - coord. início } \\
\text { - coord. outro ponto } \\
\text { - coord. fim }\end{array}$ & $\begin{array}{l}1 \text { a } 100 \% \\
\text { real } \\
\text { real } \\
\text { real } \\
\text { real } \\
\text { real } \\
\text { real } \\
\text { real } \\
\text { real } \\
\text { real }+ \\
\text { real } \\
\text { real } \\
\text { real }\end{array}$ & $\begin{array}{l}\text { - convertida para múltiplo de } 4 \\
\text { - início e centro não podem ser coincidentes } \\
\text { - distância início-centro igual a centro-fim } \\
\text { - início e centro não podem ser coincidentes } \\
\text { - ângulo diferente de } 0 \\
\text { - início e centro não podem ser coincidentes } \\
\text { - } 0<\text { comprimento }<2 * \text { raio } \\
\text { - os } 3 \text { pontos não podem ser colineares } \\
\text { - ângulo final }<>\text { ângulo inicial }\end{array}$ \\
\hline $\begin{array}{l}\text { C L } \\
\text { U I } \\
\text { R V } \\
\text { V R } \\
\text { A E } \\
\end{array}$ & $\begin{array}{l}\text { - } \mathrm{n}^{\circ} \text { pontos } \\
\text { - matriz de vértices } \\
\text { (pontos de controle) }\end{array}$ & $\begin{array}{l}\text { int }+ \\
\text { real }\end{array}$ & $\begin{array}{l}\text { - no pontos }>2 \text { e não podem ser todos } \\
\text { colineares } \\
\text { - segmentos de reta entre pontos de controle } \\
\text { não podem possuir intersecção }\end{array}$ \\
\hline $\begin{array}{l}\text { P L } \\
\text { O I } \\
\text { L N } \\
\text { I H } \\
-\quad \text { A } \\
\end{array}$ & $\begin{array}{l}\text { - no pontos } \\
\text { - matriz de vértices } \\
\text { (pontos definidos) }\end{array}$ & $\begin{array}{l}\text { int }+ \\
\text { real }\end{array}$ & $\begin{array}{l}\text { - no pontos > } 2 \text { e não podem ser todos } \\
\text { colineares } \\
\text { - segmentos de reta da poli-linha não podem } \\
\text { possuir intersecção }\end{array}$ \\
\hline $\begin{array}{l}\mathbf{P} \\
\mathrm{O} \\
\mathrm{L} \\
\mathbf{I} \\
\mathrm{G} \\
\mathrm{O} \\
\mathrm{N} \\
\mathrm{O}\end{array}$ & $\begin{array}{l}\text { - nº vértices } \\
\text { REGULAR INSCRITO } \\
\text { - raio ou } \\
\text { - comprimento lateral } \\
\text { REGULAR CIRCUNSCRITO } \\
\text { - raio ou } \\
\text { - comprimento lateral } \\
\text { QUALQUER } \\
\text { - matriz de vértices }\end{array}$ & $\begin{array}{l}\text { int }+ \\
\text { real }+ \\
\text { real }+ \\
\text { real }+ \\
\text { real }+ \\
\text { real }\end{array}$ & $\begin{array}{l}\text { - } \mathbf{n}^{0} \text { pontos }>2 \\
\text { - raio ou comprimento }<>0 \\
\text { - raio ou comprimento }<>0 \\
\text { - vertices não todos colineares, sem intersecção } \\
\text { entre segmentos }\end{array}$ \\
\hline $\begin{array}{l}\mathrm{C} \\
\mathrm{I} \\
\mathrm{R} \\
\mathrm{C} \\
\mathrm{U} \\
\mathrm{L} \\
\mathrm{O}\end{array}$ & $\begin{array}{l}\text { - resolução } \\
\text { Opção } 1 \\
\text { - coord. centro } \\
\text { - raio } \\
\text { Opção } 2 \\
\text { - coord. ponto } \\
\text { - coord. ponto oposto } \\
\text { Opção } 3 \\
\text { - coord. ponto1 } \\
\text { - coord. ponto2 } \\
\text { - coord. ponto3 } \\
\end{array}$ & $\begin{array}{l}1 \text { a } 100 \% \\
\text { real } \\
\text { real + } \\
\text { real } \\
\text { real } \\
\text { real } \\
\text { real real }\end{array}$ & $\begin{array}{l}\text { - convertida para múltiplo de } 4 \\
\text { - raio }<>0 \\
\text { - os } 2 \text { pontos não podem ser coincidentes } \\
\text { - os } 3 \text { pontos não podem ser colineares }\end{array}$ \\
\hline
\end{tabular}




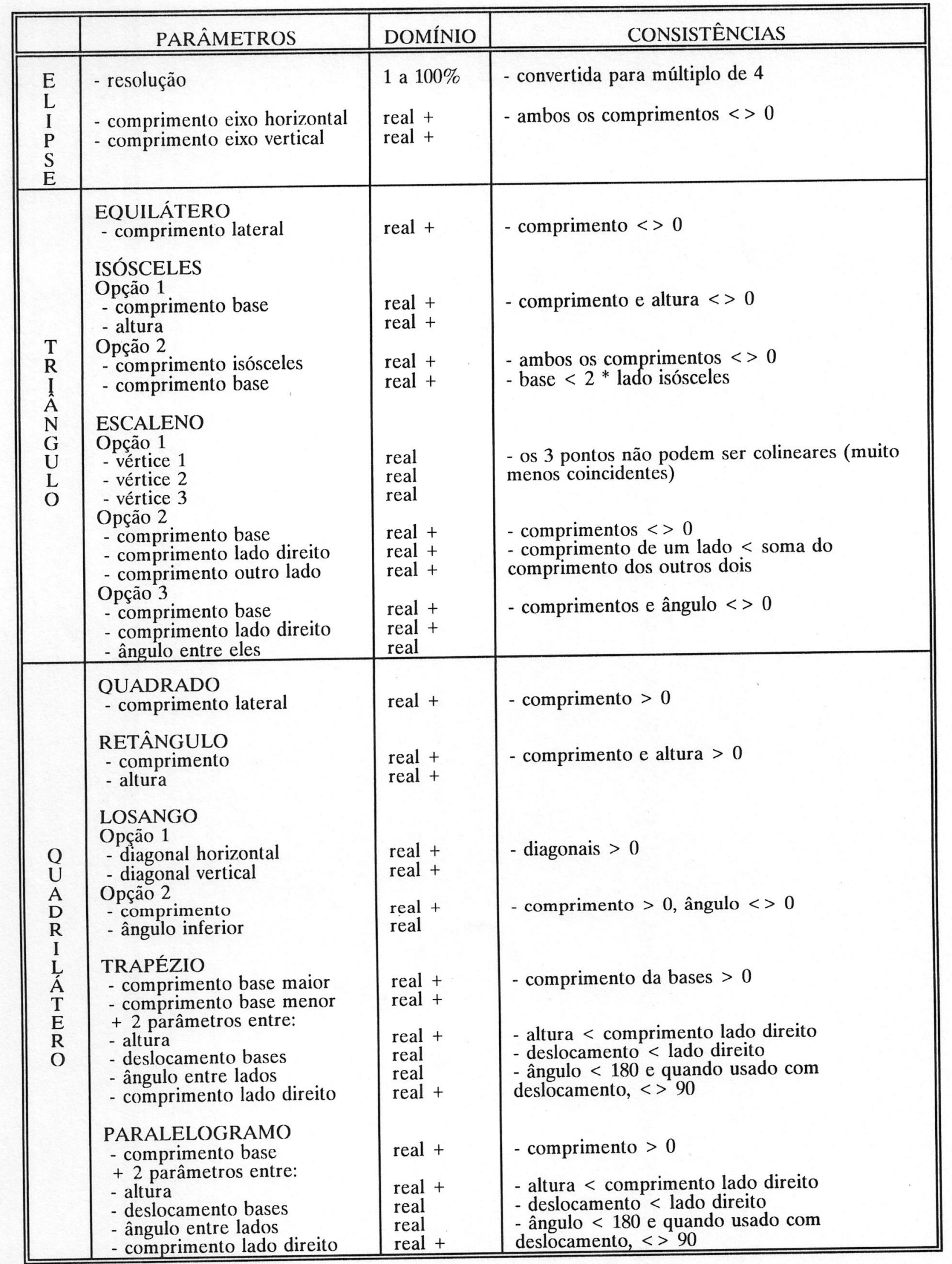

Quadro 4.1 - Resumo das primitivas planares do $(\mathrm{SM})^{2}$ e seus parâmetros 


\subsection{2 - Primitivas Sólidas}

As primitivas sólidas são descritas sobre um espaço tridimensional fictício e encontram-se inicialmente posicionadas em relação à origem do sistema de coordenadas definido neste espaço. Logo após a entrada dos parâmetros de definição, a primitiva pode ser posicionada no espaço, recebendo assim as coordenadas definidas pelo usuário.

Primitivas sólidas são geradas a partir da varredura de primitivas planares, de forma translacional ou rotacional. A translação poderá ser reta, gerando sólidos cujas arestas laterais são perpendiculares à base, ou oblíqua, caso exista uma inclinação diferente. A rotação ocorrerá sempre em relação a um eixo do sistema de coordenadas. Maiores detalhes sobre operações de varredura são fornecidos no item 4.4.

\subsubsection{1 - PRISMA}

Denomina-se prisma o sólido limitado por polígonos planos no qual duas faces são polígonos paralelos e congruentes (bases), e as outras (laterais) são paralelogramos. Um prisma reto possui arestas laterais perpendiculares aos planos das bases e faces laterais retangulares. Um prisma oblíquo possui arestas oblíquas aos planos das bases. Prisma regular é o prisma reto cujas bases são polígonos regulares. No $(\mathrm{SM})^{2}$, um prisma é definido pelos parâmetros de sua base (polígono regular inscrito ou circunscrito, ou polígono qualquer) e pela especificaçāo da translação reta ou oblíqua.

Um prisma possui $n+2$ faces, sendo $n$ faces laterais e 2 bases, $n$ arestas laterais, $3 n$ arestas e $2 n$ vértices. A figura 4.11 ilustra exemplos de primas.

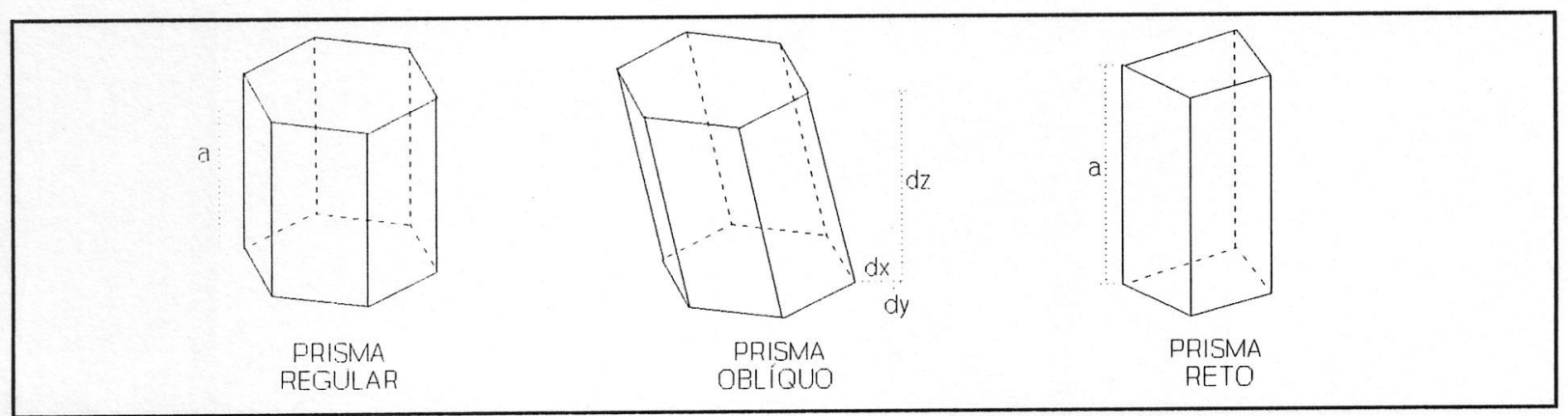

Figura 4.11 - Exemplos de prismas e seus parâmetros de definição 


\subsubsection{2 - PIRÂMIDE}

Pirâmide é o sólido limitado por polígonos planos no qual uma das faces é um polígono qualquer e as demais são triângulos com um vértice comum. Pirâmide reta é aquela na qual a reta perpendicular à base passando por este vértice comum encontra a base em seu centróide. Qualquer pirâmide que não seja reta é denominada pirâmide oblíqua. Pirâmide regular é uma pirâmide reta cuja base é um polígono regular, gerando faces laterais na forma de triângulos isósceles congruentes.

Ao seccionar uma pirâmide por um plano paralelo à base, são gerados dois sólidos: o que contém o vértice, que origina uma nova pirâmide, e o que contém a base da pirâmide inicial, que é um tronco de pirâmide de bases paralelas. A nova pirâmide e a pirâmide primitiva possuem elementos lineares homólogos (arestas das bases, arestas laterais, alturas, ...) proporcionais, possuindo entre si uma razão de semelhança. Formulada a princípio para pirâmide reta, esta definição de tronco de pirâmide de bases paralelas foi estendida no $(\mathrm{SM})^{2}$ para incorporar tronco de pirâmide oblíqua, mantendo as bases paralelas.

Uma pirâmide possui $n+1$ faces, sendo $n$ laterais e 1 base, $n$ arestas laterais, $2 n$ arestas e $n+1$ vértices. A figura 4.12 a seguir ilustra exemplos de pirâmides.

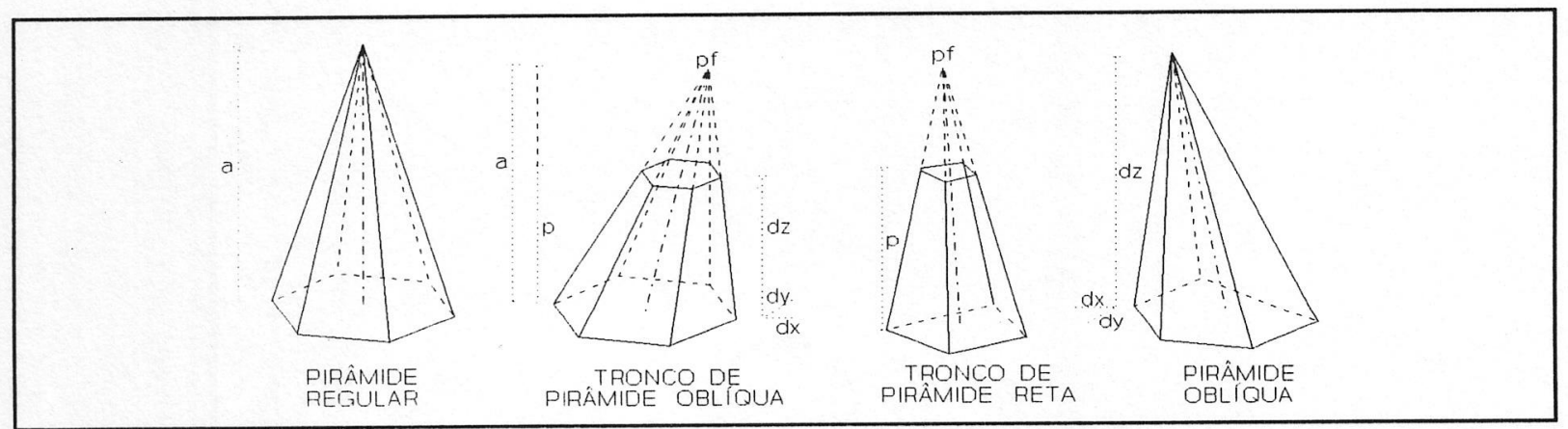

Figura 4.12 - Exemplos de pirâmides e seus parâmetros de definição

\subsubsection{3 - BLOCO}

De uma maneira genérica, os blocos são prismas cujas bases são formadas por quadriláteros, possuindo ao todo 6 faces, 12 arestas e 8 vértices. Os blocos formados pelos quadriláteros notáveis, permitindo sua definição através de parâmetros, são: paralelepípedo, ortoedro, romboedro, cubo e trapezóide. 
Paralelepípedo é um prisma cujas bases são paralelogramos. Em um paralelepípedo oblíquo, a superfície total é a reunião de seis paralelogramos, e em um paralelepípedo reto, corresponde à reunião de quatro retângulos (faces laterais) com dois paralelogramos (bases).

Um paralelepípedo reto-retângulo, ou ortoedro, é um prisma reto cujas bases são retângulos. Sua superfície total é a reunião de seis retângulos.

Romboedro é um paralelepípedo que possui as doze arestas congruentes entre si, com superfície formada por seis losangos. Um romboedro reto é composto por quatro quadrados (faces laterais) e dois losangos (bases). Um romboedro reto-retângulo, ou cubo, é um romboedro reto cujas bases são quadrados, ou um paralelepípedo retângulo cujas arestas são congruentes. A superfície de um cubo é a reunião de seis quadrados.

Fora da família dos paralelepípedos encontra-se o trapezóide, que é um prisma cujas bases são trapézios. Em um trapezóide oblíquo, as faces laterais correspondem a quatro paralelogramos, em um trapezóide reto correspondem a quatro retângulos.

Exemplos de blocos contendo os parâmetros utilizados em sua definição são apresentados na figura 4.13 .

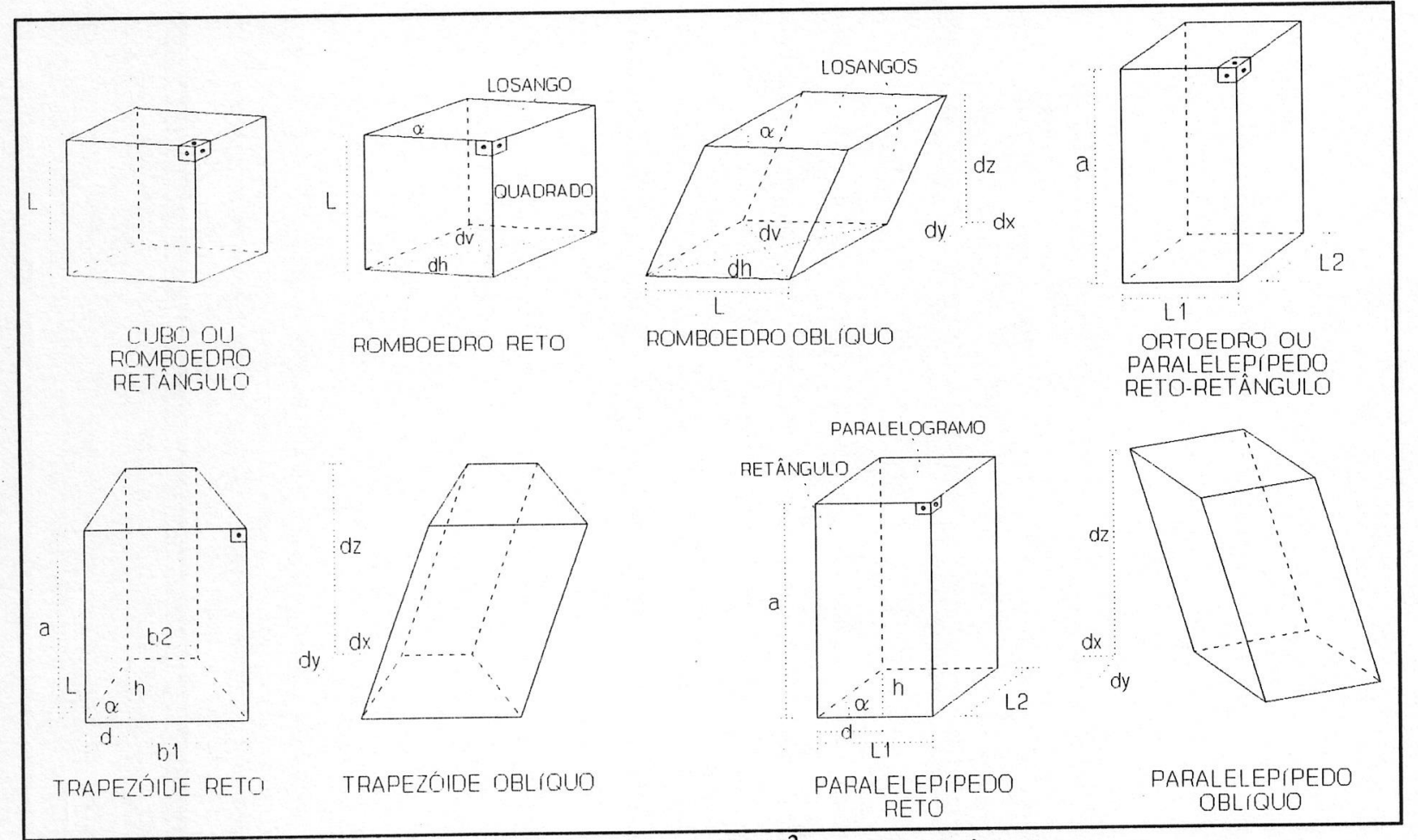

Figura 4.13 - Tipos de blocos disponíveis no (SM) $)^{2}$ e seus parâmetros 


\subsubsection{4 - CILINDRO}

Superfície cilíndrica é uma superfície gerada por uma reta $g$ (geratriz) que se mantém paralela a uma reta dada $r$ (direção) e percorre os pontos de uma linha dada $d$ (diretriz). Se a superfície cilíndrica for gerada pela rotação em torno da reta de direção $e$, esta receberá o nome de eixo.

Denomina-se cilindro o sólido limitado por uma superfície cilíndrica fechada e dois planos paralelos que a cortam em todas as geratrizes. Se a diretriz for uma circunferência, obtém-se um cilindro circular; caso seja uma elipse, obtém-se um cilindro elíptico. Circular ou elíptico, um cilindro reto possui geratrizes perpendiculares ao plano da diretriz; já o cilindro oblíquo possui geratrizes oblíquas em relação à base.

A superfície lateral é a reunião das geratrizes; a superfície total é a lateral mais os círculos (ou elipses) das bases.

Um cilindro circular reto pode ser gerado pela rotação de um retângulo em torno de um eixo que contém um de seus lados. O mais freqüente, no entanto, é definir-se uma base circular (ou elíptica) e transladá-la em relação a sua direção ou eixo. A figura 4.14 ilustra os tipos de cilindros gerados pelo $(\mathrm{SM})^{2}$.
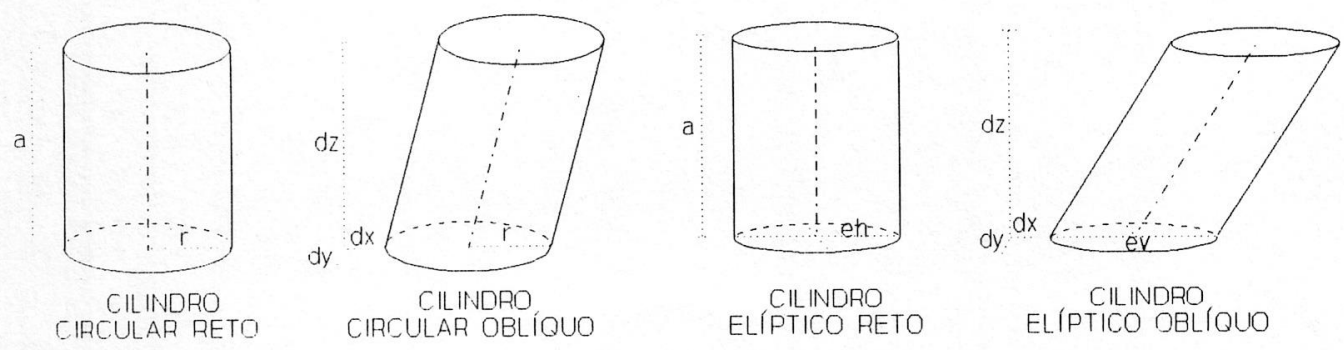

Figura 4.14 - Exemplos de cilindro gerados pelo (SM) ${ }^{2}$

\subsubsection{5 - CONE}

Superfície cônica é uma superfície gerada por uma reta $g$ (geratriz) que passa por um ponto dado $V$ (vértice) e percorre os pontos de uma linha dada $d$ (diretriz), com $V$ fora de $d$. Uma superfície cônica de rotação é gerada pela rotação da geratriz $g$ em torno de uma reta $e$ (eixo), fixa, sendo a reta $g$ oblíqua ao eixo $e$, e $V$ a intersecção das retas $g$ e $e$. Ela possui duas folhas. 
Denomina-se cone o sólido limitado por uma superfície cônica fechada, de uma só folha, e um plano que corta todas as suas geratrizes. Cone circular tem como diretriz um círculo, enquanto cone elíptico tem como diretriz uma elipse. $\mathrm{O}$ eixo de um cone é a reta determinada pelo vértice e pelo centro da base. Em um cone reto o eixo é perpendicular ao plano da base; todos os demais são considerados cones oblíquos. A superfície lateral é a reunião das geratrizes; a superfície total é a lateral mais o círculo (ou elipse) da base.

Ao seccionar um cone por um plano paralelo à base, são obtidos dois sólidos: o que contém o vértice, que origina um novo cone proporcional ao inicial, e o que contém a base do cone inicial, que é um tronco de cone de bases paralelas. Esta última definição foi estendida no $(\mathrm{SM})^{2}$ para incorporar tronco de cone oblíquo, mantendo as bases paralelas.

O cone possui com o cilindro a mesma relação que a pirâmide possui com o prisma. Como no $(\mathrm{SM})^{2}$ as curvas são aproximadas por segmentos de reta, cones circulares nada mais são do que pirâmides regulares inscritas e cilindros circulares nada mais são do que prismas regulares inscritos. A figura 4.15 mostra os tipos de cones implementados no (SM) ${ }^{2}$.

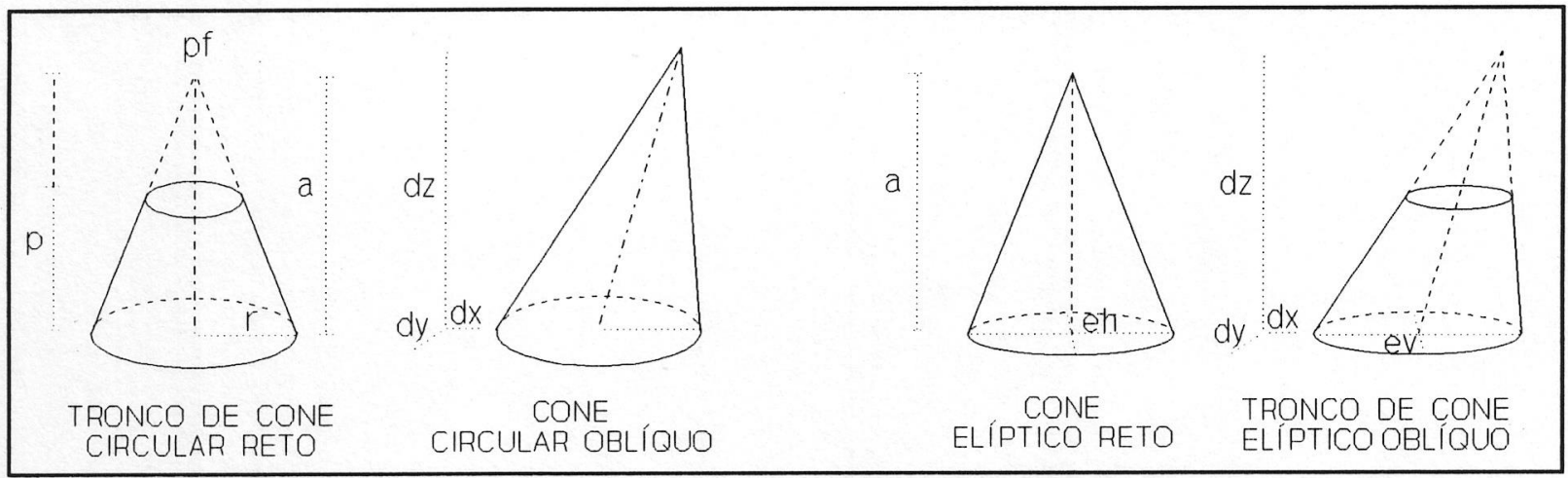

Figura 4.15 - Tipos de cones disponíveis no modelador

\subsubsection{6 - ESFERA}

Denomina-se esfera o conjunto de pontos do espaço tais que a distância entre seu ponto central e o ponto do espaço seja menor ou igual ao seu raio. A esfera também pode ser definida como o sólido de revolução gerado pela rotação de um semi-círculo em torno do eixo que contém o diâmetro. $\mathrm{O}(\mathrm{SM})^{2}$ implementa esta segunda definição na geração de esferas. Devido a este fato, as esferas geradas possuem em sua representação "gomos" oriundos das etapas que compõem a rotação. A figura 4.16 explica esta forma de definição. 


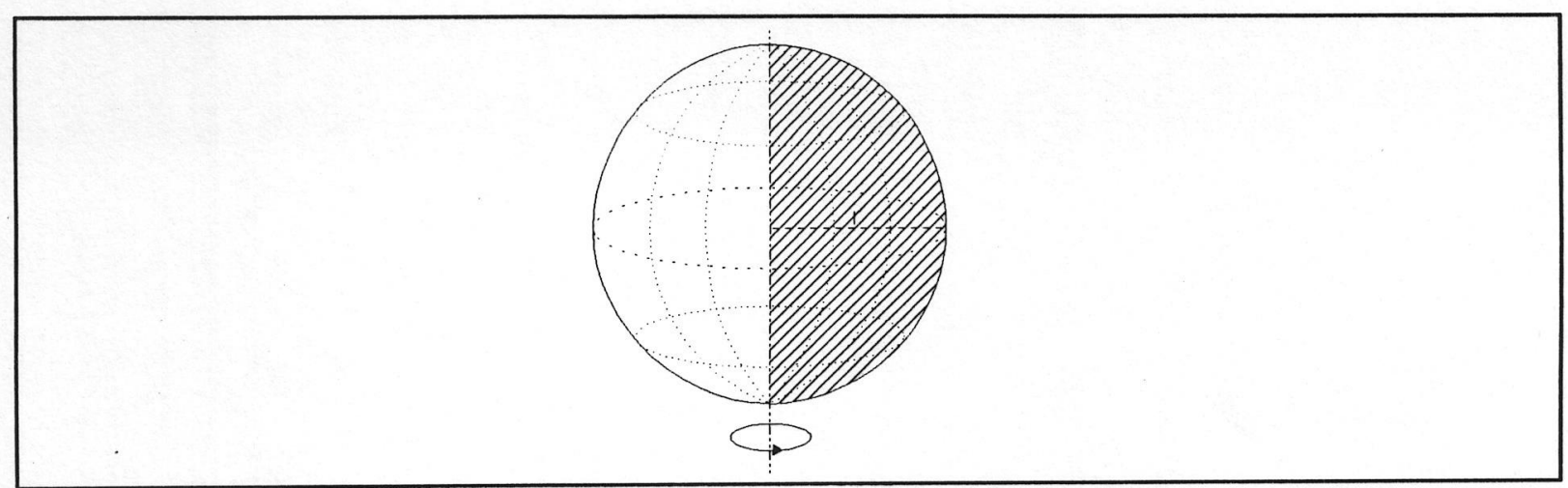

Figura 4.16 - Exemplo de esfera gerada pelo $(\mathrm{SM})^{2}$

\subsubsection{7 - TORO}

Toro é o sólido gerado através da rotação de um círculo ou elipse em torno de um eixo que lhe é externo e coplanar. Se for utilizado um círculo, obtém-se um toro de seção circular, ou simplesmente toro; caso seja gerado a partir de uma elipse, denomina-se toro de seção elíptica.

Assim definidos, os toros gerados possuem em sua representação "gomos" oriundos das etapas que compõem a rotação. A figura 4.17 elucida esta abordagem.

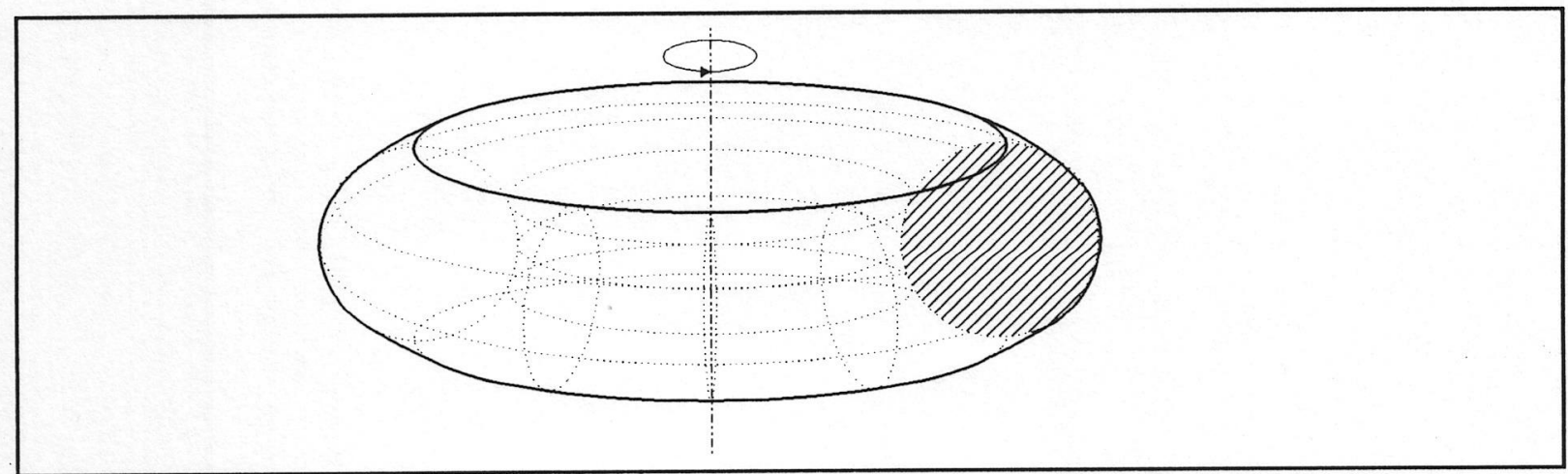

Figura 4.17 - Exemplo de toro gerado por rotação 


\subsubsection{8 - DEFINIÇÃO DE PRIMITIVAS SÓLIDAS}

Visando à geração de sólidos complexos através de primitivas, de forma a poupar tempo e evitar se possível o uso de outras operações, como as booleanas, que são caras e complexas quando aplicadas sobre sólidos B-Rep, o (SM $)^{2}$ permite atribuir à definição da primitiva uma característica quanto ao preenchimento de seu interior, podendo gerar sólidos maciços, ocos ou, quando possível, vazados.

O quadro 4.2 relaciona as primitivas disponíveis no $(\mathrm{SM})^{2}$, acompanhadas de suas formas de definição e de preenchimento possíveis. Apresentado em seguida, o quadro 4.3 resume os tipos de primitivas sólidas anteriormente descritas, relacionando os parâmetros de definição e consistência para cada caso.

\begin{tabular}{|c|c|c|c|c|c|c|}
\hline & Primitiva & & $\mathrm{rma}$ & Pree & nchim & ento \\
\hline & & Reta & Oblíqua & Maciço & Oco & Vazado \\
\hline Bloco & Cubo & $\mathrm{X}$ & & $\mathrm{X}$ & $\mathrm{X}$ & $\mathrm{X}$ \\
\hline & Ortoedro & $\mathrm{X}$ & $\mathrm{X}$ & $\mathrm{X}$ & $\mathrm{X}$ & $\mathrm{X}$ \\
\hline & Romboedro & $\mathrm{X}$ & $X$ & $\mathrm{X}$ & $\mathrm{X}$ & $\mathrm{X}$ \\
\hline & Trapezóide & $\mathrm{X}$ & $\mathrm{X}$ & $\mathrm{X}$ & $\mathrm{X}$ & $\mathrm{X}$ \\
\hline & Paralelepípedo & $\mathrm{X}$ & $\mathrm{X}$ & $\mathrm{X}$ & $\mathrm{X}$ & $\mathrm{X}$ \\
\hline Prisma & Regular inscrito & $\mathrm{X}$ & $\mathrm{X}$ & $\mathrm{X}$ & $\mathrm{X}$ & $\mathrm{X}$ \\
\hline & Regular circunscrito & $\mathrm{X}$ & $\mathrm{X}$ & $\mathrm{X}$ & $\mathrm{X}$ & $\mathrm{X}$ \\
\hline & Qualquer & $\mathrm{X}$ & $\mathrm{X}$ & $\mathrm{X}$ & $\mathrm{X}$ & $\mathrm{X}$ \\
\hline Pirâmide & Regular inscrita & $\mathrm{X}$ & $\mathrm{X}$ & $\mathrm{X}$ & $\mathrm{X}$ & $\mathrm{X}$ \\
\hline & Regular circunscrita & $\mathrm{X}$ & $\mathrm{X}$ & $\mathrm{X}$ & $\mathrm{X}$ & $\mathrm{X}$ \\
\hline & Qualquer & $\mathrm{X}$ & $\mathrm{X}$ & $\mathrm{X}$ & $\mathrm{X}$ & $\mathrm{X}$ \\
\hline Cilindro & Convencional & $\mathrm{X}$ & $\mathrm{X}$ & $\mathrm{X}$ & $\mathrm{X}$ & $\bar{X}$ \\
\hline & Elíptico & $\mathrm{X}$ & $\mathrm{X}$ & $\mathrm{X}$ & $\mathrm{X}$ & $\mathrm{X}$ \\
\hline Cone & Convencional & $\mathrm{X}$ & $\mathrm{X}$ & $\mathrm{X}$ & $\mathrm{X}$ & $\mathrm{X}$ \\
\hline & Elíptico & $\mathrm{X}$ & $\mathrm{X}$ & $\mathrm{X}$ & $\mathrm{X}$ & $\mathrm{X}$ \\
\hline Esfera & Convencional & & & $\mathrm{X}$ & $\mathrm{X}$ & \\
\hline Toro & Convencional & & & $\mathrm{X}$ & $X$ & \\
\hline & Elíptico & & & $\mathrm{X}$ & $\mathrm{X}$ & \\
\hline
\end{tabular}

Quadro 4.2 - Definição e preenchimento das primitivas disponíveis no (SM) ${ }^{2}$

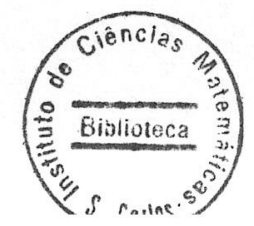




\begin{tabular}{|c|c|c|c|}
\hline & PARÂMETROS & DOMÍNIO & CONSISTÊNCIAS \\
\hline $\begin{array}{l}\mathrm{P} \\
\mathrm{R} \\
\mathrm{I} \\
\mathrm{S} \\
\mathrm{M} \\
\mathrm{A}\end{array}$ & $\begin{array}{l}\quad \text { Definição da base } \\
\text { - no vértices } \\
\text { REGULAR INSCRITO } \\
\text { - raio ou } \\
\text { - comprimento lateral } \\
\text { REGULAR CIRCUNSCRITO } \\
\text { - raio ou } \\
\text { - comprimento lateral } \\
\text { QUALQUER } \\
\text { - matriz de vértices } \\
\qquad \text { Demais definições } \\
\text { TRANSLAÇÃO RETA } \\
\text { - altura } \\
\text { TRANSLAÇÃO OBLÍQUA } \\
\text { - deslocamento x,y,z } \\
\text { PREENCHIMENTO } \\
\text { - espessura }\end{array}$ & $\begin{array}{l}\text { int }+ \\
\text { real }+ \\
\text { real }+ \\
\text { real }+ \\
\text { real }+ \\
\text { real } \\
\text { real } \\
\text { real } \\
1 \text { a } 99 \%\end{array}$ & $\begin{array}{l}\text { - } \mathrm{n}^{\mathrm{o}} \text { pontos }>2 \\
\text { - raio ou comprimento }<>0 \\
\text { - raio ou comprimento }<>0 \\
\text { - vertices não todos colineares, sem intersecção } \\
\text { entre segmentos } \\
\text { - altura (coord_z) }>0 \\
\text { - coord_z }>0 \\
\text { - só vale para preenchimento }<>\text { maciço }\end{array}$ \\
\hline $\begin{array}{c}\mathbf{P} \\
\mathbf{I} \\
\mathbf{R} \\
\hat{A} \\
\mathbf{M} \\
\mathbf{I} \\
\mathrm{D} \\
\mathrm{E}\end{array}$ & $\begin{array}{l}\quad \text { Definicão da base } \\
\text { - no vértices } \\
\text { REGULAR INSCRITO } \\
\text { - raio ou } \\
\text { - comprimento lateral } \\
\text { REGULAR CIRCUNSCRITO } \\
\text { - raio ou } \\
\text { - comprimento lateral } \\
\text { QUALQUER } \\
\text { - matriz de vértices } \\
\quad \text { Demais definições } \\
\text { - proporção } \\
\text { TRANSLAÇÃO RETA } \\
\text { - altura } \\
\text { TRANSLAÇÃO OBLÍQUA } \\
\text { - deslocamento x,y,z } \\
\text { PREENCHIMENTO } \\
\text { - espessura }\end{array}$ & $\begin{array}{l}\text { int }+ \\
\text { real }+ \\
\text { real }+ \\
\text { real }+ \\
\text { real }+ \\
\text { real } \\
1 \text { a } 100 \% \\
\text { real } \\
\text { real } \\
1 \text { a } 99 \% \\
\end{array}$ & $\begin{array}{l}\text { - } \mathrm{n}^{0} \text { pontos }>2 \\
\text { - raio ou comprimento }<>0 \\
\text { - raio ou comprimento }<>0 \\
\text { - vertices não todos colineares, sem intersecção } \\
\text { entre segmentos } \\
\text { - }<100 \% \text { gera tronco de pirâmide } \\
\text { - altura (coord_z) }>0 \\
\text { - coord_z }>0 \\
\text { - só vale para preenchimento }<>\text { maciço }\end{array}$ \\
\hline $\begin{array}{l}\mathrm{E} \\
\mathrm{S} \\
\mathrm{F} \\
\mathrm{E} \\
\mathrm{R} \\
\mathrm{A}\end{array}$ & $\begin{array}{l}\text { - resolução } \\
\text { - raio } \\
\text { PREENCHIMENTO } \\
\text { - espessura } \\
\end{array}$ & $\begin{array}{l}1 \text { a } 100 \% \\
\text { real }+\end{array}$ & $\begin{array}{l}\text { - convertida para múltiplo de } 4 \\
\text { - raio }>0 \\
\text { - só vale para preenchimento }<>\text { maciço }\end{array}$ \\
\hline
\end{tabular}




\begin{tabular}{|c|c|c|c|}
\hline & PARÂMETROS & DOMÍNIO & CONSISTÊNCIAS \\
\hline $\begin{array}{l}\text { C } \\
\text { I } \\
\text { L } \\
\text { I } \\
\text { N } \\
\text { D } \\
\text { R } \\
\text { O }\end{array}$ & $\begin{array}{l}\quad \text { Definição da base } \\
\text { - resolução } \\
\text { CONVENCIONAL } \\
\text { - raio } \\
\text { ELÍPTICO } \\
\text { - comprimento eixo horizontal } \\
\text { - comprimento eixo vertical } \\
\qquad \quad \text { Demais definições } \\
\text { TRANSLAÇÃO RETA } \\
\text { - altura } \\
\text { TRANSLAÇÃO OBLÍQUA } \\
\text { - deslocamento x,y,z } \\
\text { PREENCHIMENTO } \\
\text { - espessura }\end{array}$ & $\begin{array}{l}1 \text { a } 100 \% \\
\text { real }+ \\
\text { real }+ \\
\text { real }+ \\
\text { real } \\
\text { real } \\
1 \text { a } 99 \% \\
\end{array}$ & $\begin{array}{l}\text { - convertida para múltiplo de } 4 \\
\text { - raio }>0 \\
\text { - comprimento dos eixos }>0 \\
\text { - altura (coord_z) }>0 \\
\text { - coord_z }>0 \\
\text { - só vale para preenchimento }<>\text { maciço }\end{array}$ \\
\hline $\begin{array}{l}\mathrm{C} \\
\mathrm{O} \\
\mathrm{N} \\
\mathrm{E}\end{array}$ & $\begin{array}{l}\quad \text { Definição da base } \\
\text { - resolução } \\
\text { CONVENCIONAL } \\
\text { - raio } \\
\text { ELÍPTICO } \\
\text { - comprimento eixo horizontal } \\
\text { - comprimento eixo vertical } \\
\text { Demais definições } \\
\text { - proporção } \\
\text { TRANSLAÇÃO RETA } \\
\text { - altura } \\
\text { TRANSLAÇÃO OBLÍQUA } \\
\text { - deslocamento x,y,z } \\
\text { PREENCHIMENTO } \\
\text { - espessura }\end{array}$ & $\begin{array}{l}1 \text { a } 100 \% \\
\text { real }+ \\
\text { real }+ \\
\text { real }+ \\
1 \text { a } 100 \% \\
\text { real } \\
\text { real } \\
1 \text { a } 99 \%\end{array}$ & $\begin{array}{l}\text { - convertida para múltiplo de } 4 \\
\text { - raio }>0 \\
\text { - comprimento dos eixos }>0 \\
\text { - }<100 \% \text { gera tronco de cone } \\
\text { - altura (coord_z) }>0 \\
\text { - coord_z }>0 \\
\text { - só vale para preenchimento }<>\text { maciço }\end{array}$ \\
\hline $\begin{array}{l}T \\
O \\
R \\
O\end{array}$ & $\begin{array}{l}\text { - resolução } \\
\text { - raio externo } \\
\text { CONVENCIONAL } \\
\text { - raio } \\
\text { ELÍPTICO } \\
\text { - comprimento eixo horizontal } \\
\text { - comprimento eixo vertical } \\
\text { PREENCHIMENTO } \\
\text { - espessura }\end{array}$ & $\begin{array}{l}1 \text { a } 100 \% \\
\text { real }+ \\
\text { real }+ \\
\text { real }+ \\
\text { real }+ \\
1 \text { a } 99 \%\end{array}$ & $\begin{array}{l}\text { - convertida para múltiplo de } 4 \\
\text { - raio externo }>\text { raio ou } \\
\text { raio externo }>\text { compimento eixo horizontal } / 2 \\
\text { - raio }>0 \\
\text { - comprimento dos eixos }>0 \\
\text { - só vale para preenchimento }<>\text { maciço }\end{array}$ \\
\hline
\end{tabular}




\begin{tabular}{|c|c|c|c|}
\hline & PARÂMETROS & DOMÍNIO & CONSISTÊNCIAS \\
\hline \multirow{30}{*}{$\begin{array}{l}\text { B } \\
\text { L } \\
\text { O } \\
\text { C } \\
\text { O }\end{array}$} & Definição da base & & \\
\hline & QUADRADO & & \\
\hline & - comprimento lateral & real + & - comprimento $>0$ \\
\hline & RETÂNGULO & & \\
\hline & - comprimento & real + & - comprimento e altura $>0$ \\
\hline & - altura & real + & \\
\hline & LOSANGO & & \\
\hline & Opção 1 & & \\
\hline & - diagonal horizontal & real + & - diagonais $>0$ \\
\hline & $\begin{array}{l}\text { - diagonal vertical } \\
\text { Opção } 2\end{array}$ & real + & \\
\hline & - comprimento & real + & - comprimento $>0$, ângulo $<>0$ \\
\hline & - ângulo inferior & real & \\
\hline & TRAPÉZIO & & \\
\hline & - comprimento base maior & real + & - comprimento da bases $>0$ \\
\hline & - comprimento base menor & real + & 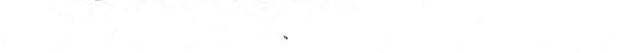 \\
\hline & + 2 parâmetros entre: & & \\
\hline & - altura & real + & - altura $<$ comprimento lado direito \\
\hline & - deslocamento bases & real & - deslocamento $<$ lado direito \\
\hline & $\begin{array}{l}\text { - ângulo entre lados } \\
\text { - comprimento lado direito }\end{array}$ & $\begin{array}{l}\text { real } \\
\text { real }+\end{array}$ & $\begin{array}{l}\text { - ângulo }<180 \text { e quando usado com } \\
\text { deslocamento, }<>90\end{array}$ \\
\hline & PARALELOGRAMO & & \\
\hline & $\begin{array}{l}\text { - comprimento base } \\
+2 \text { parâmetros entre: }\end{array}$ & & - comprimento $>0$ \\
\hline & - altura & real + & - altura $<$ comprimento lado direito \\
\hline & - deslocamento bases & real & - deslocamento < lado direito \\
\hline & $\begin{array}{l}\text { - ângulo entre lados } \\
\text { - comprimento lado direito }\end{array}$ & $\begin{array}{l}\text { real } \\
\text { real }+\end{array}$ & $\begin{array}{l}\text { - ângulo }<180 \text { e quando usado com } \\
\text { deslocamento, }<>90\end{array}$ \\
\hline & Demais definições & & \\
\hline & TRANSLAÇÃO RETA & & \\
\hline & - altura & real & - altura (coord_z) $>0$ \\
\hline & TRANSLAÇÃO OBLÍQUA & & \\
\hline & - deslocamento x,y,z & real & - coord_z $>0$ \\
\hline & $\begin{array}{l}\text { PREENCHIMENTO } \\
\text { - espessura }\end{array}$ & 1 a $99 \%$ & - só vale para preenchimento $<>$ maciço \\
\hline
\end{tabular}

Quadro 4.3 - Resumo das primitivas sólidas e seus parâmetros 


\section{3 - TRANSFORMAÇÕES GEOMÉTRICAS}

As transformações geométricas são intensamente utilizadas pelo (SM) ${ }^{2}$ para definir, validar, calcular e posicionar objetos em uma cena. Estão também disponíveis para utilização direta pelo usuário, para alterar a posição, orientação e tamanho dos objetos componentes de uma cena. As transformações geométricas básicas são a translação, a rotação e o escalamento. Transformações adicionais são o espelhamento e a deformação. Estas transformações são descritas a seguir, baseando-se em [Fol90, Rog90, Hea86, Per90].

Existem muitas vantagens em utilizar transformações geométricas. A mais importante delas é a possibilidade de aplicá-las a todos os pontos de um objeto aplicando-as apenas aos seus vértices. Outra grande vantagem é o uso de formas matriciais, que permitem combinar várias transformações antes de aplicá-las ao objeto, realizando uma transformação complexa em uma única etapa.

\subsection{1 - Translação}

A movimentação de um objeto para uma outra posição no sistema de coordenadas, de modo que todos os pontos do objeto sejam deslocados de uma mesma distância em relação à sua posição anterior é conhecida por translação e é ilustrada na figura 4.18.

A transformação de translação é obtida adicionando-se as constantes de translação a todas as coordenadas que definem o objeto. No espaço bidimensional, translada-se um objeto descrito no plano $x y$ adicionando valores constantes às coordenadas de seus vértices. Para cada ponto $P(x, y)$ a ser movido para a nova posição $P^{\prime}\left(x^{\prime}, y^{\prime}\right)$ tem-se:

$$
x^{\prime}=x+d x \quad y^{\prime}=y+d y
$$

No espaço tridimensional, um sólido representado por um conjunto de faces poliedrais é transladado aplicando esta transformação a cada vértice das faces que compõem o sólido. O conjunto dos vértices transladados define a nova posição do objeto. Assim, para cada ponto $P(x, y, z)$ a ser movido para a nova posição $P^{\prime}\left(x^{\prime}, y^{\prime}, z^{\prime}\right)$ tem-se:

$$
x^{\prime}=x+d x \quad y^{\prime}=y+d y \quad z^{\prime}=z+d z
$$




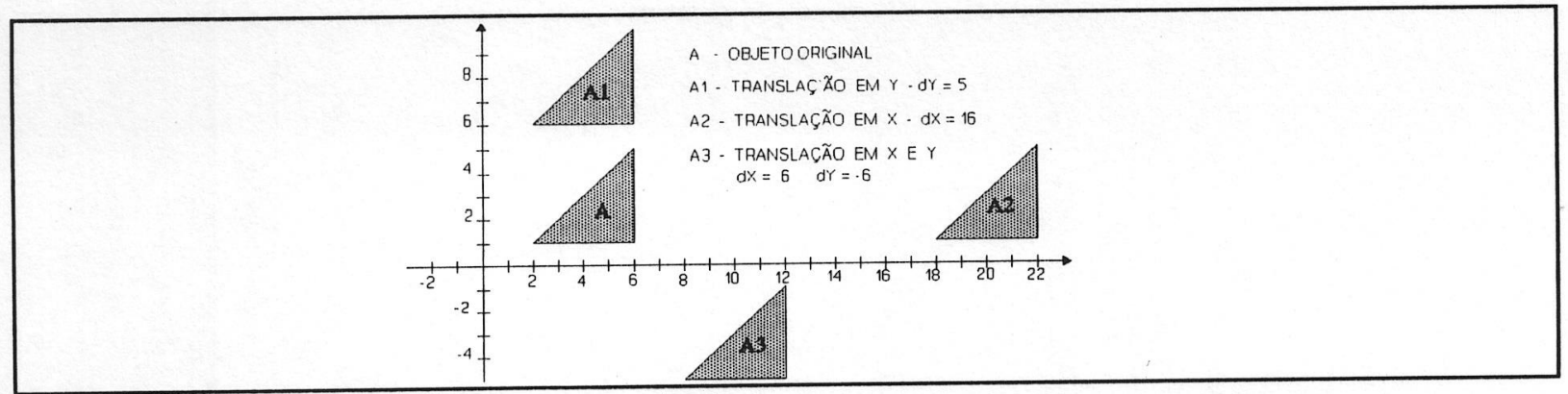

Figura 4.18 - Exemplo de translação (2D)

\subsection{2 - Rotação}

A movimentação de um objeto para outra posição, de modo que todos os pontos do objeto mantenham a mesma distância em relação à origem que possuíam antes da transformação é chamada de rotação. Para a obtenção de uma rotação em torno de um ponto diferente da origem, é necessário fazer uma combinação de transformações de translação e de rotação. A figura 4.19 ilustra este processo.

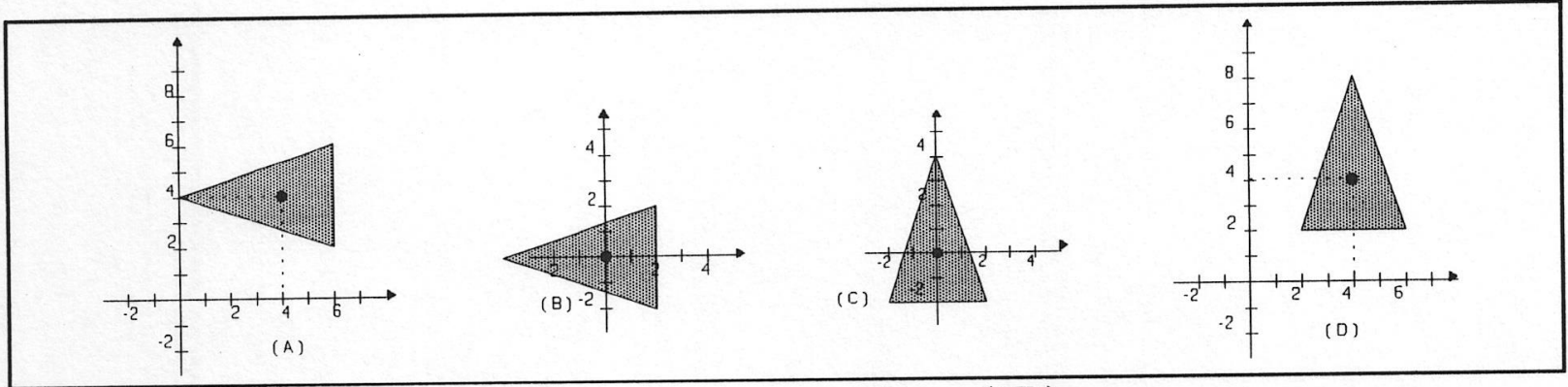

Figura 4.19 - Rotação em relação a um ponto qualquer (2D)

Esta rotação é especificada através de um ângulo $\alpha$, que determina o valor do deslocamento angular no sentido anti-horário. Em aplicações 2D, o eixo de rotação é sempre perpendicular ao plano $x y$. A rotação de pontos através de um ângulo $\alpha$ é feita em relação à origem, e é definida matematicamente por:

$$
x^{\prime}=x \cdot \cos \alpha-y \cdot \sin \alpha \quad y^{\prime}=x \cdot \operatorname{sen} \alpha+y \cdot \cos \alpha
$$

Em aplicações 3D, o eixo de rotação pode ter qualquer orientação espacial. Os eixos de rotação mais fáceis de manipular são os paralelos aos eixos coordenados. Pode-se também usar uma composição de rotações em relação aos três eixos para se ter uma rotação em um eixo arbitrário. As rotações em relação aos eixos são definidas matematicamente por: 


$\begin{array}{lll}\text { eixo } x & \text { eixo } y & \text { eixo } z \\ x^{\prime}=x & x^{\prime}=z \cdot \sin \alpha+x \cdot \cos \alpha & x^{\prime}=x \cdot \cos \alpha-y \cdot \sin \alpha \\ y^{\prime}=y \cdot \cos \alpha-z \cdot \sin \alpha & y^{\prime}=y & y^{\prime}=x \cdot \sin \alpha+y \cdot \cos \alpha \\ z^{\prime}=y \cdot \sin \alpha+z \cdot \cos \alpha & z^{\prime}=z \cdot \cos \alpha-x \cdot \sin \alpha & z^{\prime}=z\end{array}$

\section{3 .3 - Escalamento}

A alteração no tamanho de um objeto, independentemente de ter ocorrido de maneira uniforme, recebe o nome de transformação de escala ou escalamento.

A transformação de escala é obtida pela multiplicação de todas as coordenadas que definem o objeto por fatores de escala não nulos. Um fator de escala maior que 1 provoca a ampliação do objeto na direção do eixo afetado pelo fator. Fator de escala entre 0 e 1 provoca a redução. Fator negativo provoca um espelhamento da imagem em relação ao eixo não afetado por este fator. Quando fatores de escala iguais são aplicados em todas as direções, um objeto proporcional ao original é obtido. Porém, quando fatores de escala diferentes são aplicados a um objeto, obtém-se objetos com suas proporções alteradas. Exemplos de escalamento uniforme e não uniforme são apresentados na figura 4.20.

Esta operação pode ser realizada sobre formas poligonais planares através da multiplicação das coordenadas $(x, y)$ de cada vértice por fatores de escala para os eixos $x(s x)$ ou $y(s y)$ :

$$
x^{\prime}=s x \cdot x \quad y^{\prime}=s y \cdot y
$$

Da mesma forma, para objetos sólidos poliedrais multiplicam-se as coordenadas $(x, y, z)$ de cada vértice pelos fatores de escala correspondentes:

$$
x^{\prime}=s x \cdot x \quad y^{\prime}=s y \cdot y \quad z^{\prime}=s z \cdot z
$$

É importante observar que o escalamento é sempre feito em relação à origem: fatores entre 0 e 1 aproximam o objeto, enquanto fatores maiores que 1 afastam-no. Para realizar o escalamento em relação a um ponto diferente da origem, deve ser feita uma combinação de transformações de translação e escala: translada-se o ponto de referência para a origem; realiza-se o escalamento e translada-se o ponto de referência para a sua posição original. 


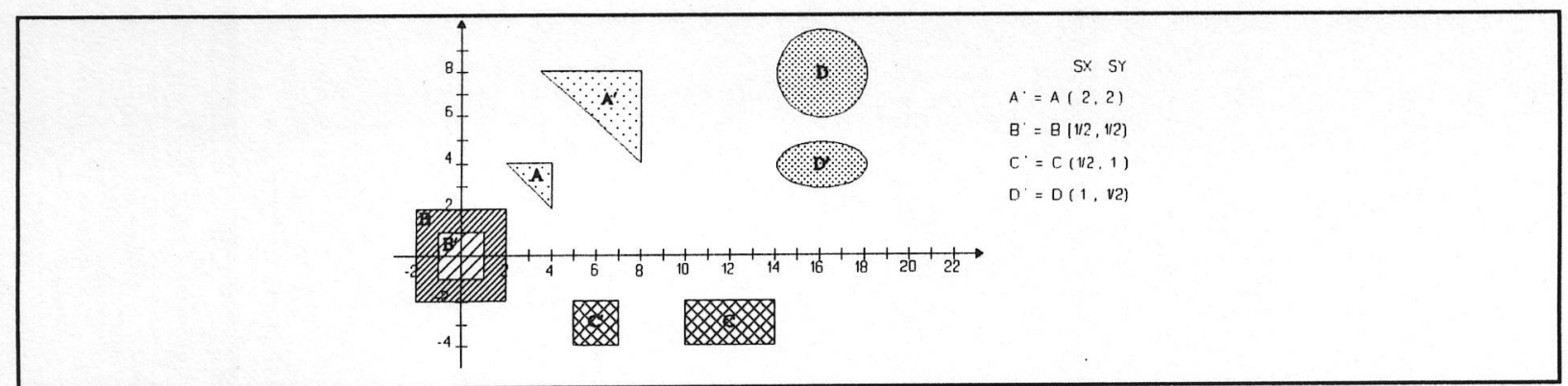

Figura 4.20 - Exemplos de escalamento (2D)

\subsection{4 - Espelhamento ou Reflexão}

Algumas orientações de sólidos não podem ser obtidas utilizando simplesmente rotações: elas requerem a reflexão, a transformação que produz a imagem espelhada (simétrica) de um objeto gerada em relação a um eixo (plano) de reflexão. Enquanto uma rotação 2D ocorre inteiramente no plano em relação a um eixo normal ao plano, a reflexão é uma rotação de $180^{\circ}$ que percorre o espaço $3 \mathrm{D}$ e rebate a figura em relação a um eixo definido no plano inicial. No espaço tridimensional, as reflexões ocorrem em relação a um plano. Em analogia à reflexão $2 \mathrm{D}$, reflexões $3 \mathrm{D}$ equivalem a uma rotação de $180^{\circ} \mathrm{em}$ relação a um eixo que percorre o espaço 4D e é rebatido no espaço 3D original. Dois exemplos de reflexão são mostrados na figura 4.21 a seguir.

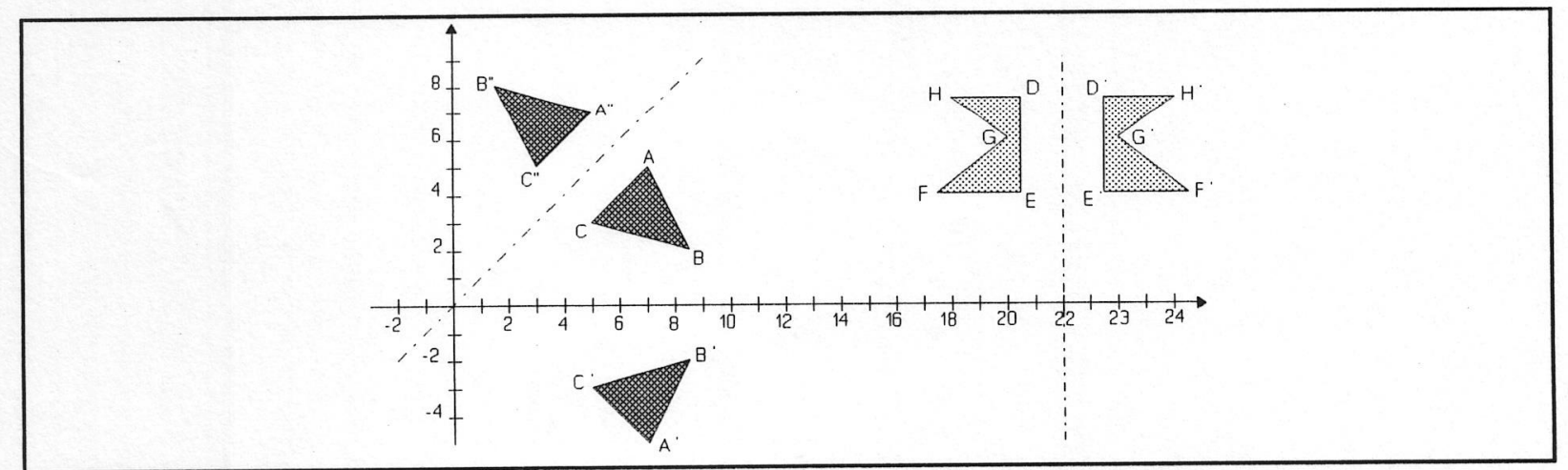

Figura 4.21 - Exemplos de reflexão de polígonos (2D)

Para gerar uma reflexão 2D em relação a um dos eixos coordenados, basta aplicar o fator de escalamento -1 ao outro eixo; para espelhar em relação à origem, utilizar -1 aos dois eixos. 
Em uma reflexão 3D através do plano $x y$, somente os valores da coordenada $z$ serão alterados, recebendo o sinal inverso ao inicial. Da mesma forma, nos planos $x z$ e $y z$, somente as coordenadas $y$ e $x$, respectivamente, sofrerão inversão de sinal.

Para refletir um objeto por um eixo (plano) diferente dos eixos (planos) coordenados, utiliza-se um procedimento que incorpora as transformações simples anteriormente definidas: aplica-se translação e rotação até que o eixo (plano) coincida com um dos eixos (planos) coordenados; realiza-se a reflexão em relação a este eixo (plano); aplicam-se as transformações inversas à da etapa inicial, retornando o eixo (plano) à sua posição original.

\subsection{5 - Deformação}

O cisalhamento ou deformação é uma transformação que produz distorções no formato, semelhantes ao efeito de possuir o objeto, em seus vértices, apoios móveis que podem deslizar, gerando uma deformação na qual se mantém o paralelismo entre suas arestas, mas não os comprimentos e ângulos existentes entre as mesmas. Tais deformações ocorrem mais comumente na direção dos eixos coordenados, como ilustrado na figura 4.22 a seguir. Os fatores de deformação podem possuir qualquer valor real, sendo que valores negativos irão gerar deslocamentos dos vértices para a esquerda e para baixo, respectivamente.

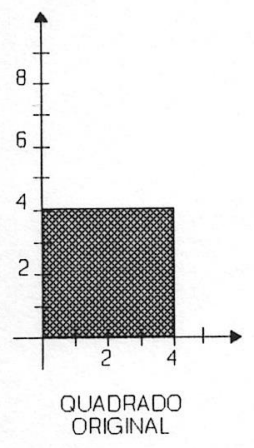

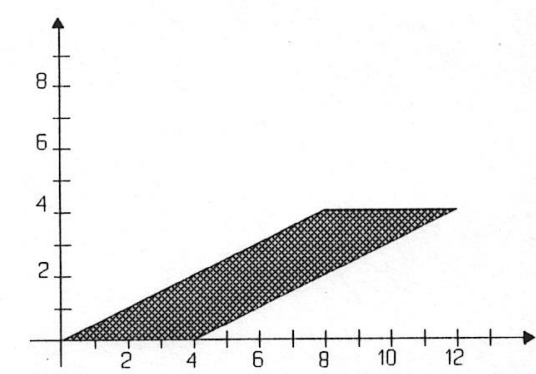

QUADRADO TRANSFORMADO EM PARALELOGRAMO APÓS DEFORMAÇÃO EM X - ShX $=2$

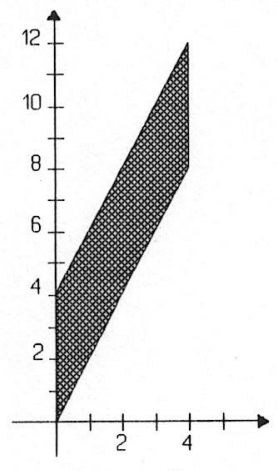

DEFORMAÇÃO EM Y $\operatorname{ShY}=2$

Figura 4.22 - Exemplos de operação de deformação (2D) 


\subsection{6 - Composição de Transformações}

Transformações geométricas complexas podem ser realizadas a partir de transformações mais simples. Para realizar, por exemplo, uma rotação no espaço em relação a um eixo qualquer, fornecidos o eixo e o ângulo de rotação, deve-se:

- transladar o objeto de forma que o eixo de rotação passe pela origem;

- rotacionar o objeto de forma que o eixo de rotação coincida com um dos eixos coordenados;

- realizar a rotação especificada;

- aplicar as rotações inversas para retornar o eixo de rotação para a sua orientação original;

- aplicar a translação inversa para retornar o eixo de rotação para a sua posição original.

Ao invés de aplicar cada transformação ao objeto, é muito mais eficiente aplicar a composição destas transformações de um única vez. Surge um problema: a translação é tratada como uma soma, enquanto a rotação e a escala são tratadas como multiplicação. Para resolvê-lo, utilizam-se formas matriciais e coordenadas homogêneas [Rog90], que permitem tratar as transformações anteriores como multiplicações. Com o uso de coordenadas homogêneas, as matrizes de transformação ficam definidas como apresentado no quadro 4.4 .

Obtém-se a inversa da matriz de translação invertendo o sinal das distâncias $d x, d y$ e $d z$, o que produz a translação na direção oposta.

Obtém-se o escalamento inverso substituindo os fatores de escalamento $s x$, sy e $s z$ por seus recíprocos $1 / s x, 1 / s y$ e $1 / s z$. A matriz inversa gera o escalamento inverso, retornando à situação original.

A matriz de rotação inversa é obtida substituindo o ângulo de rotação $\alpha$ por $-\alpha$. Como somente a função seno é afetada pela mudança no sinal do ângulo de rotação, para obter a matriz inversa deve-se inverter somente o sinal dos coeficientes que envolvem a função seno ou, de outra forma, calcular a matriz transposta da matriz de rotação original, pois $R^{-1}=R^{t}$. 


\begin{tabular}{|c|c|c|c|}
\hline & TRANSLAÇÃO & ESCALAMENTO & DEFORMAÇÃO \\
\hline $\begin{array}{l}\text { P } \\
\text { L } \\
\text { A } \\
\text { N } \\
\text { O }\end{array}$ & {$\left[\begin{array}{ccc}1 & 0 & 0 \\
0 & 1 & 0 \\
d x & d y & 1\end{array}\right]$} & {$\left[\begin{array}{ccc}s x & 0 & 0 \\
0 & s y & 0 \\
0 & 0 & 1\end{array}\right]$} & {$\left[\begin{array}{ccc}1 & s h y & 0 \\
s h x & 1 & 0 \\
0 & 0 & 1\end{array}\right]$} \\
\hline $\begin{array}{l}\text { E } \\
\text { S } \\
\text { P } \\
\text { A } \\
\text { Ç } \\
\text { O }\end{array}$ & {$\left[\begin{array}{cccc}1 & 0 & 0 & 0 \\
0 & 1 & 0 & 0 \\
0 & 0 & 1 & 0 \\
d x & d y & d z & 1\end{array}\right]$} & {$\left[\begin{array}{cccc}s x & 0 & 0 & 0 \\
0 & s y & 0 & 0 \\
0 & 0 & s z & 0 \\
0 & 0 & 0 & 1\end{array}\right]$} & $\begin{array}{l}{\left[\begin{array}{llll}x & y & z & 1\end{array}\right] *\left[\begin{array}{cccc}1 & 0 & 0 & 0 \\
0 & 1 & 0 & 0 \\
0 & 0 & 1 & 0 \\
d x & d y & d z & 1\end{array}\right]} \\
=\left[\begin{array}{llll}x+d y+g z & b x+y+i z & c x+f y+z & 1\end{array}\right]\end{array}$ \\
\hline
\end{tabular}

Quadro 4.4 - Matrizes de transformação no plano e no espaço (parte 1)

\begin{tabular}{|c|c|c|c|c|c|c|c|}
\hline & \multicolumn{5}{|c|}{ ROTAÇÃO } & \multicolumn{2}{|c|}{ ESPELHAMENTO } \\
\hline $\begin{array}{l}\text { P } \\
\text { L } \\
\text { A } \\
\text { N } \\
\text { O }\end{array}$ & & {$\left[\begin{array}{r}\cos \\
\sin \\
0\end{array}\right.$} & $\begin{array}{ll}\alpha \alpha & - \\
\alpha & c\end{array}$ & $\left.\begin{array}{ll}\operatorname{in} \alpha & 0 \\
\operatorname{s} \alpha & 0 \\
0 & 1\end{array}\right]$ & & {$\left[\begin{array}{ccc}c & \text { em } x \\
1 & 0 & 0 \\
0 & -1 & 0 \\
0 & 0 & 1\end{array}\right]$} & $\begin{array}{c}e m y \\
{\left[\begin{array}{ccc}-1 & 0 & 0 \\
0 & 1 & 0 \\
0 & 0 & 1\end{array}\right]}\end{array}$ \\
\hline $\begin{array}{l}\text { E } \\
\text { S } \\
\text { P } \\
\text { A } \\
\text { Ç } \\
\text { O }\end{array}$ & {$\left[\begin{array}{l}1 \\
0 \\
0 \\
0\end{array}\right.$} & $\begin{array}{cc}\text { eixo } & x \\
0 & 0 \\
\cos \alpha & \sin \alpha \\
-\sin \alpha & \cos \alpha \\
0 & 0 \\
& \\
\text { eixo } z\end{array}$ & 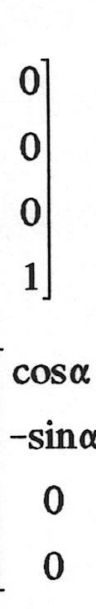 & 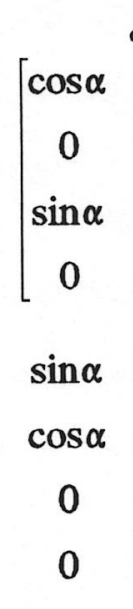 & 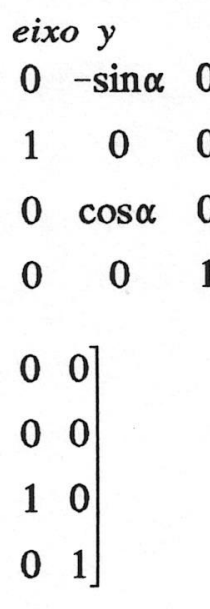 & $\begin{array}{l}\text { plano } x y \\
{\left[\begin{array}{cccc}1 & 0 & 0 & 0 \\
0 & 1 & 0 & 0 \\
0 & 0 & -1 & 0 \\
0 & 0 & 0 & 1\end{array}\right]} \\
\text { plano } y z\end{array}$ & $\begin{array}{c}\text { plano } x z \\
{\left[\begin{array}{cccc}1 & 0 & 0 & 0 \\
0 & -1 & 0 & 0 \\
0 & 0 & 1 & 0 \\
0 & 0 & 0 & 1\end{array}\right]} \\
{\left[\begin{array}{cccc}-1 & 0 & 0 & 0 \\
0 & 1 & 0 & 0 \\
0 & 0 & 1 & 0 \\
0 & 0 & 0 & 1\end{array}\right]}\end{array}$ \\
\hline
\end{tabular}

Quadro 4.4 - Matrizes de transformação no plano e no espaço (parte 2) 


\subsection{7 - Considerações em relação às Transformações Geométricas}

As transformações geométricas aplicadas devem manter os objetos sempre dentro dos limites do sistema de coordenadas que está sendo utilizado. Objetos fora destes limites devem ser ou cortados ou distorcidos, dependendo do critério a ser utilizado.

Estas transformações funcionam bem para polígonos e sólidos poliedrais já definidos. Primitivas podem ser transformadas de maneira mais eficiente aplicando-se as equações de transformação aos parâmetros que as definem. Por exemplo, um círculo deve ser escalado ajustando o seu raio, reposicionando o seu centro (se necessário) e retraçando-o novamente através do algoritmo utilizado para gerar sua primitiva.

Como mostrado, transformações que envolvem manipulações complexas podem ser facilmente construídas a partir de transformações simples. Segundo Rogers [Rog90], esta é a abordagem recomendada, pois geralmente é menos suscetível a erros e é computacionalmente mais eficiente que a abordagem matemática direta.

Cuidado especial deve ser tomado com a seqüência de transformações a ser aplicada, pois em geral a multiplicação de matrizes não é comutativa, podendo levar a resultados diferentes em função da seqüência utilizada.

Como os cálculos de rotação envolvem funções trigonométricas e várias operações aritméticas para cada ponto, o tempo dispendido com cálculos pode tornar-se excessivo, principalmente quando se tem muitos pontos ou serão aplicadas várias rotações. Para animações e outras aplicações que podem envolver ângulos de rotação pequenos (menores que $10^{\circ}$ ), pode-se ter uma melhoria significativa na eficiência se as funções trigonométricas forem substituídas por valores aproximados, sendo este erro menor à medida que o ângulo se aproxima de zero. 


\section{4 - OPERAÇÕES DE VARREDURA}

O princípio de varredura baseia-se na noção de mover uma região, denominada gerador, por um caminho, denominado diretor, utilizando duas formas básicas: a translacional (conhecida por "sweeping") e a rotacional (conhecida por "swinging"), que podem ser combinadas com o escalamento. Ambas as operações utilizam uma lâmina 2D para definir o formato desejado. No caso do "sweeping", a lâmina 2D representa a seção transversal, e no caso do "swinging", o perfil axial. "Swing" e "sweep" são essencialmente operações similares: o elemento básico é uma face percorrendo um caminho, enquanto faces laterais são criadas. A geometria do caminho e as curvas das arestas da face que está sendo varrida determinam a geometria da superfície das faces laterais. As curvas das arestas entre as laterais podem ser determinadas por meio do percurso varrido pelo vértice ou - mais caro e menos preciso - descobrindo a intersecção entre as superfícies das faces laterais.

A técnica de varredura utilizada no $(\mathrm{SM})^{2}$ permite gerar um sólido através de uma figura plana fechada e uma trajetória, que pode ser linear ou circular. Em trajetórias circulares, é possível definir a resolução a ser utilizada na geração do sólido. Os vértices do polígono gerador devem estar orientados no sentido horário, para que seja possível definir corretamente o interior do sólido gerado. Nestas condições, o resultado de qualquer tipo de varredura é um sólido bem definido, limitado e com volume. Os conceitos aqui apresentados foram colhidos de [Cas90a, Fil87, Mor85, Req80].

\subsection{1 - Varredura Translacional}

A varredura translacional implementada no $(\mathrm{SM})^{2}$ ocorre ao longo de um eixo não coplanar ao plano de definição da lâmina geradora. Valores de deslocamento positivos realizam translação no sentido crescente do eixo diretor, e valores negativos realizam translação no sentido decrescente do mesmo. A varredura translacional de um perfil ou com eixo coplanar à lâmina geradora constituem casos especiais, que não geram sólidos, e portanto não foram incorporados ao modelador. O SM ${ }^{2}$ dispõe de três tipos de varredura translacional: simples, cônica e com torção, explicadas a seguir. 


\subsubsection{1 - VARREDURA TRANSLACIONAL SIMPLES}

A varredura translacional simples pode ser reta ou oblíqua. Ambas partem do polígono gerador contendo $n$ vértices. A translação reta necessita da altura a ser atingida, uma vez que o deslocamento será perpendicular ao plano de definição do polígono. A translação oblíqua necessita dos deslocamentos em relação a cada um dos eixos coordenados, gerando um vetor não coplanar ao polígono gerador. O polígono superior do sólido é obtido transladando o polígono gerador na direção do vetor. Os vértices são numerados de 0 a $2 n-1$, fornecendo um total de $2 n$ vértices. Para cada lado do polígono gerador surgirá uma face, resultando em $n$ faces laterais e um total de $n+2$ faces. As faces laterais serão sempre compostas por 4 arestas, formando retângulos para a translação reta e paralelogramos para a translação oblíqua. As faces superior e inferior são compostas por $n$ arestas cada, gerando um total de $3 n$ arestas. A figura 4.23 exemplifica este tipo de varredura e mostra a seqüência correta de numeração dos vértices.

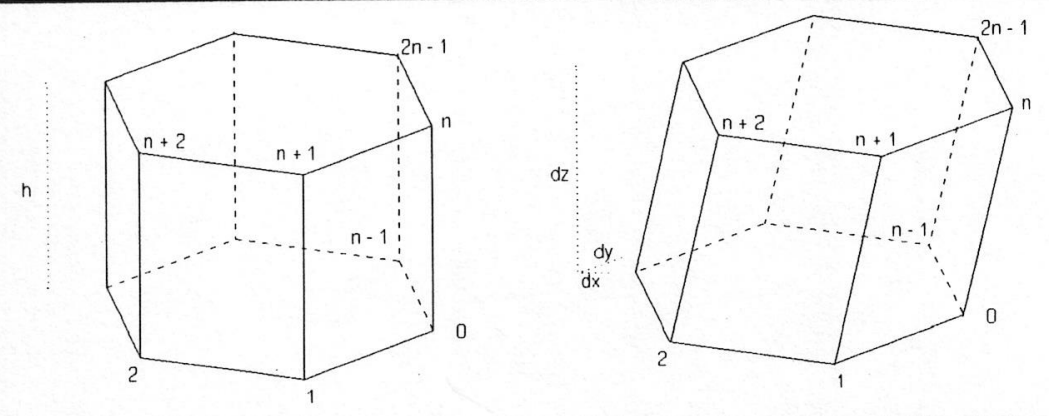

Figura 4.23 - Exemplos de varredura translacional simples

\subsubsection{2 - VARREDURA TRANSLACIONAL CÔNICA}

$\mathrm{Na}$ varredura translacional cônica, os vértices do polígono gerador, além de serem transladados, convergem para um ponto chamado ponto de fuga [Cas90a]. Na varredura translacional cônica reta, o ponto de fuga está localizado na posição do centróide do polígono gerador, a uma distância $d>0$. Na varredura translacional cônica oblíqua, o ponto de fuga pode possuir qualquer deslocamento em relação aos eixos coordenados, desde que não seja coplanar ao polígono gerador. Se a altura $h$ de translação for igual à distância $d$ do ponto 
de fuga, a face superior será reduzida a um único vértice. Neste caso, as $n$ faces laterais serão triangulares, o total de arestas será $2 n$ e o total de faces e vértices será $n+1$. Nos demais casos, a contagem de faces, arestas e vértices, bem como a seqüência de numeração dos vértices permanece igual ao translacional simples. A figura 4.24 mostra exemplos de varredura translacional cônica, destacando os parâmetros de definição e a seqüência de numeração dos vértices.

Além do polígono gerador, os parâmetros solicitados pelo $(\mathrm{SM})^{2}$ são o deslocamento em $x, y$ e $z$ ou as coordenadas do ponto de fuga e a proporção entre a distância $d$ e a altura de translação $h(d / h)$. A figura 4.24 mostra exemplos de varredura translacional cônica, destacando os parâmetros de definição e a seqüência de numeração dos vértices.

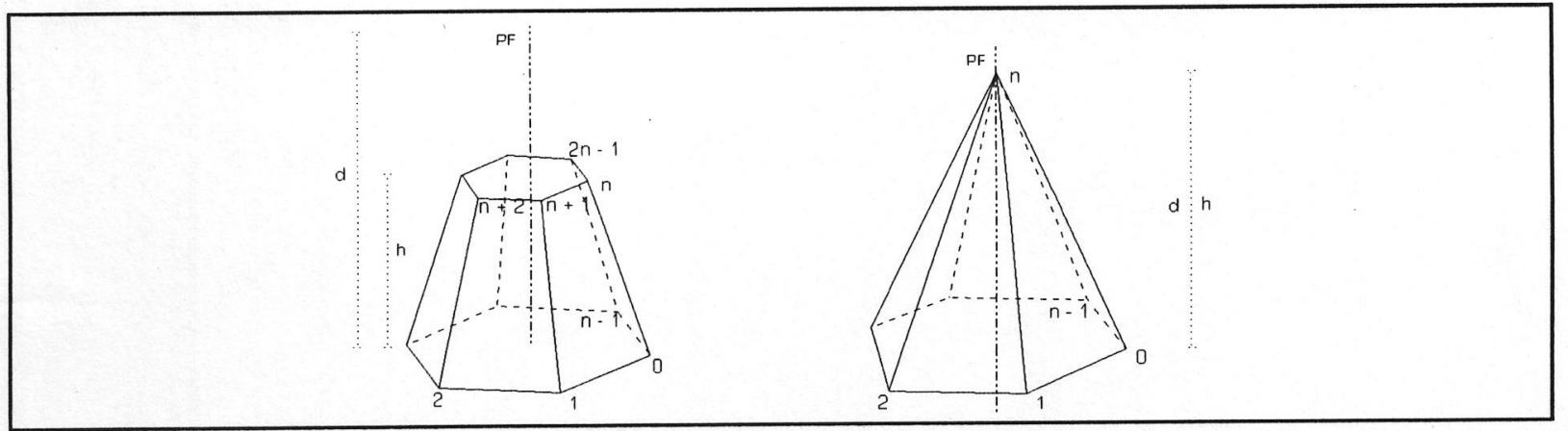

Figura 4.24 - Exemplos de varredura translacional cônica

\subsubsection{3 - VARREDURA TRANSLACIONAL COM TORÇÃO}

A varredura translacional com torção consiste de uma combinação da translação com a rotação. A translação ocorre perpendicularmente ao plano de definição do polígono gerador, enquanto a rotação ocorre no citado plano e em relação ao centróide do polígono. Como os dois movimentos são perpendiculares entre si, um não interfere no outro. Assim, o sólido obtido é o mesmo, quer se aplique primeiro a rotação ou a translação.

Este tipo de varredura utiliza os seguintes parâmetros: o polígono gerador com $n$ vértices, a altura total da translação $h$, a torção total $\theta$ e a resolução $p$ (número de passos) a ser utilizada. A cada passo ocorre um incremento na translação $d h=h / p$ e um incremento de rotação $d \theta=\theta / p$ do polígono gerador. Esta operação se repete até atingir a altura total 
de translação. Um exemplo deste tipo de varredura é apresentado na figura 4.25. A cada passo, o número de vértices cresce $n$ unidades, totalizando vértices $(p+1){ }^{*} n$ vértices. Como na varredura translacional simples, cada aresta do polígono gera uma face retangular a cada passo. Como ele é transladado $p$ vezes, o total de faces laterais é $p^{*} n$. Devido à torção que a face retangular sofre, fazendo com que seus vértices não sejam coplanares, trocou-se a face retangular por duas triangulares. Por fim, levando-se em consideração as faces inferior e superior do sólido, tem-se que o número total de faces é $2^{*} p^{*} n+2$. O total de arestas é obtido considerando 3 vezes o número de triângulos mais 2 vezes as arestas do polígono gerador e descontando a ocorrência em duplicidade de cada aresta, o que totaliza $3^{*} p^{*} n+n$.

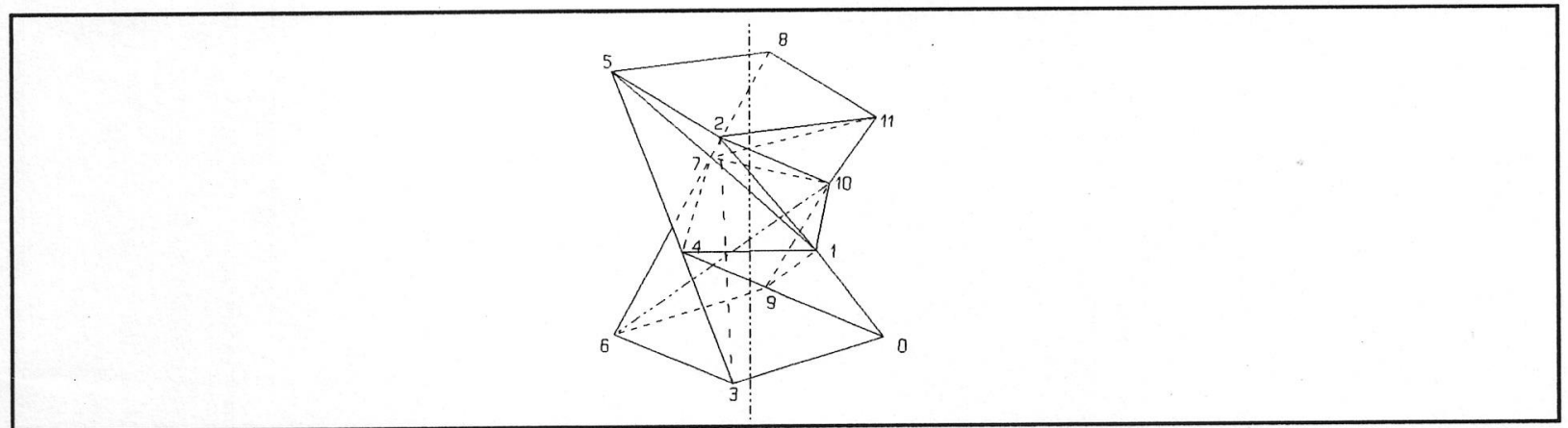

Figura 4.25 - Exemplo de varredura translacional com torção

\subsection{2.- Varredura Rotacional}

A varredura rotacional ocorre em torno de um eixo coplanar e externo ao polígono gerador. Valores positivos para o ângulo realizam rotação no sentido anti-horário, enquanto valores negativos realizam rotação no sentido horário.

$\mathrm{O}(\mathrm{SM})^{2}$ dispõe de três tipos de varredura rotacional: para polígonos abertos, para polígonos fechados e helicoidal, explicadas a seguir. 


\subsubsection{1 - VARREDURA ROTACIONAL SIMPLES ABERTA}

A varredura rotacional simples aberta consiste na rotação de uma curva poligonal aberta em torno do eixo formado pela reta que liga seu ponto inicial ao final. Utiliza como parâmetros o número de vértices da poli-linha geradora $n$, a resolução $p$ ( $\mathrm{n}^{0}$ passos) e 0 ângulo total de rotação $\theta$. A cada passo ocorre um incremento angular $d \theta=\theta / p$, definindo uma porção do sólido resultante, denominada de setor. A cada passo na rotação da poli-linha geradora, o número total de vértices é acrescido de $n-2$, ou seja, o número total de vértices da poli-linha menos os dois pontos que estão sobre o eixo. Assim, o número total de vértices é $(n-2) * p+2$.

De cada aresta da poli-linha geradora resulta uma face no setor. Por ser aberta, o número de arestas da poli-linha é $n$-1. Como as duas arestas limitantes da poli-linha possuem um vértice sobre o eixo de rotação, ao sofrerem a revolução, as $2 p$ faces geradas pelo pontos extremos serão triangulares, e as $(n-3)^{*} p$ restantes serão retangulares, totalizando $(n-1)^{*} p$ faces e $(2 n-3) * p$ arestas. Quando o ângulo total de revolução for menor que $360^{\circ}$, aparecerão duas novas faces, formadas através do polígono composto pela polilinha e seu eixo, no início e no final da revolução. As arestas dessas novas faces devem ser computadas no cálculo geral. Nesse caso, o total de faces, arestas e vértices será, respectivamente, $(n-1)^{*} p+2,(2 n-3) * p+n$ e $(n-2)^{*} p+n$. A figura 4.26 apresenta exemplos deste tipo de varredura, destacando os parâmetros utilizados e a seqüência correta de numeração.
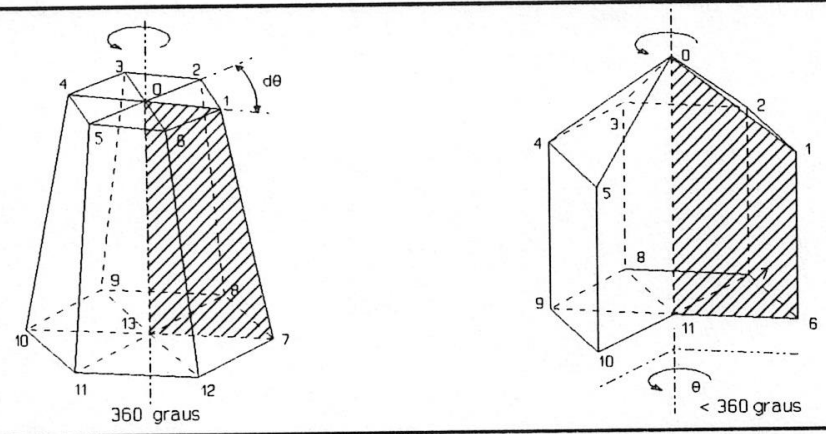

Figura 4.26 - Exemplos de varredura rotacional simples aberta 


\subsubsection{2 - VARREDURA ROTACIONAL SIMPLES FECHADA}

A varredura rotacional simples fechada possui os mesmos parâmetros de definição que a aberta $(\theta, n, p)$. Neste tipo de varredura não se deve definir vértices do polígono gerador sobre o eixo de rotação, pois o algoritmo causará multiplicidade do vértice, que fisicamente é único. Também não poderá existir intersecção entre o polígono gerador e o eixo de rotação. Caso o usuário do $(\mathrm{SM})^{2}$ especifique uma operação nestas situações, receberá uma mensagem de erro. Como o polígono gerador é fechado, o número de arestas é igual ao de vértices $(n)$ e cada aresta dará origem a uma face retangular, resultando em $n^{*} p$ faces. São gerados $\mathrm{n}$ vértices a cada setor, totalizando $n^{*} p$ vértices. $\mathrm{O}$ total de arestas é $2^{*} n^{*} p$.

Quando o ângulo total de revolução for inferior a $360^{\circ}$, aparecerão duas novas faces, que devem ser adicionadas aos cálculos, assim como suas arestas e vértices. Assim, o total de faces, arestas e vértice nestas condições será, respectivamente, $n^{*} p+2,\left(2{ }^{*} p+1\right)^{*} n$ e $n^{*}(p+1)$. Exemplos deste tipo de varredura são apresentados na figura 4.27.
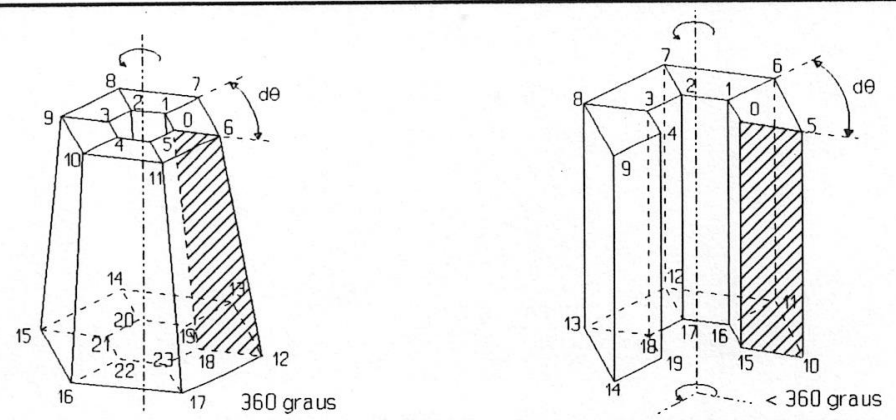

Figura 4.27 - Exemplos de varredura rotacional simples fechada

\subsubsection{3 - VARREDURA ROTACIONAL HELICOIDAL}

A varredura helicoidal combina a varredura rotacional com a translação. $O$ mecanismo de funcionamento é o mesmo da varredura rotacional com polígono fechado, somado a um deslocamento $h$ feito a cada passo no sentido crescente do eixo de rotação. É importante observar que, quando o ângulo de revolução for maior que $360^{\circ}$, ao completar 
cada volta, o incremento de translação deve ser suficientemente grande para não ocorrer interferência entre as partes do sólido que está sendo gerado. Nesse caso, o número de setores $p$ multiplicado pelo incremento de translação $d h$ deve ser maior que a altura máxima do polígono gerador naquela direção. A seqüência de numeração dos vértices que descrevem um sólido deste tipo é exatamente igual ao da varredura rotacional com polígono fechado quando o ângulo de revolução for diferente de $360^{\circ}$. Uma ilustração de varredura rotacional helicoidal é apresentada na figura 4.28 a seguir.

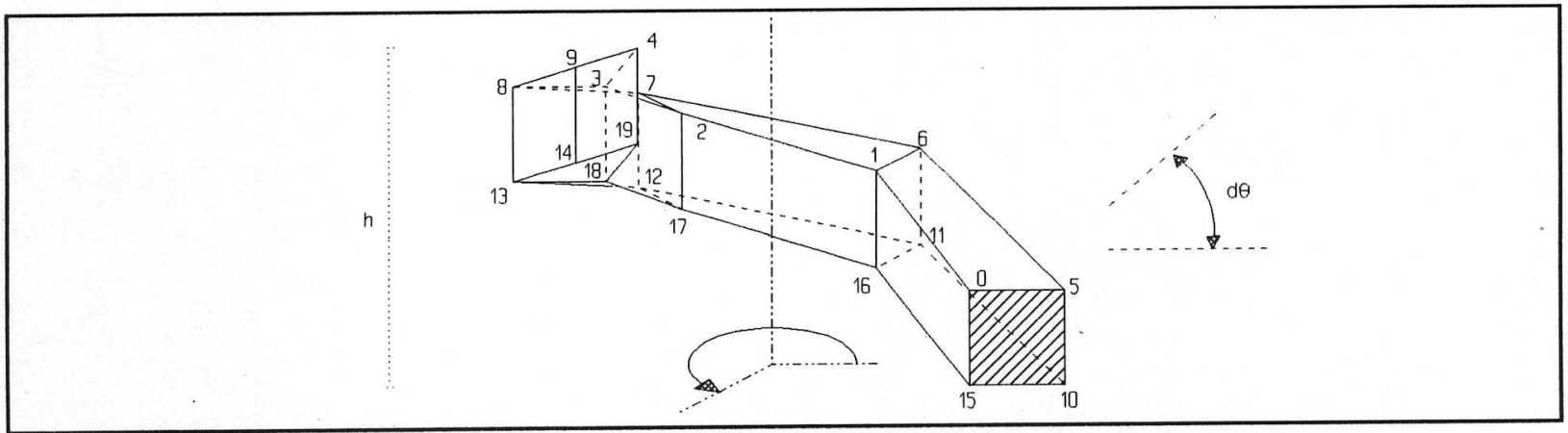

Figura 4.28 - Exemplo de varredura rotacional helicoidal

\subsection{3 - Considerações sobre Operações de Varredura}

As varreduras translacional e rotacional são formas de descrição não ambíguas, mas não são únicas, e o seu domínio está limitado a objetos com simetria translacional ou rotacional. $\mathrm{O}$ poder descritivo da varredura está intimamente relacionado à capacidade de descrição da face ou curva geradora. Por este motivo, pretende-se incorporar ao (SM) ${ }^{2}$ recursos mais sofisticados de definição dos elementos geradores, partindo das primitivas planares já mencionadas e aplicando os conceitos de Geometria Planar Construtiva [Fo190], que combina primitivas através de operações booleanas (união, intersecção e diferença) regularizadas. De imediato, já é possível utilizar poli-linhas, arcos e curvas B-Spline planas unidas entre si para a definição da curva geradora na varredura rotacional simples aberta.

A varredura rotacional é muito utilizada em modeladores geométricos cuja finalidade são aplicações relacionadas à geração e análise de objetos torneados; já a varredura translacional é aplicada na descrição de placas metálicas. Translacional ou rotacional, a varredura oferece uma boa forma de descrever objetos para serem manipulados 
em representação B-Rep. Os quadros 4.5 e 4.6 resumem as principais características de cada tipo de varredura, apontam os parâmetros necessários e descrevem a seqüência da numeração utilizada para as faces, considerando o cuidado necessário para com a orientação na definição do interior do sólido.

A matemática existente por trás da operação de varredura é mais complexa do que parece à primeira vista. Muito pouco é conhecido sobre varredura aplicada a um caminho genérico e, além disto, ela depende de certas convenções, que deverão ser padrão ou parametrizadas. É necessário fixar um ponto de referência no objeto - para percorrer a trajetória - e definir a orientação inicial e a sua variação durante o percurso. A varredura genérica pode também envolver o movimento de um objeto não rígido, que sofre deformações no decorrer da varredura. Podem ainda ocorrer problemas relacionados à degeneração, como a auto-intersecção [Hof87], ilustrada na figura 4.29, ou a varredura por um caminho paralelo ao elemento gerador, que resultará em uma área ao invés de um volume. Se tais casos forem considerados como erro, serão necessários algoritmos para a sua detecção; caso sejam permitidos, será necessário dar uma interpretação correta para os resultados.

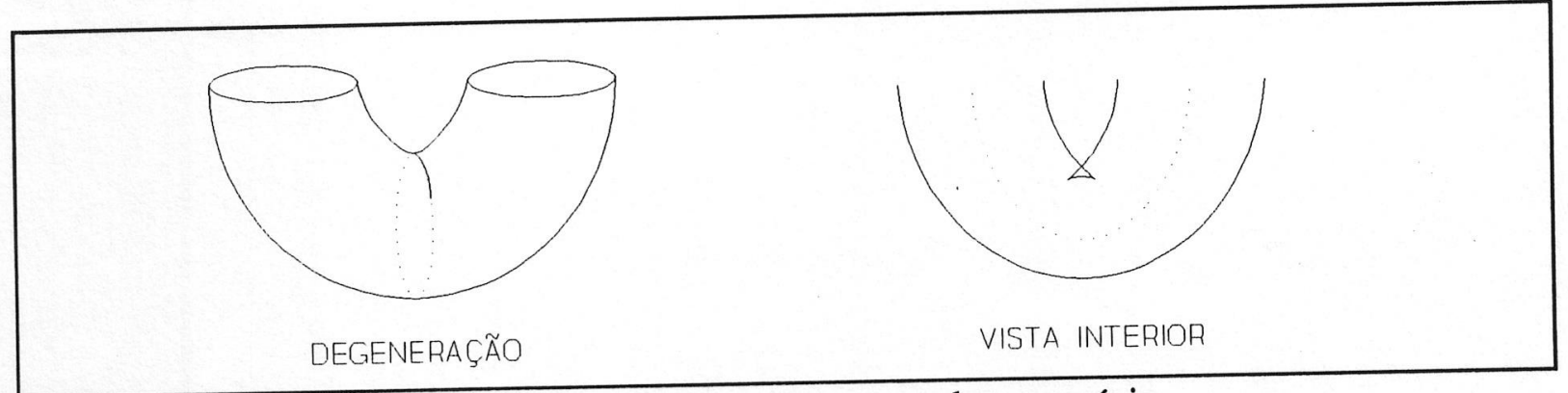

Figura 4.29 - Exemplo de degeneração em uma varredura genérica

Outra consideração importante a ser feita diz respeito à varredura utilizando como elemento gerador um sólido. Apesar da representação por varredura fornecer um meio natural para descrever o volume de um sólido obtido pelo movimento de outro sólido rígido seguindo uma trajetória no espaço, existem poucos algoritmos conhecidos para computar as propriedades dos sólidos gerados. Wang apresenta uma proposta em [Wan86]. O movimento pode incluir componentes translacionais e rotacionais, com também alteração na orientação do eixo, podendo resultar em um volume com geometria muito complexa. Tais volumes varridos são importantes no contexto da automação industrial, como na remoção de material durante o detalhamento de peças [Voe77] e a detecção de interferência dinâmica entre objetos [Boy79]. 


\begin{tabular}{|c|c|c|c|}
\hline & $\begin{array}{c}\text { ROTACIONAL SIMPLES } \\
\text { ABERTA } \\
\end{array}$ & $\begin{array}{c}\text { ROTACIONAL SIMPLES } \\
\text { FECHADA }\end{array}$ & ROTACIONAL HELICOIDAL \\
\hline $\begin{array}{l}\text { PARÂME- } \\
\text { TROS }\end{array}$ & $\begin{array}{l}\text { - face válida com } n \text { vértices } \\
\text { - rotação total (>0) } \\
\text { - resolução } p \text { ( } n^{\circ} \text { passos) }\end{array}$ & $\begin{array}{l}\text { - face válida com } n \text { vértices } \\
\text { - rotação total (>0) } \\
\text { - resolução } p\left(n^{\circ} \text { passos }\right) \\
\text { - eixo coplanar à face }\end{array}$ & $\begin{array}{l}\text { - face válida com } n \text { vértices } \\
\text { - altura total }(>0) \\
\text { - rotação total }(>0) \\
\text { - resolução } p\left(\mathrm{n}^{\circ} \text { passos }\right) \\
\text { - eixo coplanar à face }\end{array}$ \\
\hline FACES & $\begin{array}{l}\text { parcial }=>(n-1) p+2 \\
\text { completa }=>(n-1) p\end{array}$ & $\begin{array}{l}\text { parcial }=>n p+2 \\
\text { completa }=>n p\end{array}$ & $n p+2$ \\
\hline ARESTAS & $\begin{array}{l}\text { parcial }=>(2 n-3) p+n \\
\text { completa }=>(2 n-3) p\end{array}$ & $\begin{array}{l}\text { parcial }=>n(2 p+1) \\
\text { completa }=>2 n p\end{array}$ & $n(2 p+1)$ \\
\hline VÉRTICES & $\begin{array}{l}\text { parcial }=>(n-2) p+n \\
\text { completa }=>(n-2) p+2\end{array}$ & $\begin{array}{l}\text { parcial }=>n(p+1) \\
\text { completa }=>n p\end{array}$ & $n(p+1)$ \\
\hline $\mathrm{F}-\mathrm{A}+\mathrm{V}$ & parcial e completa $=>2$ & parcial $=>2$, completa $=>0$ & 2 \\
\hline $\begin{array}{l}\text { FACE } \\
\text { INICIAL }\end{array}$ & $\begin{array}{l}\text { parcial }=>\{0\} ; \\
\text { for }\left(\mathrm{i}=(n-2)^{*} p+n-1 ; \mathrm{i}>0 ;\right. \\
\quad \mathrm{i}-=p+1)\{\mathrm{i}\} \\
\text { completa }=>\text { não tem }\end{array}$ & $\begin{array}{l}\text { parcial } \\
\text { for }\left(\mathrm{i}=(n-1)^{*}(p+1) ; \mathrm{i}<=0 ;\right. \\
\quad \mathrm{i}-=p+1)\{\mathrm{i}\} ; \\
\text { completa }=>\text { não tem }\end{array}$ & $\begin{aligned} \text { for }(\mathrm{i}= & =(n-1)^{*}(p+1) ; \mathrm{i}<=0 \\
\mathrm{i}- & =p+1)\{\mathrm{i}\}\end{aligned}$ \\
\hline \multirow[t]{2}{*}{$\begin{array}{l}\text { FACE } \\
\text { LATERAL }\end{array}$} & $\begin{array}{l}\text { parcial }- \text { triang. superiores } \\
\text { for }(\mathrm{i}=1 ; \mathrm{i}<=p ; \mathrm{i}++)\{0, \mathrm{i}, \mathrm{i}+1\} \\
\text { parcial }- \text { faces retangulares } \\
\text { for }\left(\mathrm{i}=1 ; \mathrm{i}<(n-3)^{*}(p+1)\right. \\
\quad \mathrm{i}+=p+1) \\
\{\text { for }(\mathrm{j}=0 ; \mathrm{j}<p ; \mathrm{j}++) \\
\{\mathrm{v} 1=\mathrm{i}+\mathrm{j} ; \quad \mathrm{v} 4=\mathrm{v} 1+1 ; \\
\quad \mathrm{v} 2=\mathrm{v} 1+p+1 ; \mathrm{v} 3=\mathrm{v} 2+1 ; \\
\quad\{\mathrm{v} 1, \mathrm{v} 2, \mathrm{v} 3, \mathrm{v} 4\}\}\} \\
\text { parcial }- \text { triang. inferiores } \\
\text { for }\left(\mathrm{i}=(p+1)^{*}(n-3)+1 ;\right. \\
\left.\quad \mathrm{i}<(n-2)^{*} p+n-2 ; \mathrm{i}++\right) \\
\quad\left\{\mathrm{i},(n-2)^{*} p+n-1, \mathrm{i}+1\right\} ;\end{array}$ & $\begin{array}{l}\text { parcial } \\
\text { for }\left(\mathrm{i}=0 ; \mathrm{i}<n^{*}(p+1) ; \mathrm{i}+=p+1\right) \\
\begin{array}{l}\text { for }(\mathrm{j}=0 ; \mathrm{j}<p ; \mathrm{j}++) \\
\{\mathrm{v} 1=\mathrm{i}+\mathrm{j}: \mathrm{v} 4=\mathrm{v} 1+1 ; \\
\quad \mathrm{v} 2=(\mathrm{v} 1+p+1) \bmod \left(n^{*}(p+1)\right) \\
\quad \mathrm{v} 3=\mathrm{v} 2+1 ; \\
\quad\{\mathrm{v} 1, \mathrm{v} 2, \mathrm{v} 3, \mathrm{v} 4\}\}\}\end{array}\end{array}$ & \multirow[t]{2}{*}{$\begin{array}{l}\text { for }\left(\mathrm{i}=0 ; \mathrm{i}<n^{*}(p+1) ; \mathrm{i}+=p+1\right) \\
\begin{array}{l}\{\text { for }(\mathrm{j}=0 ; \mathrm{j}<p ; \mathrm{j}++) \\
\{\mathrm{v} 1=\mathrm{i}+\mathrm{j}: \mathrm{v} 4=\mathrm{v} 1+1 \\
\quad \mathrm{v} 2=(\mathrm{v} 1+p+1) \bmod \left(n^{*}(p+1)\right) \\
\quad \text { v3 }=\mathrm{v} 2+1 \\
\quad\{\mathrm{v} 1, \mathrm{v} 2, \mathrm{v} 3, \mathrm{v} 4\}\}\}\end{array}\end{array}$} \\
\hline & $\begin{array}{l}\text { completa -triang. superiores } \\
\text { for }(\mathrm{i}=1 ; \mathrm{i}<p ; \mathrm{i}++)\{0, \mathrm{i}, \mathrm{i}+1\} \\
\{0, p, 1\} ; \\
\text { completa -faces retangulares } \\
\text { for }\left(\mathrm{i}=1 ; \mathrm{i}<(n-3)^{*} p ; \mathrm{i}+=p\right) \\
\{\text { for }(\mathrm{j}=0 ; \mathrm{j}<p-1 ; \mathrm{j}++) \\
\{\mathrm{v} 1=\mathrm{i}+\mathrm{j}: \mathrm{v} 4=\mathrm{v} 1+1 ; \\
\quad \mathrm{v} 2=\mathrm{v} 1+p ; \mathrm{v} 3=\mathrm{v} 2+1 ; \\
\quad\{\mathrm{v} 1, \mathrm{v} 2, \mathrm{v} 3, \mathrm{v} 4\}\}\} \\
\left\{\mathrm{i}+p-1, \mathrm{i}+2^{*} p-1, \mathrm{i}+p, \mathrm{i}\right\} \\
\text { completa }- \text { triang. inferiores } \\
\text { for }\left(\mathrm{i}=p^{*}(n-3)+1 ;\right. \\
\left.\quad \mathrm{i}<(n-2)^{*} p ; \mathrm{i}++\right) \\
\quad\left\{\mathrm{i},(n-2)^{*} p+1, \mathrm{i}+1\right\} \\
\left\{(n-2)^{*} p,(n-2)^{*} p+1\right. \\
\left.p^{*}(n-3)+1\right\}\end{array}$ & $\begin{array}{l}\text { completa }=>\mathrm{p} / \text { todas as faces } \\
\text { for }\left(\mathrm{i}=0 ; \mathrm{i}<n^{*} p ; \mathrm{i}+=p\right) \\
\{\text { for }(\mathrm{j}=0 ; \mathrm{j}<p-1 ; \mathrm{j}++) \\
\{\mathrm{v} 1=\mathrm{i}+\mathrm{j}: \mathrm{v} 4=\mathrm{v} 1+p \\
\quad \mathrm{v} 2=(\mathrm{v} 1+p) \bmod \left(n^{*} p\right) \\
\quad \mathrm{v} 3=\mathrm{v} 2+1 ; \\
\quad\{\mathrm{v} 1, \mathrm{v} 2, \mathrm{v} 3, \mathrm{v} 4\}\}\} \\
\left\{\mathrm{i}+p-1,(\mathrm{i}+2 p-1) \bmod \left(n^{*} p\right)\right. \\
\left.\left.(\mathrm{i}+p) \bmod \left(n^{*} p\right), \mathrm{i}\right\}\right\}\end{array}$ & \\
\hline $\begin{array}{l}\text { FACE } \\
\text { FINAL }\end{array}$ & $\begin{array}{l}\text { parcial }\{0\} \\
\text { for }\left(\mathrm{i}=p+1 ; \mathrm{i}<(n-2)^{*} p+n-1\right. \\
\quad \mathrm{i}+=p+1)\{\mathrm{i}\} \\
\left\{(n-2)^{*} p+n-1\right\} \\
\text { completa }=>\text { não tem }\end{array}$ & $\begin{array}{l}\text { parcial } \\
\text { for }\left(\mathrm{i}=p ; \mathrm{i}<n^{*}(p+1) ; \mathrm{i}+=p+1\right) \\
\quad\{\mathrm{i}\} ; \\
\text { completa }=>\text { não tem }\end{array}$ & $\begin{array}{l}\text { for }\left(\mathrm{i}=p ; \mathrm{i}<n^{*}(p+1) ; \mathrm{i}+=p+1\right) \\
\quad\{\mathrm{i}\}\end{array}$ \\
\hline
\end{tabular}

Quadro 4.5 - Principais características da varredura rotacional 


\begin{tabular}{|c|c|c|c|}
\hline & TRANSLACIONAL SIMPLES & TRANSLACIONAL CÔNICA & TRANSLACIONAL COM TORÇÃO \\
\hline $\begin{array}{l}\text { PARÂME- } \\
\text { TROS }\end{array}$ & $\begin{array}{l}\text { - face válida contendo } n \\
\text { vértices } \\
\text { - deslocamento em } \mathrm{x}, \mathrm{y}, \mathrm{z}\end{array}$ & $\begin{array}{l}\text { - face válida contendo } n \text { vértices } \\
\text { - deslocamento em } x, y, z \text { ou } \\
\text { coord. ponto de fuga }\end{array}$ & $\begin{array}{l}\text { - face válida contendo } n \text { vértices } \\
\text { - altura total }(>0) \\
\text { - ângulo total }(>0) \\
\text { - resoluçãp } p \text { (nº passos) }\end{array}$ \\
\hline FACES & $n+2$ & $n+1$ & $2 p n+2$ \\
\hline ARESTAS & $3 n$ & $2 n$ & $3 p n+n$ \\
\hline VÉRTICES & $2 n$ & $n+1$ & $(p+1) n$ \\
\hline$F-A+V$ & 2 & 2 & 2 \\
\hline $\begin{array}{l}\text { FACE } \\
\text { INFERIOR } \\
\end{array}$ & $\begin{array}{l}\text { for }(\mathrm{i}=0 ; \mathrm{i}<n ; \mathrm{i}++) \\
\quad\{\mathrm{i}\}\end{array}$ & $\begin{array}{l}\text { for }(\mathrm{i}=0 ; \mathrm{i}<n ; \mathrm{i}++) \\
\quad\{\mathrm{i}\}\end{array}$ & $\begin{array}{l}\text { for }\left(\mathrm{i}=0 ; \mathrm{i}<(p+1)^{*} n ; \mathrm{i}+=p+1\right) \\
\quad\{\mathrm{i}\} ;\end{array}$ \\
\hline $\begin{array}{l}\text { FACE } \\
\text { LATERAL }\end{array}$ & $\begin{array}{l}\text { for }(\mathrm{i}=0 ; \mathrm{i}<n-1 ; \mathrm{i}++) \\
\quad\{n+\mathrm{i}, n+\mathrm{i}+1, \mathrm{i}+1, \mathrm{i}\} \\
\{2 n-1, n, 0, n-1\}\end{array}$ & $\begin{array}{l}\text { para proporção }=100 \% \\
\text { for }(\mathrm{i}=0 ; \mathrm{i}<n ; \mathrm{i}++) \\
\quad\{\mathrm{i}, n,(\mathrm{i}+1) \bmod n\} ; \\
\text { para outras proporções, } \\
\text { vale a sequiência da } \\
\text { translacional simples }\end{array}$ & $\begin{array}{l}\text { for }\left(\mathrm{i}=0 ; \mathrm{i}<=n^{*}(p+1) ; \mathrm{i}+=p+1\right) \\
\{\text { for }(\mathrm{j}=0 ; \mathrm{j}<p ; \mathrm{j}++) \\
\{\mathrm{v} 1=\mathrm{i}+\mathrm{j} ; \mathrm{v} 4=\mathrm{v} 1+1 ; \\
\text { v2 }=(\mathrm{v} 1+p+1) \bmod \left(n^{*}(p+1)\right) \\
\text { v3 }=\mathrm{v} 2+1 ; \\
\{\mathrm{v} 1, \mathrm{v} 4, \mathrm{v} 3\} \\
\{\mathrm{v} 1, \mathrm{v} 3, \mathrm{v} 2\} ;\}\}\end{array}$ \\
\hline $\begin{array}{l}\text { FACE } \\
\text { SUPERIOR }\end{array}$ & $\begin{array}{l}\text { for }(\mathrm{i}=2 n-1 ; \mathrm{i}>=n ; \mathrm{i}--) \\
\quad\{\mathrm{i}\} ;\end{array}$ & $\begin{array}{l}\text { proporção }=100 \% \text { não tem } \\
. \text { outras }=\text { translacional simples }\end{array}$ & $\begin{array}{l}\text { for }\left(\mathrm{i}=(p+1)^{*} n-1 ; \mathrm{i}>=p ; \mathrm{i}-=p+1\right) \\
\quad\{\mathrm{i}\}\end{array}$ \\
\hline
\end{tabular}

Quadro 4.6 - Principais características da varredura translacional

\section{5 - Considerações finais}

O principal objetivo ao concentrar esforços no estudo e desenvolvimento das operações básicas descritas é o de aumentar o poder descritivo do modelador sem aumentar a complexidade das operações envolvidas. Assim, procurou-se oferecer um conjunto de primitivas concisas e compactas, cujo tamanho, formato, posição e orientação são determinados por um conjunto de parâmetros fornecidos conforme disponibilidade de dados pelo usuário. As primitivas sólidas podem ser definidas em diversas resoluções, de forma reta ou oblíqua, podendo ainda serem maciças, ocas ou vazadas. As primitivas planares, utilizadas pelos vários tipos de varredura, poderão futuramente ser combinadas através de operações booleanas 2D regularizadas (união, intersecção e diferença), gerando sólidos complexos a partir de operações simples e eficientes. Esta abordagem é altamente desejável, uma vez que operações booleanas aplicadas diretamente sobre sólidos são muito mais complexas, lentas e menos confiáveis. Pratt reforça esta idéia e aconselha utilizar meios alternativos para a descrição de objetos, evitando assim o uso desnecessário de operações booleanas [Pra90]. 


\section{Capítulo 5}

\section{O MODELADOR (SM) ${ }^{2}$}

\section{1 - CONSIDERAÇÕES INICIAIS}

Este capítulo descreve o $(\mathrm{SM})^{2}$ - Sistema de Modelagem de Sólidos Multirrepresentacional, modelador em desenvolvimento pelo grupo de Computação Gráfica e Processamento de Imagens do ICMSC-USP. O (SM) ${ }^{2}$ possui, atualmente, a representação B-Rep como principal e permanente, e a representação implícita como secundária. A coexistência das duas formas de representação exigiu a implementação de um procedimento de conversão da representação implícita para a B-Rep, descrita em [Siq94]. As técnicas de modelagem implementadas no decorrer deste trabalho são o instanciamento de primitivas e vários tipos de varredura translacional e rotacional, além de operações de transformação geométrica. Também encontra-se disponível a técnica de modelagem por semi-espaços [Siq94]. Alguns procedimentos para visualização realística estão operacionais [Ces94].

As principais características do modelador são apresentadas a seguir, destacando as operações implementadas em decorrência deste trabalho. A seção 5.2 apresenta a descrição funcional e as principais características de projeto do $(\mathrm{SM})^{2}$. A seção 5.3 fornece, inicialmente, uma visão geral do modelador, bem como do núcleo B-rep e das estruturas de dados utilizadas. A seguir, descreve o módulo de modelagem, com ênfase no instanciamento de primitivas e operações de varredura, e comenta sobre os recursos disponíveis para a visualização dos sólidos modelados. A seção 5.4 apresenta alguns exemplos de geração de sólidos por instanciamento de primitivas e por varredura no $(\mathrm{SM})^{2}$. Finalmente, a seção 5.5 faz algumas considerações em relação às características apresentadas.

Maiores detalhes sobre o $(\mathrm{SM})^{2}$ podem ser obtidos nos documentos específicos referentes ao projeto, à implementação e à utilização do modelador [Mag94b, Mag94c, Mag94d], bem como na nota técnica sobre o uso de operadores de Euler [Mag94a]. 


\section{2 - O PROJETO DO (SM)}

A análise de requisitos e especificação de um software é uma tarefa muito delicada, pois constitui o ponto de partida para o seu sucesso ou fracasso. Uma especificação detalhada não pode, normalmente, ser obtida nos primeiros estágios de desenvolvimento. Isto é verdade principalmente no caso de sistemas complexos e voltados para pesquisa, onde não se tem uma idéia exata do resultado a ser obtido, de qual será o produto final, do que é realmente necessário. Por estas e muitas outras razões, é aconselhável desenvolver um protótipo - modelo construído para assessorar usuários e desenvolvedores na definição do produto. Na prototipagem os requisitos essenciais são definidos, gerando um conjunto abreviado de especificações do produto, que permitem criar, testar e refinar o protótipo. A partir dos resultados obtidos, são sugeridas modificações a serem especificadas e incluídas na nova versão do protótipo, e assim por diante. Esta sequência evolui até que todos os requisitos estejam formalizados ou até que o protótipo tenha evoluído para um produto.

No desenvolvimento do $(\mathrm{SM})^{2}$ foi escolhida metodologia de análise orientada a fluxo de dados, uma vez que a estrutura de dados interna é complexa, e o uso de uma linguagem formal para especificação dificultaria ainda mais o detalhamento do projeto. Segundo Pressman [Pre87], um modelo orientado a fluxo de dados pode ser aplicado a qualquer sistema baseado em computador, independente do seu tamanho ou complexidade. Além disto, a simplicidade da simbologia envolvida permitiu que a orientação a fluxo de dados se tornasse o método de análise de requisitos mais largamente utilizado.

A abordagem escolhida foi a análise e projeto estruturados, propostos por Gane e Sarson [Gan83]. Para a especificação de funcionalidade foram utilizados Diagramas de Fluxo de Dados - DFDs - e tabelas padronizadas que descrevem e relacionam itens de dados, processos e depósitos de dados. Uma descrição minuciosa do projeto, discutindo aspectos relacionados ao protótipo desenvolvido, aos componentes e requisitos do sistema e ao projeto lógico desenvolvido, pode ser obtida na Documentação de Projeto [Mag94b]. 


\subsection{1 - Experiência anterior: o protótipo SMS}

Antecedendo os trabalhos com o $(\mathrm{SM})^{2}$, foi desenvolvido o SMS - SISTEMA DE MODELAGEM DE SÓLIDOS, com o intuito de adquirir experiência para a construção de um modelador híbrido CSG_B-Rep, utilizando conceitos de orientação a objetos. O projeto lógico, descrito em [Sco93a], utilizou parte da metodologia orientada a objetos proposta por Booch [Boo91]. Uma parte deste projeto foi implementada, permitindo adquirir experiência na manipulação das representações internas e no uso de operadores de Euler para a construção de sólidos simples. O SMS utilizava uma variação da estrutura semi-aresta proposta por Mäntylä [Män88], sendo composta hierarquicamente pelos objetos cena, sólido, sólido B-Rep, face, ciclo, semi-aresta, vértice, mais os elementos aresta (ligado a sólido BRep), curva (ligado à aresta) e superfície (ligado à face). Como o SMS foi implementado em linguagem $C$, conceitos de orientação a objetos (herança, polimorfismo, troca de mensagens) eram simulados no ambiente [Sco93, Sco93b], seguindo a proposta de Duff e Howard [Duf90].

O SMS era dotado somente da representação B-Rep. Sólidos eram descritos por operações de varredura translacional e rotacional simples e mostrados como fio-de-arame, sem nenhum recurso adicional para uma visualização mais realística. A experiência adquirida permitiu constatar a necessidade de alteração de algumas características do modelador:

- a estrutura de dados deveria incorporar também o elemento casca, o que permitiria aumentar o poder descritivo do modelador através da geração de sólidos ocos, além de facilitar o desenvolvimento de operações complexas de manipulação da forma, como as booleanas [Tsu92];

- os elementos curva e superfície poderiam ser descartados, pois estavam sem função na estrutura de dados, uma vez que o $(\mathrm{SM})^{2}$ será, provisoriamente, poliedral;

- curvas e superfícies somente deveriam existir durante a descrição de objetos sólidos por varredura, não devendo permanecer na cena;

- o uso da abordagem orientada a objetos através da simulação de conceitos de orientação a objetos foi considerada inviável, uma vez que estava prejudicando o desempenho do sistema. Uma solução seria adotar $\mathrm{C}++$, mas por diversas razões práticas, considerou-se que a linguagem de desenvolvimento mais adequada seria $\mathrm{C}$. Com isso, optouse por um método de projeto convencional (estruturado). 


\subsection{2 - Descrição informal do (SM) ${ }^{2}$}

A descrição do $(\mathrm{SM})^{2}$ ora apresentada faz parte do processo de análise de requisitos do sistema, e tem evoluído com a experiência de desenvolvimento adquirida durante a construção do SMS e do próprio (SM) ${ }^{2}$. Uma visão completa do modelador é apresentada, procurando especificar funções, escopo e limitações do sistema. Deve-se ressaltar que somente parte do que está descrito encontra-se operacional, e dessa, apenas uma porção foi implementada no decorrer deste trabalho.

$\mathrm{O}(\mathrm{SM})^{2}$ deve ser um modelador capaz de suportar várias formas de representação de objetos sólidos, tendo a representação B-Rep como principal e permanente. Deve permitir a criação, edição e acesso a representação de objetos sólidos e cenas compostas por um ou mais objetos. Além dos processos ativados pelos usuários durante a fase de modelagem interativa, outros processos que acessam estas representações são as rotinas de visualização - consideradas parte integrante do modelador - , programas aplicativos externos ao modelador ou outros modeladores. Estes processos utilizam as representações internas para responder a questões práticas referentes aos objetos modelados, como cálculo de volume, área, centro de massa, etc.

Em uma etapa inicial, o sistema deve suportar apenas objetos poliedrais. Desta forma, faces curvas existentes nos objetos devem ser aproximadas por facetas planares, levando em consideração a precisão estabelecida pelo usuário. Pretende-se futuramente estender a representação B-Rep para descrever objetos com faces curvas de forma exata.

$\mathrm{O}(\mathrm{SM})^{2}$ é composto por três subsistemas, ilustrados na figura 5.1, que devem ser desenvolvidos e operar de forma independente, ainda que colaborem entre si e estejam funcionalmente interligados:

- o Subsistema de Interface, responsável por fornecer aos usuários as diversas maneiras de descrever sólidos, bem como um conjunto de operações de manipulação da forma que possam ser executadas sobre os sólidos e cenas existentes. Deve também fornecer recursos para a visualização dos sólidos e cenas representados e interfaces para comunicação com outros modeladores ou aplicativos. As tarefas a serem realizadas pelo modelador são descritas através da interface, capturadas por procedimentos deste subsistema, que ativam procedimentos dos outros subsistemas; os resultados das tarefas são recebidos pelos procedimentos e exibidos através da interface. 


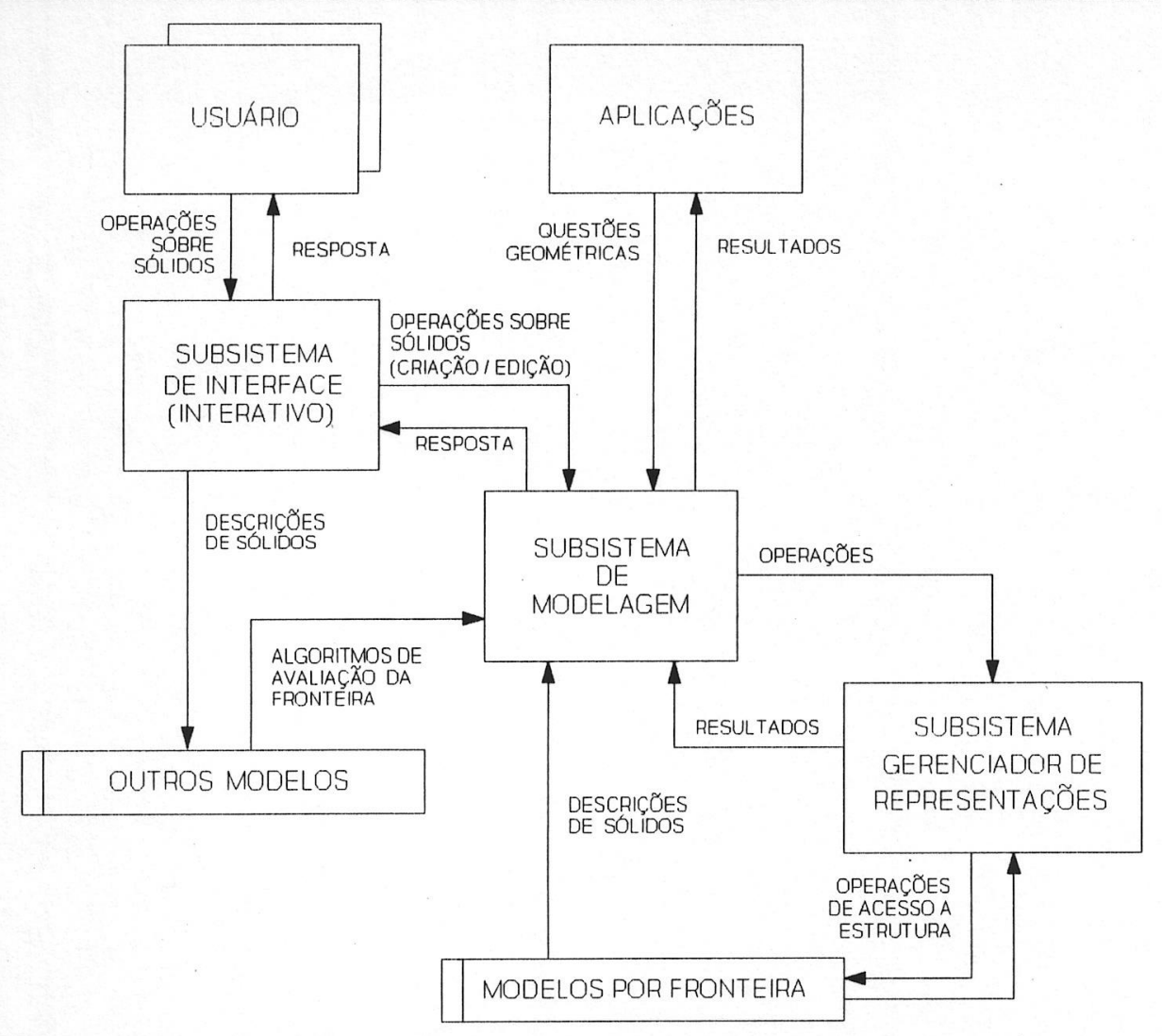

Figura 5.1 - Componentes do modelador $(\mathrm{SM})^{2}$

- o Subsistema de Modelagem, responsável por traduzir as descrições de sólidos e operações de manipulação recebidas do Subsistema de Interface em comandos para a geração das representações internas. Deve admitir múltiplas representações internas, a serem mantidas enquanto consistentes, dispondo dos procedimentos para conversão necessários. Contém os procedimentos que interpretam a descrição de um novo modelo ou de uma modificação, e a seguir acionam os procedimentos do Subsistema de Representação para criar ou alterar, respectivamente, uma representação. Responde também a questões geométricas e topológicas solicitadas pelo sistema.

- O Subsistema Gerenciador de Representações, responsável pela manutenção, gerenciamento e acesso ao conjunto de representações internas (estruturas de dados) admitidas pelo sistema. Deve também incluir funções para armazenamento da descrição de sólidos e cenas em bases de dados permanentes. Cada forma de representação do (SM) ${ }^{2}$ possui uma estrutura de dados e procedimentos específicos de manipulação da estrutura. As informações das representações são lidas por procedimentos de outros subsistemas, mas são criadas e modificadas apenas pelos procedimentos do Subsistema de Representação. 
Os usuários interagem com o modelador para descrever e editar sólidos através de uma interface gráfica interativa que constitui o Subsistema de Interface. Os comandos recebidos pela Interface são traduzidos em solicitações para o Subsistema de Modelagem, que implementa as técnicas de modelagem disponíveis no sistema e é responsável pela execução das operações de manipulação da forma. Para tal, esse subsistema interage com o Subsistema de Representação, que acessa e altera, quando necessário, as representações de sólidos mantidas pelo sistema. Os programas aplicativos interagem diretamente com o Subsistema de Modelagem, emitindo solicitações através de uma linguagem de comandos.

Através da interface, um usuário pode gerar sólidos da maneira que lhe for mais conveniente. Inicialmente, estarão disponíveis quatro formas básicas, sendo que outras poderão ser acrescentadas à medida em que o modelador evoluir:

- criando instâncias de primitivas sólidas pré-definidas, como blocos, prismas, pirâmides, esferas, cilindros, cones e toros). Para tal devem ser fornecidos o tipo de primitiva, os parâmetros de definição (comprimento, altura, raio, etc., dependendo do caso) e de preenchimento (tipo - maciço, oco ou vazado - e espessura, se necessário);

- definindo o formato da base, que pode ser obtido a partir de primitivas planares como círculo, elipse, triângulo, quadrilátero ou polígono - combinadas entre si através de operações booleanas regularizadas de união, intersecção ou diferença, e realizando uma varredura translacional simples, cônica ou com torção, de forma reta ou oblíqua, ou a varredura rotacional de polígono fechado ou rotacional helicoidal;

- definindo um perfil a partir de uma combinação de poli-linhas, arcos ou aproximações de curvas de forma livre, e realizando varredura rotacional simples com polígono aberto;

- fornecendo equações para definição de sólidos através de semi-espaços, aos quais é associada uma representação implícita que mantém uma ligação com a representação BRep, permitindo que procedimentos de manipulação trabalhem de maneira conjunta e sejam percebidos como um único processo [Siq94].

Uma vez obtida a descrição inicial para o objeto desejado, a representação inicial é traduzida para um modelo B-Rep, e um segundo conjunto de operações ficará disponível para efetuar alterações na forma ou na posição ocupada pelo sólido no espaço. Essas operações são ativadas pela Interface e executadas pelo Subsistema de Modelagem. Entre elas, estão: 
- as transformações geométricas, que permitem alterar a posição, orientação e tamanho dos objetos componentes de uma cena, como a translação, a rotação, o escalamento, o espelhamento e a deformação;

- as operações locais, que realizam pequenas alterações no sólido definido, ajustando a geometria das faces ou usando operadores de Euler para adicionar poucos elementos à representação interna, modificando uma região localizada da estrutura de dados de uma meneira eficiente, como a torção ("tweaking"), o chanframento e o arredondamento;

- as operaçoes globais, que combinam sólidos primitivos para gerar outros mais complexos, como a colagem, as operações booleanas de união, intersecção ou diferença, ou particionam um sólido em dois ou mais novos sólidos, como a operação de corte.

Todas as operações serão ativadas pela seleção de menus e ícones através do "mouse" e, quando conveniente, por linhas de comando textuais. Dessa maneira, o Subsistema de Interface pode incluir um analisador simples para checar a sintaxe dos comandos. A Interface deve ainda, sempre que possível, fornecer mecanismos para desfazer operações errôneas, bem como impedir a execução de operações incorretas (esse último caso requer interação com o Subsistema de Modelagem). Uma vez que o comando tenha sido analisado e considerado correto, a interface encaminha o comando ou seleção em solicitações ao Subsistema de Modelagem.

O Subsistema de Interface deve também fornecer procedimentos para visualizar os objetos sendo modelados, e para tal possui o módulo de visualização, que interage com o Subsistema de Representação. Além disso, fica a cargo deste subsistema fornecer uma interface para comunicação com outros modeladores e aplicações externas, acionar mecanismos para armazenar descrições dos sólidos em uma base de dados permanente e para efetuar a conversão entre representações.

O Subsistema de Modelagem é responsável pelo disparo das operações solicitadas pelo usuário através da interface. Caso a solicitação envolva comandos ou expressões, requer um interpretador ("parser") para analisar o comando ou expressão, checar sua validade (sintática e semântica) e ativar os procedimentos de modelagem associados.

O processo de modelagem deve acontecer sobre a representação inicial do objeto e sobre a representação B-Rep correspondente, até que ocorra uma operação que não possa ser refletida nas duas representações. Neste caso, a representação inicial não será mais alterada, podendo ser mantida para facilitar a obtenção de respostas a perguntas geométricas 
e topológicas (por exemplo, é muito mais fácil calcular o volume de uma esfera a partir dos parâmetros utilizados na primitiva - o raio - do que em sua definição B-Rep). Entretanto, se as duas representações se tornarem inconsistentes, o usuário deverá ser comunicado de que a representação inicial não mais reflete o objeto sendo modelado, sempre que esta for acessada.

O Subsistema de Representação é responsável pelo gerenciamento e acesso direto às estruturas de dados: qualquer acesso às representações de objetos exigido pelo Subsistema de Modelagem é feito através deste gerenciador. A B-Rep constitui a principal forma de representação interna do sistema, armazenando as informações topológicas e geométricas sobre os objetos, além de atributos adicionais, como cor, material, etc. É baseada na estrutura semi-aresta ("half-edge") proposta por Mäntylä [Män88], estando o sólido descrito por uma estrutura hierárquica composta pelos elementos primitivos sólido, casca ("shell"), face, ciclo ("loop"), aresta, semi-aresta e vértice.

A representação só pode ser manipulada através de algoritmos básicos de acesso que garantam a integridade topológica dos objetos. Estes algoritmos implementam os operadores de Euler e alguns procedimentos geométricos básicos. Os operadores de Euler são baseados nos descritos em [Män88], porém estendidos de forma a gerenciar a inclusão do elemento casca. Os operadores de Euler garantem a integridade topológica da representação B-Rep, e fornecem a base para a implementação dos mecanismos para desfazer operações errôneas ou indesejadas. Uma base de dados auxiliar armazena a sequência de operadores de Euler utilizados e seus parâmetros. O Subsistema de Representação cuida da construção de objetos e cenas derivados dos dados contidos nestas bases. Da mesma forma, para desfazer uma operação, o Subsistema de Representação percorre essas bases, ativando os operadores inversos.

Os procedimentos geométricos percorrem a estrutura de dados acessando e manipulando apenas as informações geométricas, e são usados para responder a questões geométricas e garantir a validade dos objetos depois da execução de uma operação local. Estes algoritmos podem ser agrupados em duas classes: os que detectam se duas entidades topológicas (face, aresta ou vértice) interceptam-se e os que detectam se uma entidade está contida em outra (algoritmos de classificação). 


\section{3 - A IMPLEMENTAÇÃO DO (SM)²}

$\mathrm{O}(\mathrm{SM})^{2}$ está sendo desenvolvido em estação de trabalho Sparc 2 da SUN Microsystems, para o ambiente "XWindow", utilizando a linguagem de programação "C" e a ferramenta "XView" [He190]. Está atualmente com cerca de 50.000 linhas de código, sendo cerca de 18.000 linhas geradas em decorrência deste trabalho.

$\mathrm{O}(\mathrm{SM})^{2}$ possui cinco módulos principais, como ilustrado na figura 5.1. Estes módulos estão sendo desenvolvidos de forma independente, ainda que funcionalmente interligados. O módulo de Representação, ou Núcleo, é responsável pela manutenção, gerenciamento e acesso a representações internas. O módulo de Modelagem é responsável pelas operações que atuam sobre a representação interna, gerando objetos e cenas e respondendo a questões geométricas e topológicas. $\mathrm{O}$ módulo de Visualização é responsável pela apresentação de detalhes da cena conforme o interesse do usuário. $O$ módulo de Interface cuida da interação com o usuário. Dando suporte a estes módulos está o Gerenciador de Arquivos, responsável pelo armazenamento e recuperação das representações e cenas em bases de dados permanentes.

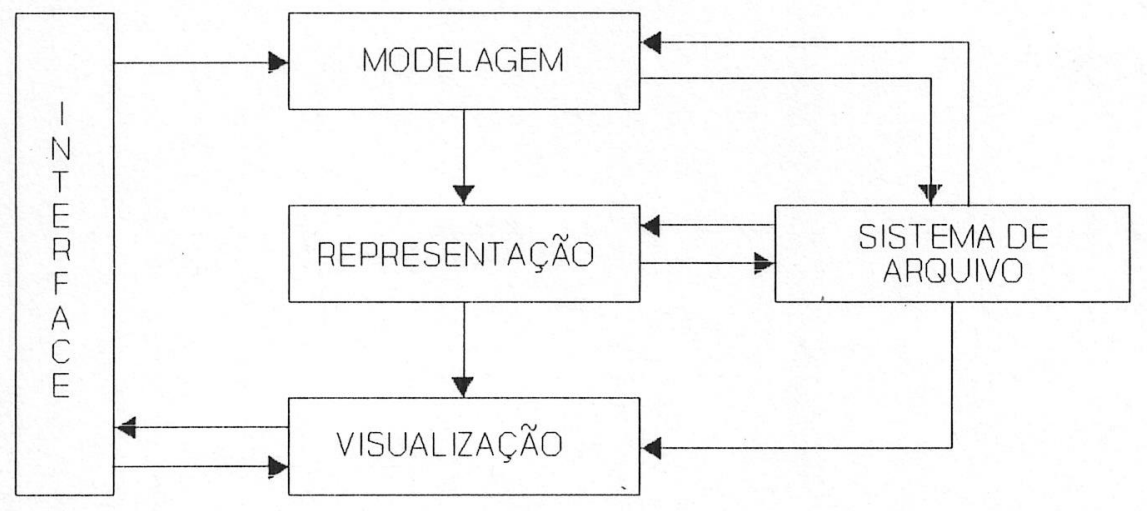

Figura 5.2 - Estrutura modular do $(\mathrm{SM})^{2}$

Além destes cinco módulos principais, dois outros foram criados: o Geral, contendo arquivos secundários (de apoio ou de uso geral) e o as, contendo arquivos acoplados ao $(\mathrm{SM})^{2}$ mas executados em separado. 


\subsection{1 - Conteúdo dos módulos do (SM) ${ }^{2}$}

Os sete módulos do $(\mathrm{SM})^{2}$ encontram-se divididos em sub-módulos, criados e distribuídos de acordo com a sua função dentro do sistema. O quadro 5.1 descreve cada um destes módulos e sub-módulos.

\begin{tabular}{|c|c|}
\hline $\begin{array}{l}\text { MÓDULO } \\
\text { SUBMÓDULO }\end{array}$ & CONTEÚDO \\
\hline AS & $\begin{array}{l}\text { sub-módulos executáveis acoplados ao }(\mathrm{SM})^{2} \text { e disparados automaticamente } \\
\text { por ele. Estão relacionados ao módulo de modelagem }\end{array}$ \\
\hline tradutor.c & $\begin{array}{l}\text { procedimentos que permitem realizar a tradução de uma equação, } \\
\text { envolvendo análise léxica, sintática e semântica, utilizados na geração de } \\
\text { sólidos por semi-espaços definidos implicitamente }\end{array}$ \\
\hline tradutor.h & inclusões de biblioteca e definições do módulo tradutor.c \\
\hline mmi.c & $\begin{array}{l}\text { procedimentos que permitem construir um novo sólido através da modelagem } \\
\text { implícita }\end{array}$ \\
\hline mmi.h & inclusões de biblioteca e definições do módulo mmi.c \\
\hline GERAL & sub-módulos de apoio ou de uso geral \\
\hline apoio.c & $\begin{array}{l}\text { procedimentos geométricos de apoio, como verificação de pertinência, } \\
\text { intersecções, etc. }\end{array}$ \\
\hline apoio.h & inclusões de biblioteca e definições do módulo apoio.c \\
\hline codlog.h & $\begin{array}{l}\text { definição das constantes equivalentes a cada operador de Euler, utilizadas } \\
\text { pelos arquivos ".log" e pelo módulo cbrep.c }\end{array}$ \\
\hline codmmi.h & $\begin{array}{l}\text { definição do formato dos dados a serem gravados nos arquivos temporários } \\
\text { referentes à representação implícita }\end{array}$ \\
\hline matriz.c & $\begin{array}{l}\text { procedimentos relacionados a operações envolvendo manipulação e obtenção } \\
\text { de matrizes }\end{array}$ \\
\hline matriz.h & inclusões de biblioteca e definições do módulo matriz.c \\
\hline $\operatorname{sm} 2 . \mathrm{c}$ & $\begin{array}{l}\text { programa principal, cuja única função é a de inicializar a interface do } \\
\text { modelador }\end{array}$ \\
\hline $\operatorname{sm} 2 . \mathrm{h}$ & $\begin{array}{l}\text { inclusões de biblioteca e definições gerais do sistema (tipos, estruturas de } \\
\text { dados, constantes) }\end{array}$ \\
\hline INTERFACE & $\begin{array}{l}\text { sub-módulos para comunicação com o usuário, visando a descrição, edição e } \\
\text { utilização dos sólidos modelados }\end{array}$ \\
\hline interfac.c & $\begin{array}{l}\text { procedimentos que manipulam a interface gráfica, identificam tarefas, } \\
\text { verificam parâmetros, ativam procedimentos de outros módulos responsáveis } \\
\text { pela execução e exibem os resultados obtidos }\end{array}$ \\
\hline interfac.h & inclusões de biblioteca e definições do módulo interfac.c \\
\hline MODELAGEM & $\begin{array}{l}\text { sub-módulos que interpretam as descrições de um novo sólido ou de uma } \\
\text { modificação e acionam procedimentos do módulo de representação para } \\
\text { criar ou alterar uma representação }\end{array}$ \\
\hline face.c & $\begin{array}{l}\text { procedimentos que permitem gerar, editar e manipular faces, como } \\
\text { transformações geométricas e operações sobre faces }\end{array}$ \\
\hline
\end{tabular}




\begin{tabular}{|c|c|}
\hline $\begin{array}{l}\text { MÓDULO } \\
\text { SUBMÓDULO }\end{array}$ & CONTEÚDO \\
\hline face.h & inclusões de biblioteca e definições do módulo face.c \\
\hline primitiv.c & $\begin{array}{l}\text { procedimentos que permitem construir um novo sólido através do } \\
\text { instanciamento de primitivas }\end{array}$ \\
\hline primitiv.h & inclusões de biblioteca e definições do módulo primitiv.c \\
\hline solido.c & $\begin{array}{l}\text { procedimentos que permitem editar e manipular sólidos, como } \\
\text { transformações geométricas e operações sobre sólidos }\end{array}$ \\
\hline solido.h & inclusões de biblioteca e definições do módulo sólido.c \\
\hline varredur.c & $\begin{array}{l}\text { procedimentos que permitem construir um novo sólido através da varredura } \\
\text { translacional ou rotacional }\end{array}$ \\
\hline varredur.h & inclusões de biblioteca e definições do módulo varredur.c \\
\hline REPRESENTAÇÃO & $\begin{array}{l}\text { sub-módulos que gerenciam as estruturas de dados existentes no sistema, } \\
\text { criando e modificando as representações }\end{array}$ \\
\hline cbrep.c & $\begin{array}{l}\text { procedimentos que permitem construir e manipular um sólido B-Rep a partir } \\
\text { dos operadores de Euler }\end{array}$ \\
\hline cbrep.h & inclusões de biblioteca e definições do módulo cbrep.c \\
\hline cena.h & $\begin{array}{l}\text { definições relacionadas às estruturas de dados existentes na cena: estrutura } \\
\text { semi_aresta e atributos de sólidos }\end{array}$ \\
\hline lista.c & $\begin{array}{l}\text { procedimentos que manipulam estruturas de dados existentes no sistema que } \\
\text { são formadas por listas }\end{array}$ \\
\hline lista.h & inclusões de biblioteca e definições do módulo lista.c \\
\hline opanivel.c & $\begin{array}{l}\text { procedimentos que implementam os operadores de Euler em alto nível } \\
\text { (manipulando entidades como arestas, semi-arestas, vértices, etc.) }\end{array}$ \\
\hline opanivel.h & inclusões de biblioteca e definições do módulo opanivel.c \\
\hline opbnivel.c & $\begin{array}{l}\text { procedimentos que implementam os operadores de Euler em baixo nível } \\
\text { (manipulando ponteiros) }\end{array}$ \\
\hline opbnivel.h & inclusões de biblioteca e definições do módulo opbnivel.c \\
\hline opcena.c & $\begin{array}{l}\text { procedimentos que manipulam as estruturas de dados referentes a cena, que } \\
\text { são formadas por listas }\end{array}$ \\
\hline opcena.h & inclusões de biblioteca e definições do módulo opcena.c \\
\hline tiposol.c & $\begin{array}{l}\text { procedimentos para colocar atributos do tipo de sólido gerado (por equação - } \\
\text { forma implícita) }\end{array}$ \\
\hline tiposol.h & inclusões de biblioteca e definições do módulo tiposol.c \\
\hline $\begin{array}{l}\text { SISTEMA DE } \\
\text { ARQUIVO }\end{array}$ & $\begin{array}{l}\text { sub-módulos que gerenciam as operações de acesso a disco: recuperação } \\
\text { (leitura) e armazenamento (gravação) }\end{array}$ \\
\hline esdisco.c & $\begin{array}{l}\text { procedimentos que manipulam recuperação e armazenamento dos arquivos } \\
\text { do tipo ".cen" e ".log" }\end{array}$ \\
\hline esdisco.h & inclusões de biblioteca e definições do módulo esdisco.c \\
\hline VISUALIZAÇÃO & $\begin{array}{l}\text { sub-módulos que permitem visualizar cenas de maneira realística, com cor, } \\
\text { iluminação, sombreamento, perspectiva, etc }\end{array}$ \\
\hline visual.c & $\begin{array}{l}\text { procedimentos que gerenciam as operações de visualização, como } \\
\text { transformações geométricas, técnicas de projeção, de sombreamento }\end{array}$ \\
\hline visual.h & definições relacionadas a parâmetros de visualização \\
\hline
\end{tabular}

Quadro 5.1 - Conteúdo dos módulos existentes no modelador (SM) ${ }^{2}$ 
$\mathrm{O}$ código encontra-se inteiramente padronizado, no que diz respeito à estrutura e formato. Os módulos ".c" possuem um arquivo de cabeçalho ".h" de mesmo nome. Além dos arquivos de cabeçalho referentes a arquivos de código, outros arquivos de cabeçalho foram criados, visando destacar definições específicas. Para facilitar o acesso, as rotinas contidas nestes arquivos foram organizadas em ordem alfabética, e sua documentação também, segue um formato padrão. Todas as rotinas são descritas na documentação de implementação [Mag94c], de acordo com o padrão ilustrado no quadro 5.2, que lista, a título de exemplo, as rotinas do módulo primitiv.c.

\begin{tabular}{|c|c|c|}
\hline \multicolumn{3}{|c|}{ MODULO : PRIMITIV.C } \\
\hline ROTINA & ENTRADAS & RETORNO \\
\hline $\begin{array}{l}\text { Acumular_curva } \\
\text { Acumula uma curva recém-definida com a } \\
\text { curva que estava sendo gerada, ligando o ponto } \\
\text { final da curva anterior com a nova curva }\end{array}$ & $\begin{array}{l}\text { nrvertcurva - número de vértices da curva anterior } \\
\text {.vertcurva - matriz contendo a curva anterior } \\
\text {.nrvertamais - número de vértices da nova curva } \\
\text { (a ser incluida) } \\
\text {.vertamais - matriz com vértices da nova curva }\end{array}$ & $\begin{array}{l}\text {.matriz contendo os vértices } \\
\text { da curva acumulada } \\
\text {.nrvertcurva - número de } \\
\text { vértices da curva acumulada }\end{array}$ \\
\hline $\begin{array}{l}\text { Bspline } \\
\text { Calcula os pontos de uma curva B-Spline, a } \\
\text { partir dos pontos de controle fornecidos }\end{array}$ & $\begin{array}{l}. \mathrm{u} \text { - parâmetro para calcular o ponto da curva } \\
\mathrm{n} \text { - número de pontos de controle } \\
. \mathrm{k} \text { - ordem de continuidade da curva } \\
\text { pontos - ponteiro p/ matriz de pontos de controle }\end{array}$ & $\begin{array}{l}. x \text { - valor resultante para a } \\
\text { coordenada } x \\
. y-\text { valor resultante para a } \\
\text { coordenada } y \\
\end{array}$ \\
\hline $\begin{array}{l}\text { Bspline_no } \\
\text { Calcula o valor do no', que relaciona o } \\
\text { parâmetro u com os pontos de controle para a } \\
\text { geração da curva B-Spline }\end{array}$ & i - nó sendo considerado & $\begin{array}{l}.0 \text { se } i<k \\
(i-k+1) \text { se } k<=i<=n \\
(n-k+2) \text { se } i>n\end{array}$ \\
\hline $\begin{array}{l}\text { Bspline_peso } \\
\text { Calcula a função peso para uma curva do tipo } \\
\text { B-Spline }\end{array}$ & $\begin{array}{l}. \mathrm{i} \text { - no' sendo considerado } \\
. \mathrm{k} \text { - ordem de continuidade da curva } \\
. \mathrm{u} \text { - parâmetro que está sendo utilizado }\end{array}$ & valor para a função peso \\
\hline $\begin{array}{l}\text { Criar_bloco } \\
\text {.Recebe um quadrilátero, define os vértices e o } \\
\text { preenchimento para um bloco, posiciona no } \\
\text { espaço e gera a estrutura B-Rep correspondente }\end{array}$ & $\begin{array}{l}\text {.nrvertices - número de vértices da base geradora } \\
\text {.vertices - matriz contendo os vértices da base } \\
\text { (utiliza variáveis globais da interface) }\end{array}$ & .nenhum \\
\hline $\begin{array}{l}\text { Criar_cilindro } \\
\text { Recebe um círculo ou elipse, define os vértices } \\
\text { e o preenchimento para um cilindro, posiciona } \\
\text { no espaço e gera a estrutura B-Rep } \\
\text { correspondente }\end{array}$ & $\begin{array}{l}\text {.nrvertices - número de vértices da base geradora } \\
\text {.vertices - matriz contendo os vértices da base } \\
\text { (utiliza variáveis globais da interface) }\end{array}$ & .nenhum \\
\hline $\begin{array}{l}\text { Criar_cone } \\
\text {.Recebe um círculo ou elipse, define os vértices } \\
\text { e o preenchimento para um cone, posiciona no } \\
\text { espaço e gera a estrutura B-Rep correspondente }\end{array}$ & $\begin{array}{l}\text {.nrvertices - número de vértices da base geradora } \\
\text {.vertices - matriz contendo os vértices da base } \\
\text { (utiliza variáveis globais da interface) }\end{array}$ & .nenhum \\
\hline $\begin{array}{l}\text { Criar_esfera } \\
\text { Recebe um arco, define os vértices e o } \\
\text { preenchimento para uma esfera, posiciona no } \\
\text { espaço e gera a estrutura B-Rep correspondente }\end{array}$ & $\begin{array}{l}\text {.nrvertices - número de vértices do arco gerador } \\
\text {.vertices - matriz contendo os vértices do arco } \\
\text { (utiliza variáveis globais da interface) }\end{array}$ & .nenhum \\
\hline $\begin{array}{l}\text { Criar_piramide } \\
\text { Recebe um polígono, define os vértices e o } \\
\text { preenchimento para uma pirâmide, posiciona no } \\
\text { espaço e gera a estrutura B-Rep correspondente }\end{array}$ & $\begin{array}{l}\text {.nrvertices - número de vértices da base geradora } \\
\text {.vertices - matriz contendo os vértices da base } \\
\text { (utiliza variáveis globais da interface) }\end{array}$ & .nenhum \\
\hline $\begin{array}{l}\text { Criar_prisma } \\
\text { Recebe um polígono, define os vértices e o : } \\
\text { preenchimento para um prisma, posiciona no } \\
\text { espaço e gera a estrutura B-Rep correspondente }\end{array}$ & $\begin{array}{l}\text {.nrvertices - número de vértices da base geradora } \\
\text {.vertices - matriz contendo os vértices da base } \\
\text { (utiliza variáveis globais da interface) }\end{array}$ & .nenhum \\
\hline
\end{tabular}




\begin{tabular}{|c|c|c|}
\hline \multicolumn{3}{|c|}{ MODULO : PRIMITIV.C } \\
\hline ROTINA & ENTRADAS & RETORNO \\
\hline $\begin{array}{l}\text { Criar_toro } \\
\text { Recebe um círculo ou elipse, define os vértices } \\
\text { e o preenchimento para um toro, posiciona no } \\
\text { espaço e gera a estrutura B-Rep correspondente }\end{array}$ & $\begin{array}{l}\text {.nrvertices - número de vértices da base geradora } \\
\text {.vertices - matriz contendo os vértices da base } \\
\text { (utiliza variáveis globais da interface) }\end{array}$ & nenhum \\
\hline $\begin{array}{l}\text { Gerar_vertices_arco } \\
\text { Captura diversas variáveis globais e obtem } \\
\text { entre elas os pontos necessários para gerar um } \\
\text { arco, definido através de seus vértices }\end{array}$ & $\begin{array}{l}\text {.nenhum } \\
\text { (utiliza variáveis globais da interface) }\end{array}$ & $\begin{array}{l}\text { matriz contendo os vértices } \\
\text { que definem o arco, } \\
\text { ou NULL caso as variáveis } \\
\text { utilizadas não permitam } \\
\text { defini-lo corretamente }\end{array}$ \\
\hline $\begin{array}{l}\text { Gerar_vertices_espessura } \\
\text { Gera os vértices para a casca interna do sólido, } \\
\text { quando seu preeenchimento é oco ou vazado }\end{array}$ & $\begin{array}{l}\text {.nrvertsolido - número de vértices do sólido } \\
\text {.solido - matriz contendo os vértices do sólido } \\
\text {.tipo preenchimento - oco ou vazado } \\
\text {.tipo solido - tipo do sólido sendo gerado } \\
\text {.tipo figura - tipo da figura que define a base } \\
\text {.espessura - fator de escala que define a espessura } \\
\text {.dx, dy - deslocamento em x e y (p/ sólido obliquo) }\end{array}$ & $\begin{array}{l}\text { matriz contendo os vértices } \\
\text { que definem a casca interna, } \\
\text { ou NULL caso as variáveis } \\
\text { utilizadas não permitam } \\
\text { defini-la corretamente }\end{array}$ \\
\hline $\begin{array}{l}\text { Gerar_vertices_círculo } \\
\text { Captura diversas variáveis globais e obtem } \\
\text { entre elas os pontos necessários para gerar um } \\
\text { círculo, definido através de seus vértices }\end{array}$ & $\begin{array}{l}\text { nenhum } \\
\text { (utiliza variáveis globais da interface) }\end{array}$ & $\begin{array}{l}\text { matriz contendo os vértices } \\
\text { que definem o círculo, ou } \\
\text { NULL caso as variáveis } \\
\text { utilizadas não permitam } \\
\text { defini-lo corretamente }\end{array}$ \\
\hline $\begin{array}{l}\text { Gerar_vertices_curva_livre } \\
\text {.Utiliza os pontos de controle recebidos para } \\
\text { gerar uma curva pseudo B-Spline, definida } \\
\text { através de seus vértices }\end{array}$ & $\begin{array}{l}\text {.nenhum } \\
\text { (utiliza variáveis globais da interface) }\end{array}$ & $\begin{array}{l}\text { matriz contendo os vértices } \\
\text { que definem a curva livre, ou } \\
\text { NULL caso as variáveis } \\
\text { utilizadas não permitam } \\
\text { defini-la corretamente }\end{array}$ \\
\hline $\begin{array}{l}\text { Gerar_vertices_elipse } \\
\text {.Captura diversas variáveis globais e obtem } \\
\text { entre elas os pontos necessários para gerar uma } \\
\text { elipse, definida através de seus vértices }\end{array}$ & $\begin{array}{l}\text {.nenhum } \\
\text { (utiliza variáveis globais da interface) }\end{array}$ & $\begin{array}{l}\text { matriz contendo os vértices } \\
\text { que definem a elipse } \\
\text { ou NULL caso as variáveis } \\
\text { utilizadas não permitam } \\
\text { defini-la corretamente }\end{array}$ \\
\hline $\begin{array}{l}\text { Gerar_vértices_poli_linha } \\
\text {.Consiste os pontos que definem a poli-linha } \\
\text { quanto a colinearidade e interseções }\end{array}$ & $\begin{array}{l}\text { nenhum } \\
\text { (utiliza variáveis globais da interface) }\end{array}$ & $\begin{array}{l}\text { matriz contendo os vértices } \\
\text { que definem a poli-linha } \\
\text { ou NULL caso não passem } \\
\text { pela consistencia realizada }\end{array}$ \\
\hline $\begin{array}{l}\text { Gerar_vertices_poligono } \\
\text {.Captura diversas variáveis globais e obtem } \\
\text { entre elas os pontos necessários para gerar o } \\
\text { polígono do tipo especificado, definido através } \\
\text { de seus vértices }\end{array}$ & $\begin{array}{l}\text { nenhum } \\
\text { (utiliza variáveis globais da interface) }\end{array}$ & $\begin{array}{l}\text { matriz contendo os vértices } \\
\text { que definem o polígono, ou } \\
\text { NULL caso as variaveis } \\
\text { utilizadas não permitam } \\
\text { defini-lo corretamente }\end{array}$ \\
\hline $\begin{array}{l}\text { Gerar_vertices_quadrilatero } \\
\text {.Captura diversas variáveis globais e obtem } \\
\text { entre elas os pontos necessărios para gerar o } \\
\text { quadrilátero do tipo especificado, definidos } \\
\text { através de seus vértices }\end{array}$ & $\begin{array}{l}\text { nenhum } \\
\text { (utiliza variáveis globais da interface) }\end{array}$ & $\begin{array}{l}\text { matriz contendo os vértices } \\
\text { que definem o quadrilátero, } \\
\text { ou NULL caso as variáveis } \\
\text { utilizadas não permitam } \\
\text { defini-lo corretamente }\end{array}$ \\
\hline $\begin{array}{l}\text { Gerar_vertices_triangulo } \\
\text {.Captura diversas variáveis globais e obtem } \\
\text { entre elas os pontos necessários para gerar o } \\
\text { triângulo do tipo especificado, definidos através } \\
\text { de seus vértices }\end{array}$ & $\begin{array}{l}\text { nenhum } \\
\text { (utiliza variáveis globais da interface) }\end{array}$ & $\begin{array}{l}\text { matriz contendo os vértices } \\
\text { que definem o triângulo, ou } \\
\text { NULL caso as variáveis } \\
\text { utilizadas não permitam } \\
\text { defini-lo corretamente }\end{array}$ \\
\hline
\end{tabular}

Quadro 5.2 - Descrição dos procedimentos e funções do módulo Primitiv.c 


\subsection{2 - O núcleo do (SM) ${ }^{2}$}

O Núcleo do modelador $(\mathrm{SM})^{2}$ possui dois componentes principais: o Gerenciador de Representações, que permite o acesso e a manipulação das estruturas de dados envolvidas, e o Construtor, que cuida da construção de objetos e cenas derivados dos dados contidos nestas estruturas. A representação interna principal utiliza uma variação da estrutura semi-aresta ("half-edge") proposta por Mäntylä [Män88]. Nesta representação, o sólido é descrito por uma estrutura hierárquica composta pelos elementos primitivos sólido, casca ("shell"), face, ciclo ("loop"), aresta, semi-aresta e vértice, apresentada na figura 5.2. O quadro 5.3 ilustra e descreve, através de fragmentos de código em linguagem " $\mathrm{C}$ ", cada componente desta estrutura de dados.

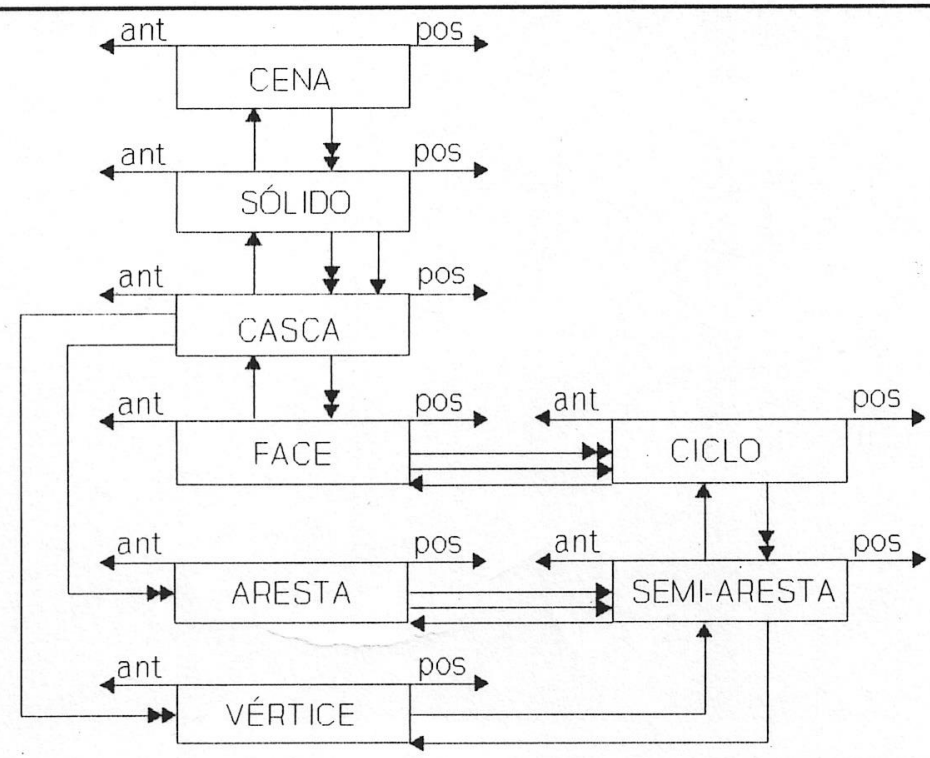

Figura 5.3 - Visão hierárquica da estrutura de dados utilizada no (SM) ${ }^{2}$

Atua sobre esta estrutura de dados um conjunto de operadores de Euler, baseados nos operadores descritos em [Män88], porém estendidos de forma a gerenciar a inclusão do elemento casca. Uma descrição completa dos operadores de Euler utilizados, bem como exemplos de como utilizá-los no contexto do (SM)² é encontrada em [Mag94a].

A estrutura atual suporta apenas objetos poliedrais. Desta forma, faces curvas existentes nos objetos são aproximadas por facetas planares, levando em consideração a precisão estabelecida pelo usuário. Pretende-se futuramente estender a representação B-Rep para descrever objetos com faces curvas de forma exata. 


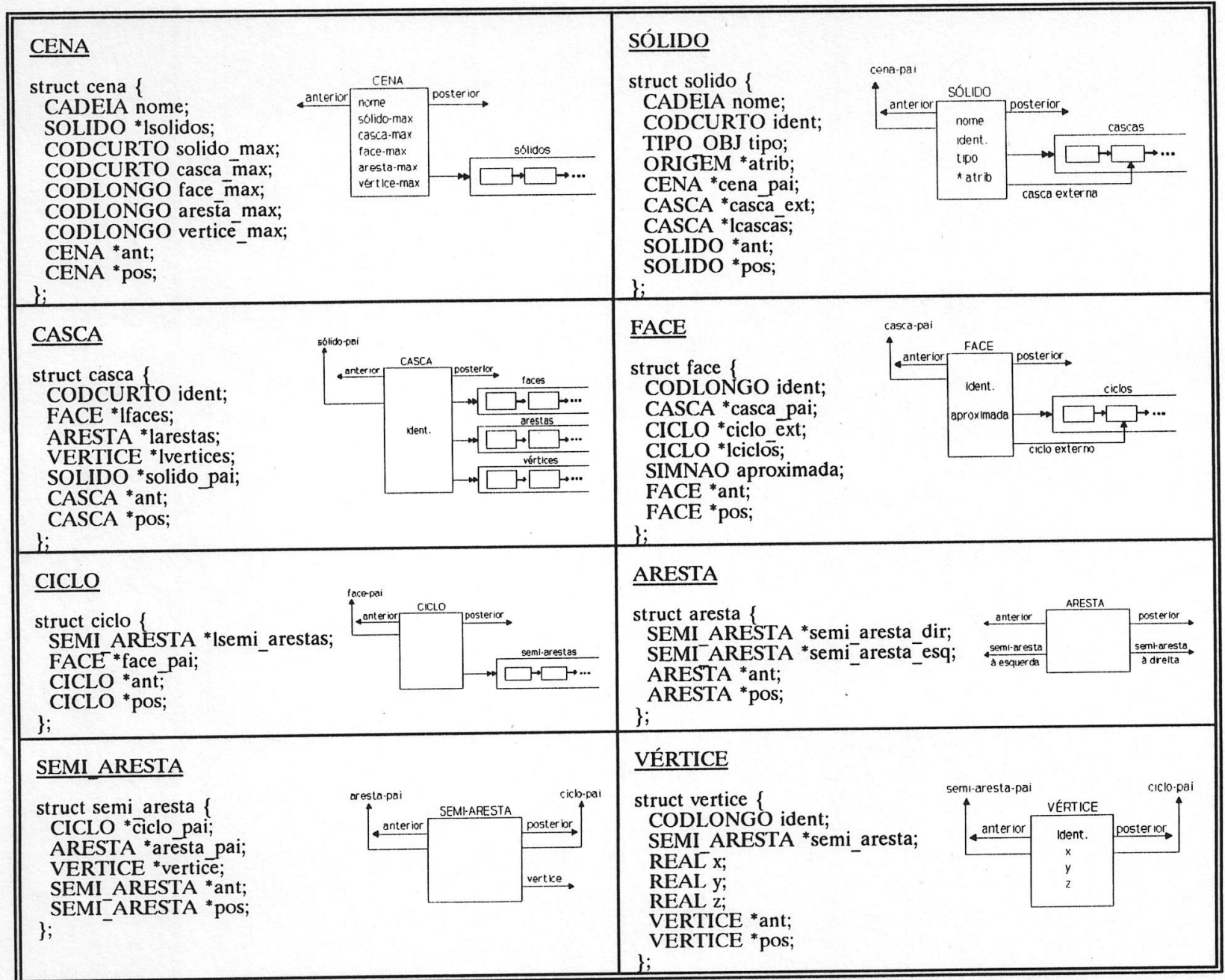

Quadro 5.3 - Componentes da estrutura de dados B-Rep do (SM) ${ }^{2}$

\subsection{3 - A modelagem de sólidos}

Como já foi visto, a geração de uma primitiva envolve a definição de uma curva ou face geradora e a sua varredura translacional ou rotacional por um caminho definido pelo tipo de primitiva e parâmetros fornecidos. Assim sendo, a forma de construção de um sólido B-Rep independe do fato de ter sido definido por instanciamento de primitivas ou por varredura, pois, em síntese, sempre está ocorrendo a varredura. Baseado nesta constatação, a construção de sólidos por instanciamento de primitivas ou varredura no (SM) ${ }^{2}$ envolve um único tipo de arquivo, denominado Log B-Rep, que possui a extensão padrão ".log", descrito a seguir. 
O arquivo ".log" é um arquivo texto criado para armazenar as operações B-Rep aplicadas na construção de um sólido B-Rep. Cada linha contém um operador de Euler e seus respectivos argumentos, que geram a estrutura semi-aresta correspondente ao sólido, descrita no ítem 5.3.1. O formato de cada linha depende do operador aplicado. $\mathrm{O}$ quadro 5.4 a seguir apresenta a lista de operadores e seus respectivos formatos. O quadro 5.5 descreve os argumentos, apontando seu tipo, formato e significado. Maiores detalhes sobre este arquivo, bem como sobre os tipos abstratos de dados envolvidos podem ser obtidos na documentação de implementação do $(\mathrm{SM})^{2}$ [Mag94c]. Exemplos de arquivos ".log" são apresentados em [Mag94a].

\begin{tabular}{|c|c|c|}
\hline OPERADOR & FORMATO & DADOS \\
\hline KEF & "\%d \%hd \%hd \%lu \%lu \n" & cod_op, sn1, cn, vn1, vn2 \\
\hline KEMR & $\begin{array}{l}\text { "\%d \%hd \%hd \%lu \%lu \%lu } \\
\backslash \text { n" }\end{array}$ & cod_op, sn1, cn, fn1, vn1, vn2 \\
\hline KEV & $\begin{array}{l}\text { "\%d \%hd \%hd \%lu \%lu \%lu } \\
\backslash \text { n" }\end{array}$ & cod_op, sn1, cn, fn1, vn1, vn2 \\
\hline KFMRH & "\%d \%hd \%lu \%lu \n" & cod_op, sn1, fn1, fn2 \\
\hline KSHMS & "\%d \%s \%hd \%hd \%hd \n" & cod_op, nome, sn1, sn2, cn \\
\hline KVFSHS & "\%d \%hd \n" & cod_op, sn1 \\
\hline MEF & $\begin{array}{l}\text { "\%d \%hd \%hd \%lu \%lu \%lu } \\
\% \text { lu \%lu \%lu \%hd \%d } \backslash \text { n" }\end{array}$ & $\begin{array}{l}\text { cod_op, sn1, cn, fn1, vn1, vn2, } \\
\text { vn3, vn4, fn2, at, ap }\end{array}$ \\
\hline MEKR & $\begin{array}{l}\text { "\%d \%hd \%hd \%lu \%lu \%lu } \\
\% \text { lu \%lu \n" }\end{array}$ & $\begin{array}{l}\text { cod_op, sn1, cn, fn1, vn1, vn2, } \\
\text { vn3, vn4 }\end{array}$ \\
\hline MEV & $\begin{array}{l}\text { "\%d \%hd \%hd \%lu \%lu \%lu } \\
\% \text { lu \%lu \%lu \%lf \%lf \%lf } \backslash \text { " }\end{array}$ & $\begin{array}{l}\text { cod_op, sn1, cn, fn1, fn2, vn1, } \\
\text { vn2, vn3, vn4, x, y, z }\end{array}$ \\
\hline MFKRH & $\begin{array}{l}\text { "\%d \%hd \%hd \%lu \%lu \%lu } \\
\% \text { \%lu \%lu \%lu \n" }\end{array}$ & $\begin{array}{l}\text { cod_op, sn1, cn, fn1, vn1, vn2, } \\
\text { fn2 }\end{array}$ \\
\hline MSHKS & "\%d \%hd \%hd \n" & cod_op, sn1, sn2 \\
\hline MVFSHS & $\begin{array}{l}\text { "\%d \%s \%d \%hd \%hd \%hd } \\
\% \text { \% \% \%lu \%lf \%lf \%lf } \backslash \mathrm{n} "\end{array}$ & $\begin{array}{l}\text { cod_op, nome, tipo, sn1, cn, at } \\
\text { ap, fn1, vn1, x, y, z }\end{array}$ \\
\hline COLA_CASCA & "\%d \%hd \%lu \%lu \n" & cod_op, sn1, fn1, fn2 \\
\hline COLA_SÓLIDO & "\%d \%hd \%hd \%lu \%lu \n" & cod_op, sn1, sn2, fn1, fn2 \\
\hline
\end{tabular}

Quadro 5.4 - Operadores de Euler e seus respectivos formatos 


\begin{tabular}{||c|c|l|c||}
\hline \hline ARGUMENTO & TIPO & \multicolumn{1}{|c|}{ DESCRIÇÃO } & FORMATO \\
\hline \hline cod_op & int & Constante que identifica o operador & $\% \mathrm{~d}$ \\
\hline sn1 & CODCURTO & Identificador do primeiro sólido & $\%$ hd \\
\hline sn2 & CODCURTO & Identificador do segundo sólido & $\%$ hd \\
\hline cn & CODCURTO & Identificador da casca & $\%$ hd \\
\hline fn1 & CODLONGO & Identificador da primeira face & $\%$ lu \\
\hline fn2 & CODLONGO & Identificador da segunda face & $\%$ lu \\
\hline vn1 & CODLONGO & Identificador do primeiro vértice & $\%$ lu \\
\hline vn2 & CODLONGO & Identificador do segundo vértice & $\%$ lu \\
\hline vn3 & CODLONGO & Identificador do terceiro vértice & $\%$ lu \\
\hline vn4 & CODLONGO & Identificador do quarto vértice & $\%$ lu \\
\hline $\mathrm{x}$ & REAL & Coordenada $x$ do vértice a ser criado & $\%$ lf \\
\hline $\mathrm{y}$ & REAL & Coordenada y do vértice a ser criado & $\%$ lf \\
\hline $\mathrm{z}$ & REAL & Coordenada $\mathrm{z}$ do vértice a ser criado & $\%$ lf \\
\hline nome & CADEIA & Nome do sólido & $\% \mathrm{~s}$ \\
\hline tipo & TIPO_OBJ & Tipo do sólido & $\%$ d \\
\hline at & CODCURTO & Identificador da lista de atributos & $\%$ hd \\
\hline ap & SIMNAO & Identificador de face aproximada & $\%$ d \\
\hline \hline
\end{tabular}

Quadro 5.5 - Lista de argumentos dos operadores de Euler, utilizados nos arquivos ".log"

\subsection{4 - A visualização de objetos}

$\mathrm{O}(\mathrm{SM})^{2}$ permite duas formas de visualizar os sólidos presentes em uma cena: a forma fio-de-arame ("wire-frame") e a forma iluminada ("shaded"). A forma fio-de-arame desenha apenas as arestas dos sólidos, sem remover as linhas ocultas. É uma forma rápida de se obter o desenho da cena, e por isso é sempre utilizada quando a cena sofre alguma alteração. Já a forma iluminada permite uma visualização ("rendering") mais próxima do real, mais atraente, escondendo as partes ocultas dos sólidos e retirando as ambigüidades que a forma fio-de-arame apresenta. A forma de visualização iluminada permite uma compreensão melhor dos sólidos obtidos e a geração de alguns efeitos de iluminação, como sombras e transparência. Como a geração de uma cena iluminada é lenta, ela só é executada quando selecionada. Maiores detalhes sobre os algoritmos e estruturas de dados utilizadas na visualização de uma cena iluminada no $(\mathrm{SM})^{2}$ podem ser obtidos em [Ces94]. 


\subsection{5 - A interface}

O módulo de interface atualmente disponível é provisório, deixando a desejar com relação à facilidade de uso e flexibilidade. A ausência de uma facilidade para apontar os elementos ao invés de fornecer identificadores torna o modelador difícil de ser utilizado em uma aplicação prática. Além disto, é necessário desenvolver mecanismos que permitam utilizar os objetos modelados em aplicações que despertem interesse prático. Uma versão definitiva da interface deverá ser direcionada ao conjunto de aplicações para as quais se deseja utilizar o modelador. Uma aplicação mais imediata seria a visualização de objetos no ensino de geometria, o que requer, por exemplo, operações de seccionamento e cálculo de áreas e volumes. Também já está prevista na interface a inclusão de operações de edição de sólidos, como operações de modificação local e global, bem como recursos para desfazer operações ou refazer sólidos. Essas extensões têm por objetivo habilitar o uso do modelador como ferramenta de apoio a pesquisas em algoritmos e aplicações na área de CAD.

\section{4 - EXEMPLOS DE UTILIZAÇÃO}

A seguir, são apresentados alguns exemplos de sólidos gerados por instanciamento de primitivas e varreduras translacional e rotacional através do $(\mathrm{SM})^{2}$. No diretório /modela/trab estão disponíveis os arquivos contendo as cenas armazenadas em disco referentes aos exemplos listados, bem como vários outros arquivos contendo exemplos adicionais (arquivos ".cen"). Também estão disponíveis exemplos da seqüência de operadores de Euler utilizados na construção de sólidos B-Rep (arquivos ".log"). Informações sobre a utilização do sistema para a geração e visualização de sólidos podem ser obtidas no Manual do Usuário [Mag94d]. 


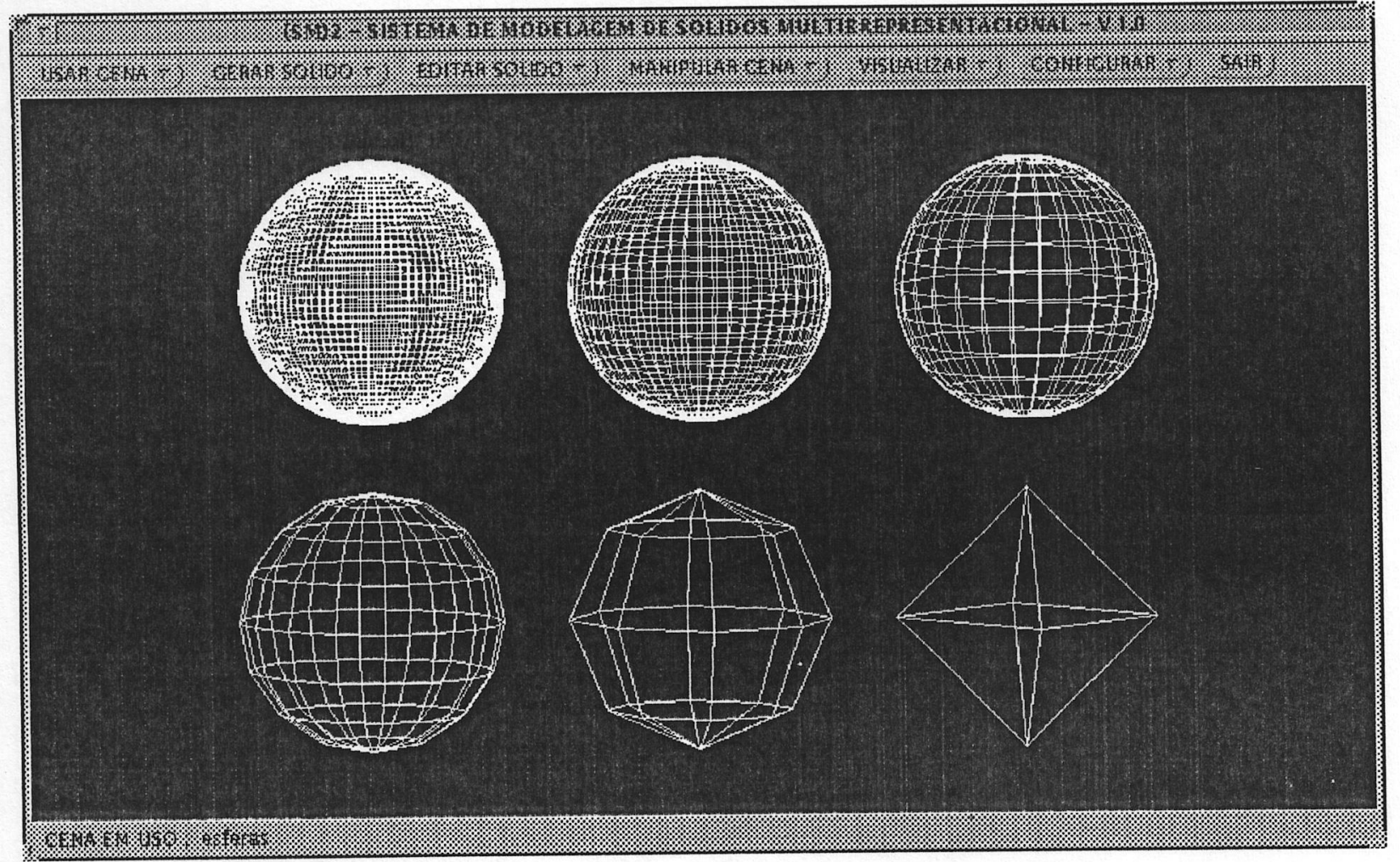

Figura 5.4 - Primitiva esfera do $(\mathrm{SM})^{2}$, em diferentes resoluções

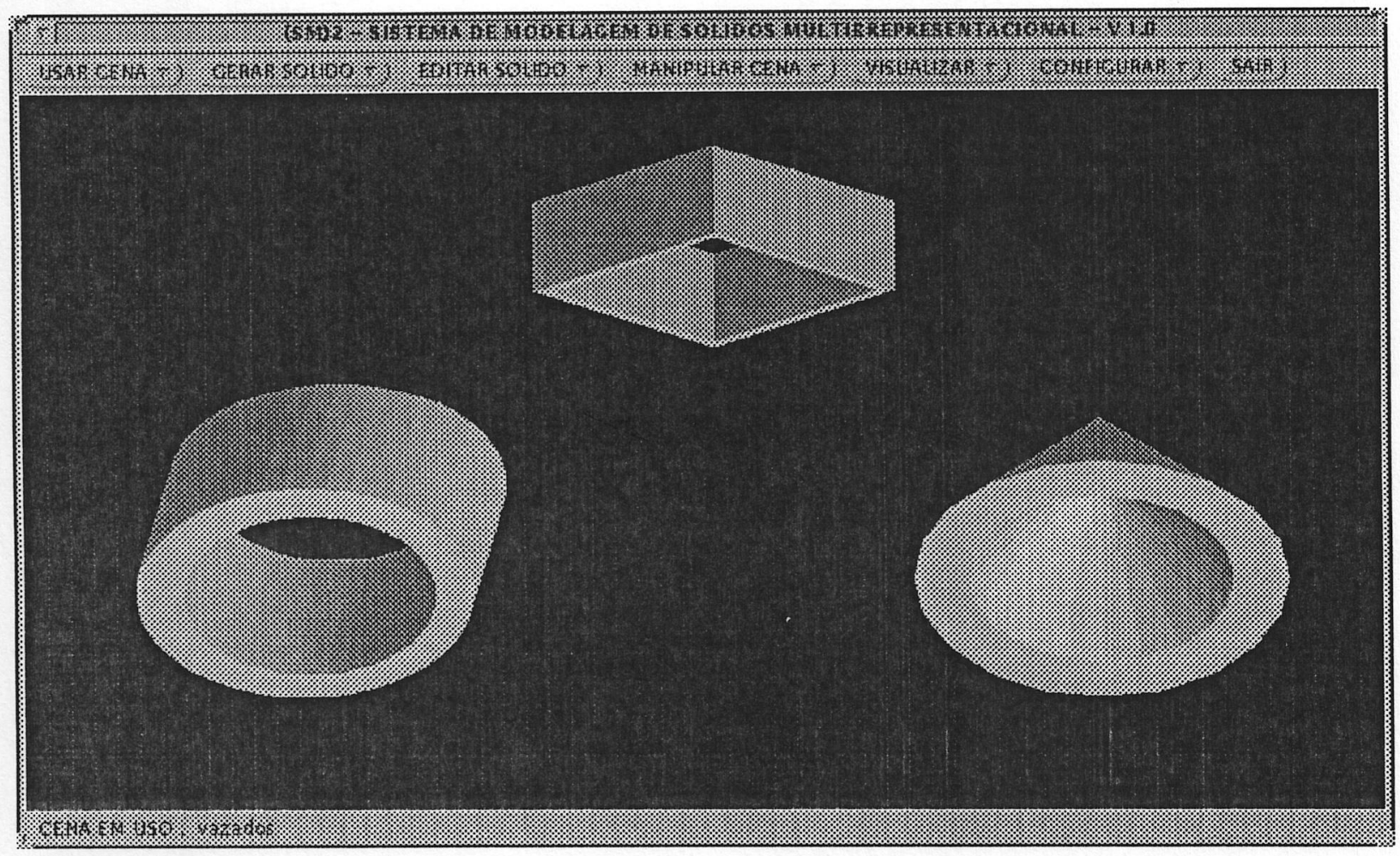

Figura 5.5 - Exemplos de primitivas vazadas (cilindro, bloco e cone), iluminadas com Flat Shading 


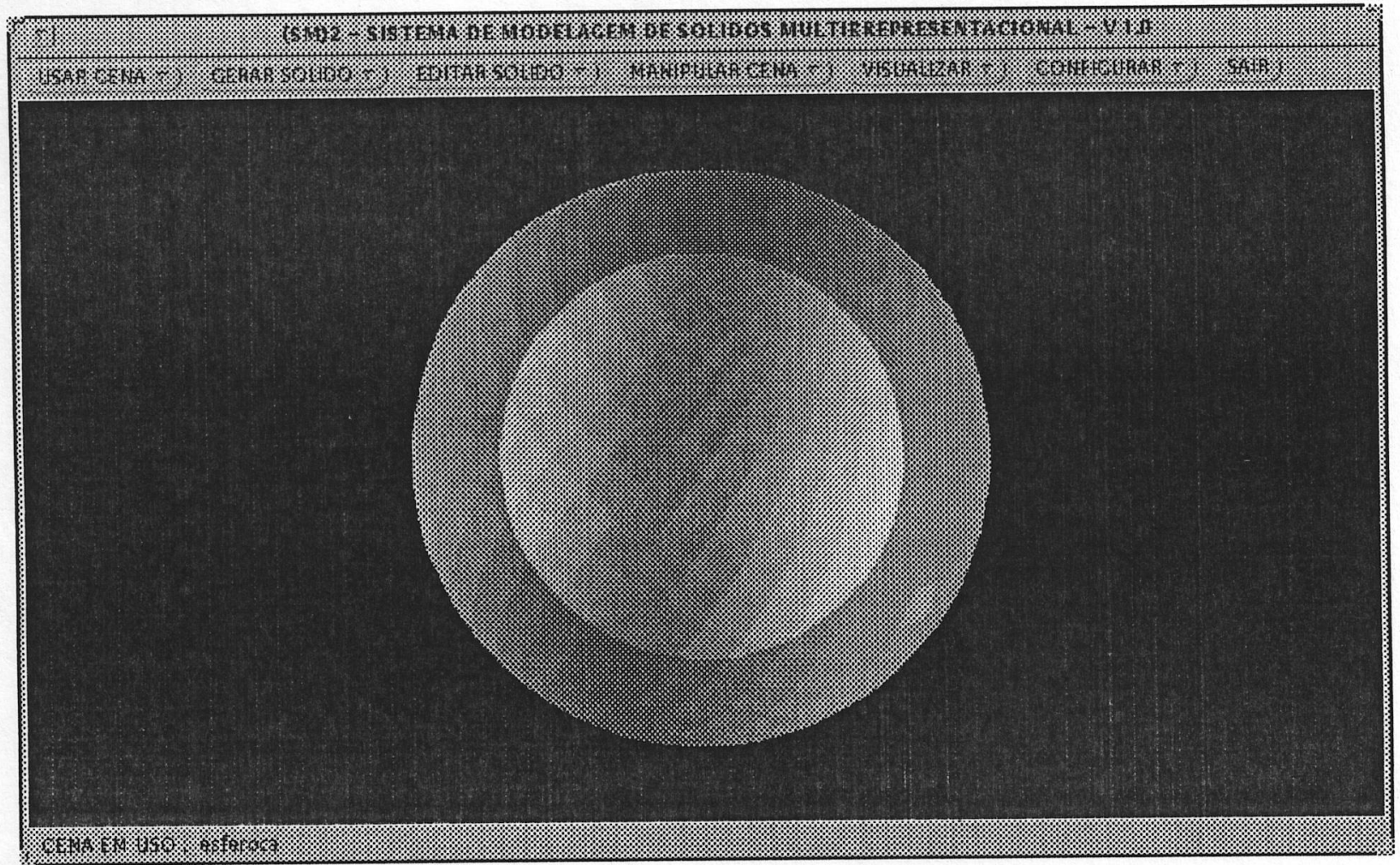

Figura 5.6 - Esfera oca, iluminada com Flat Shading e efeito de transparência

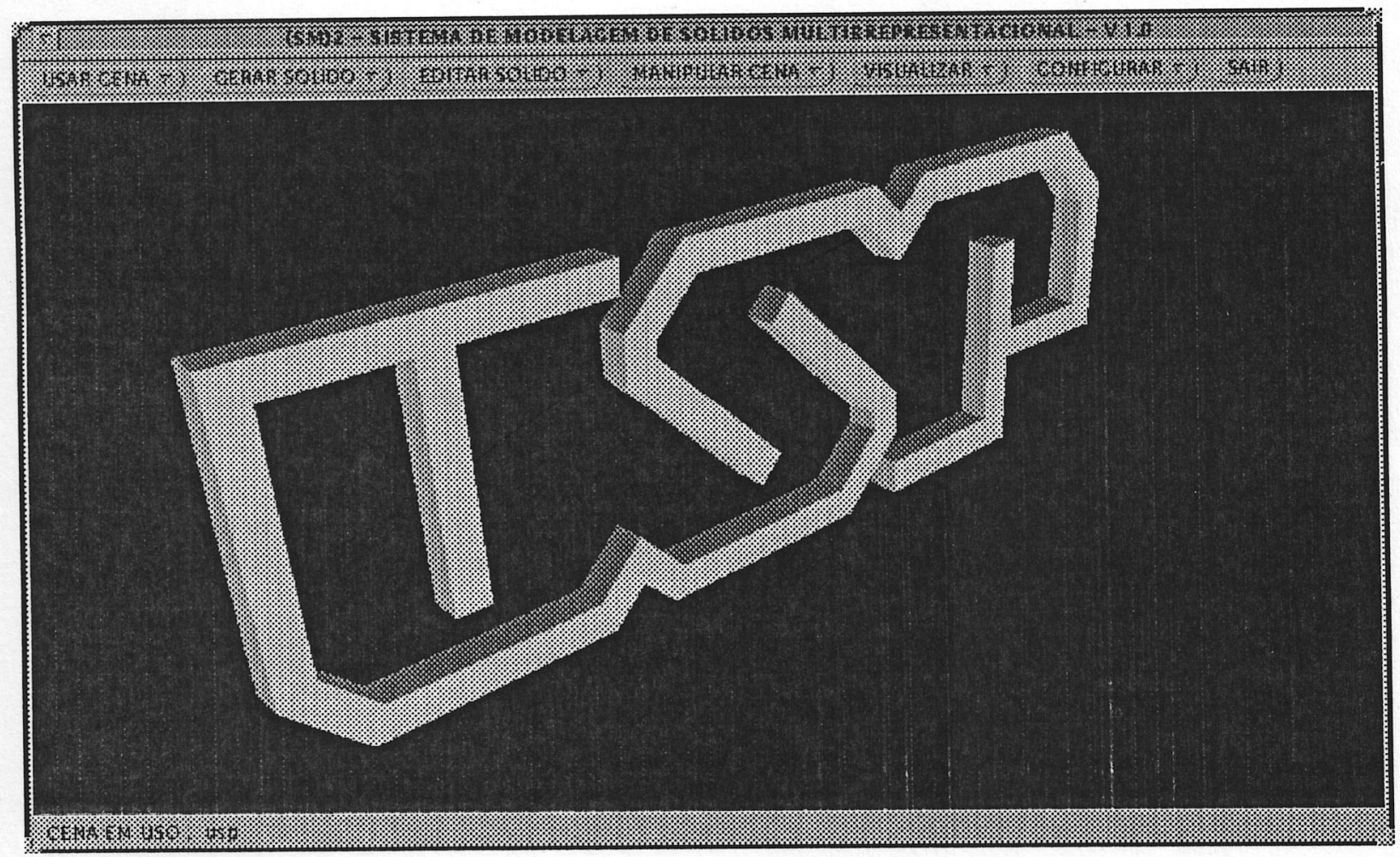

Figura 5.7 - Modelos gerados por varredura translacional simples de polígono definido através de seus pontos (Flat Shading) 


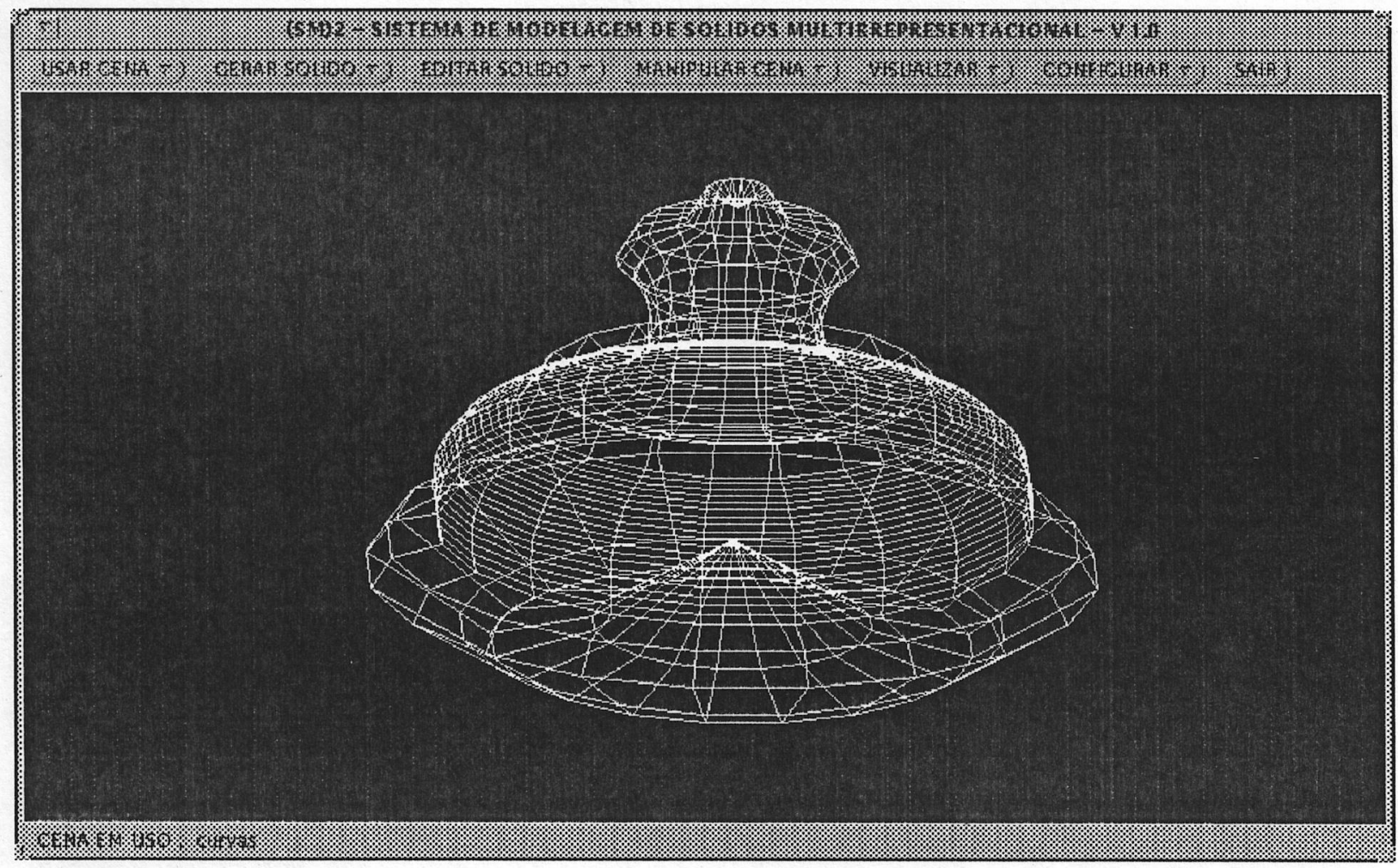

Figura 5.8 - Modelo gerado por varredura rotacional de uma curva definida por B-Spline, poli-linha e arco

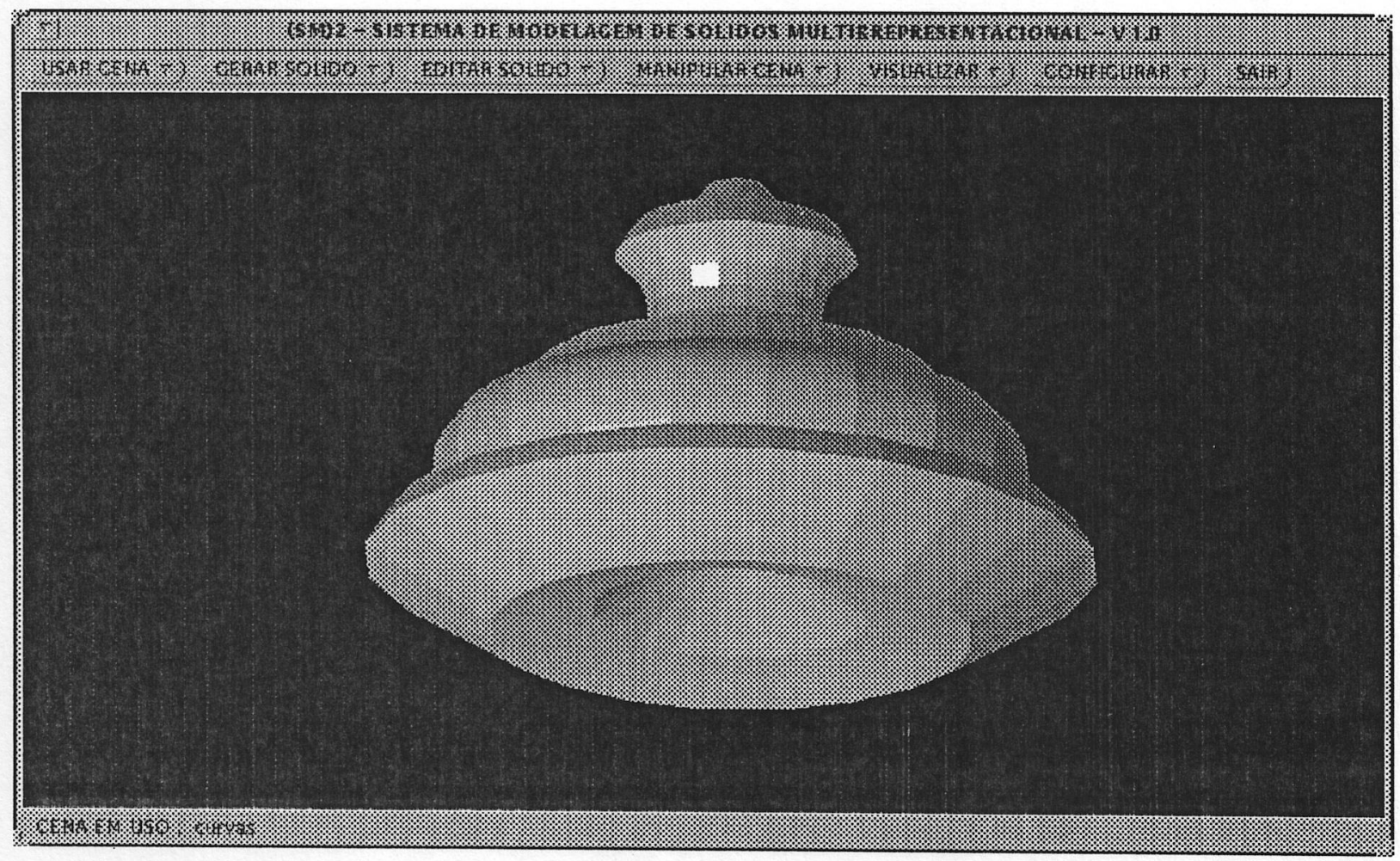

Figura 5.9 - O mesmo modelo da figura anterior, iluminado com Flat Shading 


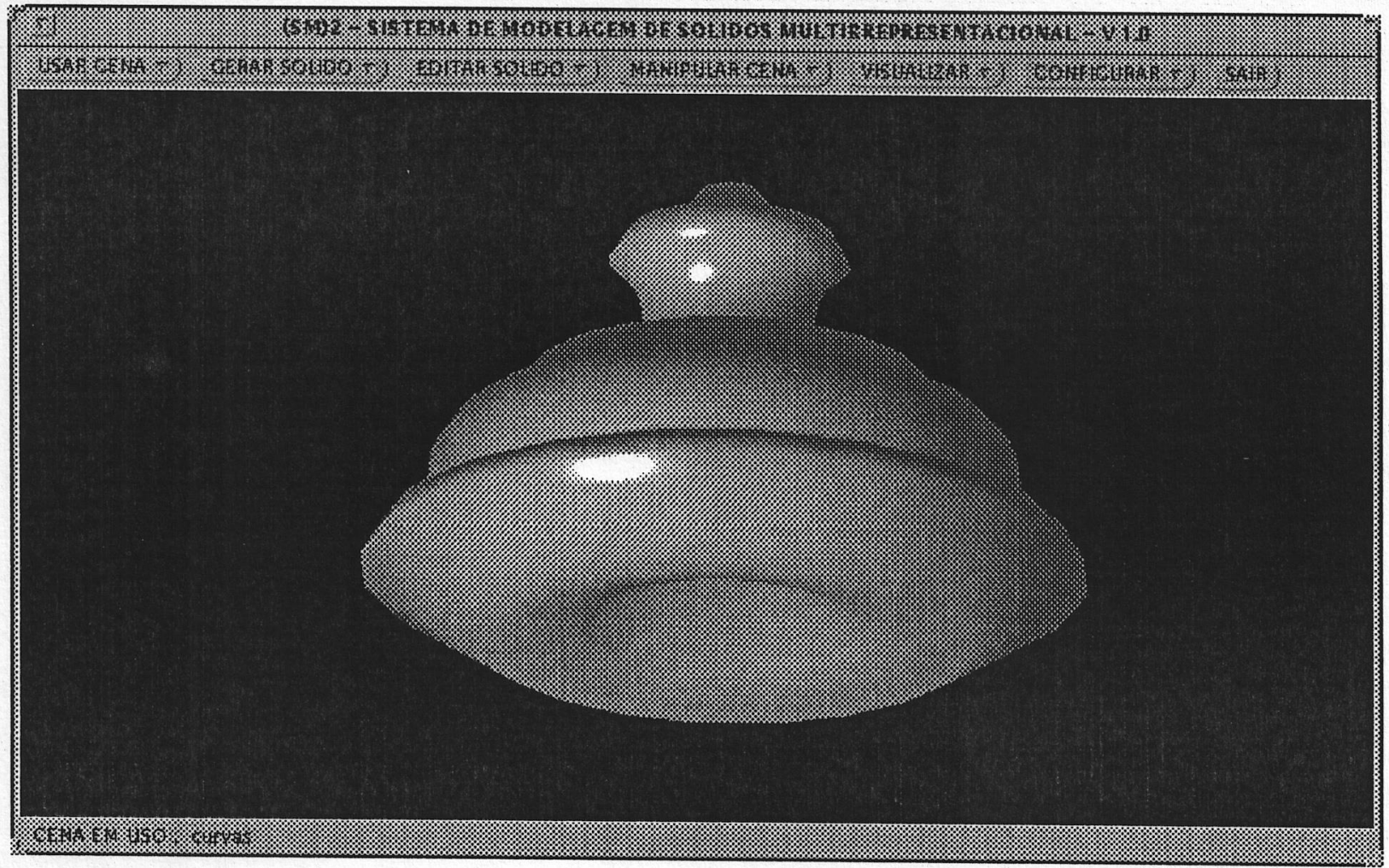

Figura 5.10 - O mesmo modelo da figura anterior, iluminado com Phong Shading

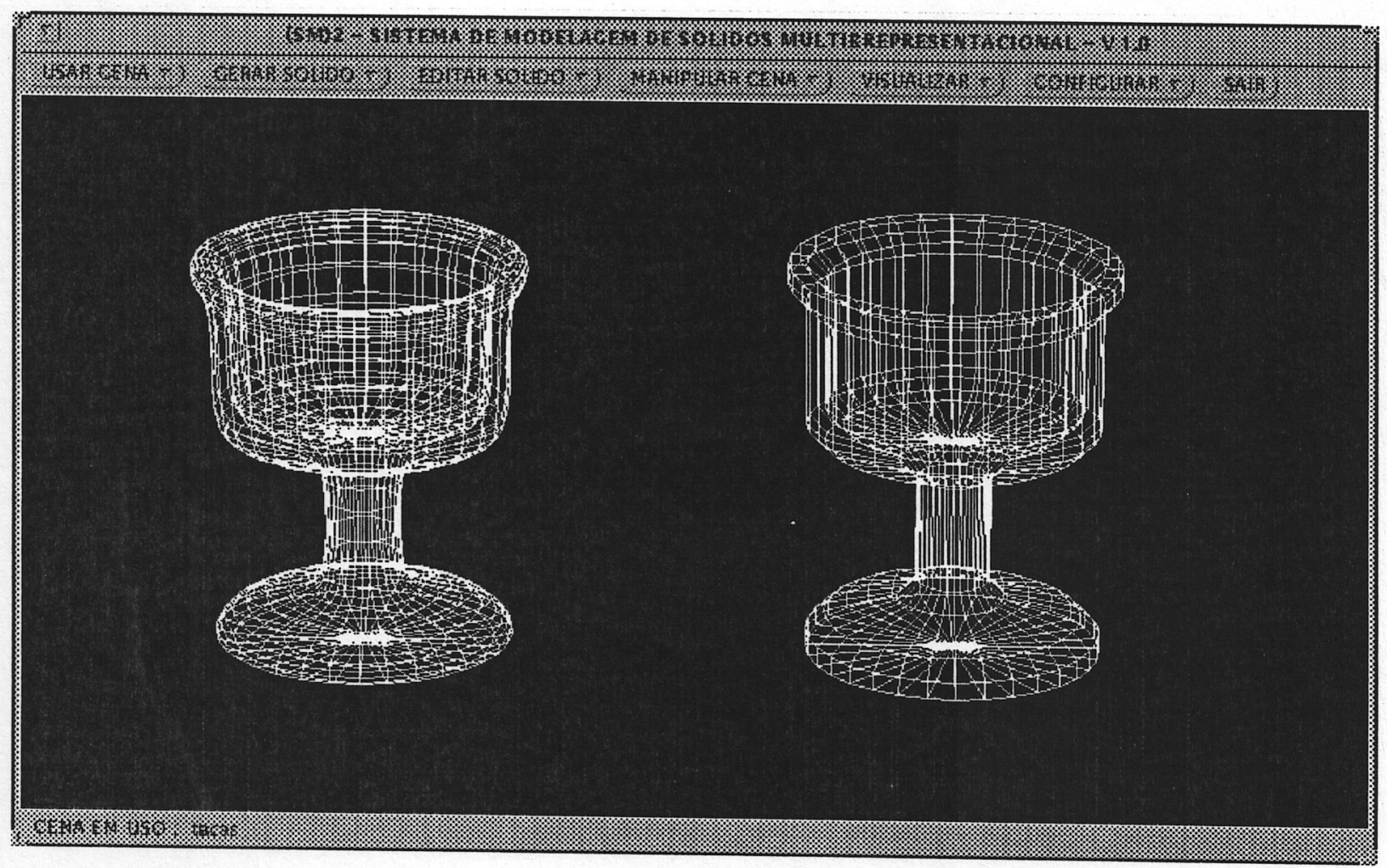

Figura 5.11 - Modelos gerados por varredura rotacional de uma curva B-Spline (à esquerda) e de uma poli-linha (à direita) 


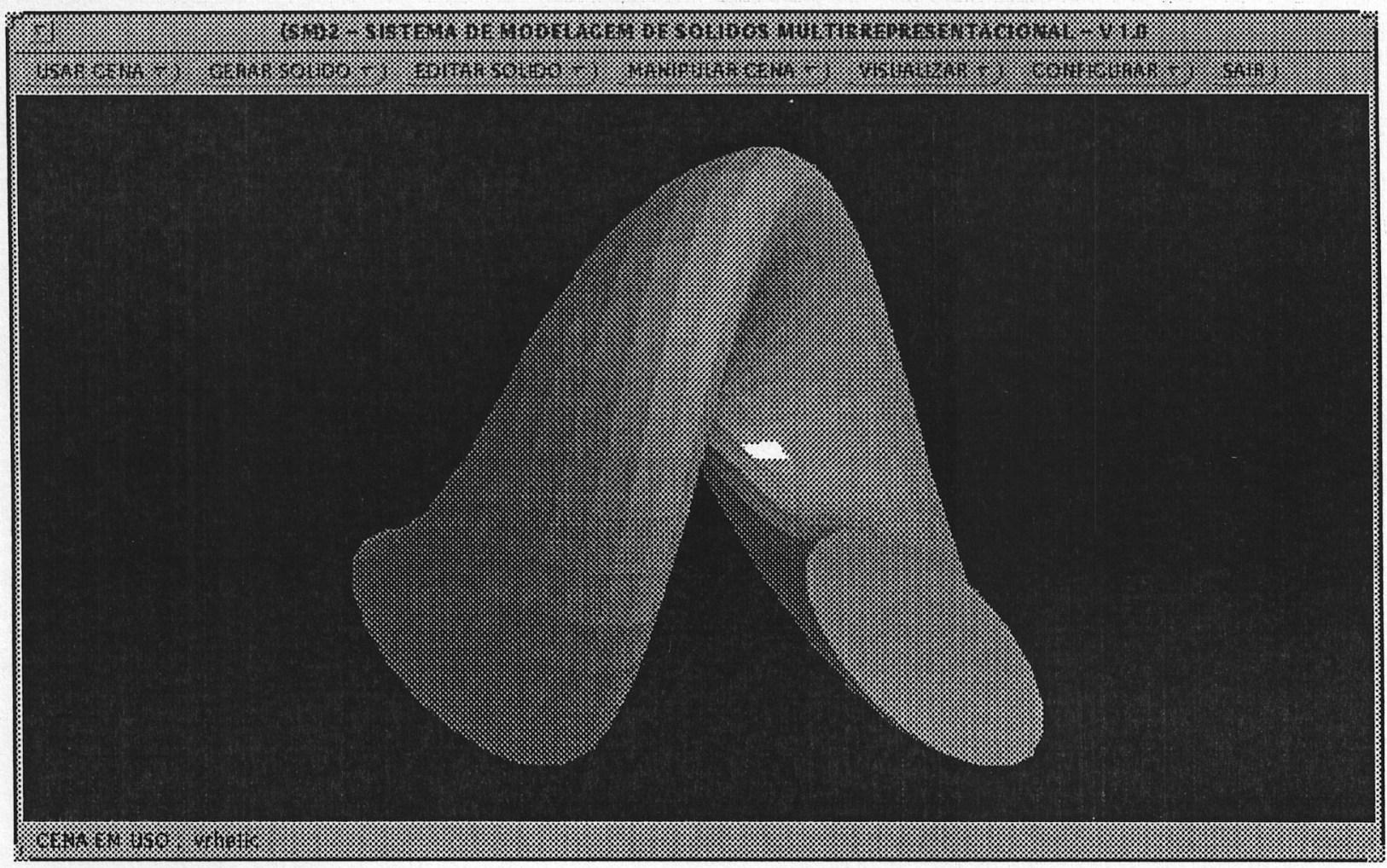

Figura 5.12 - Modelo gerado por varredura rotacional helicoidal de uma elipse (Flat Shading)

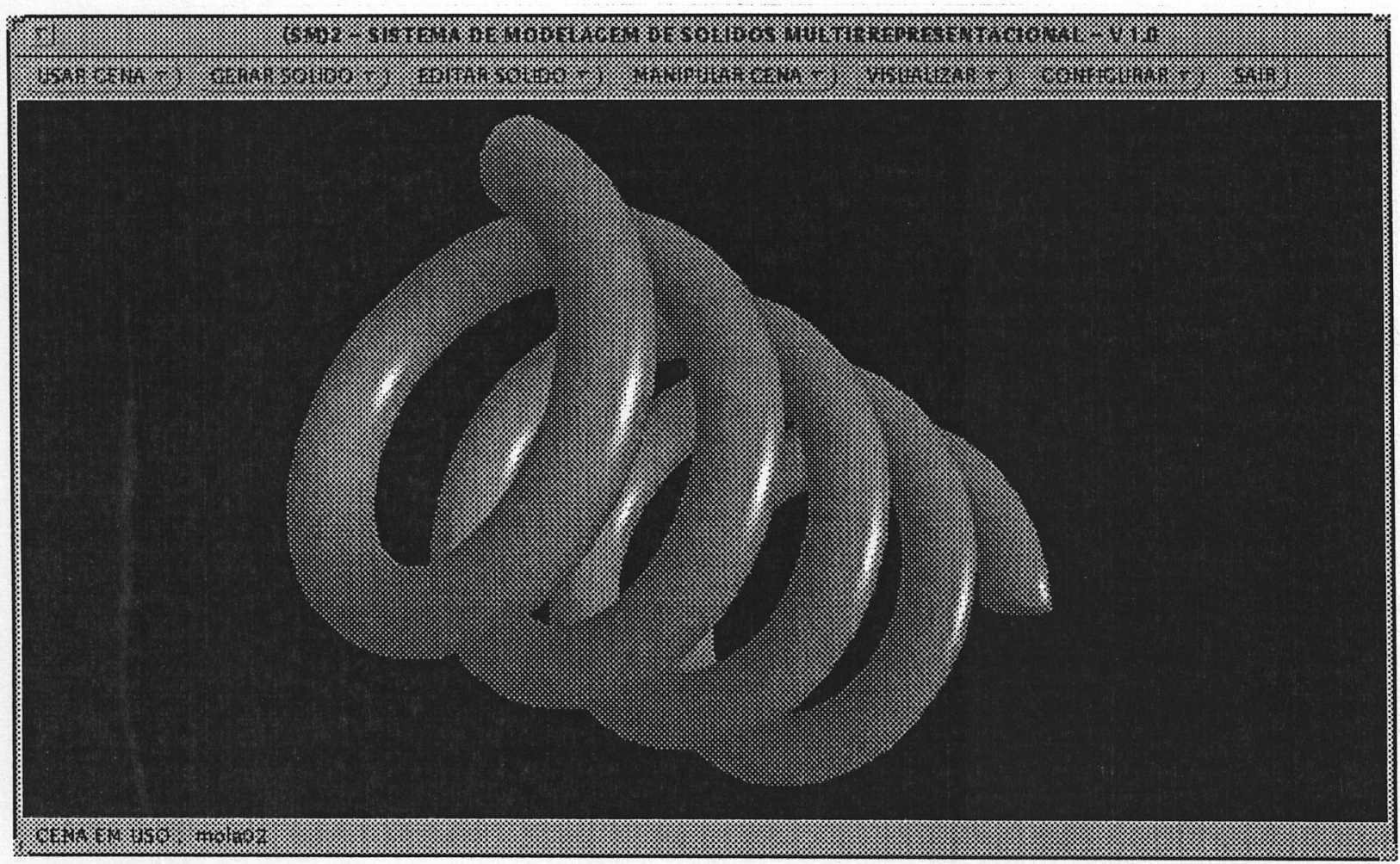

Figura 5.13 - Modelo gerado por varredura rotacional helicoidal de um círculo (Phong Shading) 


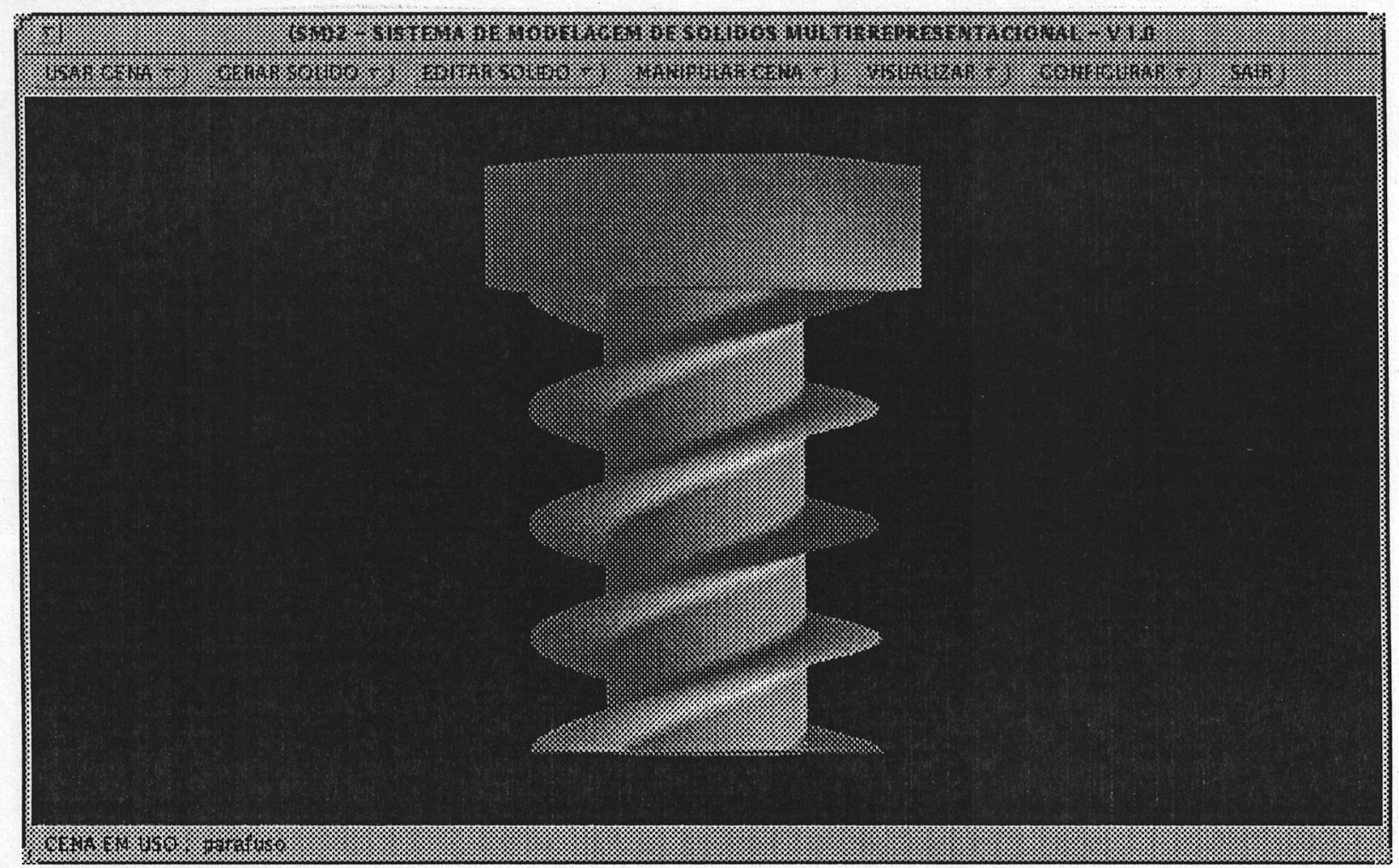

Figura 5.14 - Modelos gerados pela varredura translacional com torção de um polígono (rosca) e varredura translacional simples de um hexágono (cabeça) (Phong Shading)

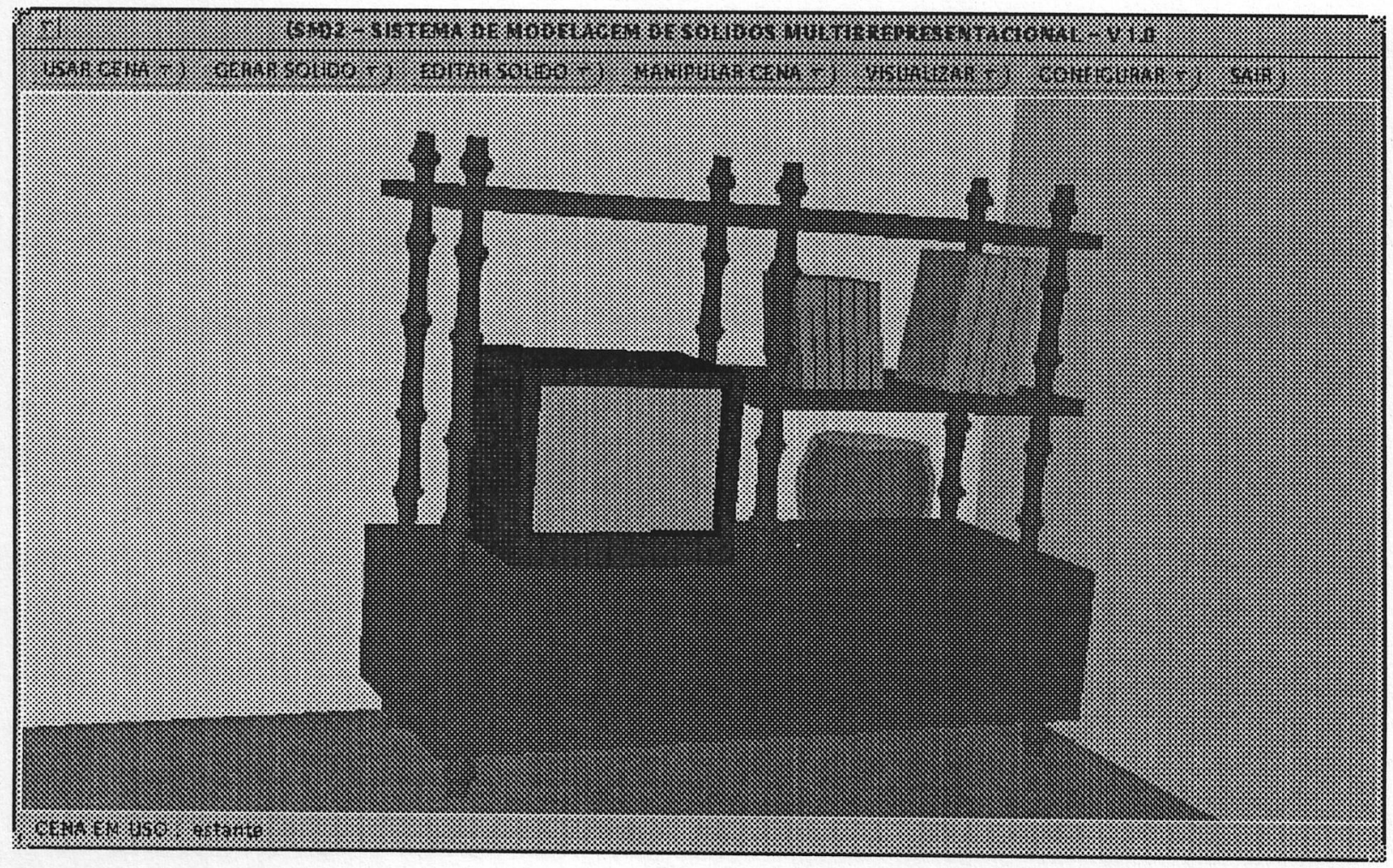

Figura 5.15 - Cena gerada utilizando primitivas e diferentes tipos de varredura (Flat Shading) 


\section{5 - CONSIDERAÇÕES FINAIS}

Uma vez apresentadas as principais características de projeto e implementação da primeira versão do $(\mathrm{SM})^{2}$ e visando auxiliar seu desenvolvimento futuro, é interesssante discutir alguns de seus aspectos do ponto de vista da utilização. Dentre estas características, algumas vantajosas, tem-se:

- Permite carregar para a memória quantas cenas desejar, tornando possível a troca da cena em uso (ativa) a qualquer momento, o que dá ao sistema uma certa flexibiladade;

- Armazena e recupera cenas em bases permanentes (arquivos), permitindo ao usuário construir uma cena por etapas e não perdê-la;

- Sempre que recupera uma cena, faz com que ela se torne a cena em uso (cena ativa); analogamente, sempre que remove uma cena da memória, faz com que a cena seguinte passe a ser a cena ativa;

- Verifica todos os parâmetros fornecidos pelo usuário antes de executar a operação;

- Permite a existência de faces e curvas somente durante a realização de operações de varredura translacional e rotacional;

- Possibilita a geração de objetos primitivos maciços, ocos e vazados, o que facilita a descrição e evita a execução de operações complexas, como as booleanas;

- Permite a descrição de objetos com geometria complexa, difíceis ou impossíveis de serem descritos por modeladores tradicionais, através da integração da técnica de descrição por semi-espaços e da forma de representação implícita ao modelador [Siq94], o que aumenta significativamente seu potencial descritivo;

- Permite integrar novas formas de representação, através do reaproveitamento de parte do código que gera a estrutura B-Rep poliedral a partir de outras representações.

Entre as limitações, estão:

- O sistema é poliedral, ou seja, todas as curvas e superfícies são aproximadas por segmentos de retas e planos, respectivamente;

- O uso de uma resolução muito alta tende a deixar o sistema bastante lento, devido ao uso de muitos segmentos de reta na definição de uma curva;

- Não dispõe de facilidades para apontar os elementos da cena, o que obriga a identificar componentes através de nomes, que não são explicitamente indicados na cena; 
- Não realiza, atualmente, operações de edição sobre as faces geradoras, limitando o poder descritivo das operações de varredura, por serem aplicadas somente sobre faces simples;

- Até o momento, as operações de varredura translacional somente podem ser realizadas através de caminhos lineares, ou seja, utilizando um único vetor;

- Permite a construção de sólidos que ocupem uma mesma região do espaço;

- Ao apresentar sólidos em fio-de-arame, não remove linhas e superfícies escondidas;

- A descrição de modelos por semi-espaços definidos através de funções implícitas exige uma certa familiaridade com a matemática, o que pode dificultar a sua utilização por usuários menos experientes. 


\section{CAPÍ́tULO 6}

\section{CONCLUSÕES}

\section{1 - CONSIDERAÇÕES INICIAIS}

A necessidade de modeladores de sólidos precisos e com grande poder descritivo tem feito crescer a pesquisa por sistemas cuja arquitetura se aproxima ao máximo do ideal [Mil86, Mil89, Fis91], isto é, seja poderosa o bastante para manipular maior número de objetos da forma mais eficiente possível. Esta busca por arquiteturas híbridas mais abrangentes tem originado sistemas de modelagem complexos [Nie92] e com as mais variadas combinações de representações concebíveis, como o GeneSys, desenvolvido no Brasil [Fis91].

Seguindo esta filosofia, procura-se desenvolver no ICMSC-USP o $(\mathrm{SM})^{2}$, um modelador de sólidos multirrepresentacional. Este trabalho constituiu-se do projeto global para o (SM $)^{2}$, da definição de uma interface provisória e do desenvolvimento de operações básicas de modelagem, como o instanciamento de primitivas, operações de varredura rotacional e translacional e transformações geométricas. Deve-se enfatizar que o sistema aqui desenvolvido representa um ponto de partida para pesquisas em modelagem de sólidos, tendo servido de veículo para o estudo da modelagem de sólidos por fronteira. Já está incorporado ao (SM) ${ }^{2}$ um módulo de modelagem por semi-espaços [Siq94], no qual sólidos são definidos por equações implícitas e descritos através de semi-espaços. A representação implícita criada é convertida, pelo modelador, para a representação B-Rep. Esta técnica permite a geração de sólidos cuja fronteira possui forma complexa, as quais não são facilmente descritas pelas técnicas anteriores. Pretende-se, no futuro, torná-lo um modelador híbrido que incorpore outras técnicas de descrição de sólidos e diferentes tipos de superfícies (não apenas planares), e ainda, que seja preciso, de grande poder descritivo e que possua uma interface poderosa e amigável. 


\section{2 - CONTRIBUIÇÕES DO TRABALHO}

Esta etapa da construção do $(\mathrm{SM})^{2}$ teve como principal objetivo dar continuidade ao projeto que visa à construção de um modelador de sólidos multirrepresentacional. Como contribuições deste trabalho pode-se mencionar:

- A aquisição de experiência no desenvolvimento de sistemas de modelagem B-Rep, criando uma base para futuros trabalhos e estudos nesta área, no ICMSC-USP;

- O domínio no uso de operadores de Euler, resultando na elaboração da nota técnica sobre o assunto [Mag94a];

- A padronização da documentação do sistema, através da geração de tabelas e gabaritos para o projeto e normas de padronização para comentários em códigos fonte;

- O desenvolvimento de um projeto global para o (SM) ${ }^{2}$, incluindo o detalhamento do núcleo do modelador, das diversas operações de modelagem e de alguns recursos de visualização;

- A implementação de três sub-módulos de modelagem: instanciamento de primitivas, varredura e transformações geométricas, deixando o $(\mathrm{SM})^{2} \mathrm{em}$ um estágio que permite sua utilização em algumas aplicações, como no ensino de geometria, e a inclusão de novas técnicas de modelagem e visualização;

- O desenvolvimento de três documentos diretamente relacionados ao modelador, um sobre o projeto, outro sobre a implementação, e um manual para o usuário do sistema, que deverão ser bastante úteis para futuras extensões a serem incluídas no modelador;

- A elaboração de uma comunicação sobre o modelador (SM) ${ }^{2}$ junto com o grupo de Computação Gráfica e Processamento de Imagens, a ser apresentada no SIBGRAPI'94 [Mag94]. 


\section{3 - SUGESTÕES PARA FUTUROS TRABALHOS}

Existem diversos trabalhos que podem ser realizados com base no modelador criado, entre estes:

- A implementação das várias operações de modelagem de alto nível sobre sólidos, como arredondamento, chamframento, "tweaking", corte, colagem, união, intersecção e diferença entre sólidos, já previstas no projeto desenvolvido;

- A implementação de operações booleanas em 2D, permitindo a união, intersecção e diferença entre primitivas planares, visando a definição de faces geradoras mais elaboradas para a realização de operações de varredura;

- A implementação da varredura genérica, na qual a face geradora percorre uma trajetória qualquer, podendo realizar transformações no polígono gerador à medida em que percorre a trajetória;

- A implementação de um mecanismo que permita desfazer operações, sejam estas errôneas ou indesejadas [Hir86];

- O desenvolvimento de uma interface mais amigável e poderosa, direcionada ao conjunto de aplicações para as quais deseja-se utilizar o modelador;

- A conversão da representação B-Rep para a forma implícita [Sha93], transformando o $(\mathrm{SM})^{2}$ em um modelador híbrido;

- A inclusão de outras formas de representação, juntamente com algoritmos de conversão para B-Rep;

- A incorporação de diferentes tipos de superfície, incluindo superfícies de forma livre, já prevista ao definir a estrutura de dados;

- O desenvolvimento de um sistema de visualização. que possua algoritmos de . iluminação e remoção de superfíces escondidas (já em andamento). 


\section{4 - CONSIDERAÇÕES FINAIS}

Apesar de existirem diversos modeladores de sólidos, a maioria foi desenvolvida no exterior. Sistemas de modelagem de sólidos desenvolvidos no Brasil são poucos, e os grupos trabalhando nesta área também são poucos e na maioria recentes. Portanto, esta é uma área de pesquisa no Brasil que necessita crescer, já que pode trazer inúmeras contribuições para a medicina, automação de projetos e análises de peças, automóveis, aviões, navios, etc...

O estudo, projeto e construção do (SM) vai de encontro a estes anseios, constituindo um passo importante nesta direção, uma vez que se constrói um produto aberto, permitindo o seu uso como ferramenta de apoio a pesquisas em algoritmos e aplicações na área de CAD. A presença e detecção de limitações faz parte deste processo de aprendizagem, constitui um fator bastante importante, que auxiliará o desenvolvimento futuro. 


\section{REFERÊNCIAS BIBLIOGRÁFICAS}

- [Ale61] ALEXANDROFF, P. Elementary concepts of topology. New York: Dover, 1961.

[Ayr76] AYRES Jr, Frank. Geometria analítica plana e sólida. São Paulo: McGrawHill, 1976. (Coleção mini-Schaum, v. 3)

[Bad78] BADLER, N., BAJCSY, R. Three dimensional representations for computer graphics and computer vision. Computer graphics, New York, v. 12, n.3, p.153-160, 1978.

[Bae79] BAER, A., EASTMAN, C., HENRION, M. Geometric modelling: a survey. Computer aided design, Guildford, v. 11, n. 5, p. 253-272, sept. 1979.

[Bau75] BAUMGART, B. G. A Polyhedron representation for computer vision. In: NATIONAL COMPUTER CONFERENCE, 44, 1975. Proceedings..., p. $589-596$

[Ber75] BERNASCON, Y. L., BRUN, J. M. Automated aids for the design of mechanical parts. Society of Manufacturing Engineers, 1975. (Tech. Paper, MS75-508)

[Bez72] BÉZIER, P. Numerical control: mathematics and applications. Trad. A. R. Forrest. Londres: Wiley, 1972.

[Bis85] BISHOP, A. W. Computer simulation of the real world for the mechanical and industrial designer. In: MORTENSON, M. G. Geometric modeling. New York: J. Wiley, 1985. p. 666-681.

¿[Boh84] BOHM, W. et al. A survey of curve and surface methods in CAGD. Computer aided geometric design. v.1, n. 1, p. 2-60, jul. 1984.

[Boo91] BOOCH, G. Object oriented design with applications. Benjamin/Cummings, 1991.

[Bou87] BOULOS, P., CAMARGO. I. Geometria analítica: um tratamento vetorial. 2 ed. São Paulo: McGraw-Hill, 1987. 385 p.

[Boy79] BOYSE, J. W. Interference detection among solids and surfaces. Communications of the ACM, New York, v. 22, n. 1, p. 3-9, jan. 1979.

[Boy82] BOYSE, J. W., GILCHRIST, J. E. GMSolid: interactive modeling for design and analisys of solids. IEEE computer graphics and applications, Los Alamos, v. 2, n. 2, p. 27-40, mar. 1982. 
[Bra73] BRAID, I. C. Designing with volumes. Cambridge: Cambridge University, 1973. Dissertação (PhD) - Cambridge University, 1973.

[Bra75] BRAID, I. C. The synthesis of solids bounded by many faces. Communications of the ACM, New York, v.8, n. 4, p. 209-216

[Bra78] BRAID, I. C. On storing and changing shape information. Computer graphics, New York, v. 12, n. 3, p. 252-256, aug. 1978.

[Bra80] BRAID, I. C., HILLYARD. R. C., STROUD, I. A. Stepwise construction of polyedra in geometric modeling. In: BRODIE, K. W. (ed.) Mathematical methods in computer graphics and design. London: Academic, 1980. p. 123-141.

[Bro82] BROWN, C. M. PADL-2: a technical summary. IEEE computer graphics and applications, Los Alamitos, v. 2, n. 2, p. 69-84, mar. 1982.

[Car87] CARLBOM, I. An algorithm for geometric set operations using cellular subdivision techniques. IEEE computer graphics and applications, Los Alamitos, p. 44-55, may. 1987.

[Car78] CAROLI, A. et al. Matrizes, vetores e geometria analítica. 9 ed. São Paulo: Nobel, 1978. 167 p.

[Cas90] CASACURTA, A., LASCHUK, A. SIHMOS: sistema híbrido de modelagem de sólidos. In: JORNADA EPUSP/IEEE EM COMPUTAÇĀO VISUAL, 1, 1990, São Paulo. Anais... São Paulo: EPUSP, 1990. p. 267-276.

[Cas90a] CASACURTA, A., LASCHUK, A. Sweeping: representação de sólidos rígidos. In: JORNADA EPUSP/IEEE EM COMPUTAÇÃO VISUAL 1, 1990, São Paulo. Anais... São Paulo: EPUSP, 1990. p. 277-289.

[Cas59] CASTELJAU, F. Outillage méthodes calcul. Paris: André Citröen Automobiles, 1959.

[Cav92] CAVAlCANTI, P. R., CARVAlHO, P. C., MARTHA, L. F. Criação e manutenção de subdivisões espaciais. In: SIBGRAPI - SIMPÓSIO BRASILEIRO DE COMPUTAÇÃO GRÁFICA E PROCESSAMENTO DE IMAGENS, 5, 1992, Águas de Lindóia. Anais... p. 105-114.

4Cen92] CENSI, A. L. C., LADEIRA, M. C. AutoCad: release 11. 2 ed. São Paulo: Érica, 1992. $410 \mathrm{p}$.

[Ces94] CÉSAR, C. N. L., OLIVEIRA, M. C. F. Uma versão rápida do algoritmo scanline para rendering de sólidos. São Carlos: ICMSC-USP. Comunicação submetida ao SIBGRAPI - 1994. (no prelo) 
[Cha65] CHASEN, S. H. The introduction of man computer graphics into the aerospace industry. In: FALL JOINT COMP. CONF. Proceedings... Washington: Spartan Books, 1965. 883 p.

- [Chi85] CHIYOKURA, H., KIMURA, F. A method of representing the solid design process. IEEE computer graphics and applications, Los Alamitos, v. 5, n. 4, p. 32-41, apr. 1985.

[Coo63] COONS, S. A. An outline of the requirements for a computer aided design system. In: SPRING JOINT COMP. CONF. Proceedings... Baltimore: Spartan Books, 1963. 299 p.

[Des92] DESAULNIERS, H., STEWART, N. F. An extension of manifold boundary representations to the r-sets. ACM Transactions on Graphics. New York, v. 11 , n. 1 , p. $40-60$, jan. 1992 .

[Do185] DOLCE, O., POMPEO, J. N. Fundamentos de matemática elementar. 6 ed. São Paulo: Atual, 1985. 10 v. (v.9: Geometria plana)

[Dol85a] DOLCE, O., POMPEO, J. N. Fundamentos de matemática elementar. 6 ed. São Paulo: Atual, 1985. 10 v. (v. 10: Geometria espacial - posição e métrica)

[Duf90] DUFF, C., HOWARD, B. Migration patterns. Byte, p. 223-232, oct. 1990.

[Eas77] EASTMAN, C., HENRION, M. Glide: a language for design information systems. Computer Graphics, New York, v. 11, n. 2, p. 24-33, jul. 1977.

[Eas79] EASTMAN, C., WEILER, K. Geometric modeling using the Euler operators. In: ANNUAL CONF. COMPUTER GRAPHICS IN CAD/CAM SYSTEMS, 1, 1979, Cambridge. Proceedings... p. 248-254.

[Eng73]

ENGELI, M. E. A language for 3D graphics applications. International Computing Symposium, 1973. p. 459-466.

[Fer86] FERREIRA, A. B. H. Novo dicionário da língua portuguesa. 2 ed. Rio de Janeiro: Nova Fronteira, 1986. 1838 p.

[Fig92] : FIGUEIREDO, L. H., GOMES, J. M. Physically-based sampling of implicit Objects. In: SIBGRAPI - SIMPÓSIO BRASILEIRO DE COMPUTAÇÃO GRÁFICA E PROCESSAMENTO DE IMAGENS, 5, 1992, Águas de Lindóia. Anais... p. 81-88.

[Fil87] FILGUEIRAS, L. V. L. Fundamentos de computação gráfica. Rio de Janeiro: L.T.C., 1987. 356 p.

[Fis90] FISCHER, R. Formas de representação para objetos tridimensionais. Rio de Janeiro: Pontifícia Universidade Católica, 1990. Dissertação (Projeto Final do Curso de Engenharia da Computação). PUC-RJ, 1990. 
[Fis91] FISCHER, R. Genesys: sistema híbrido para modelagem de sólidos. Rio de Janeiro: Laboratório de CAD inteligente - Depto de Informática, 1991. 127 p. Dissertação (Mestrado em Ciência da Computação). Pontifícia Universidade Católica do Rio de Janeiro - PUC, 1991.

[Fis91a] FISS, M., TSUZUKI, M. S. G. Operações booleanas entre sólidos. In: Congresso de Iniciação Científica e Tecnológica em Engenharia, 10, 1991, São Carlos. Resumos... São Paulo: EDUSP, 1991. p. 194.

[Fit81] FITZGERALD, W., GRACER, F., WOLFE, R. GRIN: interactive graphics for modeling solids. IBM journal of research development, New York, v. 25 , n. 4, p. 281-295, jul. 1981.

[Fo190] FOLEY, J.D. et al. Computer graphics: principles and practice. 2 ed. Massachusetts: Addison Wesley, 1990. 1174 p.

[Fra82] FRANKLIN, W. R. Efficient polyhedron intersection and union. Graphics interface, p. 73-80, may 1982.

[Fri82] FRITSH, F. (ed.). Algorithms for computing the volume and other integral properties of solids. I. Known methods and open issues. Communications of the ACM, New york, v. 25, n. 9, p. 635-650, sept. 1982.

[Gan83] GANE, C., SARSON, T. Análise estruturada de sistemas. Rio de Janeiro: L.T.C., 1983. 257 p.

[Gar91] GARCIA, M.B., TSUZUKI, M.S.G. Escalonamento automático de features. In: Congresso de Iniciação Científica e Tecnológica em Engenharia, 10, 1991, São Carlos. Resumos... São Paulo: EDUSP, 1991. p. 423.

[Gol87] GOLDMAN, R. N. The Role of surfaces in solid modeling. In: FARIN, G. E. (ed.). Geometric modeling: algorithms and new trends. Philadelphia: Society for Industrial and Applied Mathematics, 1987. p. 69-89.

[Gol79] GOLDSTEIN, R., MALIN, L. 3D modeling with the synthavision system. In: ANNUAL CONF. COMPUTER GRAPHICS IN CAD/CAM SYSTEMS, 1, 1979, Cambridge. Proceedings... p. 244-247.

[Gom90] GOMES, J. M., VELHO, L. C. Conceitos básicos de computação gráfica. São Paulo: VII Escola de Computação, 1990. 311 p.

[Gut64] GUTTERMAN, M. M. APT numerical description study. I.I.T. Research Institute, 1964. (Report, 578-T45-10)

[Har87] HARRINGTON, S. Computer graphics - a programming approach. 2 ed. São Paulo: McGraw-Hill, 1987. 466p. 
[Hea86] HEARN, D., BAKER, M. P. Computer graphics. New Jersey: Prentice-Hall, 1986. $352 \mathrm{p}$.

[Hel90] HELLER, D. XView programming manual for version 11 of the xwindow system. Sebastopol: O'Reilly, 1990. 739 p.

[Hil82] HILLYARD, R. The Build group of solid modelers. IEEE Computer Graphics and Applications. Los Alamitos, v. 2, n. 2, p. 43-52, mar. 1982.

[Hir86] HIROSHI, T. el al. Undo and redo operations for solid modeling. IEEE Computer Graphics and Applications, Los Alamitos, p. 35-42, abr. 1986.

$\gamma[$ Hof 87]

HOFFMANN, C. M., HOPCROFT, J. E. Geometric ambiguities in boundary representations. Computer-aided design, Guildford, v. 19, n. 3, p. 141-147, apr. 1987.

[Hof89] HOFFMANN, C. M. Geometric and solid modeling. San Mateo: Morgan Kaufmann, 1989. p. 1-338.

[Hos74] HOSAKA, M. et al. A Unified method for processing polyhedra. In: CONF. ON INFORMATION PROCESSING, 1974, Netherlands. Proceedings... p. 768-772.

[Iez85] IEZZI, G. Fundamentos de matemática elementar. 6 ed. São Paulo: Atual, 1985. 10 v. (v. 3: Trigonometria)

[Iez85a] IEZZI, G., HAZZAN, S. Fundamentos de matemática elementar. 6 ed. São Paulo: Atual, 1985. 10 v. (v. 4: Seqüências matrizes determinantes sistemas)

[Iez85b] IEZZI, G. Fundamentos de matemática elementar. 6 ed. São Paulo: Atual, 1985. 10 v. (v. 7: Geometria analítica)

[Jar85] JARED, G. Boundary representations: data structures, computations, operations and applications. In: ANNUAL CONF. OF THE SPECIAL INTEREST GROUP ON COMPUTER GRAPHICS OF THE ASSOCIATION FOR COMPUTING MACHINERY, 12, 1985. Tutorial notes... New York: ACM, p.1-27.

[Jud71] JUDICE, E. D. Elementos de geometria analítica. 2 ed. Belo Horizonte: Vega, 1971. $298 \mathrm{p}$.

[Kaj83] KAJIYA, J. T. New techniques for ray tracing procedurally defined objects. Computers graphics, New York, v. 17, p. 91-102, 1983.

[Kal89] KALAY, E. Y. The hybrid-edge: a topological data structure for vertically integrated geometric modeling. Computer-aided design, Guildford, v. 21, n. $3,1989$. 
[Kin76] KINDLE, J. H. Geometria analítica plana e no espaço. São Paulo: McGrawHill, 1976. (Coleção Schaum)

[Lan79] LANING, J. H., MADDEN, S. J. Capabilities of the shapes system for computer aided mechanical design. In: ANNUAL CONF. COMPUTER GRAPHICS IN CAD/CAM SYSTEMS, 1, 1979, Cambridge. Proceedings... p. 223-231.

[Lee82] LEE, Y. T., REQUICHA, A. G. Algorithms for computing the volume and other integral properties of solids: I. Known methods and open issues; II. A family of algorithms based on representation conversion and cellular approximation. Communications of the ACM. New York, v. 25, n. 9, p. 635650, sept. 1982.

[Leh79] LEHMAN, C. H. Geometria analítica. 3 ed. Porto Alegre: Globo, 1979.

[Lei77] LEITHOLD, L. O cálculo com geometria analítica. São Paulo: Harper \& Row do Brasil, 1976. v. 2.

[Lev76] LEVIN, J. Z. A parametric algorithm for drawing pictures of solid objects composed of quadric surfaces. Communications of the ACM, New York, v. 19, p. 555-563, 1976.

[Mag87] MAGNENAT-THALMAN, N. THALMAN, D. Image synthesis: theory and practice. Tokyo: Springer-Verlag, 1987. $400 \mathrm{p}$.

[Mag94] MAGAlHÃES, A. L. C. C. et al. Desenvolvimento de um modelador de sólidos multirrepresentacional com núcleo B-Rep e técnicas de descrição por varredura e semi-espaços. São Carlos: ICMSC-USP. Comunicação submetida ao SIBGRAPI - 1994. (no prelo)

[Mag94a] MAGAlHÃES, A. L. C. C., SIQUEIRA, M. F., OLIVEIRA, M. C. F. Operadores de Euler na modelagem de sólidos por fronteira: conceito, aplicação, estudos de casos. São Carlos: ICMSC-USP, 1994. 29 p. (Notas Técnicas do ICMSC)

[Mag94b] MAGALHÃES, A. L. C. C. $\left(\underline{(S M}^{2}\right.$ : documentação de projeto. São Carlos: ICMSC-USP, 1994. (Relatório Interno)

[Mag94c] MAGALHÃES, A. L. C. C. $(\mathrm{SM})^{2}$ : documentação de implementação. São Carlos: ICMSC-USP, 1994. (Relatório Interno)

[Mag94d] MAGALHÃES, A. L. C. C. $\left(\underline{\operatorname{SM})^{2}}\right.$ : manual do usuário. São Carlos: ICMSCUSP, 1994. (Relatório Interno)

[Män82] MÄNTYLÄ, M., SULONEN, R. GWB: a solid modeler with Euler operators. IEEE computer graphics and applications, Los Alamitos, v. 2, n. 7, p. 17-31, sept. 1982. 
[Män82a] MÄNTYLÄ, M. An inversion algorithm for geometric models. ACM computer graphics, New York, v. 16, n. 3, p. 51-59, jul. 1982.

[Män83] MÄNTYLÄ, M., TAMMINEN, M. Localised set operations for solid modeling. Computer graphics, New York, v. 17, n. 3, p. 279-288, jul. 1983.

[Män84] MÄNTYLÄ, M. A note on the modeling space of Euler operators. Computer vision, graphics and image processing, San Diego, v. 26, p. 45-60, 1984.

[Män86] MÄNTYLÄ, M. Boolean operations of 2-manifolds through vertex neighborhood classification. ACM transactions on graphics, New York, v. 5, n. 1, p. 1-29, 1986.

[Män88] MÄNTYLÄ, M. An introduction to solid modeling. Maryland: Computer Science, 1988. $401 \mathrm{p}$.

[Mar80] MARKOWSKY, G., WESLEY, M. A. Fleshing out wire frames. IBM journal of research and development, New york, p.582-597, sept. 1980.

[Mil86] MILLER, J. R. Sculptured surfaces in solid models: issues and alternative approaches. IEEE computer graphics and applications, Los Alamitos, p. 37-48, dec. 1986.

[Mil89] MILLER, J. R. Arquitectural issues in solid modelers. IEEE computer graphics and applications, Los Alamitos, p. 72-87, sept. 1989.

[Mor85] MORTENSON, M. E. Geometric modeling. New York: John Wiley, 1985. $763 \mathrm{p}$.

[New81] NEWMAN, W. M., Sproull, R. F. Principles of interactive computer graphics. 2a ed. São Paulo: McGraw-Hill, 1981. 541 p.

[Nie92] NIELSON, M. G. Guest editor's introduction: computer-aided design. IEEE Computer Graphics and Applications, Los Alamos, p. 29-44, sept. 1992.

[Oki73] OKINO, N. et al. TIPS-1: technical information processing system for computer aided design, drawing and manufacturing. In: COMPUTER Languages for Numerical Control. North-Holland, 1973. p. 141-150.

[Per90] PERSIANO, R. C. M., OLIVEIRA, A. A. F. Introdução à computação gráfica. Rio de Janeiro: L.T.C., 1990.

[Pra90] PRATT, M. J. Solid modeling - survey and current research issues. In: ROGERS, D. F., EASTMAN, R. A. (ed.). Computer graphics techniques: theory and practice. New York: Springer-Verlag, 1990. p. 363-405. 
[Pre87] PRESSMAN, R. S. Software engineering: a practitioner's approach. 2. ed. Singapore: McGraw-Hill, 1987. 567 p.

[Req77] REQUICHA, A. G., VOELCKER, H. B. Constructive solid geometry. Rochester: University of Rochester, 1977. (Production Automation Project Tech. Memo., 25)

[Req80] REQUICHA, A. G. Representations for rigid solids: theory, methods and systems. ACM computing surveys, New York, v. 12, n. 4, p. 437-464, dec. 1980.

[Req82] REQUICHA, A. G., VOELCKER, H. B. Solid modeling: a historical summary and contemporary assessment. IEEE computer graphics and applications, Los Alamitos, v. 2, p. 9-24, mar. 1982.

[Req83] REQUICHA, A. G., VOELCKER, H. B. Solid modeling: current status and research directions. IEEE computer graphics and applications, Los Alamitos, v. 3, p. 25-37, oct. 1983.

[Req85] REQUICHA, A. G., VOELCKER, H. B. Boolean operations in solid modeling: boundary evaluation and merging algorithms. Proceedings of the IEEE, New York, v. 73, n. 1, p. 30-44, jan. 1985.

[Req92] REQUICHA, A. G., ROSSIGNAC, J. R. Solid modeling and beyond. IEEE computer graphics and applications, Los Alamitos, p. 31-44, sept. 1992.

[Ric72] RICH, B. Geometria plana. São Paulo: McGraw-Hill, 1972. (Coleção Schaum). $312 \mathrm{p}$.

[Rob63] ROBERTS, L. G. Machine perception of three dimensional solids. Cambridge: Massachusetts Institute of Technology, 1963. (MIT Lincoln Laboratory, TR315)

[Rog90] ROGERS, D. F., Adams, J. A. Mathematical elements for computer graphics. 2a ed. São Paulo: McGraw-Hill, 1990. 611 p.

[Rot82] ROTH, S. D. Ray casting for modeling solids. Computer graphics and image processing. v. 18, n. 2, p. 109-144, 1982.

[Sco93] SCOTT, L. P. B. Protótipo evolutivo de um sistema de modelagem de sólidos orientado a objetos. São Carlos: ICMSC-USP, 1993. Dissertação (Mestrado em Ciência da Computação). Instituto de Ciências Matemáticas de São Carlos-USP, 1993. 135 p.

[Sco93a] SCOTT, L. P. B. Protótipo evolutivo de um sistema de modelagem de sólidos orientado a objetos: projeto / documentação. São Carlos: ICMSC-USP, 1993. Relatório interno. 
[Sco93b] SCOTT, L. P. B. Protótipo evolutivo de um sistema de modelagem de sólidos orientado a objetos: implementação. São Carlos: ICMSC-USP, 1993. Relatório interno.

[Sed84] SEDERBERG, T. W., ANDERSON, D. C., GOLDMAN, R. N. Implicit representation of parametric curves and surfaces. Computer vision, graphics and image processing, San Diego, v. 28, p. 72-84, 1984.

[Seg90] SEGAL, M. Using tolerances to guarantee valid polihedral modeling results. Computer Graphics, New York, v. 24, n. 4, p. 105-114, aug. 1990.

[Sei78] SEIFERT, H. et al. Different ways to design three-dimensional representations of engineering parts with PROREN2. In: CONF. INTERACTIVE TECHNIQUES COMPUTER AIDED DESIGN, 1978, Italy. Proceedings..., p. 335-343.

[Sha93] SHAPIRO, V., VOSSLER, D. L. Separation for boundary to CSG conversion. ACM Transactions on Graphics. New York, v. 12, n. 1, p. 35-55, jan. 1993.

[Shi83] SHIRMA, Y., OKINO, N., KAKUZU, Y. Research on 3D geometric modeling by sweep primitives. In: COMPUTER AIDED DESIGN, 1983. Proceedings... p. 671-680.

[Siq94] SIQUEIRA, M. F. Modelagem por semi-espaços definidos implicitamente. São Carlos: ICMSC-USP, 1994. 104 p. Dissertação (Mestrado em Ciência da Computação). Instituto de Ciências Matemáticas de São Carlos-USP, 1994.

[Spu78] SPUR, G. Status and further development of the geometric modeling system COMPAC. In: GEOMETRIC MODELING PROJECT MEETING, 1978, St. Louis. Proceedings..., p. 1-35. (P-78-GM-01)

[Ste84] STEINBERG, H. A. A smooth surface based on biquadratic patches. IEEE computer graphics and applications, Los Alamitos, v. 4, p.20-23, 1984.

[Sut63] SUTHERLAND, I. E. Sketchpad: a man-machine graphical communication system. In: SPRING JOINT COMP. CONF., 1963, Baltimore. Proceedings... Spartan Books, 1963, p. 329.

[Sut74] SUTHERLAND, R. F., SPROULL, R. F., SCHUMACKER, R. A. A Characterization of ten hidden-surface algorithms. ACM computing surveys, New York, v. 6, n. 1, p. 1-55, mar. 1974.

[Tav92] TAVARES, G. et al. Topological methods in geometric modeling. In: CONGRESSO NACIONAL DE MATEMÁTICA APLICADA E COMPUTACIONAL, 15, 1992. Sociedade Brasileira de Matemática Aplicada e Computacional, 1992. 
[Til83] TILLER, W. Rational B-splines for curve and surface representation. IEEE computer graphics and applications, Los Alamitos, v. 3, p. 61-69, 1983.

[Til80] TILOVE, R. B. Set membership classification: a unified approach to geometric intersection problems. IEEE transactions on computers, Los Alamitos, p. 874-883, oct. 1980.

[Til84] TILOVE, R. B., REQUICHA, A. G., HOPKINS, M. R. Efficient editing of solid models by exploiting structural and spatial locality. Computer aided geometric design, v. 1, p. 227-239, 1984.

[To191] TOLEDO, M. B., TSUZUKI, M. S. G. Reconhecimento automático de features. In: CONGRESSO DE INICIACAO CIENTÍFICA E TECNOLÓGICA EM ENGENHARIA, 10, 1991, São Carlos. Resumos... São Paulo: EDUSP, 1991. p. 424.

[Tor86] TORIYA, H. et al. Undo and redo operations for solid modeling. IEEE computer graphics and applications, Los Alamitos, p. 35-42, apr. 1986.

[Tsu92] TSUZUKI, M. S. G. MSD - Modelador de sólidos didático. In: SIBGRAPI SIMPÓSIO BRASILEIRO DE COMPUTAÇÃO GRÁFICA E PROCESSAMENTO DE IMAGENS, 5, 1992, Águas de Lindóia. Comunicações... p. 17-20.

[Tur88] TURNER, J. U. Accurate solid modeling using polyhedral approximations. IEEE computer graphics and applications, Los Alamitos, p. 14-28, may 1988.

[Voe77] VOELCKER, H. B., REQUICHA, A. G. Geometric modeling of mechanical parts and processes. Computer, New York, p. 48-57, dec. 1977.

[Voe78] VOELCKER, H. B. et al. The PADL-1.0/2 system for defining and displaying solid objects. Computer graphics, New York, v. 12, n. 3, p. 257 263, aug. 1978.

[Wan86] WANG, W. P., WANG, K. K. Geometric modeling for swept volume of moving solids. IEEE Computer Graphics and Applications, Los Alamitos, v. 6, n. 12, p. 8-17, aug. 1986.

[Wei85] WEILER, K. Edge-based data structures for solid modeling in curved-surface environments. IEEE Computer Graphics and Applications, Los Alamitos, n. 5 , p. 24-36, jan. 1985 .

* [Wes80] WESLEY, M. A. Construction and use of geometric models. In: ENCARNACAO, J. (ed.). Computer aided design. Berlin: Springer-Verlag, 1980. 
